\title{
Community Capacity Building, Community Development and Health: A Case Study of 'Health Issues in the Community'
}

Richard Phillips

$\mathrm{PhD}$

University of Edinburgh

2007 


\section{Declaration}

I declare that this Thesis:

a) Has been composed by myself.

b) Is my own work.

c) Has not been submitted for any other degree or professional qualification except as specified.

Richard Phillips 


\section{Contents}

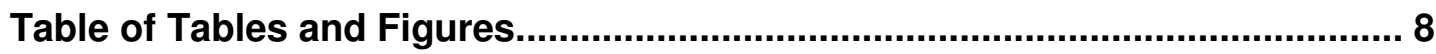

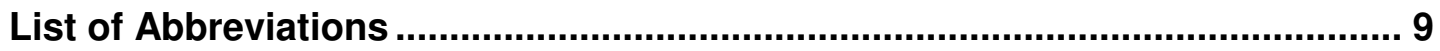

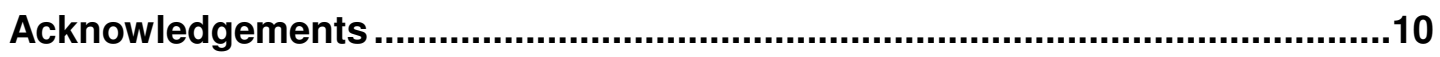



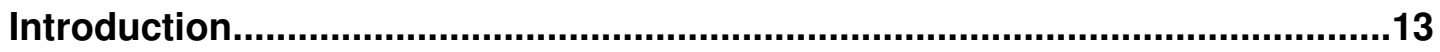

1. Health Issues in the Community course .................................................18

1.1. Introduction to the bodies of knowledge consulted 20

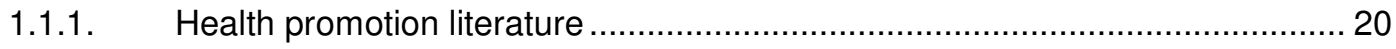

1.1.2. Community development literature.......................................................... 22

1.1.3. Social policy and political science literatures ................................................. 23

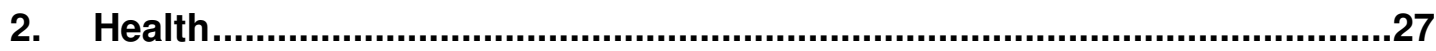

$\begin{array}{ll}\text { 2.1. Definitions of health } & 27\end{array}$

$\begin{array}{ll}\text { 2.2. 'Lay' understandings of health } & 31\end{array}$

2.3. Policy context 33

2.4. Health promotion 36

2.5. Summary 40

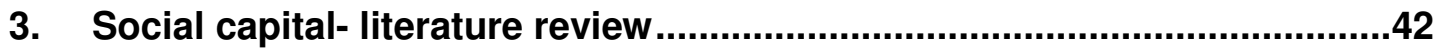

3.1. Social capital and health- arguments against 48

3.2. Social capital and health - a case for a link 51

3.3. Conclusion 55 
$\begin{array}{ll}\text { 4.1. Community } & 57\end{array}$

$\begin{array}{lll}\text { 4.2. Community capacity building } & 61\end{array}$

4.3. Origins and definitions of community capacity building 66

4.4. Approaches to community capacity building 68

4.5. Dimensions of community capacity building 76

4.6. Conceptualising CCB for the purposes of this research study 80

4.7. Measuring Capacity Building 82

$\begin{array}{lll}\text { 4.8. Conclusion } & 85\end{array}$

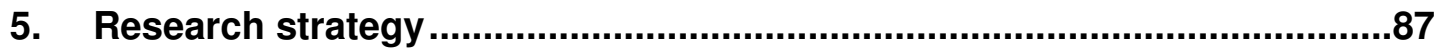

5.1. Choice of research approach 88

5.2. Research aims and questions 93

5.3. Methods 95

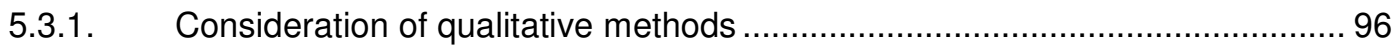

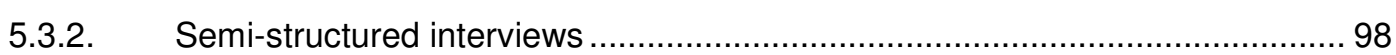

5.3.3. Consideration of other forms of interviews .............................................. 100

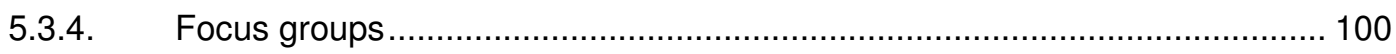

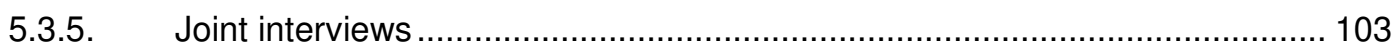

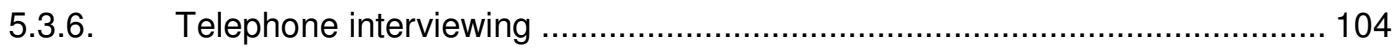

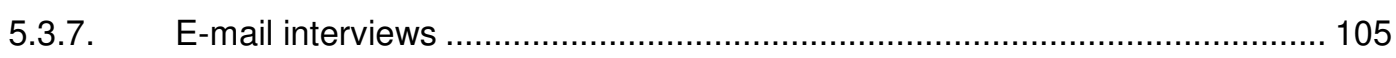

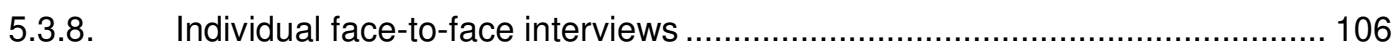

$\begin{array}{lr}\text { 5.4. Sampling } & 107\end{array}$

$\begin{array}{ll}\text { 5.5. } & \text { Ethical Considerations } \\ \end{array}$

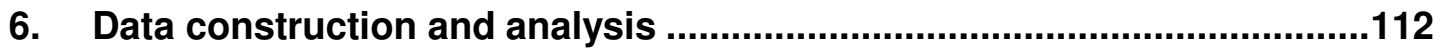

$\begin{array}{ll}\text { 6.1. Interview guides and materials } & 116\end{array}$ 
$\begin{array}{ll}\text { 6.2. Conducting the interviews } & 118\end{array}$

$\begin{array}{lr}\text { 6.3. Data Analysis } & 123\end{array}$

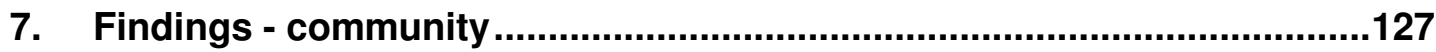

$\begin{array}{lll}\text { 7.1. } & \text { Tutors' understanding of community } & 127\end{array}$

$\begin{array}{ll}\text { 7.2. Students' understanding of community } & 131\end{array}$

$\begin{array}{ll}\text { 7.3. Shared meaning of community, boundaries and place } & 136\end{array}$

$\begin{array}{ll}\text { 7.4. } & \text { Change within communities } \\ & 141\end{array}$

$\begin{array}{ll}\text { 7.5. Expectations of collective activity } & 143\end{array}$

$\begin{array}{lr}\text { 7.6. } & \text { Positionality } \\ & 147\end{array}$

$\begin{array}{ll}\text { 7.7. } & \text { Conclusion } \\ & 151\end{array}$

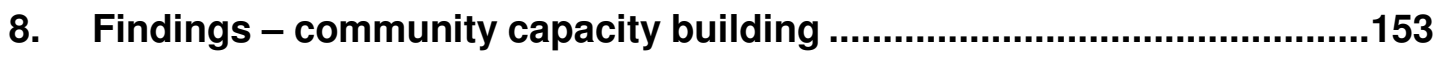

$\begin{array}{ll}\text { 8.1. Understandings of community capacity building } & 154\end{array}$

8.2. $\mathrm{CCB}$ and other concepts 163

$\begin{array}{ll}\text { 8.3. Community capacity building interview exercise } & 167\end{array}$

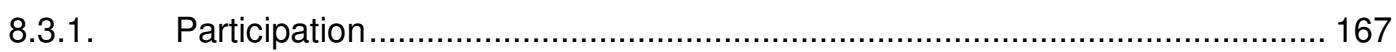

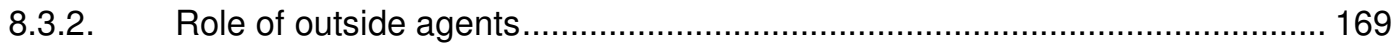

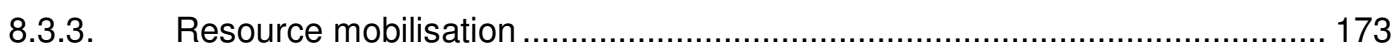

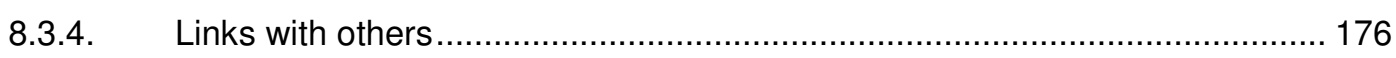

8.3.5. Missing dimension and issues about completing the exercise ..................... 179

$\begin{array}{lr}\text { 8.4. Conclusion } & 180\end{array}$

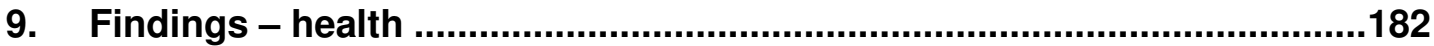

$\begin{array}{ll}\text { 9.1. Understandings of health } & 182\end{array}$

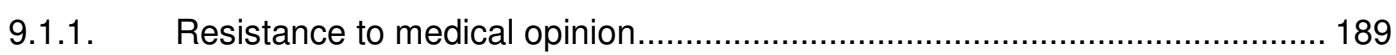

$\begin{array}{lll}\text { 9.2. Determinants of health } & 192\end{array}$ 


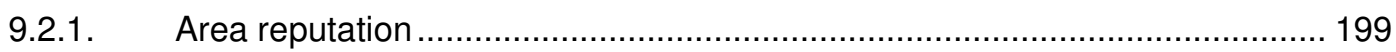

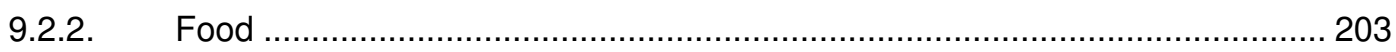

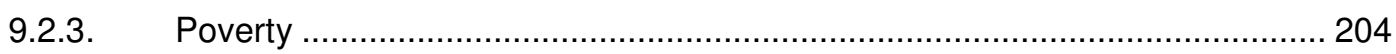

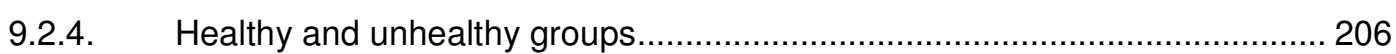

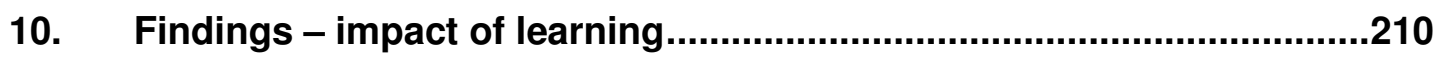

10.1. Personal change 213

10.1.1. HIIC's influence on understandings of health............................................... 213

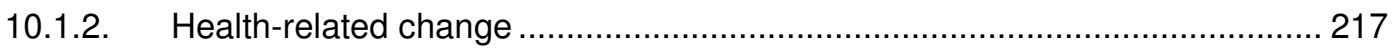

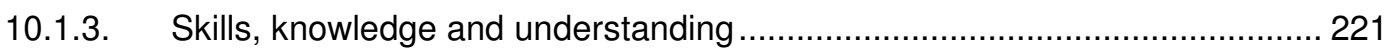

$\begin{array}{ll}\text { 10.2. Self-maintenance } & 227\end{array}$

$\begin{array}{ll}\text { 10.3. Social fabric } & 229\end{array}$

10.4. Community activism 231

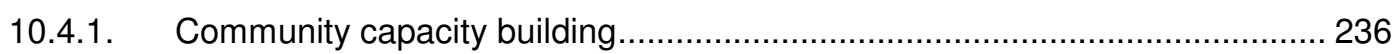

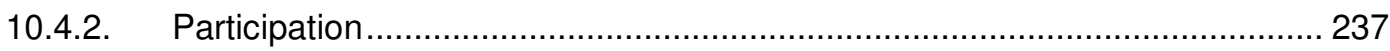

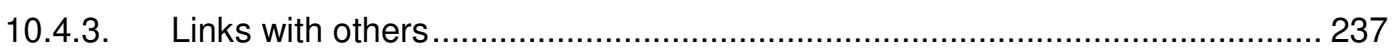

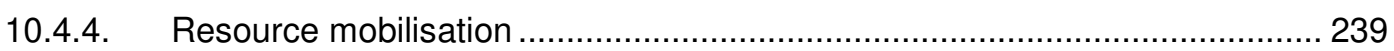

10.5. Analytical limitation 240

$\begin{array}{ll}\text { 10.6. Conclusion } & 240\end{array}$

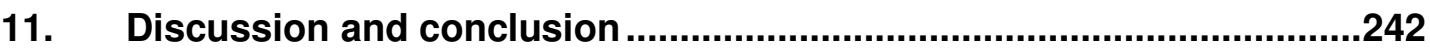

$\begin{array}{ll}\text { 11.1. Contribution } & 243\end{array}$

$\begin{array}{ll}\text { 11.2. Synthesis of research process } & 247\end{array}$

$\begin{array}{ll}\text { 11.3. Limitations of this study } & 261\end{array}$

11.4. Some reflections on the research process 269

11.5. Implications for CHEX and NHS Health Scotland 271

11.6. Suggestions for further research 274

$\begin{array}{ll}\text { 11.7. Conclusion } & 275\end{array}$ 


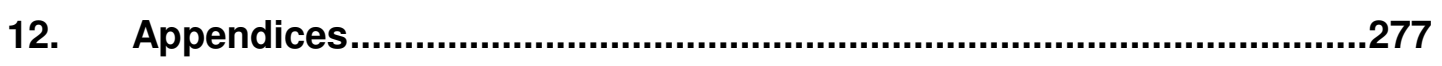

12.1. Appendix i Topic guide for stakeholder interviews 277

12.2. Appendix ii Topic guide for tutor interviews 279

12.3. Appendix iii Community capacity building exercise 281

12.4. Appendix iv Topic guide for student interviews 282

12.5. Appendix v Initial participant recruitment letter 286

12.6. Appendix vi Participant information sheet 288

12.7. Appendix vii Student letter $2^{\text {nd }}$ stage 290

12.8. Appendix viii Student reminder letter 292

12.9. Appendix ix Participant consent form 293

12.10. Appendix $\times$ Coding: $2^{\text {nd }}$ and $4^{\text {th }}$ draft 294

12.11. Appendix xi Ethical guidelines- stakeholders 297

12.12. Appendix xii Ethical guidelines- students and tutors 303

12.13. Appendix xiii Community capacity building exercise findings 309

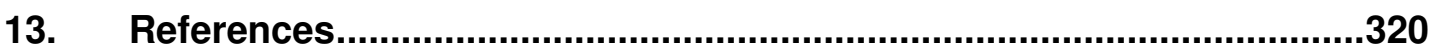




\section{Table of Tables and Figures}

Table 6-1 Course / interview location information 119

$\begin{array}{ll}\text { Table 6-2 Participant information - Students } & 120\end{array}$

Table 6-3 Participant information - Stakeholders 121

Table 6-4 Participant information - Tutors 122

$\begin{array}{ll}\text { Figure 5-1 Stages of a research strategy } & 87\end{array}$

Figure 5-2 Abductive Methodology 92

Figure 10-1 Categorising the impact of learning 212 


\section{List of Abbreviations}

$\begin{array}{ll}\text { CCB } & \text { Community capacity building } \\ \text { ESRC } & \text { Economic and Social Research Council } \\ \text { HEBS } & \text { Health Education Board for Scotland } \\ \text { HIIC } & \text { Health Issues in the Community } \\ \text { MSP } & \text { Member of the Scottish Parliament } \\ \text { NHS } & \text { National Health Service } \\ \text { SH } & \text { Stakeholder } \\ \text { T } & \text { Tutor } \\ \text { S } & \text { Student } \\ \text { RP } & \text { Researcher } \\ \text { WHO } & \text { World Health Organisation }\end{array}$




\section{Acknowledgements}

I would like to thank the following people for their support in conducting this research project:

The Economic and Social Research Council and NHS Health Scotland, who funded this PhD as a CASE collaborative studentship, award number PTA 033200200031.

My PhD supervisors, Professor Amanda Amos, Professor Lyn Tett and Emma Witney (NHS Health Scotland).

Dave Allan, Community Health Exchange (CHEX).

My research participants without whom this project would not have been possible.

Lisa Hanna and all my friends and family for their support throughout this process. 


\section{Abstract}

\section{$\underline{\text { Aims }}$}

This research project aimed to further knowledge regarding the relationship between community capacity building (CCB), community development and health within the context of the Health Issues in the Community (HIIC) programme. CCB refers to the development of capabilities to identify and address community issues and was conceptualised using four dimensions: participation, resource mobilisation, links with others and role of outside agents. HIIC is a learning resource supported by NHS Health Scotland, the national health promotion agency. The main objective of HIIC is to help students explore the processes involved in tackling health-related concerns in the community.

\section{$\underline{\text { Research questions }}$}

The main concepts in this study were explored by referring to a range of academic literatures and five research questions were formulated. 'How did HIIC tutors and students understand the concept of community and was this understanding influenced by completing HIIC?', 'How did stakeholders and tutors understand the notion of CCB?', 'Was CCB evident in the experiences of the students after their involvement with the course?', 'Did participating in the HIIC course contribute towards furthering students' understanding about health?' and 'Did participating in HIIC have any other impact on participants?'

\section{Methods and results}

Face-to-face, semi-structured interviews were conducted across Scotland with three participant groups: stakeholders, tutors and students. This involved a total of thirtyfive interviews with students and tutors from eleven different courses. Interviews were transcribed and analysed using thematic analysis. Four key themes emerged: community, $\mathrm{CCB}$, health, and impact of learning. Tutors and students suggested that people could be members of multiple communities. Community was understood as a geographical location, a common interest and as a sense of belonging. Tutors also 
considered the community as a site of professional practice. Some participants had an expectation that community members should act collectively to help one another. Completing HIIC appeared to influence students' understanding about their own circumstances, issues within their community and how it functions, rather than informing how they defined the concept of community.

CCB was seen by tutors as a process that develops competencies to address community issues. Stakeholders and tutors differed in their views about whether CCB was an individual level or a collective process. Participants likened CCB to community development, but stakeholders questioned if it shared the same value base or if it was an outcome of community development. Tutors expressed a range of opinions about their understanding of CCB. It was viewed as a potentially helpful idea in terms of understanding the work of community / health-based practitioners. However, others were unable to give a definition of CCB and some tutors considered CCB a concept with little meaning or an indicator to fulfil in the context of a funding application.

The manifestation of individual aspects of CCB were identified in the accounts of some participants, but the data did not support the contention that HIIC promoted $\mathrm{CCB}$, within the timescale of this study, although, it could be argued that latent $\mathrm{CCB}$ was developed. The data did indicate that participants' understanding about the concept of health was reaffirmed, broadened or changed and that participating in HIIC could increase an individual's awareness of social and health issues, develop interpersonal skills and widen social networks.

\section{Conclusion}

This study indicated that by exploring the concepts of CCB, community and health, a contribution was made towards understanding the processes by which participating in a HIIC course influenced students to address health-related concerns. 


\section{Introduction}

Our approach will build on work already initiated that: seeks to encourage, support and enable individuals and communities to take shared responsibility for their own health and to work together to bring about improvements. Programmes such as Health Issues in the Community are key to empowering the public and enabling people to become more involved in community issues.

Improving health in Scotland- the challenge

(Scottish Executive 2003: 25)

Inequalities in health are recognised as a major issue and statistics suggest that Scotland has a significant burden of ill health in relation to other areas of the UK (Blamey et al. 2002: 6). Various theoretical perspectives offer not only explanations about how and why health inequalities arise and persist, but also present strategies to address them. One such perspective is health promotion which has been defined as 'the process of enabling people to increase control over, and to improve, their health' (WHO 1986). As theories of health promotion developed, community-based approaches have increasingly become accepted as one way to address health inequalities. NHS Health Scotland, the national health promotion agency, supported the development of Health Issues in the Community (HIIC), a community-based learning resource that explores the processes involved in addressing health issues at a community level. HIIC is a Scotland-wide programme facilitated by tutors aimed at people or groups who have an interest in or are involved with community health initiatives. In addition, HIIC is informed by a community development approach, which emphasises the role of local people in identifying both the health-related concerns relevant to their community and potential solutions to tackle them.

Community capacity building (CCB) is a concept closely related to community development and recently linked to health promotion. However, little research has been conducted concerning CCB and health in the UK. Therefore, the HIIC course represents a research context in which to consider the concept of CCB in order to 
explore how individuals and communities might begin to address health-related concerns. More specifically, the overall aim of this study is to further knowledge regarding the relationship between $\mathrm{CCB}$, community development and health.

Some features of this $\mathrm{PhD}$ are worth noting at this point. Firstly, the main concepts featured are complex, interrelated and span three distinct bodies of literature: community development, health promotion, and social policy and political science. Secondly, this study is not a piece of health promotion research in terms of applying health promotion models to the data; instead, the focus is on exploring how participants' understandings of health are influenced through participating in HIIC. Thirdly, this study does not attempt to evaluate HIIC or community capacity building by measuring outcomes or processes; rather it is an exploration of how concepts are negotiated, reconfigured and applied. Finally, this research is funded through an Economic and Social Research Council CASE studentship, a scheme that specifically encourages collaborative research with public sector agencies. In this case the collaborative agency is the Health Education Board for Scotland (subsequently NHS Health Scotland).

In Chapter 1 the HIIC course, including the format, content and underlying approach informing the programme, is described. This chapter also presents justification for the literature sources used to explore the main concepts in this research study. These concepts are then considered in more detail in the following three chapters.

Chapter 2 deals with some of the key themes, developments and policies in health. In particular, definitions of the concept of health are considered as well as theoretical models and lay understandings of health. This chapter examines some of the important health-related policy developments in the UK, including the establishment of the National Health Service, reports on health inequalities and policy changes in Scotland post-devolution. The influence of the public health and health education movements on the development of contemporary health promotion is considered. In 
addition, it is shown how the concepts of community and community development have become important features of health promotion theory and practice.

Chapter 3 looks at social capital by discussing the work of theorists Coleman, Bourdieu and Putnam whose work has popularised the concept. The debate concerning social capital and health is discussed and it is shown that aspects of social capital are useful in exploring how individuals engage collectively to address health issues in their community.

Chapter 4 examines community capacity building beginning with the concept of community and its emphasis in policies and political discourse. This chapter suggests that the origins of CCB can be traced back to the idea of community competence and describes definitions and conceptualisations of CCB and its measurement. Having reviewed and discussed the main concepts in Chapters 2, 3 and 4 , the following two chapters are concerned with the research process.

Chapter 5 moves on to discuss the philosophical underpinnings of this research project and details the research questions addressed. This chapter explains why semi-structured, face-to-face qualitative interviews and a criterion sampling technique were the methods of choice. In addition, the ethical considerations that developed during this thesis are presented, alongside how they were addressed.

Chapter 6 focuses on the data construction and analysis processes. This chapter details how participants were recruited from the following groups: HIIC stakeholders, tutors and students. In addition, the chapter describes development of interview guides and materials and the interview procedure. The process of data analysis is outlined and it is shown how thematic analysis was used to interpret and code the interview transcripts. 
In Chapter 7 the findings relating to the concept of community are presented. It is shown that community was conceptualised in different ways, including as a geographical location or as a sense of belonging. The nature of the relationships within a community is an important feature noted in the participants' accounts, along with an expectation that community members should help each other.

Chapter 8 details the data analysis regarding CCB and related concepts. It suggests that CCB and community development are broadly similar, but that CCB may lack a system of values that are perceived to inform community development. For some participants, CCB was a problematic concept, one with little meaning. However, others suggested that it might be a helpful way to explain the professional practice of community development / health promotion workers. This chapter also shows how participants engaged with the $\mathrm{CCB}$ research model developed for the purposes of the interview.

Chapter 9 shifts the emphasis to the findings relating to the concept of health and shows that a range of influences, such as an ability to function, gender roles and previous professional experience informed participants' understandings of health. This chapter also shows how some participants presented an account of how they resisted medical opinion. The determinants of health are considered under the following headings: social, physical and psychological. It is demonstrated that these categories were inadequate to encapsulate wider and complex influences on health such as poverty, access to healthy food and an area's reputation. Finally, it is demonstrated how participants identified unhealthy groups in their community.

Chapter 10 focuses on the way in which participating in HIIC influenced participants' learning and affected other aspects of their lives. This chapter draws from adult learning research and considers four areas of impact: personal change, self-maintenance, social fabric and community activism. Notably it is shown that participants' understandings about the concept of health were reaffirmed, broadened 
or had changed significantly as a consequence of attending the course. This chapter demonstrates that participating in a HIIC course was an influential event for many, with both negative and positive consequences. It is indicated that within the time scale of this project, participating in HIIC did not stimulate community capacity building. However, some accounts suggested that latent community capacity building may have been developed along with individual aspects of community capacity building.

In Chapter 11 the overall findings are discussed in relation to the literature and broader reflections on the research process are presented. This chapter suggests that exploring the concepts of community capacity building, community development and health in relation to the HIIC programme contributed towards furthering knowledge about the ways in which individuals were influenced to address health concerns in their community. 


\section{Health Issues in the Community course}

The Health Issues in the Community (HIIC) course is a Scottish-wide learning resource funded by NHS Health Scotland, managed by Community Health Exchange (CHEX), a partner organisation. HIIC is targeted towards people who are involved with or have an interest in community health initiatives, for example, members of self-help groups or community organisations, and community health workers. According to the tutor guidelines the main aim of a HIIC course is to "enable participants to explore and understand the educational, social, political and community development processes that are involved in addressing health issues in the community' (Health Education Board for Scotland 2002b: 1)

The HIIC course is informed by a community development approach to health and the main characteristics of this perspective have been identified as the following:

1. A holistic approach, the whole person rather than depersonalised issues, diseases or parts of the body.

2. It is done with people, not to them. Community participation at all stages of the process.

3. Community members identify their own needs. Issues are seen to be interrelated and not separated into 'health' or 'housing'.

4. Results are often unpredictable.

5. Lay understanding is prioritised over professional mystification.

6. Emphasis is placed on common concerns as opposed to isolated individuals' problems.

7. It aims to promote wider participation by communities in their own health and health care delivery.

(Adams, L cited by Cox \& Findlay 1990: 6)

HIIC is based on a collection of materials contained in a learning pack, developed between 1994-96 and was officially launched in June 1997. A second edition of the learning pack was produced in May 2002 in conjunction with a review group. The course materials are divided into two main parts, each consisting of eight units. Part 
one examines key ideas such as 'health', 'poverty', 'inequality', 'power' and 'participation'. In part one, course students prepare and give a presentation to an invited audience about a specific health-related issue that concerns them. The second half of the course includes units on 'working together' and 'how to take action around a health issue'. For the final assignment, students write an essay in which they identify a health issue that is relevant to their community; explain why this issue affects people's health; and explore how the principles of community development can be applied to address this issue.

A social model of health informs the concept of health outlined in HIIC. This particular approach to understanding health-related issues assumes that economic and social conditions as well as behavioural factors influence health (Health Education Board for Scotland 2002b). In the first part of HIIC students discuss what affects their health and the health of their community. In the second unit students examine cultural and historical beliefs about health, for example, harmony and balance, germ theory and the biomedical model of health; and consider lay and professional beliefs about health. In unit three, students discuss health inequalities and refer to theories such as the inverse care law which states that ' $[\mathrm{t}]$ he availability of good medical care tends to vary inversely with the need for the population served' (Tudor Hart 1971: 405), and reports, such as, the Independent Inquiry into Inequalities in Health (Acheson 1998). Students are also encouraged to examine definitions of poverty and consider how deprivation relates to ill health.

The University of Edinburgh accredits HIIC and students have the opportunity to gain ten SCOTCAT (Scottish Credit Accumulation and Transfer) points ${ }^{1}$, when they complete a full HIIC course, which involves attending parts one and two and successfully completing both assignments. Between April 1997 and November 2003

\footnotetext{
${ }^{1}$ Referred to now as Scottish Credit and Qualification Framework credits. SCQF credits provide a standardised indication of how much learning is required to achieve a particular qualification.
} 
thirty-six full courses had been facilitated, with 270 students completing the course of which 147 gained accreditation (Allan 2004a).

\subsection{Introduction to the bodies of knowledge consulted}

The purpose of this chapter is to introduce the areas of literature that were considered relevant to this thesis. This study focused on the concept of community capacity building and the Scottish-wide health-related training programme, Health Issues in the Community (HIIC), which adopts a community development approach. HIIC students and tutors explore complex, interrelated ideas and issues, such as health and health inequalities, community identity and community development. The literatures I drew on reflected both the content of the HIIC course, and the social and political context in which the course is situated. The three main bodies of knowledge are those of health promotion, community development, and social policy and political science and their relevance is outlined below.

\subsubsection{Health promotion literature}

Health promotion is a fundamental component of this thesis for four main reasons. First, HIIC was supported by the then Health Education Board for Scotland (HEBS), and almost $£ 250,000$ had been allocated for the HIIC programme between 2001 and 2005 (personal communication Witney 07/05/2005). Established in 1991, HEBS was the primary organisation for health promotion in Scotland and its operational ethos, according Taylor (2002:109 - 10), was informed by the World Health Organisation's (WHO) definition of health promotion- health promotion seeks to empower people to have both control over their health and the means to improve their health.

Second, definitions of health promotion and its development share a similar ethos to the HIIC course. According to Naidoo \& Wills (2000) WHO has shifted the definition of health promotion to one with an emphasis on the health and well-being of entire populations. In this context, it is 'lay' people, rather than medical 
professionals, who identify and express health issues that concern them. In addition, the responsibility for health lies not exclusively within the individual's control, instead broader social factors that affect health are also considered. Thus, health promotion has become a broad concept that, as Tones (1990) argues, 'incorporates all measures deliberately designed to promote health and handle disease' (as cited by Naidoo \& Wills 2000: 83). According to Whitehead (2004: 314), the health promotion literature in the last ten years has shown an increasing tendency towards 'policy-driven initiatives that work through social examination and modification, particularly at the level of collective action', with an emphasis on the 'social action[s] that promote and lead to community empowerment'.

Third, drawing from health promotion sources is relevant because the concept of health is central to the HIIC course. Students and tutors explore social and medical models of health. In addition, the course cites some important health promotion policy documents, for example, the Alma-Alta Declaration (WHO 1978) and Health 21, (WHO 1998), as well as reproducing articles such as 'Medicine as an instrument of social control' (Zola 1972), that reflect a particular stance about health and health care.

Fourth, included in the health promotion literature is the concept of community capacity building (CCB) (Crisp, Swerissen, \& Duckett 2000; Gibbon, Labonte, \& Laverack 2002; Hawe et al. 1998; Labonte \& Laverack 2001a; Labonte \& Laverack 2001b). This is not an unexpected finding as health promoters have had a long-term interest in the related concepts of community and community development. For example, health promotion practice is often conducted in a community setting and health promotion work can be underpinned by the values and methods of community development. The definitions and models of CCB found in health promotion sources (Goodman et al. 1998; Labonte \& Laverack 2001b) are based on work conducted in Australia, Canada and North America, a synthesis paper reviewing research concerning the conceptualisation and measurement of community capacity showed little work had been done in the UK (Kwan et al. 2003). In summary, the health 
promotion literature provides definitions, models and theories of the key concepts used in this thesis.

\subsubsection{Community development literature}

Community development is the second body of work relevant to this study for a number of reasons. First, the HIIC course uses a community development approach, which means its content is informed by a distinctive ethos and is delivered using particular methods. For example, HIIC tutors use group-work methods to discuss community health-related issues and seek to promote collaborative working among students as they complete course assignments. The processes involved in this method of facilitation are seen as important factors in developing students' confidence, self-esteem and political awareness.

Second, community development is considered to be a major influence on health promotion strategy (Green \& Raeburn 1990). Naidoo and Wills (2000) identify three common elements shared by all community development approaches to health promotion and which also feature in the HIIC course. First, community members are encouraged to identify priorities that concern them. Second, health is promoted through community development methods. For example, self-esteem, confidence and sense of control can be increased as members work together to address a concern. In addition, skills developed through participation are transferable to other contexts, not just health related. The third characteristic is that health inequalities are recognised and that practitioners aim to work with groups who are marginalised and vulnerable. By concentrating on the social determinants of ill health, such as class, unemployment and poverty, rather than individual behaviour, community development approaches attempt to empower local people to act collectively to influence the political, economic and social issues that impact on their lives.

Community, a key concept in community development theory, is also an important concept in the HIIC course for a number of reasons. Firstly, HIIC challenges 
students to identify phenomena that affect the health of the community as a whole. Second, HIIC aims to raise students' awareness about how local people can take action about a specific health-related concern within their community. Thus, I would suggest that by exploring the concept of community the contextual understanding of the impact of HIIC might be increased. Finally, HIIC can be understood as part of recent policy developments that encourage community participation to address health inequalities (CHEX 2005).

The community development literature also includes regeneration research exploring CCB in the UK (Banks \& Shenton 2001; Diamond 2004), North America (Chaskin 2001) and Australia (Simpson, Wood, \& Daws 2003). These studies provide theoretical models as well as critical accounts of CCB. For example, Banks and Shenton (2001) reviewing two regeneration projects argue that CCB processes can be viewed as being on a strategic (a focussed and more planned approach to CCB) / developmental (part of broader community development processes, where CCB is not an explicit objective) continuum. In addition, the community development literature suggests that the origin of the concept of $\mathrm{CCB}$ evolved from the notion of community competence (Cottrell 1976).

In summary, the community development literature is relevant to this thesis as it provides the rationale and theoretical background to some of the main themes in this study.

\subsubsection{Social policy and political science literatures}

The final literatures considered are those of social policy and political science. HIIC course is informed and influenced by wider political and policy developments. By exploring current political discourses that emphasise encouraging community involvement in addressing social problems, it is possible to understand why courses like HIIC are supported politically at the time of writing. 
One particular relevant feature in the literature related to theories that highlight changes in how political power is exercised. It has been argued that political power is discharged towards concerns about populations, for example, management of their health and well-being, whereas previously power was exercised to maintain and defend a state's territory (Foucault 1980; 1997). In addition, certain aspects of the nature of human existence- for example, morals, sentiments and guiding beliefs of individuals and groups- have now become the means by which the regulation of the individual might be joined to the obligations of good government (Rose 2001). Thus, levels of trust between people, a sense of community and the degree of voluntary activity are increasingly important considerations to those in power (Walters 2002) and have become the site of political strategies to address problems such as social exclusion and health inequalities. 'Third Way' thinking, communitarianism and social capital are recent political concepts and perspectives that are particularly relevant in explaining the political and social context of the HIIC course.

The influence of Third Way theory is reflected in current government policy. The Third Way perspectives can be viewed as a political position that attempts to describe and explain so called 'modernising shifts' in society, such as the move from manufacturing-based economy to one characterised by information technology or the decline in the role of class politics to the growth of consumerist values (Giddens 1998; Giddens 2000). Giddens, one of the key figures who theorised 'Third Way' thinking, was concerned with the relationship between three spheres of society: government, the market and civil life. Giddens argues that it is possible to revitalise the connections between these spheres by adopting a 'new social contract'. This 'contract' emphasises the rights and responsibilities of citizens, suggests that the state should have a regulatory role and calls for the strengthening of civil society. These developments are perceived to be a requisite for effective government and for an efficient market economy- considered an important mechanism to tackle social problems. For example, Third Way proponents argue that investment in employment is a key strategy in reducing social and health inequalities (Paton 1999). In certain 
locations, HIIC has been delivered as part of a pre-employment training package and has also been advertised as an opportunity to develop new skills in order to improve a person's chances of finding employment. Therefore, it is possible to link 'Third Way' rhetoric about reducing inequalities and the HIIC course.

Third Way perspectives are also closely linked to particular interpretations of communitarianism, which extol the promotion of strong families and communities as the basis of society. In addition, families and communities are viewed as a means of addressing certain social problems. Aspects of communitarian thought reflect one of the potential effects of the HIIC course, such as strengthening communities.

Social capital, a term originally popularised in political science literature, refers to social networks, trust, and benefits accrued through membership of particular social groups (Portes 1998). Social capital is relevant to this study for two main reasons. First, it has been suggested that levels of certain aspects of social capital- such as trust, reciprocity and membership of voluntary associations- correlate with health outcomes. For example, rates of heart disease and infant mortality (Kawachi et al. 1997; Kawachi 2001). Second, social capital is cited in current political, community development and health promotion discourses, in conjunction with other phrases such as community capacity building (see for example Crisp, Swerissen, \& Duckett 2000; Laverack \& Wallerstein 2001; Smith, Baugh-Littlejohns, \& Thompson 2001). Hence, the concept of social capital might be helpful in exploring how completing HIIC influences students to address health concerns in their community.

In summary, political power is exercised in relation to managing the health and wellbeing of a population and abstract notions, such as 'sense of community' become part of the apparatus by which people are governed. Reinforcing this form of political power are contemporary concepts and perspectives that promote strong communities in order to address social ills. As the aims of HIIC appear to complement features of the political agenda, notably, regarding the role of 
communities, it is possible to understand why HIIC is promoted and supported at the time of writing. In the next chapters, the following concepts in further detail: health, health promotion, social capital, community and CCB are discussed. 


\section{Health}

Health is a significant social, political and personal issue and a vast amount of related literature exists. As already noted participating in a HIIC course encourages people to think about what the concept of health means to them, to identify factors that influence the health of their community and to explore ways in which the healthrelated concerns of a community can be addressed. Thus, in simple terms, HIIC is concerned with definitions and understandings of the concept of health as well as examining potential responses to health matters. This pattern is reflected in this chapter, which aims to highlight some of the key features in the health literature that help to understand the broader health-related context in which HIIC can be located. In other words, this chapter addresses the following question, 'What are some of the key developments and policies in the field of health that might have influenced the development of HIIC?' It should be noted, however, that many of the concepts and developments considered in this chapter are complex and their origins and evolution are fiercely disputed and therefore should not be seen as a series of events that are seamlessly and chronologically ordered.

This chapter is divided into three sections. First, some definitions of health are explored and three conceptual 'models' of health are briefly considered. Second, research concerning how lay people think about health is summarised. Third, key features of the UK government's health policy are highlighted and the concept of health promotion is examined.

\subsection{Definitions of health}

The WHO's (1946: 100) definition of health as 'a state of complete physical, mental and social well-being, and not merely the absence of disease or infirmity', is a well known and often quoted statement regarding health. According to this definition, health could be interpreted as an ideal state, which assumes that a person cannot be considered healthy if suffering from minor ailments and so by this definition many 
people would be unhealthy (Blaxter 2004 ; Seedhouse 1986). In addition, it has been claimed by Blaxter (2004) that conceptualising health in this way perpetuates the view that illness is a departure from the norm and that this can then be reinterpreted or reformulated as illness as a deviance from social and moral norms. However, as illness is a common feature in people's lives it has been questioned whether it can be justifiably classified as deviance (Pflanz \& Rhode 1970).

Health viewed as normal and disease seen as a departure from the norm reflects elements found within early belief systems and philosophical thought. For example, Platonic notions of health were correlated with the body's functions acting in harmony. Conversely, disease was understood as a disturbance in this equilibrium. Broadly, health was understood as the correct balance between the gods, the environment and the processes within the body. Consequently, disease- considered as reflecting imbalance- could be corrected by rectifying deficiencies (by diet) or the removal of excess (by purging or bleeding) (Mishler 1981). However, as Blaxter (2004) noted, equating health with normality can be problematic and raises questions such as, 'Normal for whom?' and 'Does the norm mean average?' In which case, the 'norm' may not equate with perfect health. Or perhaps the use of 'normal' refers to an ideal state which is unachievable (Blaxter 2004). In addition, '[h]ealth and disease cannot be defined merely in terms of anatomical, physiological, or mental attributes. Their real measure is the ability of the individual to function in a manner acceptable to himself [sic] and to the group of which he [sic] is part' (Dubos 2001: 9).

Health as a function or as a level of fitness to accomplish everyday tasks was a theory promoted by, among others, the American sociologist Talcott Parsons (1951). Within this context, Parsons viewed medicine as an institution which supervised certain deviant behaviours in contemporary societies and argued that the pressures of daily living may be such as to urge people into adopting a 'sick role', in order to be released from their responsibilities (White 2002). 
Health has been defined as a commodity and refers to purchasing treatments (Seedhouse 1986). In this sense, Seedhouse goes on to argue, health is conceptualised as something that can be prescribed, for example, through drug treatments, and becomes separated from the individual. Additionally, as health can be restored by the appropriate medical intervention, it becomes viewed as an idealised state. However, Seedhouse notes that one of the implications of defining health as a commodity is that it masks an individual's potential that exists beyond their illness.

Seedhouse proposed that health could be understood more appropriately as the 'foundations for achievement'. He suggests that the foundations that make up health are: basic needs, such as food and shelter; access to information about the conditions which have an influence in a person's life; the skills and ability to understand this information; and the realisation that people are never totally isolated from one another or their environment. Therefore, '[h]ealth in its different degrees is created by removing obstacles and by providing the basic means by which biological and chosen goals can be achieved' (Seedhouse 1986: 61).

The concept of health is a key consideration in the discipline of health promotion (which is explored below). In this context, health is informed by the WHO's definition of health (see page 27). In presenting the theoretical underpinnings of health promotion, Tones and Green (2004) suggest that the concept of health includes three key components: physical, mental and social. Physical health can be viewed in two ways: firstly, as reducing the effects of disease and disability and secondly, as enjoying an adequate level of fitness to achieve personal goals or a sense of wellbeing. Tones and Green suggest that mental health can have both cognitive and affective dimensions. The cognitive element refers to the extent to which individuals reach their potential and the affective aspect concerns emotions and feelings, including a spiritual dimension. Social health is thought to be comprised of three main features. First, independence- a socially mature person behaves with more independence and autonomy. Second, interpersonal 
relationships- social health is characterised by the ability to relate to a variety of other people and be able to work with them. Third, responsibility- social maturity involves accepting responsibility for others.

The concept of health has also been incorporated into theoretical models, three of which are highlighted here: the biomedical, the biopsychosocial and the social. Blaxter (2004) argues that the biomedical model of health in a stereotyped form is based on the biological sciences and focuses on disease and ill health. Following Mishler (1981), Blaxter cites the four principles contained in the biomedical model of health as:

a) A doctrine of etiological cause - that disease is caused by a specific biological factor such as germs, bacteria, or parasites.

b) An assumption of generic disease - that each disease has universal features within a human population, regardless of culture, time and place.

c) Ill-heath is a deviation from normal biological functioning.

d) Scientific neutrality.

Blaxter argues that elements of these four characteristics can be found in modern medical practice, although she acknowledges that biomedicine now accepts multiple and interactive causes of ill health. Blaxter suggests that one of the main criticisms of the biomedical model is that it focuses on disease prevention or elimination at an individual level, rather than acknowledging the wider social circumstances in which diseases thrive. In addition, it has been argued that psychology research has also influenced more recent variants of the biomedical model of health. For example, Wade and Halligan (2004) suggest that psychology not only challenged the mechanistic model of illness by demonstrating that psychological factors impact on illness, but is also reflected in contemporary biopsychosocial models of illness.

To suggest that biopsychosocial models are a recent development is perhaps slightly disingenuous. For example, in 1977 Dr George Engel presented a holistic alternative to the dominant biomedical model, prevalent since the middle of the $20^{\text {th }}$ century, 
which became known as the biopsychosocial model (Engel 1977). According to Borrell-Carrió et al. (2004) Engel's ideas were expounded both as a scientific project and as a radical ideology which sought to counter 'the dehumanization of medicine and disempowerment of patients' (Borrell-Carrió, Suchman, \& Epstein 2004: 576). Essentially Engel postulated that medical practitioners should be concurrently concerned with the biological, psychological and social dimensions of illness, in order to comprehend and to be in a position to offer both an appropriate and empathetic response to patients' suffering.

The contemporary social model of health, according to Blaxter (2004), can be traced to around the middle of the $20^{\text {th }}$ century; a time when there was a growing dissatisfaction with the dominant biomedical model of health. Two writers who were influential in the development of the social model are Ivan Illich and Aaron Antonovsky. Reflections on their work (Antonovsky 1996; Illich 1976) led to calls for a re-focus on the factors that promote health, instead of being solely concerned with the prevention of disease. Blaxter argued that the social model of health reflected a significant break with the biomedical model, as biological processes within the social model are placed in a social context and the individual is treated holistically, rather than as a set of bodily systems. This model of health could be seen, in part, as a response to a medicalized conceptualisation of health that is considered to be widespread in medical practice and research (Larson 1999). In the following section, the research concerning lay understandings of health is considered and can also be viewed as another riposte to professional medicine.

\section{2. 'Lay' understandings of health}

Another example of how professional knowledge about health has been challenged is reflected in the interest in how lay individuals understand the concept of health. For example, sociological research in health spans a number of years (for a review see Lawton 2003), although it has been noted that many of these 'health' studies actually focused on illness rather than on health accounts (Hughner \& Kleine 2004; Lawton 
2003). However, there are a number of examples where understandings of health have specifically been explored (see Blaxter 1983; Blaxter 1990; Calnan 1987; Cornwell 1984; Herzlich 1973; MacInnes \& Milburn 1994).

In a recent compilation of the existing literature concerning how individuals think about health, Hughner and Kleine (2004: 415) suggested that the themes distilled from the review could be categorised into four: definitions of health, explanations for health, external / uncontrollable factors influencing health and the place health occupies in people's lives. Definitions of health included the absence of disease and the ability to conduct daily responsibilities. In addition, health was seen as an aspiration in terms of achieving a state of harmony and balance in everyday life as well as health provides the means to live a fulfilling life.

The second category, explanations for health, included understandings about where good health originates from, which came from a range of information sources, such as health care professionals, personal experience and folk knowledge. In the literature, themes concerning the causes and control of health were influenced by 'personal practices and responsibilities' (Hughner \& Kleine 2004: 416). For example, accounts included references to 'living correctly' to maintain bodily health. External factors that contributed to health included government policies, institutions and the social environment, which impacted on an individual's capacity to manage their health. In addition, contemporary environmental factors, such as food quality and psychological stress, were identified as influencing health. Genetics was one of the uncontrollable factors that was cited as impacting on health. In the context of the place that health occupies in people's lives, it was found that the importance of good health was taken for granted and that health was not seen as something to be consciously achieved on a day-to-day basis. In addition, researchers found that people were aware of lifestyle choices that can promote health. However, despite this there was also disparity between health beliefs and behaviour. 


\subsection{Policy context}

In Britain, according to Davey-Smith et al. (2001), there has been a long tradition of observing and considering social inequalities of health. They cite the following examples: Edwin Chadwick's Report into the sanitary conditions of the labouring population of Great Britain (1842), Engels' Condition of the working class in England in 1844 (1888), Rowntree's study of York, Poverty: a study of town life (1902), and Margery Spring-Rice's Working class wives: their health and condition (1939). In addition, other significant events, such as the second Boer War (18991902) highlighted the extent of poor health. In Scotland, for example, during recruitment for this war nearly $50 \%$ of the Scottish recruits from poor backgrounds were deemed unfit on physical grounds (Player \& Murray 2003). The subsequent years saw the gradual introduction of more formalised welfare provision. Although a detailed examination of how the welfare state evolved (see for example Timmins 1996) is not appropriate in this thesis, it is worth highlighting a number of its key developments.

During the Second World War the Beveridge Report (HMSO 1942) was published and made an important contribution to thinking about poverty and health (Player \& Murray 2003) as it called for the 'slaying of the five giants of want, disease, ignorance, squalor and idleness'. In 1946, the National Health Service Act was passed and two years later, the National Health Service (NHS) was created. Initially, the NHS was based on the principle of universality, comprehensiveness and being free at the point of delivery. In other words, the service would be for every member of the British population, regardless of status, cover all types of health needs and would not require the patient to pay directly for any treatment (Alcock, Payne, \& Sullivan 2004). However, the extent to which the ideological principles on which the NHS was purported to be founded has been disputed (Powell 1996; Seedhouse 1994). Indeed the issue of cost, the increasing demand for services and the control of expenditure and how resources were divided were features in the early years of the NHS and have remained so ever since (Alcock, Payne, \& Sullivan 2004). 
The government in 1977 set up a working group on inequalities and health chaired by Sir Douglas Black. The authors of The Black Report (Department of Health and Social Security 1980) as it became known, argued that the main explanations for inequalities in health were related to material deprivation and to particular aspects of the socio-economic context. The report presented a structural explanation of health inequalities in that the social class gradient largely reflected the extent to which people had access to the material determinants of health status, such as income, housing, education and safer working environments. These findings, according to Williams (2003b), were confirmed and added to by further research. For example, Whitehead (1987) found evidence indicating that social inequalities of health were still widening. However, this was generally ignored by the Conservative government, as indicated by the then Secretary of State, Virginia Bottomley's, preference for the term health 'variations' rather than inequalities in the early 1990s. Health policies introduced around this time were largely influenced by the medical model of health and failed to address the wider determinants of health (Paton 1999). For example, the Conservative government's White Paper, The Health of the Nation (Department of Health 1992), identified five priority areas, (coronary heart disease and stroke, accidents, mental health, cancers, and HIV and sexual health) but was criticised for concentrating on individual lifestyle and ignoring the factors beyond individual control (Paton 1999).

In 1997 a change in administration saw health inequalities being placed more centrally on the political agenda (Crinson 2005). The New Labour government established an Independent Inquiry into Inequalities of Health, known as The Acheson Report (1998), which stated that causality runs from social and economic inequality to ill health and not vice-versa, and that inequalities could be demonstrated across various measures of health and its determinants. Paton (1999) suggested that 'Third Way' (an influential political discourse among some New Labour politicians) supporters responded to the Acheson Report by arguing that social inequalities could be reduced through investment in employment, rather than through income 
redistribution. However, the effectiveness of this approach was questioned in the following pessimistic statement:

[W]ith New Labour actively resisting European moves to find a genuine Third Way to avoid the vicissitudes of globalised capitalism, the outlook for a systematic attack on inequalities and health, correlated as they are with inequalities in income, is bleak.

(Paton 1999: 68-69)

At this point, it is worth considering policy developments in Scotland, as HIIC is a Scottish-wide programme. Another significant change at this time was the devolution of certain political powers to Scotland. Scotland's new political institutions were formed by legislation enacted by the UK parliament in 1998 (Woods 2004) and consequently, Scotland could enact primary legislation on nearly all health matters. Political devolution gave each country the responsibility to decide on health policies that corresponded to its circumstances and subjected 'the making of policy and the performance of health services to greater democratic accountability through the processes of political scrutiny' (Woods 2004: 326).

As noted in the recent NHS Health Scotland Corporate Plan 2005-08 (NHS Health Scotland 2005) since devolution a number of policy documents and reports have been produced. In 1999 the Scottish Executive published the White Paper Towards a Healthier Scotland (Scottish Executive 1999b), which sets out the major features of the health of the Scottish population. In addition, the White Paper states that health improvement needed to function at three levels: to ameliorate the deficient circumstances experienced by many people in Scotland; to concentrate efforts on unhealthy lifestyles, which contribute to poor health; and to target specific healthrelated issues such as smoking and alcohol. More recently, Improving Health in Scotland: the challenge (2003) presented a framework to inform the mechanisms required to deliver a faster rate of health improvement (Scottish Executive 2003) and proposed to meet two key objectives: to improve life expectancy and healthy life expectancy for adults in Scotland by 2012, and to reduce inequalities between the most well-off and deprived groups. It was recommended that health improvement 
work should be focussed around four main themes: early years, teenage transitions, the workplace, and community-led. In addition, seven programme areas were identified under which particular initiatives would be developed: physical activity, healthy eating, smoking, alcohol, mental health and well-being, health and homelessness, and sexual health.

\subsection{Health promotion}

Health promotion can be viewed as a strategy to address health needs and health inequalities. The origins of modern health promotion (and health education, a related concept) have been traced to the $19^{\text {th }}$ century, when advances in scientific knowledge about diseases, a fear about disease affecting the upper classes and a growing sense of altruism towards the poor led to the development of public health as a formalised discipline (Last 2004; Zealley 2004). For example, the occurrence of widespread disease led to sanitary reform for heavily populated industrial towns (Naidoo \& Wills 2000) and in conjunction with the public health movement the idea of educating the public for the good of its health' (Naidoo \& Wills 2000: 72) evolved.

However, Lupton (1995) argues that the interests of reformers from the early public health movement were generally directed towards maintaining the supply of fit workers for a growing industrial sector and subduing dissatisfaction among the working classes that was believed would lead to revolution, rather than promoting social change solely on the basis of humanitarian principles. Conversely, Dubos (2001) has argued that the elimination of epidemic diseases resulted largely from the campaigns for pure food, water and air initiated by the humanitarian movements committed to the abolishment of the perceived social evils of the Industrial Revolution.

It has been suggested that contemporary health promotion practice developed, partially, in response to individualistic emphasis in health education. In the UK, the Central Council for Health Education was established in 1927 and was mainly 
involved in publishing information and instruction with the aim to change 'unhealthy' behaviour. Almost forty years later, in 1968, the Health Education Council (HEC) was established to develop and implement widespread programmes of education (Naidoo \& Wills 2000). The HEC followed closely the biomedical model of health as espoused by the then Department of Health and Social Security; however, in subsequent years, health education was criticised for its focus on individual responsibility and for not recognising the structural constraints that affected people's choices.

In the 1970s, a number of influential writers and critiques challenged the efficacy and social cost of medicine and emphasised the need to address the environmental as well as the behavioural determinants of health, contributing to the development of health promotion as a concept. First, Thomas McKeown (1976) argued that the reduction in mortality rates in western countries over the previous two centuries had on the whole been due to control of infectious diseases. Thus, health authorities should concentrate on environmental conditions rather than progress in medical or surgical procedures. Second, Ivan Illich (1976) suggested that many biomedical treatments were more likely to result in other medically caused illnesses (iatrogenesis), rather than improving people's health. Third, Lalonde's co-authored report A New Perspective on the Health of Canadians (1974) argued that the effectiveness of health spending could be greatly enhanced through empowering people in communities to identify local health needs and to establish agencies by which these needs could be addressed. Lalonde introduced the term health promotion and argued that in order to improve public health attention should be focussed on the environmental factors that impact on health and individual lifestyle choices related to health states (Bunton \& MacDonald 1992). Thus, Lalonde challenged the 'traditional view of the health field' (1974: 11) which he suggested assumes that all health improvement stemmed from medical science. Subsequently, during the late 1970s health promotion emerged as a movement, discipline and profession (Tones \& Green 2004). 
As noted above the concept of health promotion evolved from a range of influences and critiques and its theoretical underpinnings became more sophisticated as health promotion theory developed. According to Bunton and MacDonald (1992) health promotion adopts a range of political strategies, from the conservative to the radical. In a conservative sense, health promotion can be seen as a method to direct individuals to assume responsibility for their own health and so reducing the financial costs to health services. However, more progressive forms of health promotion seek to influence the relationships between the health care provider and the individual by evading institutionalised medical forms of care for an emphasis on public policy and multi-sectoral action (Bunton \& MacDonald 1992). Radical health promotion aims to foster significant social change, through community development to encourage collective action to challenge the state (Grace 1991; Minkler 1989).

More recently, health promotion has become viewed as a political activity and has been defined as the processes 'by which the ecologically-driven socio-politicaleconomic determinants of health are addressed as they impact on individuals and the communities within which they interact' (Whitehead 2004: 314). In this context, health promotion can be viewed as an intrinsically political process that attempts to change and to enable communities by engaging them in activities that impact on their public health, which could be done through the following methods: agenda setting, political lobbying and advocacy, critical consciousness-raising and social education programmes (Whitehead 2003).

According to Mittlemark (1999) the development of health promotion practice within communities has been justified for a number of reasons. First, it is considered natural for health promoters to practice at this level of human organisation. The social and physical environments at a community-wide level influence the well-being of the people in them and the settings of which communities are composed. For example, schools and workplaces provide opportunities to involve people from different backgrounds in health promotion. Health promoters can utilise the existing structures within a community to channel intense and sustained 
intervention[s]'(Mittelmark 1999: 3). For example, Mittelmark identifies two types of programmes - disease prevention and community development, the latter being of interest for the purposes of this thesis. It is suggested that within a community development programme the main objective is community development for health promotion with an emphasis on building a community's capacity to develop and manage health promotion programmes or to improve the basic foundations for a thriving community, such as equitable access to education and economic security. The challenge in this context is to identify, develop and increase the existing capacities and resources within the community rather than depend on external resources.

Second, according to Ritchie et al. (2004) the focus on community in health promotion came partly from a recognition that behaviour is influenced by the environment in which people live and that local values, norms and behaviour patterns affect an individual's attitudes and behaviours. Consequently, there has been a move towards assuming that long-term, large-scale behavioural change is best achieved by changing the standards of acceptable behaviour in a community or changing community norms about health-related behaviour (Thompson \& Kinne 1999).

Third, a number of reports and declarations were influential in developing health promotion theory and practice and an emphasis on the concept of community emerged during the 1970s (Boutilier, Cleverly, \& Labonte 2000). The Alma Ata Declaration (WHO 1978) reflected a recognition of the importance of community participation in health care by stating that people have the right and responsibility to take part on an individual or collective basis in the planning and implementation of their health care. In addition, government reports such as A New Perspective on the Health of Canadians (Lalonde 1974) assessed the impact of behavioural risk factors on morbidity and premature morality, giving rise to community-based interventions to reduce risk factors for conditions such as heart disease and cancer. These interventions included education, community mobilisation and policy strategies. 
In 1984, WHO Europe argued that health is influenced largely by policies in nonhealth areas, such as housing, transportation and food distribution. WHO proposed 'an intersectoral model of community development, necessitating the cooperation of institutions such as schools, workplaces and governments to create and / or improve on conditions required for an optimal level of health' (Boutilier, Cleverly, \& Labonte 2000: 251). The Ottawa Charter for Health Promotion (WHO 1986) was an important document in the evolution of the health promotion discourse that underpins health promotion via community development and defined health promotion as ways of enabling people to assume control over, and to improve, their health. The Charter supported the validity of community development as a health promotion strategy by demanding an active role for the public through real and effective community action in identifying health priorities, making decisions, planning strategies and implementing them to achieve better health. Central to this health promotion strategy is the 'empowerment of communities, their ownership and control of their own endeavours and destinies' (WHO 1986: 2).

\subsection{Summary}

In summary, the aim of this chapter was to explore the health-related context in which HIIC can be placed by setting out some of the key developments in the health literature that not only influenced the development of the HIIC course, but are also reflected in the course materials. It was demonstrated that the concept of health has been defined in a variety of ways, and has been incorporated into theoretical models that partially reflect assumptions about the causes of health and how to address ill health or health-related concerns. The social model of health was seen as a particular response to the medical conceptualisation of health and attempts to place biological processes into a social context and views individuals holistically. It was also argued that lay understandings of health could be seen as an attempt to challenge medical perceptions of health. Several key health policies were highlighted to show how governments had attempted to address ill health at a population level. Finally, the concept of health promotion was explored by tracing its development and showing how the concepts of community and community development have become 
increasingly influential in health promotion practice. In the next chapter, the concept of social capital is introduced and some of the evidence both supporting and disputing the link between social capital and health is considered. 


\section{Social capital- literature review}

In Chapter 1, it was noted that the HIIC course is concerned with helping students to explore and understand the processes involved in addressing health-related issues in the community. Thus, a pertinent question to ask is 'What is the means by which HIIC students go about addressing health-related issues in their community?' One initial way to explore this question is to consider a concept that attempts to examine the link between an individual and wider social structures. It has been suggested that one such concept is social capital (Coleman 1988a).

Social capital has become a concept used in a wide range of academic disciplines, for example politics, social policy, economics and sociology (for an extensive list see Woolcock 1998); consequently, a large body of social capital research exists. Broadly, social capital refers to the benefits acquired through membership of networks and other social structures (Portes 1998). Levels of social capital have been linked to a variety of issues - such as economic growth and political participation. For example, it has been argued that high levels of social capital in certain regions in Italy can be correlated with a positive effect on governmental and economic performance (Putnam 1993). There is also a growing interest in the relationship between social capital and health (see for example, Baum 1999; Campbell, Wood, \& Kelly 1999; Gillies 1998; Kawachi et al. 1997; Kawachi 2001).

This chapter is divided into two main sections. Firstly, I introduce, discuss and compare the theories of three academics, James Coleman, Pierre Bourdieu and Robert Putnam, whose work has contributed towards popularising the concept of social capital. Secondly, I will review some of the literature concerning social capital and health.

James Coleman (1988b) explored the links between educational attainment and social inequality, and developed the concept of social capital to refer to resources 
that characterise family and community relations which contribute to the cognitive and social development of young people. Thus, social capital can be viewed as a connection between structure and individual agents and according to Coleman is

...defined by its function. It is not a single entity but a variety of different entities, with two elements in common: they all consist of some aspect of social structures, and they facilitate certain actions of actors...'within the structure'...social capital is productive, making possible the achievement of certain ends that in its absence would not be possible... Unlike other forms of capital, social capital inheres in the structure of relations between actors and among actors.

(Coleman 1988a: S98)

Coleman's work identifies two important forms of social capital. Firstly, information channels, which involve trusting others to give accurate information. To illustrate the importance of information channels as a form of social capital, Coleman used a university setting as an example and suggested that academics maintain current research knowledge by exploiting their daily contact with colleagues (information channels). Coleman argued that from this example two important facets of social capital emerge. Firstly, the value of having access to a particular network- thus, academics could increase their individual knowledge through their network of colleagues. Secondly, the specific context in which the network is placed- hence, accessing this information is contingent on being in a university where academics are familiar with the latest research.

The second form of social capital Coleman identified was social norms, which are behaviours accepted within a particular social network. Coleman suggested that social capital is promoted through the closed or restrictive nature of certain networks, by members of such networks dictating the actions of others within the network by the threat of expulsion. In this way social norms, and hence social capital, are established and reinforced within a network. Interestingly, this observation that closed social networks can facilitate social capital has not been made by other leading researchers in the field, such as Putnam (Grix 2001b). 
Coleman's work on the relationship between social capital and educational attainment has drawn a number of criticisms. Morrow (1999) argued that Coleman's approach is not sufficiently contextualised, and that in areas of deprivation, educational achievement may not appear obviously beneficial. If young people from deprived areas do not perceive educational attainment as sufficiently rewarding, it is understandable and rational that they may react by leaving the educational system. Social capital in this situation is therefore low. Thus, according to Morrow's critique, Coleman's formulation of social capital fails to take into account existing social structures. However, my understanding of Coleman's work is that social structures are a significant feature of social capital. In addition, Coleman argues that social capital can lead to negative or positive consequences depending on the context. Given these points it is perhaps difficult to fully accept Morrow's criticism in this case.

According to Morrow (1999), another criticism concerns Coleman's (and Putnam's) treatment of gender issues and social capital. For example, it has been suggested that Coleman and Putnam's theories infer that women's employment has a negative effect on generating social capital (Frazer \& Lacey 1993). Morrow argues that Coleman distinguishes between social capital inside and outside the family. Social capital within the family concerns the relationships between family members (Coleman 1988a). Thus, Coleman, according to Morrow, argues that single-parents and families where both parents work, have low levels of social capital 'because parents simply do not have enough time to give their children enough attention' (Morrow 1999: 747).

Molyneux (2002) argues that much of the existing social capital research primarily refers to male networks. However, where gender relations are considered, they are often distorted by assumptions about women that do not accurately reflect their lived experiences. The omission or misrepresentation of women in the social capital literature is clearly problematic. In addition, women have been shown to contribute to the generation of social capital. Research concerning women among low-income 
groups indicated that it is often those with strong community and kin ties, and engage with social networks and participate in voluntary programmes, all of which are features of social capital. For example, a government sponsored poverty assistance scheme, Plan Vida (Life Plan)- in Buenos Aires involved a million beneficiaries and was administered on a voluntary basis by 22,500 residents, mostly women (Feijoo 2000 cited by Molyneux 2002).

Pierre Bourdieu's $(1985 ; 1977)$ work has also contributed towards the development of social capital theory. Bourdieu argued, that in order to understand the social world the various forms of capital, such as cultural, linguistic or social, which are all rooted in economic capital, need to be explored. Social capital, according to Bourdieu,

is the aggregate of the actual or potential resources which are linked to possession of a durable network of more or less institutionalized relationships of mutual acquaintance and recognition- or in other words, to membership in a group.

(Bourdieu 1985: 243)

Bourdieu, like Coleman, broadly defined social capital as the social ties or association to specific communities that generate resources, benefits and opportunities available to individuals. In other words, social capital is constituted by social processes, both within and between groups, that result in the accumulation of resources. Bourdieu and Coleman's thinking differed in a number of ways. First, Bourdieu maintained that relations among different classes as well as groups informed the distribution of social capital. The second distinction concerns the nature of power within social relationships. Coleman essentially viewed social capital as facilitating collective aims- 'the power to' (Smith \& Kulynych 2002). For example, Coleman refers to Jewish diamond traders (rational actors) in New York, who were able to maximise their economic advantage (optimising individual opportunity) by using local social networks to grade their diamonds and so avoiding expensive legal contracts. On the other hand, Bourdieu, writing from a conflict perspective where social processes result from organised actions required to produce 
goods necessary for daily living (Pope 2003), characterised social capital as 'the power over' (Smith \& Kulynych 2002).

The final social capital researcher considered in this review is the American Robert Putnam, who, building on Coleman's work, defined social capital as those characteristics of social organisation- such as trust, norms and networks- that can enhance the efficiency of society by facilitating organised actions. Whiteley (1999) suggests that Putnam's definition refers to three aspects of social capital. Firstly, a citizen's trust in other members of society. Secondly, social norms supporting cooperation. Thirdly, networks of civic engagement. Putnam's seminal study Making Democracy Work (1993) examined the differences in democracy and economic development in regions of Italy. Putnam quantified levels of association and relations of reciprocity within a region by measuring factors such as voting activity, membership of sports clubs, and newspaper readership. He suggested that involvement in such activities (especially voluntary) was a feature of a positive civic community. The overall result of Putnam's study was that areas showing strong civic engagement, and high levels of participation in civic associations, were more likely to supplement the effectiveness and stability of democratic government. Thus, high levels of social capital were correlated with positive government and economic performance.

According to DeFilippis (2001), Putnam redefined social capital in a number of ways. First, the concept of social capital evolved from being realised by individuals as previously suggested by Coleman and Bourdieu, to being a resource possessed by individuals or groups (whether within areas, communities, or countries). Second, social capital became fused with a particular interpretation of civil society. Hence, 'voluntary, nongovernmental associations, based on trust, become the institutions through which social capital is generated' (DeFilippis 2001: 785). Finally, social capital becomes a normative characteristic assumed to encourage democratic government and stimulating economic growth. 
As Putnam's work has been widely scrutinised (see for example DeFilippis 2001; Edwards \& Foley 1997; Edwards \& Foley 1998; Fine 1998; Fine 2001; Portes 1998; Smith \& Kulynych 2002) I will highlight four considerations. Firstly, it has been suggested that Putnam's approach to social capital adopts a bottom-up perspective in examining the effect of voluntary association on the attitudes and norms of members and on social, political and economic institutions. This perspective ignores the role that political institutions have in influencing the context of associational behaviour (Hall 1999; Maloney, Smith, \& Stoker 2000). Secondly, a citizen's knowledge about civic society or the presence of certain values or attitudes does not necessarily correlate with the performance of government institutions. Rather, it is how people behave that is crucial, and as Coleman suggested social capital is a relational concept; it is specific and contextual. Thus, '[a] given form of social capital that is valuable in facilitating certain actions may be useless or even harmful to others' (Coleman 1988a: S98).

Thirdly, according to Navarro (2002), Putnam (2000) in his work Bowling Alone does not address (or rarely mentions) issues of power and politics. Navarro suggests that this is symptomatic of the influence of the language of economics, particularly in American social science, the result of the alleged triumph of capitalism, which has closed the debate about other forms of social and economic systems and instead refers only to how to manage the existing one. Lastly, although Putnam refers to trust as one of the main features of social capital he fails to distinguish between different forms of trust, for example, that between people and trust in institutions (Levi 1996). In addition, the application of Putnam's model of social capital has also proved problematic (Morrow 2001), by focussing on 'white, middle-class, churchgoing, nuclear families' which do not reflect societies with a range of cultural identities, associations and actions (Mackian 2002). 


\subsection{Social capital and health- arguments against}

Interest in linking social capital and health is a relatively recent development (Hawe \& Shiell 2000; Lomas 1998), although it has been postulated that social capital theory can be traced to Emile Durkheim's (1897) work on suicide (Turner 2003). According to Muntaner, Lynch and Davey-Smith (2001) since 1995 there has been a significant rise in the appearance of social capital in public health discourse.

However, it has been argued that the uncritical acceptance of social capital in the public health literature incorrectly assumes both a common understanding of social capital and its relevance for ameliorating poor health (Muntaner, Lynch, \& DaveySmith 2000). In addition, it has been suggested that evidence supporting a link between social capital and health is inconclusive, vague (Muntaner, Lynch, \& Davey-Smith 2000), and limited (Davey-Smith \& Lynch 2004). For example, the relationship between levels of social capital and mortality in different countries has been found to be inconsistent (Lynch et al. 2001). Others have suggested that until the weaknesses of the empirical evidence for a correlation between health and social capital have been resolved, referring to social capital as an epidemiological variable may be premature (Campbell \& McLean 2002). Campbell and McLean proposed that further research is required concerning the different forms of social capital occurring in various contexts and the ways in which they might be linked to health.

It would therefore appear that a link between social capital and health is contestable. Other issues regarding the concept of social capital and its emergence within public health research have also been highlighted. For example, Muntaner, Lynch and Davey-Smith (2000) doubt the validity of social capital for the following reasons. Firstly, constructs of social capital within the public health literature lack the depth found within other social sciences. In addition, they argue that the concept of social capital has tended to be coupled with a romanticised view of community, one that rarely includes references to social conflict. While it is difficult to argue against notions that suggest civic participation, trust in communities and good neighbourly relations contribute positively to health, the underlying assumptions of such ideas 
often refer to an idealised view of past community life that is rarely justified (Lynch \& Kaplan 1997).

Secondly, Muntaner, Lynch and Davey-Smith (2000) argue that the term social capital is used in public health as an alternative to both state-centred economic redistribution and party politics by being presented as an explanation of inequalities in health and wealth, rather than materialist / structural explanations. It has been suggested that applying the concept of social capital in this way acknowledges the difficulty in addressing structural inequalities and in this context the alternative is to encourage the poor to change their perceptions of their place in the social hierarchy (Proudfoot \& Guest 1997). However, it has also been recognised that social capital can be understood as a marker of inequality rather than as an explanation for it. Macintyre (1997: 728) in her overview of the Black Report identified a 'soft' interpretation of materialist / structural explanations for health inequalities which postulates that physical and psychosocial features relating to the class structure influence health (Marmot 2001). Macintyre suggested that this 'soft' version would maintain that, 'the conditions of life which are determined by occupational class position, and which may influence health and longevity, include psychosocial as well as physical factors, and social as well as economic capital'. Thirdly, others have argued that social capital lacks definitional clarity and consequently, 'it is hard to understand how the concept... and its different manifestations across time and place could be linked to the specific risk factors for particular population health outcomes and how these change over time (Davey-Smith \& Lynch 2004: 698).

It has been suggested that a consequence of applying social capital when it is conceptualised as a 'psycho-social mechanism' (Muntaner, Lynch, \& Davey-Smith 2000: 115) is that it tends to over emphasise the role of the individual, an approach which has been viewed as reductionist and 'victim blaming'. For example, it could be argued that unhealthy communities bring poor health upon themselves because community members do not have strong ties or a sense of community heritage. In other words the individuals themselves are lacking in social capital (Muntaner \& 
Lynch 1999). There is also a disagreement about whether to consider social capital as an individual, psychological construct or as a community level construct. Whiteley (1999) proposes that social capital develops from an individual's normative beliefs and morals and by processes of socialisation. Others argue that social capital is a community level collective construct (Campbell 2000; Hyyppä \& Mäki 2003), one that lies at the centre of participatory democracy as it encourages collective decision making based on trust (Murray 2000). Others have developed a model which dissects the concept of social capital into structural and cognitive components (Bain \& Hicks 1998). The structural component focuses on the degree of associational links and the cognitive component includes perceptions of reciprocity and trust. This model acknowledges both individual and community formulations of social capital. Thus, the tension in viewing social capital as either an individual psychological construct or as a community level construct is reduced.

Many social capital studies aggregate individual responses up to a community level in order to reflect social capital as a public good. However, Lochner, Kawachi and Kennedy (1999) proposed that community features should be measured at a community level and that these features should be seen as distinct from individual characteristics. Lochner, Kawachi and Kennedy go on to suggest that community level characteristics could be identified by observation methods; for example, a measure of reciprocity might be indicated by how many pavements are cleared after a fall of snow.

Other issues relating to research exploring the relationship between social capital and health have been identified. First, some studies examining geographies of health appear to ignore the contextual environmental characteristics of where people live and focus on the aggregated characteristics of the people living in a particular area (MacIntyre 1997; Sooman \& MacIntyre 1995). Thus, it is uncertain how precisely aggregated responses to surveys conducted in predetermined geographical boundaries measure the social environment (McKenzie, Whitley, \& Weich 2002). Second, it has been suggested that a difficulty arises regarding the concept of 
community. Essentially, McKenzie, Whitley and Weich (2002) argue that as there can be multiple forms of community, for example, interest, geographical or relational, then assessing a particular community for levels of social capital is problematic. McKenzie, Whitley and Weich identify two related concerns. Firstly, it can be difficult to identify the boundaries of any community. Secondly, separating the influence of one community over another in terms of social capital generation is also challenging. Others qualify their support for a link between social capital and health by arguing that it should not be used as an isolated concept. For example, Cattell (2001) suggests that social capital utilised with other ideas such as social exclusion, but without the moral underclass emphasis (Murray 1994), could further knowledge concerning the relationship between poverty, place of residence and health and well-being.

\subsection{Social capital and health - a case for a link}

Some have welcomed the emergence of the debate concerning social capital and health. In this context, social capital is viewed as a conduit for social agendas, previously found within the public health arena, that can be highlighted within popular and political spheres, such as the social determinants of health (Baum 1999).

Others support the view that social capital can be linked to health; or rather that high levels of social capital can be correlated to positive health outcomes. Pilkington (2002) suggests that Durkheim's (1897) study of suicide was an example of early research concerning the relationship between social capital and health. Durkheim argued that differing population characteristics of countries explained differing rates of suicide between those countries. Durkheim's contention was that rates of suicides were related to levels of social integration and that the higher levels of 'egotistic' suicide among Protestants compared to Catholics reflected an individualistic ethos (Abercrombie, Hill, \& Turner 1988). 
Other attempts have been made to examine why certain communities thrive and have healthy citizens. For example, a study by Bruhn and Wolf (1979) examined death rates from heart disease among Italian-American migrant population in Roseto, Pennsylvania. According to the researchers, death rates in the 1930 s were $40 \%$ lower than in adjacent towns and it was suggested that these differences could be explained by the level of close ties within each community. Roseto was considered rich in close familial ties, cohesive community relationships, strong interpersonal support and demonstrated an egalitarian ethos. The researchers examined the effects of Roseto community members moving away in the 1960s and it was found that the health advantage was lost. Bruhn and Wolf argued that an increased preoccupation with materialistic values and decreased community relationships were contributing factors to the development of health inequalities in this context.

Research in the USA suggests that characteristics of social capital (trust, reciprocity and membership of voluntary groups) are significant in explaining infant mortality rate, heart disease and violent crime. For example, a study found that States with high levels of social mistrust had higher age-adjusted rates of total mortality (Kawachi et al. 1997). Also it was reported that a one standard deviation increase in trust was correlated with a $9 \%$ lower level of overall mortality (Kawachi 2001). In addition, social capital has been considered to have a positive impact on general indicators of health status and not just on mortality rates. For example, data from 167,259 participants in the Center for Disease Control Behavioral Risk Factor Surveillance Surveys indicated a strong correlation between social mistrust and the number of people who evaluated their own health as only 'fair' or 'poor', rather than 'excellent', 'very good' or 'good'. Further analysis controlled for health insurance coverage, income, level of education, ethnicity, smoking and obesity and demonstrated that residents living in areas with low levels of social capital were still associated with approximately a $40 \%$ excess risk of reporting poor health (Kawachi 2001). However, Pilkington (2002) argued that close attention must be paid to precisely which aspects of health, for example- mortality or morbidity, physical or mental health- are affected by social capital. In addition, Pilkington continues, it is 
possible that social capital may only influence perceived health, rather than actual health.

The above US research suggested a link between social capital and health at a State level. Others have explored this relationship at a community level. For example, social capital may promote health through maintaining health norms, such as informal social control over 'deviant' behaviours, such as underage smoking and binge drinking (Weitzman \& Kawachi 2000). Research concerning social cohesion and crime was conducted in 343 neighbourhoods in Chicago and reported that the level of social cohesion (based on a measurement of trust), in conjunction with motivation to intervene for the public good, was a significant predictor of juvenile delinquency, crime victimisation and homicide rates (Sampson, Raundenbush, \& Earls 1997).

As noted above the idea of social capital includes a concern with levels of civic participation and the characteristics of local networks. In this sense social capital could be a 'useful starting point for conceptualizing those features of community that serve to enable and support the identity and empowerment processes that are most likely to facilitate health enhancing behaviour change' (Campbell 2000: 186). In addition, as Gilchrist (2003a: 151) states, '[t]he discourse on social capital recognises the importance of these (networks) in the terms 'bridging' or 'linking' ties, which are distinguished from the more intimate bonds of kin and friendship.' Harpham, Grant and Thomas (2002) argue that 'bridging' capital refers to social capital which joins different groups or communities, whereas 'bonding' capital describes social cohesion within a group (Narayan 1999). Harpham, Grant and Thomas suggested that the 'bridge / bond' construct is able to account for the role of government and the state in the generation of social capital.

Research suggests that relationships and regular interaction with other people have positive effects on health. For example, individuals who experience stable and 
varied networks lead happier lives compared to those who are more isolated or whose networks are uniform (Argyle 1987; Yen \& Syme 1999). It is also argued that people who have stable and varied social networks have stronger immune systems, suffer less from heart disease and recover more rapidly from emotional traumas (for example bereavement - see Pilisuk \& Parks 1986). Thus, it could be concluded that strong and heterogenous contacts have a positive influence on health. However, others have argued that it is debatable what type of networks - strong or weak ties, homogenous or heterogeneous contacts- influence health (Cattell 2001). Muntaner, Lynch and Davey-Smith (2000) argue that strong links between individuals can increase or decrease the risk of certain health outcomes. For example, close connections among young children in a nursery may heighten the risk of otitis-media (inflammation of the middle ear). In addition, strong friendship networks among peers may increase the risk of smoking or drinking. Conversely, however, in another context such links may decrease the risk of suicide.

Social networks and social capital were found to have a positive influence on improving the quality of life for some participants in Cattell's (2001) research, by ameliorating the effects of poverty and deprivation on health. As suggested by Cattell's study, social networks and social capital produce different health-related outcomes, which might be explained by arguing that class structures are also reflected within networks. For example, middle class people generally have wider, looser (Willmott 1987) and more resourceful social networks (Pearlin 1985), whereas working class people have fewer opportunities to broaden their networks. In addition, it has been argued that personal networks are crucial factors concerning the sustainability and effectiveness of the community sector and community life. For example, informal connections form a system of links and relationships, which promote and develop communication and cooperation (Gilchrist 2003a). According to Granovetter (1973), informal connections or 'weak ties' provide a context in which information, support and resources are shared across organisational, community and professional boundaries. 
This review indicated that the relationship between social capital and health remains conceptually problematic. However, for the purposes of this research project, networks, an aspect of social capital, may be a helpful construct to consider whether HIIC participants contribute to a community capacity building (CCB) process after course completion.

\subsection{Conclusion}

Social capital is a concept found in a variety of academic disciplines. It is an idea that represents for some a way of addressing some of the issues arising from social exclusion. However, it is also an idea widely criticised both conceptually and in its application. This review presented a brief consideration of the key researchers who popularised the theory of social capital. It was proposed that social capital can be generated in closed or restrictive networks. Correlating high levels of social capital to positive government and economic performance was problematic. A 'bottom-up' approach - attributing levels of civic activity to institutional and economic performance- ignores the role of governments in influencing the social and political environment in which civic activity functions. This review also considered the relationship between social capital and health. It was shown that the links between social capital and health are inconclusive. However, aspects of social capital, such as trust and social networks have been shown to impact on health outcomes. Social networks may also be a useful concept to consider in relation to understanding how HIIC students apply their learning at a community or collective level. In the following chapter, the concept of community capacity building is introduced. 


\section{Community capacity building- literature review}

Analytical concepts are always contested and bear different meanings; it is generally those with the interpretative power who are able to give them content and who influence how they are applied 'in the field'.

(Molyneux 2002: 169)

The aims of this chapter are to demonstrate why it is worthwhile to research the concept of community capacity building (CCB) and to establish a conceptual research model / tool of CCB. The concept of CCB has become commonly used in a variety of arenas and is cited in official documents and policies, such as strategies devised to promote community economic development in deprived areas and overseas development through the strengthening of social organisation and institutional development (Banks \& Shenton 2001; Eade 1997). Guidelines have also been issued concerning how charitable organisations can obtain funding to support activities which aim to build capacity within communities (Charity Commission 2000). In addition, the concept of CCB has gained a firm foothold in the health promotion literature for a number of years (Labonte \& Laverack 2001b).

In this review, I begin by discussing the concept of community and then demonstrate how CCB has been coupled to particular interpretations of community in various policy documents and government reports. I then outline the origins of the concept of CCB by suggesting that it was rooted in the notion of community competence. I then consider four articles that discuss different approaches to CCB. In the remaining part of this chapter, I discuss how $\mathrm{CCB}$ has been conceptualised as a series of dimensions and finally, briefly consider some of the issues concerning the measurement of CCB. 


\subsection{Community}

The concept of community is used in many different ways; for example, Hillery (1955) noted over ninety definitions of community. Others have argued that the meaning of community is notoriously vague (Mayo 1994; Sihlongonyane 2001) and as Smith notes (1996: 250) community 'can mean just what you want'. Thus, defining community is problematic; however, attempts have been made to clarify its meaning.

It has been argued that definitions of community refer to a number of elements, such as geographical, relational and interest (Taylor 2003). For example, the geographical element of community defines community as a collective of people from a particular place (Eng \& Parker 1994). However, Glen (1993) argues that it is not always correct to ascribe community status to a group of people simply because they live in the same locality. Confusing place and community is common, yet community may not be present in every place and can be nationalistic, reactionary and ignore other forms of community that are not based around place, such as travellers or diasporas (Brent 2004).

Definitions of community can also refer to relational elements, which Brint (2001:8) views as 'aggregates of people who share common activities and / or beliefs and who are bound together principally by relations of affect, loyalty, common values, and / or personal concern'. Consequently, it has been suggested that increasingly the experience of community is more about the configuration and sorts of relations between people (Lyon 1989). Smith (2001) suggests that community can be defined as an 'interest' and that features such as religious belief, sexual orientation, occupation, or ethnic origin, join interest community members together. Community expressed in this way has presented conceptual space within which non-place forms of community can be understood (Hoggett 1997).

It was suggested above that definitions of community refer to a number of elements. However, community has been conceptualised as a combination of these elements and other aspects. For example, in a study concerning community nursing, 
participants viewed community from a geographical, health and relational perspective. St John (1998) used in-depth interviews to examine how community nurses (from three Australian states) conceptualised the term community. It was found that the nurses' descriptions of the communities where they practiced were based on a combination of different elements such as geographical area, the groups they were working with, and their particular health needs. St John concluded that nursing practice should incorporate an active and sophisticated approach to understanding each specific community. Another example of community from a health perspective concerned research examining the psychosocial needs of haemophiliacs infected with HIV/HCV (Hepatitis C virus), when community was understood in relation to notions of shared identity and issues of survivorship (Gregg 2002).

Having briefly outlined some conceptual definitions of community, it is worth considering how the term community is used, or invoked. Glen (1993) suggests that assigning ‘community' status to certain groups is a tendency among policy makers and social commentators. In a recent article that discussed the usage of the term community within New Labour's community cohesion discourse, which is the framework governing race relations policy, it was suggested that the application of 'community' can be seen as a substitute for using racialized language, whereby practitioners and politicians avoid 'naming' to which communities they are referring (Worley 2005).

Others have argued that assigning the term 'community' to a group to legitimate a political programme or to support a plan of action does not create communities (Ramphele \& Thornton 1988). Although I would suggest that this may depend on whether or not the 'nominal' community has the power to resist or challenge this externally applied label. Mackey (1997) argues that within a political context, notions such as community are distorted to support particular agendas. Consequently, ideas of 'identity' and 'belonging' are constructed through policies. For example, the South African apartheid government perniciously used the term 'community' in its policies promoting separate development and official categories, 
such as 'White community', 'Coloured community' and 'Black community' were used interchangeably with race, ethnic group and nation (Sihlongonyane 2001). Thus, 'community' categories reinforced difference and hence contributed to the underpinning of apartheid policies (see for example Bantu Education Act No 47 1953, Reservation of Separate Amenities Act No 49 1953)

Taylor (2003) citing Glen (1993) and Purdue et al. (2000) suggests three ways in which the concept of community is used: descriptive, normative and instrumental. Descriptive uses of community refer to a group of people who have something in common, for example age, gender or ethnic origin, or who interact with one another on a regular basis. However, Taylor argues that the presence of common attributes does not necessarily correlate with a shared community identity and people who share a common interest are perhaps more likely to describe themselves as a community. As already noted examples of common interests are thought to include cultural heritage (in faith communities), social networks (from kinship), economic interests (service providers, traders) or shared experiences of power; either those exercising power (elites) or those vulnerable to abuses of power (refugees and asylum seekers).

Normative uses of community refer to assumptions about how people should live (Taylor 2003). However, as Taylor suggests, these presumptions may not correspond to how people actually live their lives. One of the main elements in this conceptualisation is a contrast between community and the impersonality of mass society and the state. For some, community represents a way of meeting basic human needs such as a sense of belonging and security (Nisbet 1960). Nisbet suggests community is an intermediate level of society between the individual and the state. Community can therefore act as a force to disperse power from the state and is a more responsive way to meet welfare needs.

Instrumental uses of community occur by confusing descriptive and normative definitions of community. For example, it has been suggested that politicians and policy makers can inappropriately assume that common location or shared interests 
imply 'social and moral coherence, a sense of security, and mutual trust' (Taylor 2003: 38). In addition, it is sometimes taken for granted that community can be transformed into agency. In other words, there is an assumption that community members will start looking after one another, participate in communal activities and work collectively to alter their circumstances. An example of this was reflected in a recent article that highlighted the anticipated calls for the Muslim community to 'exorcise the terrorism in our midst'. It was argued that such a plea reflects misguided assumptions that firstly, a wider homogeneous Muslim community exists in the UK and secondly, that such a community could indeed prevent violent acts (Preston 2005). In responding to Tony Blair's comments, just after the London bombings on the $7^{\text {th }}$ July 2005, '[i]n the end, this can only be taken on and defeated by the community itself' (BBC 2006), it was argued that '[b]y putting the onus on Muslims to defeat terror, the prime minister absolves himself of responsibility' (Saeed 2005).

Taylor also argues that confusing descriptive and normative conceptualisations of community occurs in relation to policies and services. In this way, the term community is used to portray the site or specific services or their position to the public. For example, attaching the prefix community to a service might infer the following (Taylor, Barr, \& West 2000):

- Contact with the public; a way of describing front-line staff

- Support; giving funding and resources to organisations in the community

- Location; situating a service in a neighbourhood, briefing staff to practice in a particular area.

- Consultation; asking people and organisations within a community

(As cited in Taylor 2003: 38)

Community used in the above manner may simply be a descriptive term, however, it might also highlight a way of working, which promotes the belief that delivering services should be in the immediate vicinity and include local people in the process (Taylor 2003). 
Levitas (2000) is critical of the way in which the concept of community is interpreted in contemporary political discourse, and has written about how the term is used by New Labour. Levitas suggests that the concept is used with different meanings or 'promiscuous flexibility' (Levitas 2000: 191). Different forms of geographical community, for example the term 'local community', have also been used to signify the wider constituencies of local government, or the 'world community' as a substitute for 'society'. The use of the concept of community in political discourse is explored in more detail when the development of current interest in community capacity building is examined on pages 61-65.

In summary, there are many different definitions of community and it has been conceptualised, for example, in terms of geographical location, interest and relational. Using these elements to understand the concept of community can be problematic and other studies have indicated that community can be understood using a combination of elements. In addition, three uses of the term community can be identified: descriptive, normative and instrumental. It was shown that the precise meaning of community when used in political discourse can be difficult to identify. The next section introduces the idea of community capacity building and demonstrates how it can be linked to community in a policy context.

\subsection{Community capacity building}

New Labour, elected into power in 1997, has notably accentuated the idea of community, demonstrated by its adoption as one of the central concepts in the new ideology of the party (Fremeaux 2005; Muir 2004). Hence, many government initiatives stipulate community involvement in decision-making processes, and in the design and delivery of services and local development plans (Gilchrist 2003b; Muir 2004). For example, the 'inclusive communities' Action Team was charged to examine a number of issues including ways to devolve decision-making and broaden community participation, and to build community capacity. In their subsequent report, the following justification for involving communities was made: 
COSLA*, SOLACE** and NHS Health Scotland will by July 2003 have begun a programme of work to achieve the following:

- within the context of Community Planning Partnerships support for the development of capacity and ways to promote community involvement and empowerment to deliver health improvement.

- $\quad$ specific support for the public/communities who are involved in CPP to articulate their needs to improve the delivery of services.

Inclusive Communities - Report of the Strategy Action Team

(SAT 1999:26)

\author{
(* COSLA - Convention of Scottish Local Authorities) \\ (** SOLACE- Society of Local Authority Chief Executives and Senior Managers)
}

In addition, following up features from an earlier report, Social justice... a Scotland where everyone matters (Scottish Executive 1999a) a social justice action note entitled Empowering communities was published and stated:

We are committed to tackling poverty and injustice by helping people help themselves. We can help achieve our aim for communities by developing capacity at community level. By:

- empowering communities to make decisions and influence others

- building skills and confidence

- providing the right services and products

- preventing a growing digital divide

Social justice action note: June 2000

(Scottish Executive 2000)

As Gilchrist (2003b) notes, it is recognised, however, that for such initiatives to have a meaningful effect, communities must have a significant role in identifying problems and suggesting solutions to address these concerns. To support these and other similar initiatives, resources have been allocated to fund community capacity building. However, Gilchrist raises a number of issues concerning this community capacity building approach. First, although there has been an emphasis on training 
and supporting members of the community, the establishment of systems to facilitate not only individuals in leadership positions, but also to ensure that they are accountable to the wider community, have often been neglected. Second, there is an assumption that the procedures and organisational culture within local authorities are positive environments in which to manage partnership arrangements. However, other research has suggested that community representatives have felt estranged and hindered by the formal settings and protocols that they encountered at partnership meetings (Craig \& Taylor 2002; Geddes 1998).

Interest in $\mathrm{CCB}$ at a policy level can be understood by examining how political power is exercised using the ideas of 'biopolitics' and 'ethopolitics'. Foucault (1997) applied the term biopolitics to describe a change in how power was exercised during the $18^{\text {th }}$ century. Prior to this shift, power was broadly focussed on defending territory; however, biopolitics refers to an emphasis towards populations. In other words, politics began to engage with the essential processes of human life, such as the size and nature of a population, health and illness, and birth and mortality (Rose 2001). Thus, the power of the state became mobilised to maximise the wealth and health of the population, although this presented new challenges. As Walters (2002: 390) citing Foucault (1997: 73) states,

[a]s a population, humans are governed not as a mere aggregate of individuals, but as a group of living beings which present to political authority all the problems of sanitation, birth-rate, longevity, race, heredity, etc.

Ethopolitics, according to Rose (2001: 18), refers to the means by which the nature of human existence, such as 'the sentiments, moral nature or guiding beliefs' of individuals, groups or institutions, have become the 'medium' within which the 'selfgovernment of the autonomous individual' can be joined to the 'imperatives of good government'. Hence, ethopolitics is concerned with the less substantial aspects of social life, such as degrees of trust within a society, the extent of a sense of community and levels of voluntary efforts (Walters 2002). Therefore, '[i]mproving our communities is the path to reducing crime, improving job opportunities, or 
making representative government more effective' (Walters 2002: 390). Such sentiments have been reflected in policy documents:

Why communities?

- They have direct perspectives on issues facing them

- Community involvement helps deliver programmes which more accurately meet their needs

- Resulting projects are more acceptable to the community with improvements lasting longer because communities own them

- Builds community organisational skills, making it easier to develop strong successor skills

- Successful community involvement helps to revitalise democracy'

Inclusive communities - report of the Strategy Action Team 1 (SAT 1999)

It has been argued that within an ethopolitical context communities have become the site of new strategies 'for the government of others and techniques for the government of the self' (Rose 1996: 331). For some the development of community involvement cannot be entirely explained as an outcome of 'privatisation' or market reforms introduced to the public sector (Marinetto 2003); rather community has become a 'new specialization' of government (Rose 1996). As a result, the concept of community has become incorporated into professional programmes. For example, Improving health in Scotland- the challenge (Scottish Executive 2003) presents a framework to achieve a faster rate of health improvement and suggests that communities represent a location for health improvement initiatives:

The communities we live in can have a considerable influence on our health... Our approach will build on work already initiated that:

- seeks to encourage, support and enable individuals and communities to take shared responsibility for their own health and to work together to bring about improvements. Programmes such as Health Issues in the Community are key to empowering the public and enabling people to become more involved in community issues.

- seeks to support action to address poverty, lack of physical activity and leisure facilities, poor housing and other factors that contribute to inequality.

Improving health in Scotland- the challenge

(Scottish Executive 2003: 25) 
The community becomes the focus for tackling established social problems, where the abilities and resources of communities are used by policy programmes through emphasising responsible self-help (Rose 1999), for example:

NHS Health Scotland, local authorities, working with a wide range of groups including CHEX and the Community Diet Project, should identify and pursue action to enable communities to identify, learn, develop and implement health improvement issues that are important to communities.

Improving health in Scotland- the challenge

(Scottish Executive 2003: 27)

In 1999, the Scottish Executive published a report about social justice and presented a political vision to address poverty and to promote social inclusion. This report also included a series of targets to measure the progress towards achieving a fairer society in Scotland and stated regarding the role of communities in this process,

The strength and wellbeing of communities and neighbourhoods is vital because this is where we live together. And it is how we live together can make or break a community...

Scotland has some of the most disadvantaged communities in the UK. And it is not restricted to our urban areas. Our rural communities also face many obstacles because of isolation, lack of opportunities or difficulty in accessing the opportunities that are available. We will tackle the problems in the worst of these areas and prevent others from becoming disadvantaged. We will do this through an integrated approach to strategic planning, involving communities in the renewal of their own neighbourhoods and by making sure these communities can influence what happens in their own area. We will make sure services, including health and community care, are organised around the needs of the individuals and communities rather than the benefit of the agencies which deliver those services.

Social justice - a Scotland where everyone matters

(Scottish Executive 1999a: 16)

As previously stated, Levitas (2000) critiques how the concept of community is often applied in contemporary political discourse and highlighted three important concerns. First, there is a commonly stated expectation that groups of people, who are often inadequately resourced, should organise themselves and take collective 
action to improve their circumstances. Second, the emphasis on local collective action relies overwhelmingly on unpaid work, which on the one hand, can be seen as promoting participation by local people and local organisations in providing their own services. However, on the other hand, increasing reliance on voluntary associations rather than local government may diminish accountability and transfer the costs of service provision onto individuals through their unpaid work. Third, as previously noted the conceptualisation of community in current political thinking can be contradictory and problematic. Levitas concludes that this raises a number of questions, such as 'Who has the power to define and represent community?', 'What is the response to groups of people who through their collective action challenge current political thinking?' and 'Who defines community capacity - capacity to do what, on whose behalf and in whose interests?' In the following sections, the origins of the concept of CCB are outlined and its definitions are discussed.

\subsection{Origins and definitions of community capacity building}

It has been argued that the origins of the concept of CCB has its roots within community psychology (Hawe 1994). In 1966, a group of American psychologists severed its connection with the American Psychological Association, arguing that communities have the potential or capacity to address their own problems. In so doing, this 'break-away group' challenged the idea that practitioners and programmes should focus on what was lacking in a community and for example viewed health professionals not as experts but as resources. These arguments were developed into the concept of community competence (see Cottrell 1976), which reflects some of the basic tenets of CCB. According to Iscoe (1974), the development of a competent community involves the provision and utilisation of resources in a geographical or psychological community, so that the community members can make reasoned decisions about the issues confronting them. Having outlined the origins of the concept of $\mathrm{CCB}$, its definitions are considered below. 
Despite the concept of CCB being cited in research literature, it is often inadequately defined (Hawe et al. 1998; Smith, Baugh-Littlejohns, \& Thompson 2001). For example, a recent synthesis paper concerning community capacity reported that after examining sixty-five documents it was found that half did not provide a definition of community capacity (Kwan et al. 2003). However, other academics have offered definitions that appear to be broadly similar, for example,

Community capacity is the interaction of human capital, organisational resources, and social capital existing within a given community that can be leveraged to solve collective problems and improve or maintain the wellbeing of a given community. It may operate through informal social processes and / or organized effort.

(Chaskin 2001: 295)

Community capacity building...describes a more generic increase in community groups' abilities to define, assess, analyze and act on health (or any other) concerns of importance to their members.

(Labonte \& Laverack 2001b: 114)

Community capacity is 'the characteristics of communities that affect their ability to identify, mobilize, and address social and public health problems'.

(Goodman et al. 1998: 259)

However, when CCB is poorly defined it has been suggested that this perhaps reflects the confusion about whether community capacity building can be viewed as a distinctive process or whether it is simply community development by another name (Gibbon, Labonte, \& Laverack 2002; Schuftan 1996). Community development is a concept with a number of definitions. For the purposes of this review, community development is defined as a process that ensures local people are included in defining and acting on issues that impact on their lives. In addition, the processes of community development should also involve those who are usually excluded from the decision-making mechanisms and as well as seeking to challenge 
discrimination and inequality (Association of Community Workers as cited in Health Education Board for Scotland 2002a: 101).

A study that attempted to clarify the distinction between community capacity building and other approaches to community development was based on research conducted in the David Thompson Health Region, Canada. CCB was defined as the extent to which a community can generate, implement and sustain actions for strengthening community health (Smith, Baugh-Littlejohns, \& Thompson 2001). In their analysis, the authors introduced the concept of community mobilisation, which in a health context involves communities being stimulated and persuaded by health professionals to achieve a desired social or behavioural change, whereas $\mathrm{CCB}$ relates to community members initiating collective action independently (CWHPIN 1998). In the next section, four studies that have attempted to conceptualise approaches to CCB are outlined.

\subsection{Approaches to community capacity building}

The four articles in this section refer to different approaches to community capacity building. The first study written by an Australian and a Canadian (Labonte \& Laverack 2001b), referred to a model of empowerment, developed from one of the authors' previous research (Laverack 1999), and discussed community capacity in terms of a 'parallel-track'. In this context, community capacity is viewed both as an aim and as a health enhancing process, alongside health promotion programmes. The authors defined community capacity building as increasing community groups' abilities to define, assess, understand and act on the health concerns of their members (Labonte \& Laverack 2001b: 114). In retaining an emphasis on community capacity building as an end in itself, the authors are incorporating the empowerment values attached to a broadly developmental approach to community capacity building that is also found in the work of Banks \& Shenton (2001) (see the fourth study in this section). 
The second study, based in Australia by Crisp, Swerissen and Duckett (2000), reviewed the existing literature about capacity building and health and drew attention to some of the implications for funding bodies. The authors identify four distinct approaches to capacity building: bottom-up organisational, top-down organisational, partnerships and community organising (Crisp, Swerissen, \& Duckett 2000).

A bottom-up organisational approach involves the development of skills that benefit the individual, the organisation and the wider community. The focus of this approach is the training of members of a health-related organisation. It is proposed that rather than sending staff on external training courses, a more effective way of building capacity is for an organisation to adopt an ethos of continuous learning and improvement. In this context, it is assumed that members of staff will be motivated to become more reflective about their professional practice (individually and collectively), with the aim of making health programmes more sensitive to the needs of the community (Hall \& Best 1997).

A top-down organisational approach recognises the importance of organisational capacity and the primary concern, in this context, is the infrastructure of an organisation. Within this approach, building capacity is achieved through restructuring the organisation. For example, according to Bainson (1994) the Ghana Leprosy Service (GLS) devolved the function of planning and implementation of programs from a single central agency to a regional and district level. It was found that GLS became more responsive and effective to address local needs and health issues.

A partnership approach to capacity building occurs through promoting an environment where knowledge and information can be exchanged. For example, it was reported by Vicary et al. (1996) that fifty-six agencies in rural Pennsylvania formed a coalition concerned with addressing the health needs of women and their families. Representatives from each agency met on a regular basis and an increase in 
the interactions with other agencies was reported by $83 \%$ of the members of the coalition. In addition, a majority of the representatives (87\%) reported that their involvement with the coalition had resulted in new inter-agency collaborations (Vicary et al. 1996).

The final approach noted by Crisp, Swerissen and Duckett (2000), one that is particularly relevant to this thesis, is community organising, which involves working with excluded members of a community to address health issues. Capacity building, in this context, aims to transform individuals from passive welfare recipients to active participants in a process of community change (Finn \& Checkoway 1998). It has been proposed that a community organising approach to capacity building would be more effective in communities that have existing resources, such as health or welfare professionals who become involved with health promotion (Goodman et al. 1993). However, this approach to capacity building can lead to a community's expectations being raised to an unrealistic level. For example, the Prevention of Maternal Mortality Network (PMM) facilitated a program of community mobilising and health education in West Africa. The demand for obstetric care was high and beyond the capacity of existing facilities; consequently, community members became discouraged and the use of health facilities decreased below pre-intervention levels (Kamara 1997).

In the third study Hawe et al. (1998) conducted six focus groups to explore Australian health promotion workers' understanding of capacity building; some of the main findings were as follows. First, CCB was conceptualised as one of five levels or aspects of capacity building. The other levels were individual, within health care teams, within health organisations and across organisations. Second, there was agreement concerning the need to make sense of the term capacity building. Third, the practitioners referred to working without explicit recognition or working 'invisibly'. A number of factors were identified which contributed to working 'invisibly', including a lack of clarity around the meaning of capacity building and misunderstandings regarding the work done by health promoters. Fourth, a number 
of positive outcomes of capacity building were reported, such as gaining skills in health promotion, building confidence and knowledge in health promotion, adopting health promotion values at an organisational level (for example, in policy documents), or if groups initiated health promoting activities independently.

The issue of 'invisibility' was one of the main themes from Hawe et al.'s analysis and they suggest that capacity building went unnoticed in two ways. First, from funding bodies and administrators because the official aims of most health promotion programs are national priority areas. Thus, work that engaged with health issues outside the national priority areas could remain unnoticed by funders or administrators. In addition, legitimate health promoting activities were considered (by policy/decision makers) to be those designed specifically to address 'risk factor change' among population groups. Second, in a professional environment where encouraging health promotion was deemed unwelcome, such as persuading clinicians to undertake health promotion, capacity building was hidden from 'receivers and partners' to make it more effective (Hawe et al. 1998). Despite the hidden nature of capacity building, the researchers found that health promoters supported efforts to make capacity building more visible and open to scrutiny.

The fourth study suggests that developmental and strategic approaches to CCB can be identified. Using interviews, focus groups and observational methods, Banks \& Shenton (2001) examined the role of two Groundwork Trusts, (independent organisations that work alongside local communities which aim to improve environmental conditions) in South Yorkshire and County Durham, UK. Banks and Shenton suggest that a developmental approach to CCB includes any process that results in community members working collectively to achieve social change; this is seen as being equivalent to community development. For example, a capacity building worker reported that $\mathrm{CCB}$ was a 'process of empowering local people to identify what they want and need. And also involving them in the political process' (Banks \& Shenton 2001: 289). This description of CCB is similar to definitions of community development. For example, '[t]he community development process 
works with communities to analyse, initiate and influence social change' and is about 'building active and sustainable communities' and 'changing power structures to remove the barriers that prevent people for participating issues that affect their lives' (Standing Conference for Community Development 2001: 5).

Banks and Shenton refer to community work in Craghead, County Durham as an example of a developmental approach to CCB. A community partnership was formed, supported by Groundwork West Durham. The partnership became a selfsufficient group and in 2000-2001 employed a CCB worker. The researchers argued that capacity building in Craghead could be seen as part of an ongoing community development process. In addition, capacity building in this area did not follow an explicit, strategic, or focussed approach. However, despite this the partnership developed and used its links with Groundwork positively. The researchers contrast the CCB developmental approach in Craghead with a strategic approach used in Bolton-on-Dearne.

A strategic approach involves a more targeted sense of CCB and may be part of, but not equivalent to, a wider community development process. For example, according to the European Social Fund Voluntary Organisations Network (as quoted in VSTU 1998) capacity building is not a synonym for community development, rather it is in addition to it. In this context, its purpose is to develop skills and structures in a community to enable people to initiate and participate in community development. Banks \& Shenton (2001) argue that CCB as a strategic approach is distinct from community development for two reasons. First, 'strategic' community capacity building is described as a way in which groups can achieve certain objectives. Second, it is overtly rational and systematic, compared to the informal and open nature of community development.

Banks and Shenton describe community work in Bolton-on-Dearne to illustrate a strategic approach to community capacity building. Following pit closures, 
Groundwork Dearne Valley (GDV) an organisation concerned with regeneration was established in 1995, and part of their strategy was community capacity building. This involved identifying local needs, involving local people, securing funding and implementing plans and giving local people permanent roles through training and skill development. The researchers interviewed Groundwork training officers who reported that although the scheme had been running for five years, a lot of support was still being given by Groundwork. Despite the slow progression towards independence and self-sufficiency, a number of positive outcomes could be seen. For example, Banks and Shenton identified the establishment of new community groups and the involvement of a number of local people in the planning and implementation of work.

As noted, Banks and Shenton identified two approaches to CCB: developmental and strategic. They argue that as community projects may straddle developmental and strategic approaches, it is useful to locate capacity building on a strategic/developmental continuum. They conclude that CCB comfortably embraces some interpretations of communitarianism, 'Third Way' politics, and a growing interest in citizen participation and responsibilities (Etzioni 1995); (Giddens 1998); (Tam 1998); (Roger 2000), concepts which are outlined below.

It is possible to see a relationship between CCB and certain interpretations of communitarianism (Diamond 2004; Levitas 2000). Communitarian perspectives support the promotion of strong communities to address social problems (Taylor 2003). This perspective balances between the individualism of the market, with its negative effects on community life, and dependency on the state (Tam 1998). Broadly, communitarianism is characterised by placing an emphasis on moral norms and obligations and on responsibilities and rights within the family and the community. In this sense communitarianism presents 'a political vocabulary which eschews market individualism, but not capitalism; and which embraces collective action, but not class or the state' (Driver \& Martell 1997: 33). Within this perspective the state's role is to facilitate a burgeoning community life (Calder 2003) 
and where community, 'refers to [the] practical means of furthering the social and material refurbishment of neighbourhoods, towns and larger areas' (Giddens 1998: 79), an idea which can be seen in the policy documents highlighted above (see 6165). Thus, the idea of CCB with its emphasis on developing a community's ability to identify and address issues is compatible with the aforementioned communitarian ethos.

'Third Way' is a relatively recent perspective although agreement about what it means has yet to be established (Driver \& Martell 2000; Halpern \& Mikosz 1998). For some Third Way thinking is a 'pragmatic and eclectic loosely based approach to the social, political and economic context of the late twentieth and early twenty-first century' (Popple \& Redmond 2000: 393). One of the leading academics expounding Third Way theory is Anthony Giddens $(1998 ; 2000)$ who argued that the concept expresses what others refer to as 'the modernising left' or 'modernising social democracy' (Giddens 2000) and represents a way of articulating the response to changes brought about by the 'twin revolutions' of globalisation and the knowledge economy. It is suggested that this change is characterised by a shift from manufacturing production to information technology, and a declining role of class politics but the expansion of consumerist values.

According to Giddens' theory, there are three domains of particular interest: government, the market and civil society. In his analysis, Giddens argues that the relationship between these domains is fractured, but can be reconnected by a 'new social contract', which refers to the rights and responsibilities of citizens. According to Giddens the state's role is to intervene in the market and civil society in a regulatory context and provide the resources for citizens to assume responsibility for the consequences of their actions. In addition, strengthening civil society is a necessity for effective democratic government and for an efficient market system (Giddens 2000). 
Citizen participation is an important idea that informs New Labour's social policy and is understood as 'the engaging of individuals and groups in the renewal and strengthening of their own communities' (Demos 2003: 9). For example, according to the National Neighbourhood Renewal Strategy (Neighbourhood Renewal Unit 2002) launched in 2001, the primary objective of participation is to ensure that local residents and community groups have a central role in improving their neighbourhoods.

Stoker and Bottom (2003) argued that it is possible to distinguish between policies that are informed by an assumption that people are largely responsible for problems within their own community and those policies which view these problems as originating from the inequalities and power divisions within capitalist societies. In other words, problems in communities are explained either by the inadequacies of community members or by the structures in society. For those that constructed the locus of the problem at an individual level, the solution was to instigate focussed development on 'problematic' individuals, partially to encourage compliance to the moral standards of the rest of society and to reverse their addiction to a dependency culture. Conversely, those with a structural perspective favour confrontation and community protest and encourage the powerless to challenge those in power.

However, Stoker and Bottom (2003: 6) argued that as the debate developed the two positions outlined above were largely avoided and instead a 'system level explanation and solution' was offered. In this sense, community capacity building policies can be viewed as attempting to take a middle way so that blame is neither allocated to the individual nor to social structures. Instead, the emphasis is on systems of relationships and institutions that influence how communities function. Such policies are considered reformist in nature and any changes that occur are within the boundaries of a market economy with a commitment to liberal democracy. It is within this broader social context that concepts such as social capital and community capacity building can be located. 
In summary, it was suggested above that the origins of the concept of CCB can be traced to the idea of community competence. A literature review illustrated that studies often omitted to define CCB. However, the three definitions highlighted in this chapter were considered to be broadly similar. Different approaches to CCB were discussed and it was suggested that CCB complements aspects of contemporary political discourse. Exploring the concept of CCB may help to develop understanding of how communities address health and social concerns. However, it remains to be seen whether the concept of CCB will follow that of social capital, which according to Grix (2001b) has suffered from becoming a global phrase that has become difficult to define in a meaningful way.

\subsection{Dimensions of community capacity building}

Having discussed some definitions of CCB it is worth at this point to consider characteristics or dimensions of community capacity building. Labonte \& Laverack (2001a) argued that there is a broad agreement concerning the dimensions of community capacity. However, this view is questionable when considering the literature relating to CCB dimensions (see Kwan et al. 2003 for a systematic review), which indicates that there is significant variation in dimensions identified.

Previous attempts to conceptualise CCB have involved identifying characteristics or qualities of a 'capable community' (Labonte \& Laverack 2001b). Labonte \& Laverack referred to a number of other studies (for example, Bopp et al. 1999; Goodman et al. 1998; Jackson et al. 1999a; Jackson et al. 1999b; Laverack 1999), which have attempted to classify the characteristics of CCB. However, for the purposes of this review, the work of Chaskin (2001), Goodman et al. (1998), Labonte \& Laverack (2001a; 2001b) and the Scottish Community Development Centre (Scottish Community Development Centre 2003) will be considered. In a US study Chaskin (2001) reviewed existing CCB literature; interviewed policy makers, community workers and academics; analysed data from an ongoing case study of community schemes in four North American neighbourhoods 
(Neighbourhood and Family Initiative); and devised a contextual model to understand community capacity. Chaskin's model incorporates six dimensions (shown here in italics). Three of the dimensions relate to community capacity in itself; for example, its fundamental characteristics, levels of social agency in which capacity is located and through which it may be undertaken and increased, and its functions. The fourth dimension concerns the strategies, which seek to increase community capacity. The fifth dimension focuses on the conditional influences that hinder or promote capacity and the final dimension relates to the community-level outcomes resulting from community capacity building initiatives. In the article, Chaskin explains each of the six dimensions in detail; however, for the purposes of this section, which is concerned with the aspects of $\mathrm{CCB}$, the first dimensionfundamental characteristics of community capacity is the most relevant. According to Chaskin, community capacity has four fundamental characteristics: a sense of community, a level of commitment among community members, the ability to solve problems and access to resources.

Goodman et al. (1998), as cited in Hawe et al. (1999), conducted a study commissioned by the Centres for Disease Control in the USA to construct a consensus concerning the components of community capacity. They identified ten components or dimensions of community capacity: social networks and interorganisational relationships, community resources, sense of community, understanding of community history, citizen participation, community leadership, skills, community values, critical reflexivity and community power. However, I would suggest that these dimensions reflect, in part, features that might characterise an established and identifiable community. These features might not apply in the context of this study, as HIIC students may come from differing communities or may not identify with any notion of community.

Labonte \& Laverack (2001a; 2001b) drew from Laverack's (1999) research on community empowerment and identified nine domains or dimensions of community capacity: participation, leadership, organisational structures, problem assessment, 
resource mobilisation, 'asking why?', links with others, role of outside agents and program management. Writing from a health promotion perspective, Labonte \& Laverack viewed the processes of CCB as health enhancing and gave a brief explanation of how each of the aforementioned dimensions might promote health, as summarised below.

Participation is the basis of CCB and promotes health in a number of ways. First, increasing social networks and support improves self-social esteem and decreases isolation. Second, increased participation in local political / decision-making structures may improve the general quality of life within a community through better forms of governance. The health promoting benefits of leadership are not immediately clear, according to Labonte and Laverack, although they suggest that leaders may gain materially and psychologically from the experience. In addition, a community without leadership may not be equipped to mobilise resources or influence health-related policies or debates.

Organisational structures can be unhealthy or healthy for their members. For example, an unhealthy organisational structure might be characterised by inadequate management of conflicts or by cliques developing. Ineffective organisational structures will also be generally less well equipped to mobilise resources, provide social support, develop networks or influence health-related decisions / policies. Problem assessment can facilitate communities to develop ideas of selfdetermination and power and a CCB approach maintains that communities should identify issues and the means to address their concerns, and take collective action to resolve them. 'Asking why?' implies that a community can engage critically with issues concerning social, political and economic inequalities. According to Labonte and Laverack both problem assessment and 'asking why?' are broadly associated with learning and education, which promote more general health benefits. For example, people with a higher education can improve their health by being more materially secure, by adopting healthier lifestyle behaviours and by developing self- 
social esteem. In addition, critical learning, a feature of informal education, ${ }^{2}$ can also be health enhancing through addressing 'learned helplessness', a concept which relates to how individuals internalise objective conditions of relative powerlessness as inherent, and so reduce their power to act (Seligman 1975; 1990).

Labonte and Laverack argued that resource mobilisation and health is linked in several ways. For example, external resources may decrease poverty and generate local employment and using internal resources may promote the self / social-esteem of community members. Health promotion programmes can also be seen as a form of wealth distribution, as the programme represents a service or resource which community members are not charged for. Links with others refers to social networks and it is suggested that health expectancy is positively associated with relatively large and dense social networks (Kawachi 2001). Labonte and Laverack proposed that the role of outside agents is an important link between the community and external resources. Program management may improve health through increasing people's sense of control over their living environment.

The Scottish Community Development Centre (SCDC), the national development centre for community development in Scotland, based on a partnership between the Community Development Foundation (a UK non-departmental public body funded by government to promote community development) and the University of Glasgow, published details about building community capacity within the LEAP programme. LEAP (Learning, Evaluation And Planning) was described as a method for integrating planning and evaluation for community learning, community health, volunteering and other community activities (Scottish Community Development Centre 2003). According to SCDC, building community capacity is one of the core purposes of community learning and community development. SCDC suggest that community capacity is achieved by working with communities to plan and address

\footnotetext{
${ }^{2}$ Informal education has been described as the learning that occurs in everyday life and operates through conversation, includes examining and widening experience and can occur in any setting (Smith 1997).
} 
their needs, supporting the development of skills and confidence of activists and organisations, promoting broad based participation in community affairs, assisting communities to exercise power and influence, and assisting communities to provide or manage services.

\subsection{Conceptualising CCB for the purposes of this research study}

As shown in the four examples above, a variety of dimensions have been identified in attempts to conceptualise CCB. Some authors have commented on this process; for example, Baker \& Teaser-Polk (1998) called for a flexible approach when exploring CCB and argued that some dimensions will have different meanings for particular communities and the various levels within communities. For example, community members might understand participation or resource mobilisation differently to those 'outside' the community, such as policy makers or researchers. In addition, Eng \& Parker (1994) warned against simply copying dimensions from other research and, whilst researching community competence, used qualitative methods to ensure their dimensions were valid, robust and culturally relevant. However, the focus of this thesis was not to establish the dimensions of $\mathrm{CCB}$; rather it was to explore the concept in relation to HIIC. Thus, I considered that engaging with pre-defined dimensions from the literature was an appropriate approach and the process of finalising the dimensions adopted for this study is described below.

Some dimensions of CCB may not be suitable to use in an interview context. For example, asking participants to discuss dimensions such as an understanding of community history (Goodman et al. 1998) or community leadership (Goodman et al. 1998; Labonte \& Laverack 2001b) may require them to have a certain degree of knowledge about their community. In addition, other dimensions are complex and difficult to define, such as community power (Goodman et al. 1998) or assisting communities to exercise power (Scottish Community Development Centre 2003). Dimensions such as programme management (Labonte \& Laverack 2001b) also 
imply certain assumptions regarding a community's existing infrastructure, i.e. that programmes are in place.

After considering the aim of this project and the research questions (see Chapter 5) in relation to the models of $\mathrm{CCB}$ found in the literature and in light of the issues raised above, I concluded that the work of Labonte \& Laverack (2001a; 2001b) provided the most useful basis from which to construct a research model of CCB. The proposed research sample population for this study (see Chapter 6) was drawn from HIIC courses that were facilitated in different geographical areas in Scotland, with students from different backgrounds, each potentially with a different understanding of which community they identified with. Thus, it was decided that the most relevant dimensions for this research project were: participation, resource mobilisation, links with others and role of outside agents. The rationale for selecting these dimensions was firstly, to avoid using terms that might require participants to have an 'expert' knowledge of their community, and secondly, to use concepts that could be applied in different community contexts or settings.

To conclude, from reviewing the literature it appears that a broad consensus concerning the dimensions of $\mathrm{CCB}$ has yet to be reached, despite a number of attempts to identify them. In the context of conceptualising CCB for research purposes, caution was recommended before copying dimensions from other research without prior testing. However, adapting the work of Labonte and Laverack (2001b) was considered an appropriate method for this study and I concluded that the following four dimensions participation, resource mobilisation, links with others and role of outside agents would be used to construct a research model of CCB. Having considered the dimensions of community capacity building, I shall now discuss issues relating to measuring community capacity building. 


\subsection{Measuring Capacity Building}

Crisp, Swerissen and Duckett (2000) propose that the difficulty in measuring capacity building is that each project may use a specific set of approaches and strategies and hence require different indicators. However, for Crisp, Swerissen and Duckett, the main question is whether sustainable changes to the health of an organisation or community can be attributed to an intervention. Consequently, it is more appropriate to evaluate the implementation and subsequent impact of capacity building processes. They identify three key points concerning the measurement of capacity building and health. First, actual programs for building capacity need to be specified and relevant performance indicators developed. Second, measuring capacity building within communities needs to reflect community processes, rather than aggregating impact measures for individuals (Shiell \& Hawe 1996). Third, capacity may develop in other areas irrespective of the original intentions and so additional measures of capacity may be required.

Guidelines on measuring community capacity building have been published. For example, How good is our community learning and development? (HMI 2002) sets out quality indicators for practitioners and managers to evaluate community learning and development activities as shown below. 


\section{Building Community Capacity}

\begin{tabular}{|c|c|}
\hline QUALITY INDICATOR & THEMES \\
\hline Work with communities to identify their needs & $\begin{array}{ll}- & \text { needs assessment } \\
- & \text { focus on excluded groups }\end{array}$ \\
\hline Developing skills and confidence & 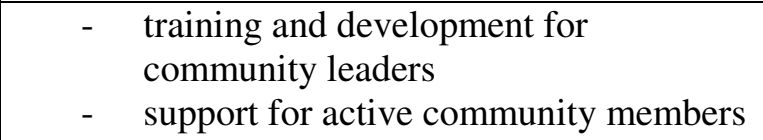 \\
\hline Promoting participation in community affairs & $\begin{array}{ll}- & \text { support for volunteering } \\
- & \text { support for community self-help } \\
- & \text { openness and accountability of } \\
& \text { organisations } \\
\end{array}$ \\
\hline $\begin{array}{l}\text { Assisting communities to exercise power and } \\
\text { influence }\end{array}$ & $\begin{array}{ll}- & \text { support for community organisations } \\
- & \text { community influence and representation } \\
\text { - } & \text { assisting communities to provide and } \\
& \text { manage services }\end{array}$ \\
\hline $\begin{array}{l}\text { Monitoring and evaluation as part of building } \\
\text { community capacity }\end{array}$ & $\begin{array}{ll}- & \text { monitoring and evaluation methods } \\
- & \text { arrangements for recording } \\
- & \text { use of monitoring information }\end{array}$ \\
\hline Community achievement & 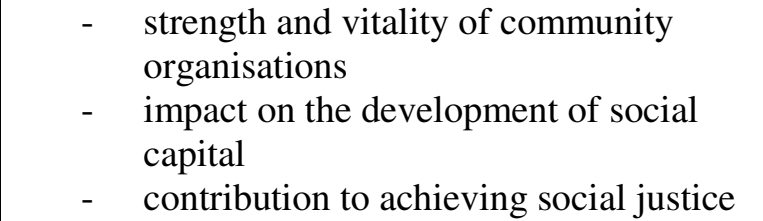 \\
\hline
\end{tabular}

(Adapted from How good is our community learning and development? HMIE 2002)

Labonte and Laverack (2001a) suggested that one way to measure CCB is to assess each dimension for change, using interviews, focus groups, surveys or documentary analysis. They identified three other studies Bopp et al. (1999), Laverack (1999) and Hawe and Shiell (2000) that also attempted to measure community capacity building by using a form of ordinal ranking. However, this level of measurement is limited as variables can be ordered, but differences within the same variable can not be measured (Fielding \& Gilbert 2000). For example, take the following hypothetical scores for 'measuring' participation: $1=$ no participation, 2 = participates in some community meetings, 3 = participates in community meetings and is involved in decision making process, 4 = participates regularly in decision making and is engaged with activities outside community. At an ordinal level, a person who scores 
four could be said to participate more than someone scoring one. However, it is not possible to state that this person participates four times as much, using this level of measurement.

Two questions can be asked concerning ranking the dimensions of CCB. First, 'How is the rank determined?' Labonte and Laverack (2001a), referring to Laverack's earlier work (1999), argued that pre-defined ranking categories can unduly influence participants' responses and that the experience of responding to such categories could be intimidating for the interviewee. However, it was found that this issue could be resolved by using a workshop methodology to discuss the dimensions and their ranking (Labonte \& Laverack 2001a). Second, 'Who assigns the rank?' Laverack (1999) and Bopp et al. (1999) proposed that ranking should be decided by the relevant stakeholders (e.g. health promoters) and the community members who are subject to the particular programme. In addition, other methods to address this question included repeat interviews with community leaders and other participants (Eng \& Parker 1994).

I would argue that a further unresolved issue after reviewing Labonte and Laverack (2001a) concerns the relationship between the various dimensions of CCB. For example, it is unclear what the implication, if any, would be for a CCB assessment if the participation dimension had a low score, but leadership scored highly, or if three out of nine domains have a low ranking score, could it be assumed that CCB was occurring? Hence, the relationship between each dimension of $\mathrm{CCB}$ requires further clarification.

Another issue about measuring CCB concerns the nature of the measurement process. For example, Baker and Teaser-Polk (1998) argue that any attempts to measure or evaluate CCB should also correspond with the intended outcome (of $\mathrm{CCB})$. In other words, the process should reflect both a recognition and an understanding of a community's history, maximise participation, embrace existing 
skills and resources, and reflect a mutual respect for different perspectives. As stated, one of the objectives of this research project was to further understanding about $\mathrm{CCB}$ in relation to HIIC; rather than to measure $\mathrm{CCB}$ in the manner highlighted above. However, I propose that exploring dimensions of community capacity building with participants would be appropriate. For example, participants could be asked if completing HIIC had influenced their level of participation in their community.

\subsection{Conclusion}

In this chapter, I attempted to outline why exploring the concept of $\mathrm{CCB}$ was relevant, and to describe the process of constructing a CCB research tool. This chapter introduced and discussed various aspects of $\mathrm{CCB}$ and was organised around a number of themes. Firstly, the concept of community was considered. It was demonstrated that there are different definitions of community and that it can be understood in relation to particular factors, such as geographical, relational and interest elements. It was noted that academics have argued that the concept of community is used in three ways: descriptive, normative and instrumental. One way in which community and policy have been linked is through the notion of community capacity building.

Researchers have argued that communities have become a site for governments to exercise power and control. In this context, values, beliefs and sentiments become important in establishing the relationship between individuals and government - this has been referred to as 'ethopolitics'. After considering the concept of community, this review then discussed CCB. A literature review concerning CCB highlighted that it was often inadequately defined. However, the definitions included in this chapter were broadly similar. One way of understanding community capacity building was to locate it on a strategic / developmental continuum. Attempts to measure $\mathrm{CCB}$ raise concerns about the relationships between the different dimensions remain unresolved. 
According to Casswell (2001) and others (Nisbet 1960) community can be seen as a mediating structure between the domain of everyday life and the social, political and economic context. Given the noted emphasis on the role of communities in improving their circumstances in policies and political rhetoric, the concept of $\mathrm{CCB}$ may further understanding regarding this process. In addition, at the time of writing CCB was an under researched concept in a Scottish and UK context. Thus, exploring $\mathrm{CCB}$ in relation to HIIC, a national programme, may present an opportunity to examine how individuals address health-related and other concerns in a range of contexts.

In the following chapters, the research process is outlined with particular attention given to methodology, methods and ethical considerations. 


\section{Research strategy}

While academics and researchers make their careers arguing about methodology, people in the 'real' world continue to be disadvantaged and oppressed and to suffer from remediable problems.

(Oakley 2000: 306)

Debates concerning research strategy involve exploring different philosophical perspectives and dealing with ontological and epistemological issues. Ontology refers to the nature of being or what exists in the world (Punch 1998). Ontological questions relate to how we perceive the nature of social reality (Blaikie 2000; Hay 2002) or, in other words, what there is to know (Williams 2003a). Epistemology refers to the theory of knowledge (Abercrombie, Hill, \& Turner 1988), and is concerned with what we know and how we know it (Williams 2003a) and focuses on the knowledge-gathering process (Grix 2001a). Two other components of a research strategy are methodology, 'the research design that shapes our choice and use of particular methods' (Crotty 1998: 7), and methods, the means by which data are collected or constructed.

Thus, the features of a research strategy can be illustrated in the following way:

$$
\text { Ontology } \longrightarrow \text { Epistemology } \rightarrow \text { Methodology } \longrightarrow \text { Methods }
$$

Figure 5-1 Stages of a research strategy

Essentially, each stage involves making a set of assumptions not only about the world but what is in the world, and how we find out about those things.

In this chapter I discuss how researchers choose their research strategy and outline the approach adopted for this study. I then state the aim of this project and describe the research questions and how they were developed from the literature reviews. I then proceed to consider a range of methods and suggest that qualitative, semi- 
structured interviews would be the most appropriate. The final two sections deal with sampling and ethical considerations.

\subsection{Choice of research approach}

As shown in Figure 5.1, the choice of research strategy begins with ontological assumptions. The social science literature that attempts to explain how to conduct a research project presents ontological perspectives as a dualism; for example, foundationalist or anti-foundationalist (Marsh \& Furlong 2000); realist or constructivist (Blaikie 1993); and objectivist or constructionist (Bryman 2001). According to Bryman (2001: 16 - 18), the first positions (foundationalist, realist, and objectivist) assume that 'social phenomena and their meanings have an existence that is independent of social actors'. The counter positions (anti-foundationalist, constructivist, and constructionist) maintain that 'social phenomena and their meanings are continually being accomplished by social actors.' Those supporting this position would argue that it is not possible to remove ourselves from our framework of beliefs to test them 'against a mind-independent reality'(Avis 2003: 1000), and as Davidson (2001: 155) states, '[a]ll that counts as evidence or justification for a belief must come from the same totality of belief to which it belongs.'

As the quote by Oakley heading this chapter implies, discussions about research strategies and the philosophical approaches justifying different paradigms have been extensive. However, according to some writers this 'paradigm war' has been characterised by distorted versions of philosophical positions. For example, Paley (2000; 2001) described how within nursing research positivism and quantitative methods are misrepresented and poorly understood by qualitative researchers. To use the words of Pawson and Tilley (1998):

[i]s there anything more to be said about the paradigm wars?...What one sees is a musty stale-mate over first principles...realists prefer to muse on causal configurations, constructivists choose empathy and negotiation

(as cited in Oakley 2000: 23) 
Up to this point, I have considered the stages of a research strategy, how ontological positions are presented in the literature. I now briefly consider how researchers decide which research strategy to use. Some academics argue vigorously that such a decision reflects a fundamental, innate view of the world. For example, Marsh and Furlong (2000) argued that as questions of ontology and epistemology go to the heart of what social science is and the manner in which it is conducted, researchers cannot simply align themselves with one position for one study and change their position for another. Thus, they liken these philosophical underpinnings to a 'skin', something you cannot remove, and should, therefore, not be treated like a 'sweater', as something you can change (Marsh \& Furlong 2000: 21). However, such a view may present certain difficulties, for example when collaborating with other researchers who subscribe to another perspective or accommodating researchers who have revised their philosophical stance through deepening their understanding.

Blaikie (1993) outlined a number of ways in which a researcher arrives at their research strategy, two of which I followed for this project: a pragmatic position and one informed by personal biography. A pragmatic position is when a researcher attempts to match the strategy with the nature of the research project or research questions. For example, Labonte (1998) suggests two reasons why a constructivist research strategy provides an appropriate theoretical framework for researching community development and health. First, features of constructivism are closely allied to how the broad aims of community development are realised. As Labonte (1998: 23) states, there is a 'high degree of interpretation and contingency in the social change processes that are community development's generic goals'. Second, Labonte suggests that criteria, developed to demonstrate the rigour of research informed by a constructivist approach, reflect the values of community development. These criteria included: credibility - long term involvement with a group or project and group members are involved in the research process; confirmability - where opportunities are made for critical self-reflection on the meanings generated from any findings; and transferability - sharing good practice based on findings with other groups or practitioners. 
Choice of research strategy can also be informed by personal biography; for example, as Grix (2001a: 57) states, '[y]our own interests, ideas, previous research and personal experience will have led you to the academic field on which you wish to concentrate'. According to Blaikie (1993) personal biography includes a researcher's personality and academic experience. Previously I had conducted a qualitative study using joint interviews with prostate cancer patients and their partners concerning their experience of living with the disease and whether it had influenced the men's understanding of masculinity (Phillips 2002).

Primarily this $\mathrm{PhD}$ research project aims to further understanding about $\mathrm{CCB}$, community development and health, within the context of HIIC, a health-related education / training resource. This study is particularly concerned with participants' understanding of key concepts, their experiences of HIIC and perceptions of HIIC's influence. However, while understandings and perceptions are important features in this work, I also recognise that participants may refer to experiences such as poverty and poor health. In short, the research approach adopted for this study needs to acknowledge both interpretation and a lived reality.

The ontological position for this research study is what Blaxter (2004) referred to as 'subtle' social constructionism. According to this perspective, the world is simultaneously objectively real and socially constructed. Using a health-related example, this position would maintain not only that diseases exist and that their occurrence within a population can be described using statistical procedures, but that health, disease and illness are also categories which are socially constructed (Blaxter 2004). The term social in social constructionism refers to the 'mode of meaning generation' (Crotty 1998: 55), which is based in institutions and conventions. The linguist Stanley Fish (1990: 186) referred to these institutions as a 'publicly available system of intelligibility' and stated that they 'are the source of the interpretative strategies whereby we construct meaning' (as cited in Crotty 1998: 53).

The epistemological perspective for this study is interpretivism. This position assumes that knowledge of the world is generated through a person's lived 
experience (Weber 2004) and is 'predicated upon the view that a strategy is required that respects the differences between people and the objects of the natural sciences and therefore requires the social scientist to grasp the subjective meaning of social action' (Bryman 2001: 13).

Methodology represents the process or plan behind the choice of analytical strategy and involves a critical examination of how research should or does proceed (Blaikie 1993). In addition, methodology provides a framework that informs the choice of methods (Mason 2002). I selected an abductive approach as the most appropriate methodology for this study.

Blaikie (1993) described an abductive methodology, which is based on the hermenuetic tradition, as the process used to create social scientific accounts of social life based on concepts and meanings used by people and the enterprises they engage in. In this context, social reality is stratified (see Figure 5.2) and access to any social world is through the accounts people give of their own actions and the actions of others. Their accounts contain the concepts that they use to structure their world and the 'theories' that they use to explain events. Once these descriptions are produced a researcher can attempt to understand them by referring to social theories or perspectives. 


\section{Everyday concepts and meanings}

provide the basis for

Social action/interaction

about which

Social actors can give accounts

from which

Social scientific descriptions can be made

$\begin{array}{lll}\text { from which } & \text { OR } & \text { understood in terms of } \\ \text { Social theories can be generated } & & \text { Social theories or perspectives }\end{array}$

Figure 5-2 Abductive Methodology

adapted from Blaikie (1993)

There is an obligation for a social scientist to use these accounts to further understanding. For example, Pyett (2003) argued that as a researcher she had a responsibility to assess and explain participants' perception of their social world. In addition, researchers should utilise their privileged position, as Pyett (2003: 1173) states:

[As researchers] have access to other data, research findings, theories and understandings of similar or contrasting situations, we have a capacity and an academic obligation to apply our critical understandings to the accounts given by participants.

Thus, a researcher's role is to apply both sociological theory and historical or contextual information to develop an understanding that moves beyond the perspective of research participants and which benefits both the researcher and the researched. Having outlined above the theoretical underpinnings for this study, in the following section I set out the study's aim and research questions. 


\subsection{Research aims and questions}

The purpose of this section is to state the aim of this project, and to describe the process of formulating the research questions as well as to present them. This research project is based on a collaborative studentship (CASE) funded by the Economic Social Research Council (ESRC) and the then Health Education Board for Scotland (HEBS). This study aims to use the Health Issues in the Community course as a case study to examine the conceptual relationship between community capacity building, community development and health.

Research questions are 'intended to guide your enquiries' and are usually developed after an initial literature review (Grix 2001a: 139). I established in Chapter 4, that community is a widely debated concept and has a range of definitions. Community can be constructed conceptually in terms of geographical location, as a shared interest, or in a relational sense. Investigating participants' notions of community is important to understand CCB as well as to contextualise HIIC's potential influence on health.

Also in Chapter 4, it was shown that CCB was an under-researched concept in the UK and at the time of writing no related Scottish studies could be found. Therefore, exploring how HIIC tutors and stakeholders (people involved with HIIC at a developmental or management level) understand CCB could contribute towards furthering knowledge about the concept.

In Chapter 1, I noted that HIIC emphasises a social model of health, which maintains that other circumstances and conditions apart from behavioural factors influence health outcomes. For example, individuals may have formed their own definition of health, informed both by objective and subjective assessments of personal life events and circumstances. In order to explore the relationship between $\mathrm{CCB}$, community development and health, it is important to consider participants' prior understandings of health and record whether their understandings had changed after attending HIIC. 
As reviewed in Chapter 1 the aim of HIIC, according to the tutor guidelines, is to enable students to understand the social, political, educational and community development processes involved in addressing health-related concerns in the community (Health Education Board for Scotland 2002b). This aim reflects the empowerment principles outlined in the Ottawa Charter for Health Promotion, which proposed that individuals should be encouraged and supported to exact control over both their health and the processes involved in improving health (WHO 1986). The idea of CCB, which broadly refers to the development of a community's abilities to identify and address issues of concern, is clearly compatible with the aims of HIIC and the Ottawa Charter. Thus, asking HIIC students to describe their communityrelated activities after completing the programme may produce accounts that clarify whether HIIC influenced the development of CCB. In addition, encouraging students to reflect on their experiences post HIIC could indicate if the experience of participating in the course had been influential in other aspects.

In view of the above observations drawn from the literature reviews, the research questions for this study were as follows:

- How did HIIC tutors and students understand the concept of community and was this understanding influenced by completing HIIC?

- How did stakeholders and tutors understand the notion of community capacity building?

- Did participating in the HIIC course contribute towards furthering students' understanding about health?

- Was community capacity building evident in the experiences of the students after their involvement with the course?

- Did participating in the HIIC course have any other impact on participants? 
The methods used to address these research questions are set out in the following section.

\subsection{Methods}

In this section, I state what methods are and how they relate to the research process, consider the utility of qualitative methods, and conclude by arguing that semistructured individual face-to-face interviews are the most appropriate method for this study.

Methods are techniques or procedures used to collate and analyse data and there are different opinions regarding how they should be selected. One view is that the choice of methods is informed by the research strategy or methodology (Mason 1996; Silverman 2000). For example, Mason (2002: 63) argues that a researcher may select qualitative interviewing because their ontological position assumes that 'people's knowledge, views, understandings, interpretations, experiences and interactions are meaningful properties of the social reality which [the] research questions are designed to explore'. Within this type of research approach the researcher and the participant engage with the interview process to explore understandings, thought processes and social norms (Mason 2002). In addition, Hopf (2004: 203) argues that compared to other methods in social science, qualitative interviews are 'closely related to the approaches of interpretative sociology'.

Another perspective states that research question(s) govern the choice of methods (Grix 2001a). For example, the research question 'Is there a relationship between gender, education and earnings, at a population level?' would probably be addressed by using quantitative methods, such as a large-scale survey. However, focus groups or face-to-face interviews would be more appropriate to explore reasons why members of a youth group smoked. Grix argues that selecting methods by any other 
criteria can potentially lead to an inappropriate question-method relationship, or in other words the incorrect use of a method. Following Mason (2002), I support the view that methodological considerations do influence the type of methods chosen. In addition, Grix (2001a) is also correct to argue that the most appropriate method should be used to answer the research question(s). In the following sections a number of qualitative methods are discussed.

\subsubsection{Consideration of qualitative methods}

There are many techniques a researcher can use to construct data and in this section I consider why semi structured interviews are the most suitable for this study.

As stated in the previous section, this project adopted a research strategy that assumes that people construct meaning as they engage with the world (Crotty 1998). In addition, a researcher can access social worlds through accounts people give, which can then be explored using social scientific theories or perspectives (Blaikie 1993). Qualitative interviews are consistent within this research approach; for example, researchers using qualitative techniques can glean interpretations from what participants say (Warren 2002). Meanings are negotiated, constructed and articulated between the researcher and the researched (Finlay 2002; Riessman 1994). Thus, data are viewed as products of the participant, the researcher and their relationship, and as Johnson (2002) states, this data refers to lived experience, values and decisions, and cultural knowledge or perspectives. Constructing this type of data through qualitative interviewing is also compatible with recording people's experiences of HIIC and their understandings of related concepts.

Qualitative interviewing also represents a forum to construct rich and complex data (Robson 2002) and is considered to be the most suitable when participants' understandings are otherwise taken for granted and where complicated and multiple perspectives on the same phenomena are expressed (Johnson 2002). Qualitative interviewing also allows the researcher to respond and to reflect on what the 
participant says (Robson 2002). Hence, the researcher can explore and clarify issues with the participant. The current research project involves complex concepts such as health, community and $\mathrm{CCB}$ and using qualitative interviews could provide an opportunity for participants to recount their experiences and to express their understandings concerning these concepts.

A further reason supporting the use of qualitative methods is that it has been suggested that values within community development approaches are also reflected in the practice of qualitative interview methods. There has been, for example, a reported therapeutic benefit when interview participants expressed their feelings and emotions about issues that concern them (Chandler 1990; Ortiz 2001). In addition, conducting interviews also gives primacy to those who are marginalised by their class, gender or disability, and it places an emphasis on the participant's voice through recounting descriptive life stories (Robinson 1994).

Arguments supporting the use of qualitative interviews in this project were outlined above. However, this method should not be considered an easy option; rather it is a 'complex and exhausting task'(Mason 2002: 67) and the planning and conducting of qualitative interviews are time consuming activities (Robson 2002). In addition, the degree of authenticity ascribed to interview accounts needs to be carefully considered as interviews are a form of social action that are co-constructed by the researcher and the interviewee (Atkinson, Coffey, \& Delamont 2003; Rapley 2001). Atkinson, Coffey and Delamont (2003: 105), referring to the work of Erving Goffman (see for example 1959; 1961; 1968), state, 'we know enough about the performance of everyday social action to be thoroughly suspicious of methodological formulations that even appear to attach particular kinds of authenticity to it'. According to Atkinson, Coffey and Delamont, Goffman's work explores the circumstances within which social actors achieve social encounters and portray social selves. Thus, our 'selves' are diligently managed and are collaborative ventures even during qualitative interviews. 


\subsubsection{Semi-structured interviews}

It was argued above that qualitative interviews are a suitable method for this research study. However, there are various forms of qualitative interviews and in this section, the reasons why semi-structured interviews were considered the most appropriate method for this project are presented.

Commonly, interviews are classified according to the level of structure imposed on the interview process (Hopf 2004). Adopting Robson's (2002) and Mason's (2002) terminology, three types of interview are described here. First, fully structuredstandardised questions are prepared prior to an interview and asked in the same sequence during each interview. This method is comparable to interview-based survey questionnaires, although open-ended questions are used. Second, semistructured-questions and / or a list of topics (referred to as an interview guide) are prepared to aid the researcher during the interview process. However, questions or topics can be addressed in any order depending on how a participant responds. During an interview a researcher can also reflect on the process and can ask supplementary questions to clarify or probe an issue further. Third, looselystructured - also referred to as 'unstructured', however, 'this is a misnomer because no research interview can be completely lacking in some form of structure' (Mason 2002: 62). Loosely-structured interviews are employed where an interviewer has a broad research interest and allows a narrative to develop within this context. It is argued that this type of method shares similar traits to a conversation (Burgess 1984).

I perceived semi-structured interviews to be the most appropriate method for this project for a number of reasons. Bryman (2001: 315) describes two circumstances when this method can be used. First, they are used when an investigation has a clear focus, so that 'more specific issues can be addressed'. The aim of this study and the research questions are related to specific contexts: HIIC and CCB. Second, in order to carry out inter-group comparisons a degree of structure in the data collection process is needed. This is a relevant consideration as this project is concerned with groups of students and tutors and their experiences of HIIC. 
In addition, King (1994) has identified a further number of circumstances in which semi-structured interviews are an appropriate method. First, when a study is concerned with meanings people attach to a particular phenomenon. The aim of this project is to explore the concepts of $\mathrm{CCB}$, community development and health.

Second, semi-structured interviews are a suitable method for researching an individual's perception of processes within a social group. As noted above, such groups are a feature of this study. For example, as Chapter 6 shows, research participants were drawn from HIIC courses (groups) containing tutors and students. In addition, the HIIC programme is influenced by a community development approach and uses group work methods. Thus, participants could describe their experience and perceptions of group processes, for example, by discussing their experience of working with other course students. Finally, semi-structured interviews allow the collection of individual historical accounts that describe how a phenomenon evolved. HIIC developed within a political and social context and was informed by a particular ethos, as noted in Chapters 1 and 2. Therefore, by interviewing stakeholders with an understanding of HIIC's development, accounts of this process could be constructed. In addition, semi-structured interviews allow an in-depth contextualised exploration of the reasons why tutors and students decided to participate in HIIC.

In summary, it was argued in this section that qualitative semi-structured interviews were the most appropriate method for this research study, as they provide a suitable forum to generate applicable data, are compatible with the research strategy and methodology adopted, and reflect a particular value base relevant to some of the main themes in this study. In addition, semi-structured interviews give the researcher opportunities to reflect and seek clarification during the interview, are an appropriate method when a research project has an explicit focus and is concerned with the meanings participants attach to events or concepts. In the remaining parts of this chapter, the merits of other types of methods are considered as well as the sampling strategy employed and some of the ethical concerns relating to recruiting and interviewing participants. 


\subsubsection{Consideration of other forms of interviews}

In this section, four other types of interviews: focus groups, joint interviews, telephone interviews and e-mail interviews are described and their merits in relation to this research project are discussed.

\subsubsection{Focus groups}

A focus group is a method of conducting an interview with several different people on a given topic or issue. Focus groups have been variously defined as a type of group interview, which uses the communication between participants to generate data (Kitzinger 1995), or as 'group discussions in which persons representing the target group discuss different aspects of a topic'(Dahlin Ivanoff 2002: 3) . The main assumption behind focus groups is that group processes or dynamics can assist participants to explore and clarify their views. It is argued that this method is suitable when the researcher uses open-ended questions and seeks to encourage participants to explore the issues of importance to them, in their own language and by forming their own questions (Kitzinger 1995). Krueger (1994) identified some features common to focus groups: they usually involve four to ten people assembled in a series of groups; participants possess certain characteristics or commonalities; and qualitative data are generated through group interaction in a focussed discussion. Focus groups differ from group interviews as the researcher is observing and recording the nature of the interaction of the group members. In addition, the researcher encourages participants to talk to other participants when they address the questions, rather than participants directing their answers to the researcher.

According to Bryman (2001) there are a number of features of focus groups that make them a distinctive research method. For example, focus groups can present the researcher with an insight into why people feel the way that they do. In addition, a focus group provides a researcher with an opportunity to examine how understanding is formed at a collective level, which it is argued, reflect the processes by which meaning is constructed on a day-to-day basis (Bloor et al. 2001; Wilkinson 1998). 
Focus groups may also give the researcher access to 'indigenous coding systems', group terms and categories (Bloor et al. 2001; Kitzinger 1995). In addition, there is the opportunity for the other participants to query and challenge each other's views and clarify inconsistencies. Finally, it has been argued that in a focus group, the researcher has less influence over the research process compared to an interview and so issues that concern the group will be raised (Wilkinson 1998).

Although focus groups provide a distinctive research technique, they are also limited in the following way. As the researcher has potentially less influence over the research process, caution needs to be exercised concerning the extent to which the group is allowed to assume control of the proceedings without jeopardising the project. For example, research is usually seeking to answer a number of particular research questions often within rigid financial and time constraints. In addition, a focus group may retain its own internal hierarchies which may affect the accounts generated (Bloor et al. 2001). Gibbs (1997) also argues that an awareness that a focus group is an organised event should not be lost; a consideration that has methodological implications and which will inform how the data are analysed.

Focus group recordings can take longer to transcribe as they include complex social interaction (Bryman 2001). Data generated from a focus group can be difficult to analyse as they include examining not only what people said, but the patterns of interaction as well (Bryman 2001). According to Kidd and Parshall (2000), focus group recordings can often include inaudible material, as it can be difficult to place recording equipment in such a way as to have a complete record of what was said. In addition, during the flow of a focus group, participants may speak at the same time, which can be problematic when trying to hear what was said and by whom (Kidd \& Parshall 2000). These recording-related issues may affect the quality of the transcript and consequently the data analysis. 
Organising a focus group can be problematic, as a researcher has to coordinate a group of people to attend on the same day, at the same time. In addition, for a focus group to be effective a certain number of people are required to participate.

However, the ideal number of participants is disputed; for example, some researchers recommend four to eight participants (Kitzinger 1995), whereas others suggest eight to twelve participants (Krueger 1994; Stewart \& Shamdasani 1990). However, it has been argued that the number of participants is less central to the outcome of a focus group than the importance of encouraging all participants' active involvement in the group discussion (Dahlin Ivanoff 2002). However, if groups are too small then the posibility of generating an effective discussion are reduced (Fallon \& Brown 2002). It has also been argued that focus groups require a degree of expertise to facilitate (Robinson 1999) to avoid potential difficulties, such as successfully managing quiet or dominant participants. A facilitator also needs to be aware of certain group dynamics that could silence voices of dissent from a particular group norm (Kitzinger 1995) and produce conformity to a dominant view (Crawford \& Acorn 1997). However, it is argued that participants provide 'checks and balances' to each other and these are a means for a group to assess and reject any extreme opinions (Robinson 1999).

The nature of a focus group can also be problematic. For example, it is argued that the presence of other participants might compromise the confidentiality of the research session (Kitzinger 1995). This would be a potential concern, especially in a group where there has been conflict between its members. However, participants have also reported feeling safer to disclose in-depth thoughts because they were in their peer group (Webb 2002). The number and depth of questions that can be asked may be limited because of the size of the focus group and time available (Powell \& Single 1996; Robinson 1999).

Given these issues concerning focus groups, I would argue that they are not an appropriate method for this research project for the following reasons. As noted above the suggested minimum number of participants for a focus group is four; it 
was unclear whether it would be possible to fulfil this criterion and recruit an adequate number of participants from a particular HIIC course to attend a focus group. Whilst having both tutors and students present might comply with the minimum suggested number, interviewing students and tutors separately was an important condition in relation to issues of confidentiality. For example, participants may have felt reluctant to describe and discuss negative experiences if other students or tutor(s) were present. In addition, the range of topics that can be discussed in a focus group is limited. As the current project was concerned with participants' understandings of complex concepts such as health, community and CCB, a focus group was not the most appropriate environment in terms of allowing enough time for in-depth answers.

\subsubsection{Joint interviews}

A number of the HIIC courses from the research sample were co-tutored (see Chapter 6). Thus, it was worthwhile considering the merits of conducting joint interviews. Joint interviewing involves the researcher speaking to two people together about how they perceived the same event. This method has been used in a variety of different reseach contexts such as marital or cohabitation relationships (Mason 1989; McKee \& O'Brien 1983) and exploring illness and disability with both carers and the care receivers (Gerhardt 1991; Parker 1993). It is argued that joint interviewing uncovers various forms of knowledge held by each person and may produce a richer account as participants fill in each other's memory lapses (Seymour, Dix, \& Eardley 1995).

However, there are a number of disadvantages in using joint interviews. First, one person may dominate the other during the interview (Arksey 1996). Second, it has been argued that joint interviews do not produce substantially better data compared to individual interviews. For example, Huby and Dix (1992) found that participants concentrated less effectively during the interview as a pair and that the participants' desire to avoid disagreement within the relationship, in front of the researcher, can affect the responses. Third, the nature of data from a joint interview is different to 
individual interviews as there is a sense that a joint interview is a collaborative event where attempts are made to produce a unified image or reality (Jordan et al. 1992). Thus, as Morgan (1988) argues, joint interviews generate more consensual data and that overt conflict during such an interview is rare (Jordan et al. 1992). Similarly, it has been suggested that participants in joint interviews are presenting themselves in a positive way (Arksey 1996) as they use the interview to legitimate their actions (Radley \& Billig 1996) or to normalise their circumstances (Voysey 1975). In addition, I would argue that conducting joint interviews present similar concerns regarding confidentiality issues as focus groups.

In summary, it was argued above that conducting joint interviews can produce particular types of accounts. This process may obscure participants' experiences of a HIIC course, which could include descriptions of group conflict.

\subsubsection{Telephone interviewing}

The research sample for this project encompassed HIIC courses throughout Scotland (see Chapter 6) and one method that is suited to reaching geographically dispersed participants is telephone interviewing. Telephone interviews are often used in surveys, but can be applied to other research contexts. According to Robson (2002), conducting telephone interviews has many similar advantages to that of face-to-face interviews. For example, a high response rate; ability to correct misunderstandings; and clarification of ambiguous statements through using probes. The main benefit, however, is that a geographically dispersed sample can be reached relatively quickly and cheaply (Thomas \& Purdon 1994).

There are a number of disadvantages with telephone interviews. Robson (2002) argues that the lack of visual cues might hinder interpreting the participants' responses. In addition, establishing rapport might be problematic as the researcher is unable to utilise other forms of communication, such as body language or visual aids (Thomas \& Purdon 1994). It has also been found that answers to open-ended 
questions are usually shorter and the entire interview tends to be quicker than faceto-face interviews (Thomas \& Purdon 1994). As this research study is seeking to analyse descriptions of experiences and conceptual understandings, telephone interviewing may not be appropriate if it curtails a participant's responses. In addition, this method relies not only on participants having suitable access to a telephone, but that the researcher can obtain the correct telephone number to contact the participant. A further disadvantage with telephone interviewing is that it prevents the gaining of contextual knowledge. For example, through the process of arranging and conducting interviews in rural locations, I developed an appreciation of some of the transport-related issues that can affect such areas. In addition, by visiting local resources, such as community centres a broader understanding was gained. For example, I was able to learn about some of the projects which participants had been involved in.

\subsubsection{E-mail interviews}

The consideration of e-mail interviews is relevant to this study because, like telephone interviews, they can overcome problems associated with a sample that is spread over a wide geographical area; for example higher research costs incurred from travelling and accommodation expenses. In addition, data collection may also take longer because of the time it takes to travel to particular locations and participants may be inaccessible if the researcher is relying on public transport. However, using e-mail interviews may address these problems and have other benefits; for example this method is not confined by geographical location or timezones and thus the researcher is not required to be present with the participant (Foster 1994). In addition, the need to transcribe the interview no longer exists and the data can be adapted to suit word processing packages or computer-based qualitative analysis software (Selwyn \& Robson 1998). This method can also assist in reducing some of the effects of interpersonal issues, such as shyness (Roberts, Smith, \& Pollock 1997), that can be exacerbated with a face-to-face interview. 
However, there are a number of drawbacks concerning e-mail interviews.

Participation is limited to those who can use e-mail and have access to the internet. In addition, participants who have had little experience of using a keyboard may attempt to curtail their responses. For example, it was found that some interviewees answered questions as quickly as possible in order to reduce the effects of their perceived negative experience (Thomas et al. 2000). There is also a lack of interaction compared to face-to-face interviews (Tatano Beck 2005). For example, the researcher is unable to perceive changes in the participant's voice (Fleitas 1998). In addition, non-verbal cues that aid communication of different emotions are not present in an e-mail interview, although instructions in the use of symbols and abbreviations to illustrate emotions can be given and this may contribute towards mitigating this concern (Lakeman 1997). After considering some of the problems associated with e-mail interviewing, I concluded that they were not a suitable method for this study.

\subsubsection{Individual face-to-face interviews}

Accepting the disadvantages of the qualitative methods above, I would argue that individual face-to-face interviews are the most suitable method for this project. According to Robson (2002: 272-3), face-to-face interviews allow the researcher to respond to a participant's account by asking further questions about an area of interest and provide an opportunity to explore a participant's underlying motives. In addition, individual face-to-face interviews may also prevent breaches of confidentiality; a concern that has been raised regarding focus group research (Kitzinger 1995) and is an issue that is relevant to this study. For example, if a student considers their experience of HIIC was negative, then they may feel reluctant to articulate such a view if participating in a focus group which included the tutor(s) and / or other students from the same course.

In conclusion, individual face-to-face semi-structured interviews are compatible with this study's research strategy and methodology, they will generate applicable data, are a method that is a suitable forum to explore complex experiences and concepts, 
and they are informed by a positive and empowering value base. Other types of interviews were considered but were deemed less appropriate for a variety of reasons. In the following section, the issue of sampling strategies are discussed.

\subsection{Sampling}

A sampling strategy is a way of identifying potential research participants from a given population. There are many different ways of sampling a research population. For example, Wengraf (2004) cites Patton (1990), who referred to at least sixteen different types of sampling technique. Thus, an in-depth consideration of the various means of sampling is beyond the scope of this work. However, it has been proposed that sampling strategies for qualitative research are often defined negatively, in other words, in terms of what they are not (Curtis et al. 2000). For example, after reviewing relevant literature relating to approaches to sampling, Curtis et al. (2000) noted that there was a broad consensus that qualitative sampling was not based on the principles informing statistical methods using probability theory.

Curtis et al. also identified a number of common features of qualitative sampling. Firstly, sample sizes are small and studied in greater depth, which can result in the generation of large amounts of information. Secondly, qualitative samples can be designed to make analytical generalisations, which are then applied to wider theory on the basis of how selected cases 'fit' with general constructs (Curtis et al. 2000: 1002), rather than statistical generalisations that are applied at a population level and based on representative statistical samples. However, according to Williams (2002) there are others who have argued that interpretative research rejects the goal of generalisation (Denzin 1983; Guba \& Lincoln 1983). Williams argues that Denzin, and Guba and Lincoln support their argument by using a particular definition of generalisation that is (mis)informed by their interpretation of a 'positivist' research approach. Williams goes on to suggest that moderatum generalisations can be made from interpretive inquiry. Moderatum generalisations are when characteristics of a given situation can be viewed as examples of a wider recognisable set of features 
(Williams 2000). Lastly, qualitative research should be reflexive and explicit about the rationale for case selection because of the ethical issues and theoretical implications involved in making the decision to include or exclude certain cases. Having outlined briefly the nature of sampling techniques for qualitative research, I set out below how they can be evaluated.

The question of sampling in qualitative research is often given less attention than other methodological concerns (Curtis et al. 2000). However, Miles and Huberman (1994: 34) outline six characteristics which can be used to evaluate qualitative sampling strategies:

a) The sample strategy should be pertinent to methodology, research strategy and research questions.

b) The sample should lend itself to producing rich information on the particular focus of the research.

c) The sample should enhance the analytic generalisability of the findings.

d) The sample should produce credible descriptions.

e) The sample strategy should be ethical.

f) Sampling strategy should be practical.

Guided by the original proposal for this study and observing the above characteristics, a number of factors needed to be considered in relation to deciding which sampling technique to use. First, this study is based on a particular methodology that accepts the validity of recruiting relatively small numbers of research participants. Second, as the focus of this study is HIIC, the 'research population' is therefore, confined to individuals who have had involvement, experience, and an understanding of HIIC. Otherwise, I would suggest, it would be difficult to produce 'rich information' and 'credible descriptions' relevant to the focus of this project. Given these constraints three potential participant groups were identified: stakeholders, course tutors and students. 
After considering various types of sampling strategies the one judged most applicable for this thesis was criterion sampling (Patton 1990). As implied, this technique involves selecting all the cases that match a criterion and the following stipulations were identified. First, student participants should have completed up to part one of the HIIC programme, so that they would be familiar with key concepts, such as health, community and community development. Students should also have six months post-course experience before being interviewed, so that participants had a period to reflect on their learning and an opportunity to act on their HIIC experiences. Second, I considered that courses prior to 2002 were unsuitable to recruit from because of the likelihood of difficulty in contacting participants. In addition, the time elapsed since these courses may have contributed towards participants being unable to recall their experiences. Before describing the data construction process, I draw attention to some of the ethical concerns relating to recruiting and interviewing participants.

\subsection{Ethical Considerations}

Ethical considerations emerge when deciding between a course of action relating 'to standards of what is morally right or wrong' (Barnes 1979: 16). Qualitative research often involves recording and analysing personal descriptions and may also engage with people and groups who are marginalised in wider society (Finch 1984; Mason 1996). Consequently, as Cloke et al. (2000) argue, particular ethical questions may arise when conducting this type of research.

The relationship between the researcher and research participants is one significant area where ethical issues have to be managed. Hammersley and Atkinson (1995) identified the following three ethical requirements. Informed consent- the researcher is responsible for explaining the research project to the participants. In addition, participants should be given the opportunity to provide their consent to be a research participant. Privacy- the researcher should be discreet in handling information that is revealed in private during an interview. Harm- the researcher should endeavour to 
minimise any possible negative consequences for the participants resulting from their participation. How these ethical issues were addressed is described below.

Prior to conducting any interviews, I consulted the ethical guidelines provided by the Public Health Sciences Section, University of Edinburgh and completed the postgraduate research ethics review form (see appendices xi and xii), which was authorised by my principal supervisor. This form involved answering a series of questions about the nature of the research project, for example, 'Does the study involve participants who are particularly vulnerable or unable to give informed consent?', and 'Could the study induce psychological distress or anxiety or cause harm or negative consequences beyond the risks encountered in normal life?' No ethical issues emerged from this process and the research study proceeded.

Another important ethical concern related to participants who had a dual role in relation to this research project. For example, one of my $\mathrm{PhD}$ supervisors was a research participant because of her involvement in HIIC as part of the group that oversees the development of the course, and as the assessor for the assignments completed by students during their course and by tutors undergoing tutor training. An ethical issue emerged in relation to student participant recruitment. In her HIIC role, my supervisor held contact details for some of the students who had been identified as potential participants. It would have been inappropriate to access these details without permission in order to contact the students, as well as potentially compromising the integrity of my supervisor in her HIIC-related role. Consequently, it was agreed that my supervisor would initially contact the students to inform them about the study and provide them with the opportunity to opt out of the project. This procedure was also repeated with one of the other interview participants who had played an advisory role in this research project, but who also held contact details for HIIC students. 
As stated above, informed consent is a crucial aspect of ethical research (Punch 2000; Silverman 2000). In view of this, addressing the issue of informed consent was broken into three stages. First, information sheets (see appendix vi) about the study were produced and posted to participants. Second, just before any interview participants were reminded about the conditions of the interview, which had also been stated in an interview consent form (see appendix ix). Thus, each participant was told that they could stop the interview at any time, that they could refuse to answer any question, that with their permission the interview would be recorded and that anything they said would be treated as confidential. In addition, their identity would not be revealed and any identifying details would be made anonymous. Participants were also informed that what they said during the interview might be used as part of my thesis and other outputs, such as reports or articles. The final stage involved asking the participant to sign a consent form to indicate their agreement to take part in the study and that they understood the conditions of the interview.

In summary, the nature of qualitative research may present certain ethical issues, in particular the relationship between the researcher and the researched. The three ethical requirements of gaining informed consent, protecting participants' privacy and ensuring no harm to participants were addressed. In the following chapter, I outline the stages of data analysis and data construction. 


\section{Data construction and analysis}

The four main stages of data construction were: identifying the research sample; developing interview guides and materials; recruitment of participants; and conducting face-to-face interviews. I will now describe these stages in more detail including the known reasons for non-participation.

The following three groups of research participants were identified:

- Stakeholders, who are involved with the HIIC course at a management, strategic or development level.

- Tutors, who facilitate HIIC courses.

- Students who had completed at least part one of a HIIC course.

Three stakeholders were selected as potential participants because of their longstanding and ongoing involvement with HIIC at the time of writing. The tutor and student participants were drawn from thirteen courses that had been identified as a potential sample. Conducted between June 2002 and November 2003, these courses incorporated twenty-one tutors and ninety-four students (Allan 2004a), and were chosen for the following two reasons. First, courses from this period meant that students had at least six months after their course had finished to reflect on and act upon their experiences. The benefits of ensuring that students have time to reflect on their learning and experiences have been noted by others. For example, it has been argued that the effects of learning may not be immediately apparent (directly after the learning experience) and are best appreciated retrospectively (Schuller et al. 2004: 6). Second, recruiting tutors and students from courses prior to 2002 might be problematic as contact details could be out of date or missing. The next sections describe the recruitment process for each participant group.

The three stakeholders were recruited through their involvement with this research project; two were supervising this study and the other had an advisory role. The stakeholders were contacted by telephone, e-mail or in person and a convenient 
interview date, time and venue was arranged. All of the stakeholders' interviews were conducted in their places of work during September 2003.

CHEX held records of course completion date, course location, name of tutors and number of students completing and accrediting. Consequently, the training and development manager from CHEX contacted six tutors in October 2003 informing them about this research study, enquiring if they wished to receive further information and stating that I would contact them shortly if they raised no objection. After allowing a period of two weeks, I contacted the training and development manager to ask if any tutors had raised any objections about being contacted directly. As no negative responses had been received, I contacted the tutors either by telephone or e-mail, the latter being more effective, to ask them if they were willing to participate and to arrange an interview venue and time.

To make the recruitment process more efficient a further eleven tutors were contacted directly after acquiring their contact details. In order that potential participants could make an informed decision regarding whether to further their involvement with this project, the following information was provided in the initial contact. First, I introduced myself as the principal researcher and gave a brief description of the research project. Second, it was stated that they were being asked to participate because of their role as HIIC tutors and a summary of the interview topics was provided. Third, I asked each tutor if they wanted to receive additional information about the study. Thus, tutors were given the opportunity to decline further involvement at this initial phase of the recruitment process.

In summary, in total seventeen tutors were approached and through the above recruitment processes thirteen interviews, with fourteen tutors, (one was a joint interview) were arranged and conducted between November 2003 and July 2004. The reasons for non-participation are discussed on page 115 . 
The recruitment process for HIIC students initially involved asking the first six tutors if they could offer any advice on how to recruit their students into the research project. However, my initial assumption that tutors would be able to be involved in recruiting their students proved to be misplaced, as the majority of tutors stated that they did not have any further involvement with course students or that they had not kept students' contact details.

As already discussed in Chapter 5, in order to conform with ethical guidelines the training and development manager from CHEX and one of my supervisors initially wrote to the students identified in the research sample. In total fifty-one letters were posted in three phases (number of letters shown in brackets): February 2004 (eighteen), March 2004 (twenty-four) and April 2004 (nine). Included with the initial letter was an information sheet about the study, an opt-out form (see appendices v and vi) and a pre-paid envelope for participants to return their reply.

I was notified of any returned completed opt-out forms. Following a period of two weeks after the initial letter was sent, I contacted by post the remaining students who had not sent an opt-out form (see appendix vii). This letter asked the participant to confirm their contact details and to indicate if they wished to be contacted by phone, e-mail, or letter to arrange an interview. In June 2004 sixteen reminder letters (see appendix viii) were sent to those students who had not responded to the first letter.

In total, sixteen replies were received from students confirming their contact details and expressing an interest in being interviewed. Two additional students were recruited opportunistically, one via another student, and the other, who was in the same building where I was conducting an interview, asked if he could be interviewed as well. 
In summary, in total twenty students were recruited, sixteen by post, two opportunistically and two who participated in pilot interviews. These interviews were conducted between February 2004 and August 2004.

From the original potential research sample, I was unable to recruit seven tutors and seventy-four students and the known reasons for non-participation are as follows.

The contact details for four tutors of the twenty-one identified were unavailable. One tutor agreed to be interviewed but then later declined due to other commitments. Another tutor, who had been contacted by telephone, was reluctant to take part in a face-to-face interview and asked if she could write down her responses. After considering this alternative method, it was deemed incompatible with the research strategy and methodology and the tutor was not recruited. The remaining tutor did not pursue the recruitment process further following my initial e-mail.

There were two initial factors affecting the level of student non-participation. First, I had decided to interview students and tutors from the same course, as I considered it more meaningful to collect accounts within a group. As seven tutors did not participate, nineteen potential students were lost from the sample. The second factor affecting student recruitment related to available contact details. Records were held for those who had registered for accreditation. Thus, thirty-one students who did not wish to receive accreditation could not be contacted by post.

From the number of students who did not participate in this study, thirteen could be accounted for. Eight students returned their opt-out forms. Two students did not attend their arranged interview dates and subsequently could not be contacted. Two students had expressed an interest, but did not respond to attempts made to arrange an interview date. In addition, the Post Office returned one letter indicating that the person no longer lived at that address. 
In the following sections, I describe the development of the interview guides and materials as well as how the interviews were conducted.

\subsection{Interview guides and materials}

Interview guides aid a researcher during the interview process and can include a list of themes or topics that the researcher wishes to discuss with the participant. In this study, for each participant group an interview guide was produced and their development is outlined below.

By engaging with the various literatures, health, community, and CCB were identified as important concepts in relation to the data construction phase. For example, at the time of writing no previous studies could be found concerning how stakeholders understood the concept of CCB. In addition, my knowledge of HIIC, particularly its development, how courses were facilitated and assessed, was minimal. Consequently, the objectives in interviewing stakeholders were to first, gain information regarding how HIIC courses were organised and managed and second, to discuss stakeholders' appreciation of how relevant concepts were related and applied. For example, 'How did HIIC influence understandings of health?' and 'How was CCB relevant to HIIC?' The stakeholder interview guide was finalised by September 2003 (see appendix i).

The three main areas of interest for the tutors' interviews were the following: their involvement and experience of tutoring a HIIC course, perceived influence of HIIC, and conceptualisation of $\mathrm{CCB}$, health and community. This raised the issue of how to present $\mathrm{CCB}$, potentially an unfamiliar idea to participants. A draft guide was prepared in October 2003 and included different ways of exploring CCB, such as asking participants to contrast a community where CCB was occurring with one where it was not and to write down the features of each community. Further reading revealed that visual techniques had been used before to research CCB. For example, 'spider-web' mapping, which involved ranking scores for each dimension of CCB 
(Bopp et al. 1999; Hawe et al. 1999; Laverack 1999). According to Labonte and Laverack (2001a: 131) the benefits of using 'spider-web' mapping were that 'its visual presentation of change in multiple domains is quickly communicated'. However, the aim of this study was not to 'score' each dimension and so this particular technique was considered inappropriate. However, I felt that adopting some form of visual representation of CCB was a useful way to present the concept. For example, I considered that it may help a participant to understand CCB and it could be used to direct a discussion about the term.

Subsequently, I developed an interview tool using a model of CCB (see appendices iii and xiii) based on four dimensions: participation, resource mobilisation, links with others and role of outside agents (Labonte \& Laverack 2001a; Labonte \& Laverack 2001b). Essentially, this tool was a piece of flip-chart paper with the four dimensions written on it. The tutors were asked to write down any comments about each dimension in relation to their experiences of the HIIC course.

The above two ideas for presenting CCB to participants, the 'dimensions' and the 'community contrast' exercises were included in a pilot tutor interview, which was conducted in October 2003 in an urban area near Glasgow. After reflecting on that experience the interview guide (see appendix ii) was finalised. In addition, it was decided that the 'dimensions exercise' was a more suitable interview tool.

Prior to interviewing any students, drafts of the $\mathrm{CCB}$, community and social capital literature reviews had been written and interviews had been conducted with three stakeholders and four tutors. These experiences, alongside the study's aim and research questions, informed the development of the student interview guide. For example, concepts such as health and community had different connotations depending on the context in which they were used. In addition, one research question referred to whether CCB was evident in students' experiences after completing HIIC. Thus, the interview guide (see appendix iv) was based on four 
main areas: biographical information and story of HIIC participation; course experience and its influence; understanding of related concepts; and post HIIC activity. This guide was drafted in January 2004 and used in February 2004 during two pilot interviews. Both pilots proceeded without any difficulties and positive feedback was received about the interview process, so further refinements to the student interview guides was considered unnecessary.

\subsection{Conducting the interviews}

With the primary objective to conduct each interview in a safe and secure environment, it was stressed, when arranging an interview, that the participant would be interviewed at a venue of their choosing, at a convenient time and date. Consequently, the interviews were conducted in a variety of locations: a public library, participant's place of work or home, a coffee shop, and a community centre. The interviews also took place in various parts of Scotland, in urban and rural areas and in an island community (see Table 6.1 for breakdown of interview and course location). To reiterate, the number of interviews conducted were as follows:

- $\quad$ three stakeholders in September 2003

- $\quad$ thirteen tutors between November 2003 and July 2004

- $\quad$ twenty students between February 2004 and August 2004

Information relating to interview participants and course sample are presented in Tables 6.1, 6.2, 6.3 and 6.4. The data in the tables concerning age, course frequency and type were collated from participants' accounts or based on my assessment. Precise data for course length was unavailable and some discrepancies were noted when comparing both tutors' and students' recollections. 
Table 6-1 Course / interview location information

\begin{tabular}{|c|c|c|c|c|c|}
\hline Course & Frequency and Type & $\begin{array}{c}\text { Course } \\
\text { Location }\end{array}$ & $\begin{array}{l}\text { Students } \\
\text { completing } \\
\text { course }\end{array}$ & $\begin{array}{l}\text { Students } \\
\text { interviewed }\end{array}$ & $\begin{array}{c}\text { Tutors } \\
\text { interviewed }\end{array}$ \\
\hline A & $\begin{array}{l}\text { once a week (for } 4 \text { - } 5 \\
\text { weeks), plus } 2 \text { day } \\
\text { residential }\end{array}$ & $\begin{array}{l}\text { urban, } \\
\text { central } \\
\text { belt* }\end{array}$ & 6 & $\begin{array}{c}2 \\
(\mathrm{~S} 1, \mathrm{~S} 2)\end{array}$ & 0 \\
\hline B & once a week & $\begin{array}{l}\text { urban, } \\
\text { central belt }\end{array}$ & 6 & $\begin{array}{c}1 \\
(\mathrm{~S} 3)\end{array}$ & $\begin{array}{c}2 \\
(\mathrm{~T} 1, \mathrm{~T} 4)\end{array}$ \\
\hline $\mathrm{C}$ & $\begin{array}{l}\text { once a week, for } 20 \\
\text { weeks, involved health } \\
\text { council staff and } \\
\text { members }\end{array}$ & $\begin{array}{l}\text { urban, } \\
\text { central belt }\end{array}$ & 12 & $\begin{array}{c}2 \\
(\mathrm{~S} 4, \mathrm{~S} 9)\end{array}$ & $\begin{array}{c}1 \\
(\mathrm{~T} 12)\end{array}$ \\
\hline $\mathrm{D}$ & 9 months & $\begin{array}{l}\text { urban, } \\
\text { central belt }\end{array}$ & $\begin{array}{c}\text { not } \\
\text { available }\end{array}$ & $\begin{array}{c}1 \\
(\mathrm{~S} 5)\end{array}$ & $\begin{array}{c}2 \\
(\mathrm{~T} 1, \mathrm{~T} 4)\end{array}$ \\
\hline $\mathrm{E}$ & $\begin{array}{l}2 \text { months, part of a pre- } \\
\text { employment training } \\
\text { scheme, guaranteed } \\
\text { interview on completion } \\
\text { for a health-related post }\end{array}$ & urban & 15 & $\begin{array}{c}2 \\
(\mathrm{~S} 6, \mathrm{~S} 7)\end{array}$ & $\begin{array}{c}2 \\
(\mathrm{~T} 3, \mathrm{~T} 5)\end{array}$ \\
\hline $\mathrm{F}$ & $\begin{array}{l}\text { 2-3 hours, } 1-2 \text { days per } \\
\text { week, for } 1 \text { year }\end{array}$ & urban & 9 & $\begin{array}{c}2 \\
(\mathrm{~S} 8, \mathrm{~S} 14)\end{array}$ & $\begin{array}{c}1 \\
(\mathrm{~T} 6) \\
\end{array}$ \\
\hline G & $\begin{array}{c}4 \text { hours, } 1 \text { day a week, for } \\
20 \text { weeks }\end{array}$ & $\begin{array}{l}\text { highland } \\
\text { town }\end{array}$ & 11 & $\begin{array}{c}4 \\
(\mathrm{~S} 10, \mathrm{~S} 11, \\
\mathrm{S} 12, \mathrm{~S} 13) \\
\end{array}$ & $\begin{array}{c}1 \\
(\mathrm{~T} 7)\end{array}$ \\
\hline $\mathrm{H}$ & once a week & $\begin{array}{l}\text { urban, } \\
\text { central belt }\end{array}$ & 5 & $\begin{array}{c}1 \\
(\mathrm{~S} 15)\end{array}$ & $\begin{array}{c}1 \\
(\mathrm{~T} 11)\end{array}$ \\
\hline I & $\begin{array}{l}2 \text { day residentials, held } \\
\text { twice }\end{array}$ & $\begin{array}{l}\text { island, } \\
\text { highlands }\end{array}$ & 5 & $\begin{array}{c}3 \\
(\mathrm{~S} 16, \mathrm{~S} 18 \\
\mathrm{S} 19)\end{array}$ & $\begin{array}{c}2 \\
(\mathrm{~T} 8, \mathrm{~T} 9)\end{array}$ \\
\hline $\mathrm{J}$ & $\begin{array}{c}\text { once a week, for } 5-6 \\
\text { months }\end{array}$ & $\begin{array}{l}\text { rural, } \\
\text { highlands }\end{array}$ & 9 & $\begin{array}{c}2 \\
(\mathrm{~S} 17, \mathrm{~S} 20)\end{array}$ & $\begin{array}{c}2 \\
(\mathrm{~T} 10, \mathrm{~T} 13)\end{array}$ \\
\hline K & $\begin{array}{c}2 \text { hours, once a week, for } \\
2 \text { years }\end{array}$ & $\begin{array}{l}\text { rural, north } \\
\text { east coast }\end{array}$ & 6 & 0 & $\begin{array}{c}1 \\
(\mathrm{~T} 2)\end{array}$ \\
\hline
\end{tabular}

* In this study, 'central belt' incorporates Edinburgh and Glasgow, and the area between them. 
Table 6-2 Participant information - Students

\begin{tabular}{|c|c|c|c|c|c|}
\hline $\begin{array}{c}\text { Students } \\
\text { interviewed }\end{array}$ & Gender & Age & Previous experience & Occupation & $\begin{array}{c}\text { Course } \\
\text { parts } \\
\text { completed }\end{array}$ \\
\hline S1 & female & $35-40$ & $\begin{array}{c}\text { administration, } \\
\text { health-related } \\
\text { voluntary activity }\end{array}$ & $\begin{array}{c}\text { development } \\
\text { worker Health } \\
\text { Promotion } \\
\text { project }\end{array}$ & both \\
\hline S2 & female & $35-40$ & $\begin{array}{l}\text { administration, social } \\
\text { issues related } \\
\text { voluntary activity } \\
\end{array}$ & as above & part 1 \\
\hline S3 & female & $55-65$ & $\begin{array}{c}\text { civil service, } \\
\text { community-based } \\
\text { voluntary activity }\end{array}$ & $\begin{array}{l}\text { care worker } \\
\text { (part-time) }\end{array}$ & both \\
\hline S4 & male & $50-60 \mathrm{~s}$ & $\begin{array}{l}\text { retired professional, } \\
\text { various health } \\
\text { service -related } \\
\text { voluntary activity } \\
\end{array}$ & retired & both \\
\hline S5 & female & $40 \mathrm{~s}$ & $\begin{array}{c}\text { community / health } \\
\text { based voluntary } \\
\text { activity }\end{array}$ & $\begin{array}{c}\text { health } \\
\text { promotion } \\
\text { specialist } \\
\end{array}$ & both \\
\hline S6 & female & $20 \mathrm{~s}$ & $\begin{array}{c}\text { housing association } \\
\text { committee and social } \\
\text { work volunteer }\end{array}$ & parent & both \\
\hline S7 & female & $40-50$ & $\begin{array}{c}\text { factory worker, } \\
\text { voluntary experience, }\end{array}$ & $\begin{array}{l}\text { community / } \\
\text { health-related } \\
\text { student } \\
\end{array}$ & both \\
\hline S8 & male & $35-40$ & $\begin{array}{c}\text { graduate } \\
\text { (geography), carer, } \\
\text { various employment }\end{array}$ & $\begin{array}{l}\text { community } \\
\text { project manager }\end{array}$ & both \\
\hline S9 & female & $35-40$ & health service & administration & both \\
\hline $\mathrm{S} 10$ & female & $50 \mathrm{~s}$ & $\begin{array}{l}\text { member of church, } \\
\text { volunteer for an } \\
\text { animal charity }\end{array}$ & not working & both \\
\hline S11 & female & $40 \mathrm{~s}$ & child care volunteer & parent & both \\
\hline S12 & male & $50 \mathrm{~s}$ & $\begin{array}{l}\text { health service } \\
\text { manager, citizen's } \\
\text { advice bureau } \\
\text { volunteer }\end{array}$ & retired & both \\
\hline
\end{tabular}


Table 6-2 Participant information continued - Students

\begin{tabular}{|c|c|c|c|c|c|}
\hline $\begin{array}{l}\text { Students } \\
\text { interviewed }\end{array}$ & Gender & Age & Previous experience & Occupation & $\begin{array}{c}\text { Course } \\
\text { parts } \\
\text { completed }\end{array}$ \\
\hline S13 & female & $40 \mathrm{~s}$ & $\begin{array}{l}\text { volunteer youth } \\
\text { worker }\end{array}$ & $\begin{array}{c}\text { children's } \\
\text { worker (school } \\
\text { and detached) } \\
\end{array}$ & both \\
\hline S14 & female & $30 \mathrm{~s}$ & nursery manager & $\begin{array}{l}\text { health promotion } \\
\text { project manager }\end{array}$ & both \\
\hline S15 & female & $30 \mathrm{~s}$ & $\begin{array}{c}\text { volunteer youth } \\
\text { worker }\end{array}$ & parent & both \\
\hline S16 & female & $40 \mathrm{~s}$ & $\begin{array}{c}\text { graduate (rural health } \\
\text { studies) }\end{array}$ & $\begin{array}{c}\text { health promotion } \\
\text { / community } \\
\text { development }\end{array}$ & part 1 \\
\hline S17 & female & $60 \mathrm{~s}$ & $\begin{array}{c}\text { teacher, volunteer } \\
\text { physical activity } \\
\text { instructor }\end{array}$ & crofter & both \\
\hline S18 & female & $20 \mathrm{~s}$ & $\begin{array}{l}\text { graduate (rural health } \\
\text { studies), interest in } \\
\text { health and nutrition }\end{array}$ & $\begin{array}{l}\text { internet call } \\
\text { centre }\end{array}$ & both \\
\hline S19 & female & $20 \mathrm{~s}$ & $\begin{array}{c}\text { graduate (rural health } \\
\text { studies) }\end{array}$ & $\begin{array}{c}\text { literacy / health } \\
\text { promotion }\end{array}$ & both \\
\hline S20 & female & $25-30$ & $\begin{array}{l}\text { occasional voluntary } \\
\text { activity, interest in art }\end{array}$ & parent & both \\
\hline
\end{tabular}

Table 6-3 Participant information - Stakeholders

\begin{tabular}{|c|c|c|c|}
\hline $\begin{array}{c}\text { Stakeholder } \\
\text { interviewed }\end{array}$ & Gender & Age & HIIC-related role \\
\hline SH1 & male & $40 \mathrm{~s}$ & management \\
\hline SH2 & female & $50 \mathrm{~s}$ & $\begin{array}{c}\text { development / } \\
\text { assessor }\end{array}$ \\
\hline SH3 & female & $40 \mathrm{~s}$ & policy / strategic \\
\hline
\end{tabular}


Table 6-4 Participant information - Tutors

\begin{tabular}{|c|c|c|c|c|}
\hline $\begin{array}{c}\text { Tutors } \\
\text { interviewed }\end{array}$ & Gender & $\begin{array}{l}\text { Age in years } \\
\text { (approximate) }\end{array}$ & $\begin{array}{l}\text { Previous } \\
\text { experience }\end{array}$ & Occupation \\
\hline $\mathrm{T} 1$ & female & $50 \mathrm{~s}$ & $\begin{array}{l}\text { facilitated several } \\
\text { HIIC courses, } \\
\text { employed in } \\
\text { HIIC-related role }\end{array}$ & $\begin{array}{c}\text { health } \\
\text { promotion / } \\
\text { community } \\
\text { development } \\
\text { manager }\end{array}$ \\
\hline $\mathrm{T} 2$ & female & $40 \mathrm{~s}$ & not available & $\begin{array}{l}\text { adult education } \\
\text { tutor }\end{array}$ \\
\hline $\mathrm{T} 3$ & female & $25-30$ & $\begin{array}{l}\text { volunteer youth } \\
\text { worker, post } \\
\text { graduate } \\
\text { (community } \\
\text { education) } \\
\end{array}$ & $\begin{array}{l}\text { health } \\
\text { promotion }\end{array}$ \\
\hline $\mathrm{T} 4$ & female & $45-50$ & $\begin{array}{l}\text { facilitated several } \\
\text { HIIC courses }\end{array}$ & $\begin{array}{c}\text { health } \\
\text { promotion / } \\
\text { community } \\
\text { development } \\
\text { worker }\end{array}$ \\
\hline T5 & female & 25 & $\begin{array}{l}\text { masters in health } \\
\text { and psychology }\end{array}$ & $\begin{array}{l}\text { health } \\
\text { promotion }\end{array}$ \\
\hline T6 & female & $40 \mathrm{~s}$ & $\begin{array}{l}\text { community } \\
\text { worker }\end{array}$ & $\begin{array}{l}\text { school based } \\
\text { community } \\
\text { worker }\end{array}$ \\
\hline $\mathrm{T} 7$ & female & $35-40$ & not available & $\begin{array}{l}\text { project manager } \\
\text { voluntary sector }\end{array}$ \\
\hline $\mathrm{T} 8$ & female & $40 \mathrm{~s}$ & not available & $\begin{array}{l}\text { health } \\
\text { promotion / } \\
\text { community } \\
\text { worker }\end{array}$ \\
\hline T9 & female & $40 \mathrm{~s}$ & $\begin{array}{l}\text { community } \\
\text { development }\end{array}$ & $\begin{array}{c}\text { community } \\
\text { development } \\
\text { worker } \\
\end{array}$ \\
\hline $\mathrm{T} 10$ & female & $50 \mathrm{~s}$ & $\begin{array}{c}\text { community } \\
\text { council volunteer, } \\
\text { lecturer }\end{array}$ & $\begin{array}{c}\text { health } \\
\text { practitioner }\end{array}$ \\
\hline $\mathrm{T} 11$ & female & $25-30$ & $\begin{array}{l}\text { graduate } \\
\text { (community } \\
\text { education) }\end{array}$ & $\begin{array}{l}\text { student support } \\
\text { worker at high } \\
\text { school }\end{array}$ \\
\hline $\mathrm{T} 12$ & female & $50 \mathrm{~s}$ & $\begin{array}{c}\text { health promotion } \\
\text { manager }\end{array}$ & $\begin{array}{l}\text { health council } \\
\text { manager }\end{array}$ \\
\hline $\mathrm{T} 13$ & female & $50 \mathrm{~s}$ & health practitioner & artist \\
\hline
\end{tabular}


Just before starting each interview, the participant was asked if they had received the information sheet about the research project and if they had any further questions. The aim of the study was reiterated and the conditions of the interview were described (see section 5.6 ethical considerations). If the participant was happy to proceed, they were asked to indicate their agreement by signing a consent form. Once this was completed the interview began. The length of the interviews ranged from eighteen minutes to two hours and ten minutes, with most taking between forty and sixty minutes. One of the tutor interviews (T8 and T9) was a joint interview because the participants stated they did not have the time to be interviewed separately. In the next section the stages of data analysis are described.

\subsection{Data Analysis}

In qualitative studies, data analysis can often start when the data collection or construction phase begins (Ezzy 2002). The aim of this section is to describe the analytical process for this study. There are many different techniques and forms of qualitative data analysis (for a review see Ezzy 2002; Ryan \& Bernard 2000). However, the most appropriate analytical method for this research project was thematic analysis, which according to Ezzy (2002) involves identifying themes or concepts from the data. The main characteristic of thematic analysis is that the classification of themes are not pre-defined prior to coding the data, rather their construction is informed by the data. The process of identification is characterised by repeatedly reviewing the data, which were interview transcripts. After conducting the interviews the analytical process was broken down into three parts: transcription, coding and interpretation (thematic analysis), although the last two stages were repeated a number of times. Each phase is described in more detail below.

Transcribing interview recordings can be problematic for the following reasons. Firstly, it can be time consuming and generates multiple pages of text, which has obvious implications for the amount of time needed for analysis. Secondly, participants may be made anxious by using a microphone to record the interview 
(Bryman 2001), although smaller recording devices can be used, which may help to minimise this concern. However, according to Heritage (1984) there are a number of advantages in transcribing an interview. First, a transcript represents an account of an interview when it is unlikely that the researcher would be able to recall what was said in sufficient detail (Silverman 2000). Second, a written record of the interview allows for in-depth and repeated reflections on the data. Third, transcripts give the opportunity for external scrutiny, for example, other researchers could assess the analysis. The final benefit of transcripts is that the data can be re-used to inform further academic interests. I would also add that if the researcher completes the transcription then they can also familiarise themselves with the data in greater depth. Transcripts for this thesis were generated by listening to an audio recording of each interview and then typing a record of what was said and by whom.

After completing each interview, I reflected on various aspects of the interaction, such as the participant's overall response and my communication style. In addition, I made general observations about where and when the interview occurred, who was present, and how long the interview lasted. These points were recorded onto a cover sheet which was attached to the respective interview transcript. The next phase of data analysis was coding.

Coding interview transcripts involves dividing data into units of meaning which are variable in size, for example, phrases, sentences or paragraphs (Basit 2003). Then a label or code is allocated to that particular unit of meaning. According to Seidel and Kelle (1995) the purpose of coding is to identify and collect examples of relevant events; and to explore these events for similarities, differences, patterns and structures. The early stages of coding are usually exploratory and sometimes known as 'open coding' (Seidel \& Kelle 1995) and as the analysis progresses the codes are refined and redrawn (see for example appendix x). 
The coding process began in March 2004. The codes at this initial stage were descriptive and broadly reflected the subjects raised in each interview. During this process, the transcripts were discussed with my supervisors and analysed in conjunction with reviewing the literatures outlined in Chapters 2, 3, and 4. Additional literature was also consulted which developed the analysis further. Subsequently, the coding schema became more abstract and conceptual compared to the initial stages.

NVivo version 1.3.146, a software programme designed to analyse qualitative data, was used to assign the codes to each transcript. The advantages and disadvantages of using computerised software have been debated elsewhere (Fielding 2002; MacMillan \& McLachlan 1999; Richards 1999). However, after reflecting on my experience of using this software, I would conclude that the main advantage related to the data management process. For example, NVivo allows the user to produce coding reports which reproduce each segment of text relating to a particular code in each interview and collates them into one document. Thus, using the software allows the researcher to 'splice' the interview text into various segments. However, this process may obscure the context and content of an interview. To counteract this, I repeatedly re-read each transcript in its original form during the analysis phase.

In the following four chapters, 7-10, the findings from this study are presented. It is worth noting at this point providing some explanatory notes on presentation. Firstly, as noted previously, three participant groups were recruited and are signified in the findings by the following abbreviations: $\mathrm{SH}-$ stakeholders, $\mathrm{T}-$ tutors and $\mathrm{S}-$ students; in addition, RP - the researcher. Also each participant was allocated a number indicating the order in which the interviews were conducted. For example, $\mathrm{S} 1$ was the first student interviewed. Secondly, a phrase or word placed inside square brackets [ ], shows that text was added when the interview was transcribed. The main reasons for this were to clarify the subject to which the participant was referring. For example, 'It [HIIC] made me more aware about health'. Grammatical refinements were also added on occasion to help the flow of the narrative. In 
addition, a record was made of a significant action during the dialogue, for example, [laughs]. The last modification related to omitting units of speech. The addition of three dots ... show where words have been removed from the dialogue. This was done to avoid reproducing confusing or irrelevant segments of narrative.

Finally, interview data are discussed in relation to other literature within each findings chapter. Incorporating and discussing additional literature sources when considering the findings shows the analytical process as I reflected on participants' accounts and consulted new material. Furthermore, the accounts included in the findings chapters included a range of concepts, themes and issues. Given that many of these were interrelated, I decided that it would be more concise to combine findings with segments of discussion, rather than presenting the findings descriptively followed by a more in-depth discussion chapter. Chapter 11 includes a consideration of the findings in relation to the research questions and overall aim of this $\mathrm{PhD}$.

In summary, thematic analysis was considered the most appropriate process for this research project and involved identifying themes and concepts from the data, which was achieved through repeatedly reviewing the data or iterative reflection. A coding schema was developed in conjunction with the analytical process. Using computer software (NVivo) allowed for efficient data management. However, it was recognised that both content and contextual data could be overlooked by basing the analysis exclusively on sections of coded and 'spliced' data, at the expense of considering the entire interview transcript. In the proceeding four chapters, findings are presented for the following themes: 'community', 'community capacity building', 'health' and 'impact of learning'. 


\section{Findings - community}

This chapter explores the discussions with participants regarding their understandings of the idea of community. I established previously that community was an important concept in the context of this research project. Its importance can be summarised as follows: first, at the time of writing there was political interest in the concept of community reflected in part by policies that aimed to strengthen communities and to encourage community members to address social and economic problems. Second, community is one of the central themes in the HIIC course as participants explore the processes involved in taking action at a community level to tackle health related concerns. Therefore, given the centrality of the concept of community in this project examining participants' conceptualisations of community is relevant.

The analysis of interview data relating to community is divided into a number of sections. In the first two sections, I present how tutors and students expressed ideas about community. The third section traces the shared meanings of community from the data, notably by participants with a community/health-related background. In addition, I outline how community membership was reinforced and how communities can be defined by their boundaries. Fourth, I present interview data that related to perceptions of community change. Fifth, I highlight data that suggests that the meaning of community for some participants included an expectation of communal activity. In the last section, I introduce the idea of 'positionality', which refers to where participants place themselves in relation to a community.

\subsection{Tutors' understanding of community}

A common response from tutors was that the notion of community can have many different meanings:

RP: One of the ideas from the course is around community. I was wondering if you could comment what you think community means? 
T12: You can have communities within communities and communities across communities.

RP: The next question was about the term community. I was wondering if you could tell me what community means to you?

T11: Eh, it's got a million meanings, hasn't it, community?

RP: What does community mean to you? Do you see it as geographic?

T8: There are other communities, but it's very difficult to identify them, but there is communities within communities here.

The above responses indicated that participants found it difficult to articulate a precise definition of community and that the concept is contestable.

A geographical component to the meaning of community was also identified:

RP: We've mentioned the word community quite a lot [in this interview], I was wondering if you [could] say something about what you think that means?

T1: Well the obvious one is geographic...people who live in a particular area... well to me they belong to a community....and certainly it's always been clear to me that we're quite territorial in the way that we live...so it's [meaning of community] very much a geographical thing for me.

In the above quote $\mathrm{T} 1$ suggests that community can be prescribed to groups of people living in the same area and that organising social relationships in this way was natural.

Other definitions of community contained references to the actions or characteristics of a group of people:

RP: What [does] community mean to you? How do you interpret community?

T6: Community is...how people perceive others who have a similar experience, you know that could be a geographic community. 
RP: Could you say what community means to you?

T7: It's a collection of people who have some common bond...sometimes it's geographical or interest.

T11: You've got community the place, but you've also got communities of interest where there is...people who have a similar, share a similar identity that group together.

Some tutors alluded to the characteristics of a positive community, for example, where people consider each other's interests. One tutor described her community as a 'safe' one, which she considered a beneficial attribute in the context of contributing towards her children's well-being:

T2: I like the fact I' $m$ in this small community, because my daughters...I feel they were protected when they were younger, people knew who they were.

Understandings of community were also expressed as something felt. For example, a 'sense of belonging' existed when a person was comfortable with other people from that community:

T6: There has to be a sense of belonging, I would say from my personal view, yeah, a community is something that you feel that you belong to.

T11: It's, I think, it's a sense of belonging to a group.

T13: [Community means] at least being able to find a niche where there are others within your area that you can...mix with and feel at ease with.

T10 was the only participant who viewed communication as a feature of community:

T10: So community has to have some communication in there and some sort of framework of concern, whether it's health, social, whatever, but some sort of network of communication. 
It is unclear if T10's 'framework of concern' expression referred to a common interest or a communal environment in which community members were active in addressing problems and issues.

Ideas of community were also related to professional practice, for example, T11 makes the following statements:

T11: I like working in the community and using community development principles.

T11: I feel in this area [location of work place] there's a big sense of community, so I'm quite close to other workers and residents in this area.

I would suggest that T11 used her professional role to construct her identity in relation to the community and other colleagues.

In summary, participants were not always able to clearly distinguish between different aspects of community. This may have indicated that tutors were unsure of an exact definition of community and / or that the concept itself is complex and contested. Conceptualisations of community included a geographical component combined with an emphasis on how people interacted with others and their experiences within a particular location. Aspects of a positive model of community were identified; for example feelings of security and community members being sensitive to each other's interests. The idea of community also had an emotional element, which related to a sense of belonging or feeling comfortable with others from that community. One tutor understood community to include a communication network. References to professional roles appeared to inform how some participants expressed their meaning of community. 


\subsection{Students' understanding of community}

Analysis of the students' transcripts highlighted some similarities between tutors' and students' understanding of community. For example, some students made reference to geographical location and others combined place and people by talking about the nature of social interactions:

RP: Could you say what community means to you?

S19: I suppose the area that you live in and the people that you interact with everyday.

RP: I was going to ask if you'd felt you learnt anything new about what community meant?

S1: Community can mean lots of things, it can be where you live, it can be about a group of people with a common goal.

RP: I remember [that] one of us mentioned the word community and you said 'that's a funny concept or idea'...could you talk a bit more about what you think community is?

S10: Different concepts. It could be the locale, the community you live in, as in the area that you live in or there's the community, i.e. the environment of the people that you live in.

S8: I would say probably [community], it's the immediate area where you live, but community can also be the people you socialise with or work with.

The concept of community was also expressed as something felt:

RP: What do you think community means?

S18: Community means...kind of belonging a lot of the time, having a sense of belonging to a group of people.

Another participant identified that the term community can have multiple meanings:

S1: Community can mean lots of things...it can be about a group of people with a common goal, common interest, common issue. 
A number of students reported that after participating in a HIIC course they had a broader sense of community, for example by considering a deprived area or people who did not interact with other local people as being part of the same community:

RP: As well as health, the course looks at community. Do you think you've learnt anything new about what community means?

S9: You tend to think [community is] the estate that you're in...But when you think about it...you've got to go wider than that...look at everyone...like the more deprived areas and some people would think, 'well, no that's not part of my community, cause I don't stay there', but you've got to do that now, it's the whole thing.

RP: What do you think it [community] means? Or what does it mean to you?

S13: There are people that live in the community who might be quite happy to be on their own, but there are also people there who are too frightened or don't have the confidence to ask for help or to make friends, so that's part of it as well.

For another participant it was a realisation of how a community functions:

RP: During the health [issues] course there may have been discussions about what community means. Did you feel if you learnt anything new about what community means?

S6: Erh, I would say beforehand I was, when you say community, you would just think of where you live, that was it. But the course showed, you know, community it's about how... a community bonds, how they work together.

Some students also referred to characteristics of a 'good' community; for example, had clean streets, was tight-knit, felt safe and included intergenerational cooperation:

RP: You mentioned that you've become much more aware of community, you were reminded about the importance of that. Could you say what community means to you?

S20: A good community would be... when the old and young mix as well.

RP: Could you make a comment about what community means? 
S16: [It's] about the community being able to work and play in a happy, safe and healthy environment alongside one another, and share ideas...having a common aim if you like.

In addition, a negative sense of community was also described as when people did not work together to address issues, or when there was a lack of community spirit:

S7: There was nothing to get into, nothing to get involved in because there wasnae [was not] really a community there, you know. It was, it's fractured, I don't think anybody knows what a community is anymore.

Some notions of community went beyond expressions of locating community in a geographical or residential area and included values and ideals (or aspirations). For example, S4, who had decided to live in the community where he had been professionally involved in its development, referred to the meaning of community as being interested in your neighbours and included family ties:

RP: During the course you may have had discussions about what community means. I was wondering if you learned anything new about that sort of idea?

S4: We discussed it and went into it in depth again...we went into what does community actually mean, going back to the family and traditional types of community to modern communities with friends and neighbours.

RP: Which do you relate to? Or was it a mixture?

S4: It's a mixture, I've got strong family connections... so that's the community from that aspect... and then in a wider, interested in neighbours to an extent.

S4 then gave an example of how he provided his neighbour, who had recently survived a heart attack, with some information concerning available health services.

Ideas of community were also defined beyond the confines of family, friendship and neighbourly ties and S14 and S8 talked about their understanding of community in a more generalised sense. S14, who worked as a health promoter in a deprived urban area, used abstract terms when relating her understanding of community and presented an egalitarian version of community: 
RP: I was wondering if you learnt anything new about what the word community means?

S14: I just think community in general...it's not just about people, it's about areas and it's about traditions and it's about values...everybody being given their place, it's like an equality.

S8, who had been a volunteer and was at the time of his interview due to start a fulltime job managing a community project, equated community to values of equality and inclusiveness and promoting the involvement of community members:

RP: Where would you place your definition [of community] now?

S8: I've real problems with this, as a community means all things to all people...I think my sense of community means that you have to include everybody, 'cause I think that if you don't, you've not won the argument, you have to take everybody with you.

I would suggest that these quotes represented descriptions of ideal communities. This might be understood as a reflection of professional identities, the values they have attached to their professional practice or signify motivations for being in a particular role. However, it is difficult to determine whether the participants were referring to actual experiences of a particular community or just stating an aspiration.

Reflecting on the comments made by S8, S13, S9 and S14 (see above), I would argue that they can be understood by applying the idea of a moralised concept of community (MCC). Andrew Mason (2000) used the terms MCC and the ordinary concept of community (OCC) in attempting to explain the contested nature of community. He argued that OCC consists of groups of people who share a variety of values and culture or way of life, who identify with the community and its practices and can recognise others as community members. However, for a group to be considered a community in a moralised sense there are two additional stipulations. First, there must be solidarity or a level of mutual concern between the members of the community. Second, organised systems of exploitation or injustice should be absent within the community. According to Baker (1987: 35) 'there can be no 
genuine sense of community between degrader and degraded or exploiter and exploited- these relationships mock the very idea of community'. Writers influenced by other ideologies, not just socialism, have written about the MCC. For example, Mason cites certain feminists who have argued that members of a patriarchal society would be unable to form a community as the relations between men and women are essentially exploitative and inequitable (Frazer \& Lacey 1993; Weiss \& Friedman 1995)

However, interpreting ideas of community in this manner is problematic as communities are presented as utopian, offering a misplaced sense of security and comfort. For example, Bauman (2001: 1) caustically states, the idea of community 'is like a roof under which we shelter in heavy rain, like a fireplace at which we warm our hands on a frosty day'. An idealised view of community is also challenged by those who argue that communities are often arenas of conflict and division (Edwards 1997; Purdue et al. 2000; Shirlow \& Murtagh 2004), for example as groups compete for resources and power (Brent 2004).

An insight into how communities can be potential sites of conflict was offered during S17's interview. During a discussion about local interest in organic gardening, I asked the participant if she could explain her observation that this interest related more to a lifestyle identity rather than practiced:

RP: Do you think they lack the skills [to practice organic gardening] or is it? S17: Well no, erm the ground is a thing for a start and in a crofting area, everyone is very jealous of their own ground and everyone's else's. I mean a crofting area is the most jealous area you will ever come into.

Other research has also explored conflict within communities. For example, in a study concerning the impact of the development of the North Sea oil industry on a Scottish town, Moore (1982) found that despite the appearances of uniformity there were serious divisions in the community where self-interest was promoted just as much as solidarity or bonds of belonging. It has been argued that divisions and 
disunity are inherent in community politics, despite what community utopians might otherwise argue (Brent 1997).

Notably, one participant, S7, did not feel that community lived up to an utopian ideal. Her observations about what community meant portrayed a fractured model of community, which consisted of groups of families and sub-communities, such as drug users or young people (see S7 above). S7 reported that she also felt isolated from her community and found it difficult to relate to other people there.

In conclusion, students expressed their understanding of community with references to geographical location, as a feeling and as a combination of place and people. I have reported that some students had developed a more inclusive definition of community, which incorporated disenfranchised groups. However, a number of participants also referred to experiences of dysfunction and disunity within their communities. Traits of good and bad communities reflected the quality of the social relationships between community members.

\subsection{Shared meaning of community, boundaries and place}

After reflecting on the tutors' transcripts, I noted that there was a similarity in some of the phrasing used when they expressed their conceptualisations of community. Another observation was that many of the tutors had similar professional backgrounds and worked as health promoters and or community development workers, which may help explain why they considered the idea of community in a similar way. For example, T3 and T5, both health promoters who co-tutored together, spoke about the meaning of community in the following way:

T3: I suppose because of my training, I'm a bit more wider in the sense about community can be like a geographic location or a kind of group of interests.

T5: [Community] could be people that live in one particular area...it's probably like a larger group coming together with a common interest. 
In addition, T7, a voluntary sector manager, stated that her professional practice reflected community development principles and suggested community was:

T7: It's a collection, a collection of people who have some common bond. Sometimes it's geographical or interest.

In another example, T12, who worked in a Health Council, an organisation that aims to represent the interests of patients and the general population in the National Health Service, also had a background in health promotion and managing community projects:

RP: Another one of the ideas from the course is around community. Could you comment what you think community means?

T12: When I worked in health promotion, there were a number of us that had different settings... well I had community.

While it is reasonable to expect community-based workers to view community as a site for professional practice, this perspective can be problematic. For example, in a USA qualitative study Drevdahl (1999) interviewed clinical staff and board members about their understandings of community. They talked about community as a target market, which Drevdahl argued served to objectify the community and contributed to perpetuating an 'us' and 'them' discourse, hiding the mutuality between community members and practitioners.

One way to understand the use of common phrases is to refer to Anthony P. Cohen's (1992) Symbolic construction of community. Cohen argued that the practice of formulating an analytical definition of community should be rejected and that it was more useful to examine the ways in which the term community is used. Symbols, one of Cohen's key ideas, are indicated by categories of social knowledge and can be overt in the form of rituals or covert as part of the meanings instinctively attributed to everyday things such as words. Thus, I would argue that in using similar phrasing 
tutors could be viewed as a community of community / health-related workers, who shared a common understanding about the idea of community.

Cohen's work is also relevant in the context of boundaries. Some of the participants in this study alluded to how a type of community membership was defined. Thus, in this sense the boundary of a community is constructed.

RP: Is there a different sense of community among the crofters compared to say the people living in this bit [main residential area]?

S17: Not really, because a lot of people that live here are related to crofters, but the division maybe is the incomer verses local, and the locals resent the fact that incomers go on committees and you know, 'how do they know anything? They've only been in the place five minutes'? And I turn round and say, 'well, if you're so damn bothered, why the hell don't you stand for the committee?' Locals can't be bothered or there's a few who do, don't get me wrong, but there's resentment that the incomer[s] are prepared to get off their backside and do something.

I suggest that S17 demonstrated community membership as defined by residency and contribution. She made the distinction between an incomer, as someone who had moved into the area and a local, as someone who had lived in the area all of their lives. S17 had moved to the area over fifteen years ago and organised a weekly activity in the local community centre. This might explain why S17 was critical of the locals' response to more recent incomers. I would argue that S17's community membership criteria was based partly on place of birth and level of contribution to the community.

S20, who attended the same course as S17, expressed the boundary of community membership in terms of an individual's contribution towards a level of perceived communality. S20 implied that she had 'just about' satisfied this criterion for community membership and made a distinction between people she perceived as being considerate to other community members and those who were not:

RP: So after you finished the course, do you think that you changed in anyway? Such as your... attitudes about the community? 
S20: Yeah, I'm probably more aware of the community, because sometimes you can be quite bad as well for just, well I'm not so bad, but you get some people who are just out for themselves, all the time, aren't they? And they don't think of the community as a whole.

S20 did not give any examples of how she thought 'thinking about the community' could be actualised into activities that made a contribution towards the community. Her involvement with the community was confined to helping at the local school with art-based activities during the summer holidays. She did not express or indicate any planned interest in being involved with other community projects.

It is interesting to compare how S20 and S17 actualised community membership, in that both referred to contributing to the wider community, yet S20 acknowledged that she 'just about' fulfilled this condition, while S17 took an exercise group for elderly people in the local community centre. I would argue that S20 may have felt that her community membership was justified because she had grown up in the area, which in some way compensated for a reduced level of community activity.

As noted, Cohen's concept of boundaries is useful to consider in this analysis. According to Cohen, boundaries frame components and signify those elements as different to others. For example, boundaries signify the beginning and the end of a community and establish its identity. I argued that in the above quotes participants referred to the boundaries of their community, which poses the question of who is included as a community member, who is not and on what criteria community membership is based. In the context of S17 and S20 community membership was based on length of residency and contribution to the community.

The theme of birthplace or place of childhood was alluded to by $\mathrm{S} 2$, who coupled it to a sense of security. S2 made a distinction between where she currently lived and where her community was. S2 also stated that she had a distinctive outlook compared to others who had lived in the area for all of their lives. In addition, S2 felt 
a 'danger' in her current location and stated that she felt safer in the area where she grew up:

S2: I live there, this is not my home, it's not my community, because I see completely differently the, say the way people who have lived there all their lives do...my children have no fear walking to the shops and meeting the neds [derogatory term for a young person]...but I feel the danger... whereas where we [used] to live, that's where we were brought up, that's where we feel safe.

The distinction between lived environment and community could be explained by Bauman (2001), who referred to the fluid nature of modern society, for example the deregulation of the work place and changes in patterns of family life. He also argued that the sense of durability and permanence that people drew from stable patterns of work, family and society have been lost. In addition, 'no aggregate of human beings is experienced as 'community' unless it is 'closely knit' out of biographies shared through a long history and an even longer life expectation of frequent and intense interaction' (Bauman 2001: 48). According to Bauman it is this experience that is usually missing and its loss is couched in terms of the 'decline' or 'demise' of community. Thus, as S2 did not share the same biographies of history with people in her locality, she did not construct her residential setting as her community.

In summary, this section presented data relevant to Cohen's work concerning community, in particular community boundaries and symbols, which were categories of social knowledge. The usage of common phrases when participants articulated their perceptions of what community meant demonstrated how the concept was symbolically understood and indicated that groups of people with similar professional roles may be viewed as a community with a shared understanding. Participants also made a distinction between residential location and 'felt' community - an emotional attachment. This difference might be related to changes in modern society, which have influenced work, family and social patterns as sources of stability. In the following section, I discuss the loss of community. 


\subsection{Change within communities}

Two participants described perceived changes to their respective communities by contrasting present experiences with observations about the past. In the following quote $\mathrm{S} 3$, the oldest participant, who lived in a small ex-mining village between Edinburgh and Glasgow, implied a loss of a sense of community:

RP: The course looks at what community means, I was wondering if you'd learnt anything new about that? Whether you viewed your community differently or? Or maybe how you viewed your community, what it means to you?

S3: Not really, because there's sort, well we always, maybe it's being a wee village, [but] we've always had... a good community thing and that has fallen away in recent years.

S3 suggested that this 'falling away' of a 'good community thing' was because people lacked the time because of work commitments and because higher living standards enabled people to exercise more choice in where they spent their leisure time. S3 argued that this change was inevitable and regrettable, but acknowledged that it also presented opportunities:

S3: [continued from above] But I think that's the same everywhere, and you know, I don't see any way of changing that.

RP: Have you got any thoughts as to why it's ['a good community thing'] fallen away?

S3: I think it's just everybody's too busy working and too much money and (laughs) you know, travel to [nearest city] and [nearest town] for nights out and things like that, whereas before you went to the local pub and you stayed locally and that was that.

RP: Do you think that's a negative change?

S3: In some ways, but you know, it's nice to be able to do that, but aye in some ways, you have lost this...everybody working together and everybody helping one another, aye it's a shame in some ways.

Changes in the community could be seen through responses to poverty. For example, when S7 was younger her mother would occasionally borrow bread or butter from neighbours. However, S7 doubted that such action would occur now; as it represented communicating to others an indication of deprivation. This scenario 
could be explained by the individualisation of social problems. According to Bauman (2001: 86) the processes of modernity have resulted in the individualisation of society, and grievances such as deprivation, have lost their 'collective character'; consequently they are suffered and managed in isolation. Thus, Bauman argues, people's gains or misfortunes become viewed as the outcome of their own efforts or lethargy.

In her interview S7 described past experiences and in response I questioned if she was perhaps idealising her memories of how community members related to each other:

RP: Do you feel that has changed looking back over your lifetime? Or do you think that is romanticising it a bit?

S7 began by recounting aspects of her childhood, spoke about her own experiences as a mother raising her children on a low income, and then returned to address the original question:

S7: Coming back to what you said about 'is that romanticising a bit'? Aye I would think probably because even way back when I was younger, it wasnae [was not] any different to what it is today. Families didnae [did not] get on...together or ...you couldnae [could not] just pop in and bother your neighbour, whereas we always seemed to believe that, aye, they were all there for us.

However, S7 added that when she was younger she felt there was an expectation that neighbours would be supportive:

S7: Whereas we always seemed to believe that aye, they were all there for us, you know?

The diminishing of this expectation may partly explain why S7 considered her community had changed. According to Konig (1968) community is defined as a global society on a local basis. He argues that the difference between the past and the present is not the loss or passing of community, rather it is the formation of new types of community. However, for Konig a characteristic aspect of community is the 
awareness of mutual bonds between people. It is the fracturing of the mutual bonds, which S7 has perhaps experienced.

In summary, the data showed that perceived changes to the community were due to a decline in the sense of communality, and to responses to poverty. The consequences of these changes were positive and negative. Whether community has been lost or reformed is debatable, although changing expectations may influence social relationships within a community.

\subsection{Expectations of collective activity}

Several participants spoke about community with reference to an assumption or an expectation concerning collective action. For example, in the following quote T7 implies that it is an indication of a community's status:

T7: It's a nice end result of a lot of the work we do, particularly in the more rural areas as well, it's about that community being a bit more sustainable in itself...if you have a good empowered community, they will come together and do things for themselves.

In contrast, a student (S6) who attended a course in an urban area described her current place of residence as a 'bad community' because there was a paucity of collective activity:

RP: Would you say that you still feel your community is where you live? Do you relate to that more or?

S6: Here...I would, to be totally honest, I would say [name of locality] is not a very good community. People don't work together...this is a quite a bad place to live. You keep yourself to yourself, you're ok. I keep myself to myself, so therefore I don't get into trouble, but it is a bad community and people don't work together to tackle issues.

The following participants S17, S20 and T13, drawn from the same course, which was delivered in a rural, remote highland area, spoke directly about their 
understanding of the idea of community in terms of what they expected from a community:

RP: Does the word community have any meaning to you or is it not something you're [not sure about]?

S17: To me community means everyone in the area pulling together as one, a single unit.

S20: What community means to me? Oh, I think community is when you kinda all work together, you know, and help, well you're all there for each other if you need be...I feel community is when you feel you can go and ask your neighbour for help.

T13: I suppose it [community] means all pulling together as a community, sort of group.

As noted, this course took placed in a rural highland area and aspects of the physical environment informed T13's understanding of community:

T13: I would say up here, [there is] very much a sense of community, because we all have to depend on each other. You know, we have one bus as day, so if you miss that bus...you have to start hitching, so people tend to pick up hitchhikers willingly...if there's a major electric failure, then we're all in the same boat...if the ferry goes off.

I would argue that living in such an environment presented people with regular opportunities to reduce the 'intimacy gap', thereby fostering relationships between community members that influenced the development of a sense of community.

It is helpful to consider the influential work by community psychologists McMillan and Chavis (1986) on the concept of 'sense of community'. They used factor analysis on responses to a list of statements about people's lived environment and their neighbours. McMillan and Chavis argued that a sense of community was characterised by the following: membership, influence, integration and fulfilment of needs, and shared emotional connection. Based on these aspects, a sense of community was defined as 'a feeling that members have of belonging, a feeling that 
members matter to one another and to the group, and a shared faith that members' needs will be met through their commitment to be together' (McMillan \& Chavis 1986: 9).

As highlighted in this section students and tutors stated their understanding of community in terms of working together, being supportive and helping each other. In addition, another student suggested that a poor community was characterised by a failure of its members to work together. As McMillan and Chavis argued an aspect of a sense of community includes an understanding that needs are satisfied through a shared sense of obligation to other community members. It is possible that T13 and S20 had experienced or had a belief in other community members offering assistance and support. For example, during the interview with S20, we discussed the drawbacks of living in an isolated rural location and I asked if she had considered moving areas:

S20: Yeah, sometimes I think, but I don't want to live somewhere really rough.

S20 then talked about the various advantages of living in her present location and went on to state how she felt supported by other people in the area:

S20: I'm feeling now that I've got quite a good sort of network, you know if I was ever stuck, I've got a lot of people I could rely on.

In addition, T13 referred to communal assistance (see quote on page 144), although S17 who attended the same course did not refer to receiving assistance from other community members. S20 and T13 expressed a sense that under certain conditions other community members could meet their needs, a function that helped to inform their sense of community.

Research suggests, however, that expectations of aid from other people living in the same geographic area have limitations. Philip Abrams, according to Bulmer (1988), explored the relationships within geographical communities in terms of the type of 
support procured from neighbours, kin and friends. Abrams suggested that personal care was shared between kinship groups whereas neighbours provided emergency support or help with practical tasks. People limited their expectations accordingly to maintain a complex balance in neighbourhood relationships, for example, 'between co-operation and privacy, helpfulness and non-interference, friendliness and distance' (Allan 1983).

Similar findings were highlighted in a report concerning Registered Social Landlords (RSL) and social capital in Scotland. Burns et al. (2001) examined mutual support among co-residents in RSL areas and in a council housing estate. RSL are registered with Communities Scotland by complying with the Housing (Scotland) Act 2001. RSLs do not trade for profit and their main objective is to rent housing to people in need. In addition, RSLs have developed a broader role in community regeneration and promoting social inclusion (Social Economy Scotland 2005). Burns et al. found that in a range of situations, reliance on local people for support was higher in the RSL areas for the following reasons. First, the presence of local family members in RSL areas. Second, the forms of support often involved a lower degree of intimacy, such as borrowing tools, and tasks reflecting mutual dependency, such as making sure a neighbour's house was secure if they were away. It was concluded that neighbours were less likely to be involved in more intimate interactions; for example, looking after children or borrowing money.

In summary, some participants suggested that levels of collective functionality reflected both the nature of social relations among community members and whether living in a particular community was a positive or negative experience. Among participants from one course, there was a common understanding that ideas of community involved forms of communal cooperation. I have suggested that the physical environment promoted opportunities for reciprocal activity and contributed towards explaining the nature of social relationships between community members. Research suggests that a sense of community is formed in part through need fulfilment and a common emotional bond. Other research reported that community 
members' expectations of aid from others was limited and that different forms of assistance are provided by family members and neighbours. Some participants suggested that they experienced their needs being met by other community members and that this form of support was a major component of their conceptualisation of community.

\subsection{Positionality}

Some participants spoke about their understandings of community in a way which I would argue highlighted their 'positionality' to their idea of community. For the purposes of this analysis, the idea of positionality relates to how individuals express their relationship to a community. For example, using a formalised definition of community may indicate a degree of distance from a community. From the data, I will highlight three examples. First, the idea of community was used as a way to organise service provision. T4, a community education / health worker, stated that community could be geographical or interest based. However, she then talked about her involvement in targeting the HIIC course to various types of communities:

T4: We've always found it difficult targeting the course... So it's been quite difficult to recruit to the course and we've tried both kinds ways of targeting like geographic communities [and we] tried to target communities of interest.

In addition, T3, a health promotion worker, stated that her colleagues viewed community in a geographical sense, reflecting how their work was organised:

T3: I still think we [colleagues] still say community, geography, neighbourhood, where I live. And for that reason, I think a lot of the examples of the group projects that they do are based on a geographic location. I've yet to work with anybody that's thought of it as a community of interest.

Viewed in this context, community is an abstract construction compared to more personalised references to community, for example when speaking about ones' own 
'lived in' community. Thus, the concept of community becomes an instrument of professional practice.

However, ideas about community formulated using a solitary feature such as geographic location or a single issue, such as campaigning to keep a cottage hospital open, may be problematic. For example, Jewkes and Murcott (1996) suggested that once a particular issue has been addressed, attempts to work with the same community become more challenging. They state that when 'trying to generate interest in community involvement in health', practitioners should consider that 'communities formed around one issue or characteristic may not share needs or interest in other areas and may not be very interested in getting involved in other issues as a group or individually' (Jewkes \& Murcott 1996: 562). Thus, while identifying communities through geographical location might be more convenient for institutions, it may not always be the most appropriate method.

Second, positionality to community changes over time and is negotiated. For example, S12, a retired NHS manager, initially denied having any identification with his local geographic community related more to community based on his previous occupation. I would argue this suggests that S12's position to community appeared to be one characterised by distance and apparent indifference:

S12: Community means so many things doesn't it? I mean community of, town's community, community of deaf people perhaps.

RP: Which aspect of community do you relate to here?

S12: Well I suppose basically my community would be the community of health service workers, social services etc, that would be my community, I think. I don't spend a great deal of time with the community at large. I'm a solitary personality in some ways...I take no interest in the community in [town], can't be arsed with it, you know.

However, S12 went on to describe his involvement with a local music group and voluntary work with an advice service: 
S12: I like just to dip in and out and not get involved in things you know. [Pause] I suppose I do, well I suppose in a way I'm involved in the community because I work for the [organisation], well do voluntary work... and I also sing in a group.

In this context, S12 appeared to accept that he was closer to the community than his initial response indicated. Thus, in S12's account his position in relation to the concept of community seemed to fluctuate from distance to involvement.

It is possible to view how 'positionality' was negotiated from S5's account. S5 indicated that she had not considered herself to be part of the local community and described a sense of isolation:

RP: During the course there may have been discussions around what community meant as a concept. I was wondering if you'd felt that you'd learned anything new about what community means?

S5: Yeah, because I hadn't looked at, hadn't even thought really about living in a community. I lived in the village, you know, didn't relate to anyone in the community, we just lived our own life, kept ourselves to ourselves basically.

Elsewhere in her interview, S5 spoke about her involvement with a community group project contributing to her feeling part of the community. However, she also explained how her current work commitments meant that she had reduced her involvement with the group project and as a result, she no longer saw herself as part of the local community:

S5: I'm not as involved with my own community now, unfortunately...I mean partly that is because I've been working full-time, I'm studying, I'm doing the cooking [health related project] as well, I just don't have the time.

S5's positionality to her immediate community was predicated on her active role in a project. In this context, S5 did not describe herself as involved in her community as she was not as active in the project as she had once been. I would argue that S5 initially felt isolated from her community then renegotiated her position using her 
involvement in a community project before withdrawing again because of other commitments.

Third, some participants talked about the idea of community in an abstract way and made reference to a formalised definition; in this context community was expressed as an external construct, rather than as a personal experience:

S14: Well, there was a definition certainly and I can't remember it [laughs].

T6: Community? Oh God, what 3 years later and oh deary me, that's three years at uni and I still didnae [did not] get that.

RP: Could you make a comment about what community means?

S16: Right, now that's a word [that has] cropped up a lot on different courses that I've done, including rural development, I have to say.

S16 then talked about community as a coming together of a group of people and articulated a contrast between a formal definition and a more personal one:

S16: For myself, community here is about the community being able to work and play in a happy, safe and healthy environment.

The above examples illustrate that participants expressed an understanding of community that was external and distant. In a qualitative study examining how the term community was used by community / health related professionals, Jewkes and Murcott (1996: 559) argued that participants also spoke of community with 'metaphors of distance'. For example, working with the community meant 'getting access', 'tap into' or 'to go and meet'. Jewkes and Murcott suggest that participants were referring to a notional community with which they worked, although they did not view themselves as being members of that community.

In summary, the idea of positionality relates to how individuals express their relationship to a community. Ideas of community might be considered in an abstract 
sense when used to organise social or health provision. However, community identity can be formed from more than just a single feature and may change. I have argued that positionality can be negotiated through actions, for example involvement with community groups, and can be characterised by distance or closeness. Some participants used formalised, received or personalised definitions of community. Use of the former may indicate that a person is making a distinction between a notional community, formed through their professional role or academic learning rather than the community of which they were a member.

\subsection{Conclusion}

The data constructed from this study suggests that the idea of community can be difficult to articulate precisely. The meaning of community was related to a range of references including geographical location, emotional attachment and particular forms of social relationships. A distinction was made between a 'good' and 'bad' community. Broadly, a 'good' community was one characterised by collective activity, security and a consideration of other members' interests. However, features of a 'bad' community included incivilities and a lack of communal cooperation. Membership of a community was linked to length of residency and community activity, with the former being a more stable and acceptable criteria, whereas the latter depended on action (to maintain the activity) and the support of the wider community. For example, one participant stated that some community members had expressed hostility towards newer members seeking to be involved with local issues through various committees.

I have argued that participants' professional roles informed conceptualisations of community. Classifying communities on the basis of geographical area or as interest groups was identified as informing the delivery of health promotion / community development provision. Participants with a community or health-related professional background appeared to express shared understandings of community and both formalised and personal definitions were reported. I also argued that descriptions of 
idealised communities reflected participants' values or methods of working with community groups.

Perceived changes to community life were based on material issues; for example, higher standards of living and greater leisure opportunities meant that community members could spend time outside of their geographical community. In addition, the reduced expectation that one could rely on other neighbours for assistance was identified as another change. However, participants from a rural highland area referred to an expectation of communal and reciprocal activity in their accounts. I also argued that aspects of the physical environment influenced the frequency of opportunities for communal activity, which could nurture and sustain a sense of community. The term positionality characterised the relationship between a participant and their idea of community. It was argued that distance between a participant and their idea of community was signified by the use of formalised definitions of community or when the ideas of community were used to inform how provision was delivered. In addition, positionality was negotiated based on community activity and fluctuated between distance and closeness.

In the following chapter, I present the findings and analysis relating to community capacity building. 


\section{Findings - community capacity building}

As I highlighted in Chapter 4 community capacity building (CCB) is a term used in a variety of contexts, for example health promotion, urban regeneration and community work, and is cited in policy documents and official publications. In the UK the use of CCB terminology is a relatively recent occurrence, although it has been argued that the notion of CCB is an elaboration of previously used ideas, such as community development and community empowerment (Gibbon, Labonte, \& Laverack 2002).

Viewing CCB as a number of dimensions or characteristics is one attempt at deconstructing the idea (Goodman et al. 1998; Labonte \& Laverack 2001b). For the purposes of this thesis I focused on four dimensions, participation, links with others, resource mobilisation and role of outside agents and used them to construct a model of CCB. The reasons for doing so were as follows: These four dimensions broadly reflected the other models of CCB that I reviewed. Second, they gave a concise representation of CCB, which compared to others, for example Goodman et al.'s (1998) model with ten dimensions, represented a more manageable and appropriate interview tool. Third, these dimensions are not context specific and could be relevant in different settings, which is an important consideration; Baker and TeaserPolk (1998: 282) stress the need to 'remain open to the various ways in which these dimensions may be operationalized because these operationalizations may vary by community'.

In this chapter, transcripts from tutor and stakeholder interviews are analysed to explore the concept of CCB. In addition, one student interview was highlighted as that participant spoke explicitly about capacity building. This chapter is divided into the following sections: the participants' understandings of $\mathrm{CCB}$, which also examines how CCB might be recognised and whether participants found the term helpful to describe their experiences. CCB related concepts are examined followed by data from the CCB paper exercise. 


\subsection{Understandings of community capacity building}

One way in which I explored the meaning of CCB was to discuss with participants their understanding of the concept.

In this study, stakeholders were participants who had an involvement with HIIC at a development, policy and management level. Comparing how stakeholders defined CCB reveals that $\mathrm{SH} 1$ emphasised encouraging an individual's potential, whereas $\mathrm{SH} 2$ and $\mathrm{SH} 3$ referred to collective action:

RP: Could you explain in the context of HIIC, how do you think CCB is defined or understood?

SH1: In the context of HIIC, I think for me there is stuff about building individual's capacity to act on life circumstances, to act on issues within their own communities.

RP: In the context of HIIC how do you think CCB is defined or understood?

SH3: I think you take a fairly pragmatic view of what CCB might be and in the context of HIIC it is very closely related to the idea around what community development is as well.

SH2: I think the building capacity part relates to that community developing particular ways of thinking about health and inequality together and taking some kind of action, so that there's greater capacity to work together.

$\mathrm{SH} 2$ then gave examples of activities that in her opinion demonstrated the building of a geographical community's capacity:

SH2: That I would call CCB, [when] something happens in the community as a result of a group of people taking action.

The above quotes suggest that $\mathrm{CCB}$ was considered as being initiated either at an individual or at a community level. Some authors have conceptualised CCB as acting at an individual level, such as:

[c]apacity building can be characterised as the approach to community development that raises people's knowledge, awareness and skills to use their 
own capacity and that from available support systems, to resolve the more underlying causes of maldevelopment; capacity building helps them better understand the decision making process; to communicate more effectively at different levels; and to take decisions, eventually instilling in them a sense of confidence to manage their own destinies.

(Schuftan 1996: 261)

Others have emphasised collective action; as Smith, Baugh-Littlejohns and Thompson (2001: 33) state, CCB is 'the degree to which a community can develop, implement and sustain actions for strengthening community health.' However, applying some of the debates in the empowerment literature is one way to resolve the tension between individual and community level CCB. Rissel (1994) suggests that empowerment can be both at an individual and community level and argues that a distinction between these two levels can be made. Individual empowerment can be defined as 'a feeling of greater control over their own lives which individuals experience following active membership in groups and organisations, and which may occur without participation in collective political action' (Rissel 1994: 41). Community empowerment includes the following, a heightened psychological empowerment among its members, 'a political action component in which members have actively participated, and the achievement of some redistribution of resources or decision making favourable to the community or group in question' (Rissel 1994: 41).

When talking about their understanding of $\mathrm{CCB}$, tutors referred to developing people's competencies:

T4: My understanding of that [CCB] now is about giving people skills, about building the capacity of the community, the skills within the community.

RP: You saw $[\mathrm{CCB}]$ as increasing an individual's skills?

T5: Skills and building their confidence, each individual, and that community can, if they are given the information and support, [they] can build it themselves. 
T6: It's about building skills, it's about having a stake in the community, it's about you having a say, it's about your...own experiences and being able to build on that to actually make any changes and to sustain it in your community.

T3: CCB is about ensuring people have the skills to have that involvement.

The above responses support the view that developing skills is an aspect of CCB. It has been argued that one of the purposes of capacity building is to develop the skills of individuals (Laverack 2005). Indeed, other academics have incorporated a specific skill dimension in their conceptualisation of CCB (see for example Goodman et al. 1998).

A critical interpretation of the notion of equipping people with skills is that this implies that the skills were previously absent. In other words, it reflects a deficit model, which is based on 'needs, deficiencies and problems' rather than 'discovering...capacities and assets' (Kretzman \& McKnight 1993: 1). An unfortunate consequence of focussing on what is lacking in individuals or a community is that it potentially downplays the effects of ill-health, poor housing, education and employment status on opportunities (Statham 2001). Taking this point further, it has been argued that the objective of capacity building projects should be to address the 'inequalities of resources and opportunities', rather than the 'inequalities of abilities' (Warburton 1998: 27).

However, the role of developing skills should not be underestimated in the context of empowering people so that they can tackle issues and concerns. Guy Steuart, according to a review of his work (Steckler et al. 1993), argued that developing the capabilities of individuals and communities to create the environment required for resolving health and social problems was just as crucial as ameliorating particular health outcomes. In describing the role of community workers, skill development was considered to be a crucial function in supporting communities to forge the 
necessary skills to participate in a manner that was appropriate to them (Croft \& Beresford 1992).

S14, a manager of a healthy eating project, was the only student who used the phrase 'capacity building' when talking about why she found her HIIC assignment challenging:

S14: I think it's just trying to put into words, what you fill in is quite difficult, 'cause you can be quite passionate about things, but trying to put them into words that are going to convey your passion about something. Also we all kind of mixed up...the jargon words like empowerment, capacity building, erm community involvement, things like that.

Later in the interview, I returned to the issue of CCB and asked S14 if she thought there was anything different about CCB compared to community development:

S14: Our management group is a volunteer management group and I would actually class this as capacity building...there were very different levels of experience to start off with, but they probably weren't as confident or developed as they are now, especially when maybe in responding to requests and agenda setting...but within the work that they have done managing myself...by the work they've done attending training courses...they've come on board with helping us with events, the capacity building that [has] gone on in that to me...that's where I see it.

S14's illustrative example of CCB mirrors the views raised by T4, T5 and T6 above: that CCB involves equipping people with skills, which is also one of the features of the 'bottom-up organisational approach' to capacity building (Crisp, Swerissen, \& Duckett 2000), which emphasised the desirability of training that was beneficial to individuals, organisations and communities. In a report for Scottish Homes, Chapman and Kirk (2001) summarised research evidence of CCB activities and argued that there was a mistaken assumption that capacity building was another name for community training and skill development schemes. According to Chapman and Kirk, capacity building signifies broader concerns than just training programmes, because the ultimate aim of capacity building is for communities to 
control and own the development process. Training courses, while providing a positive resource for volunteers, are not a panacea; as Jupp (2000: 44) states,

[r]eal capacity building involves giving groups the independence to manage resources. Not just training them in how to work on committees. Training is often helpful, but it is not sufficient in its own right.

Stakeholders were asked how they might identify CCB occurring. In response, SH1 cited examples of two HIIC students. One had developed an interest in men's health whilst participating on the course and had subsequently become involved in his community. For the second, the course had acted as a catalyst for becoming a

SH1: Much more effective activist if you like, also giving her a point to reflect on her learning... subsequently, [she has] gone back and finished her degree [and] gain employment in the area that she is active in... She is now seeking to become a tutor for HIIC.

Other stakeholders discussed the idea of using specific indicators as a way of recognising if CCB occurs:

SH2: Well in some cases, I know for example that community education now has one of its performance indicators is that CCB is built as it were... and that's got a particular range of performance [which] links to kind of awareness raising, action, people being able to do things they couldn't before.

RP: You sounded a bit unsure about the idea of these performance indicators.

SH2: I am slightly cynical about their implementation...community capacity is such a complex, slippery concept...[that] getting it down to a few performance indicators that you are supposed to... be able to measure, seems to me difficult.

RP: How do you think CCB could be recognised to be taking place in different communities?

SH3: Some kind of sensible framework of indicators that doesn't completely dominate the work.

In addition, SH3 referred to the level of an individual's involvement in their community, professional practice and project outcomes: 
SH3: I suppose some of it is about the extent to which people are involved... and you also need to look at professional practice within local organisations...to the extent to which [for example] public health practitioners are actually operating in ways that are more conducive to involvement... [Although, if you were] a community development worker...you could answer in much more immediate ways...it's about people's confidence, people's involvement, whether issues were getting addressed in immediate and practical ways.

Other research has examined community involvement at a population level. Williams (2005), using data from the 2000 General Household Survey, argued that people from the most affluent wards were more likely to be engaged in communitybased groups compared to people living in deprived wards, where "community involvement is more orientated towards one-to-one aid in deprived wards'(Williams 2005: 34). One of the implications of Williams' argument is that promoting community involvement through community-based groups in certain areas, as a method of encouraging community harmony or to deliver assistance to those in need might be problematic. Thus, caution should be exercised when using 'involvement' as an indicator of CCB as there can be different forms of involvement.

A few participants likened CCB to community development:

RP: I'd like to turn to the community capacity building idea. I was wondering if that was meaningful to you at all?

T1: Yeah, I think that's one of those, I mean it's a real jargon phrase. Much of this is jargon and normally I tried to avoid, but I suppose I slip into it as a short hand. I'm not a big fan of community capacity building because I don't think it necessarily is any better explaining what's going on than community development is.

RP: Have you heard of that phrase [community capacity building] in your work?

T11: Erm, yeah, yes I have, we've got a community capacity building project in [place] down the road.

RP: I was wondering what your thoughts were on the term, such as do you think it's a meaningful phrase or do you think it's a bit of jargon? 
T11: I think it is a bit of jargon, yeah, I don't think it's that dissimilar to community development...but to me I'm not quite sure of the difference, but I think...[CCB] is just like you know...community development, developing communities abilities and aspirations.

Similarly, in a piece of research exploring views about the concept of capacity building, it was noted that workers who had experience of community work tended to compare CCB with community development (Hawe et al. 1998).

However, other tutors reported that CCB was a jargon phrase and was not particularly meaningful:

RP: Is the phrase community capacity building meaningful to you?

T12: Well, I know what it's supposed to convey, but I don't like the phrase community capacity building, 'cause I think it's jargon and people think 'what?, what is that?'. So no it's not meaningful for me...I think it's too jargonistic basically...It's a bit condescending [laughs].

T3: I think community capacity building is a terminology we use a lot in work, but I do think it's a bit kind of a jargon.

T7: To me it means...jargon from the Scottish Executive and it means that, this is my cynical side coming out, it means that we add this into most of our funding applications, because it's what people want to hear.

The above responses demonstrate a sense of scepticism about the use of certain terminology. T7's sentiments can be found elsewhere; for example Banks and Shenton (2001), who interviewed participants of CCB schemes in the North of England, found that CCB was just viewed as a new word for community development. In addition, where previously projects were known as 'promoting community development', they were now labelled 'capacity building' just to satisfy funding criteria. Fraser (2005) in a recent article about community participation identified a number of questions concerning the process of community involvement. Fraser (2005: 287) suggests that the 'language used to represent the work' and by what criteria resources are allocated, are important considerations. Fraser wondered whether worthwhile work had been refused funding because it was not 'framed' by 
fashionable terminology. This issue of terminology was discussed by T1, who proposed that 'CCB' had replaced 'community development', because it was deemed more acceptable:

T1: I think we've got to invent phrases to replace things that have become jaded or have earned for themselves the feeling that it's something we don't want. I mean, I get the distinct impression that sometimes when communities decide to take an issue up, it is seen as problematic and almost trouble making and if it is described as community development that might give it a little bit of bad press. Perhaps CCB was put in place to alleviate some of those negative concepts attached to community development, and that's not a bad thing.

The proposition that CCB represents an acceptable 'face' of community development has been suggested by others. For example, Gilchrist (2003b: 18) argued that CCB materialised in policy statements as a way of planting community development values and methods into "what would otherwise have been rather technocratic strategies for regenerating deprived neighbourhoods'.

However, although T4 also considered CCB to be jargon, she did not appear to be resistant to the introduction of new terminology:

RP: Do you feel the phrase community capacity building is meaningful to you?

T4: It now means something to me...I think jargon changes all the time and you have to tune into what is the jargon of today.

The response of one tutor suggested that CCB was meaningful in a specific context.

T5: I think if you were talking about CCB as increasing each individual's skills [so] that community [can] build on its abilities, I think it does have a lot of meaning.

T6 suggested that CCB could have multiple interpretations:

T6: I think [CCB is] likely to mean different things to different people and I think organisations or institutions [are] likely to have a different take on what that is, as opposed to local people. 
T10 (a health professional) and T13, (an ex-health professional) co-tutored a course in a rural highland area. Both tutors appeared to be unsure of what CCB meant:

RP: One of the other ideas I am looking at as part of this project is this phrase 'community capacity building'. I was wondering if you feel this is a meaningful phrase in relation to the health issues course?

T10: What do you mean by community capacity?...I mean when I read that, when I got your letter [information sheet about the interview and study], I assumed you meant like the potential for developing the community.

In the interview with T13, I gave a personal view about what CCB meant, for two main reasons. First, an interview is a two-way process whereby the participant and the researcher are both involved in the process of constructing data. Second, I was responding to a direct question from T13 who asked me to clarify the definition of CCB. At the time I felt that it would have been inappropriate not to have replied in the way that I did. In addition, I have taken the view that as participants were willing to share their views, it would seem incongruous not to reciprocate within reason.

RP: [referring to earlier in the interview]...it sounds like you may not be too familiar with the phrase community capacity building, is that right?

T13: No [laughs].

RP: OK so it's not meaningful to you?

T13: No. What does it mean?

RP: Well, personally I think it's community development under a different name.

T13: It's a different bit of jargon?

Despite T13 admitting that she was unsure what CCB meant, she completed the exercise fluently with minimal guidance. I would argue that T13 was able to engage with an obscure idea (CCB) and apply it to her own experience. Likewise, in a Canadian qualitative study exploring factors affecting the use of community development approaches to heart health promotion, the authors reported that some participants considered community development a 'buzz-word'. However, after 
community development was explained by the researchers a participant concluded that 'I guess we may be doing it' (Robinson \& Elliott 2000: 222).

Reflecting on the joint interview with T8 and T9, I would suggest that their understanding of CCB seemed unclear as they did not answer this question directly and instead spoke about promoting the HIIC course:

RP: Would you say community capacity building is another term for community development?

T8: I'd probably see it as two-fold, I think community capacity building, but I also think it's a raising awareness of the course for other people. And I just feel that for me it's almost fifty-fifty, I don't know maybe not, maybe forty-sixty, I don't know, but confidence and capacity building, community.

T9: Yeah, there is an awareness raising and especially with regard to trying to affect the decision makers.

The idea of CCB was considered useful as one tutor suggested that the phrase could indicate a particular way of working with communities:

T1: But I do think [community capacity building] does say a wee bit about what we want to go on in this. I guess people take from it and that is to strengthen again, the ability of local people to do something that improves their area, raises an issue in their area, draws funds into the area or skills and trains people to do something that improves their life and the life of the community.

Hawe et al. (1998: 288), in an article examining how health workers understood capacity building, reported that ' $[\mathrm{t}]$ here was general consensus about the need to confront the term 'capacity-building' and make sense of meanings attached to it'.

\subsection{CCB and other concepts}

At a stakeholder level, CCB was commonly understood as being linked to community development, although slight variations were expressed regarding the nature of $\mathrm{CCB}$ : 
RP: Do you think CCB and community development are the same or different things?

SH3: I think they share a similar value base.

SH2 conceptualised CCB as a result of community development:

RP: What do you think is the difference between community development and capacity building? Or are they just linked?

SH2: They are extremely closely linked. I suppose CCB is an outcome of a community development process; that is how I would link it really. But as we both know defining CCB [laughs] is a complex and difficult area, but for me the defining point is that it's about community, not about the individual building their capacity.

SH1 questioned whether CCB was underpinned by values and suggested that it was a process.

RP: How do you think community capacity building and HIIC are linked?

SH1: Integrally...because HIIC is focussed at, I think at a range of levels and for me because CCB operates at a range of levels as well, I think they do link in very closely...there is something more about with HIIC that is actually based on a set of values, which kind of underpins values of social justice and equality and equity as well. Whereas, we might say we could build capacity in communities to do a variety of things...I am thinking about [seeing] CCB as a process.

The stakeholders' discussions indicated a reluctance to categorise CCB as the same as community development, but an acceptance that the two concepts were linked. According to Kenny (2002) a tension that community development workers sometimes face concerns the new ways in which their work can be described. Kenny (2002) also suggests that if one accepts that community development is based on a commitment to change and self-determination, then new discourses, of which capacity building is one, should be embraced and yet there is 'ambivalence in the field about how to respond to such new discourses' (Kenny 2002: 286). However, Kenny's argument is based on a particular assumption about community development, which does not acknowledge a tradition of confrontation and conflict found in other community development approaches (see for example Alinsky 1972), 
which might influence some practitioners to challenge and resist adopting new terminology that describes their work.

I asked a number of tutors if they saw a difference between CCB and community development. The responses demonstrate a fluidity in thought dialogue as participants negotiated ideas, and organised and refined their opinions. T3 initially referred to capacity building and not CCB and suggested that there was a difference, but she was unsure about her explanation:

T3: Yes, I think there is a difference in that capacity building that I see is more about knowledge and then as an individual. Although if you are doing it as a group collectively it is increasing the community capacity, but I don't know whether it is right or wrong, but I do tend to see community capacity building as an individual thing, although it happens in groups, it impacts on the individual...so does community development, but it's more about a process and a benefit to the community, as below the process brings individual benefits...I suppose you could build somebody's capacity without using community development.

T3 suggested that in general terms CCB and community development were the same. She also argued that essentially the difference between the two ideas was that CCB was about equipping people with skills while community development was concerned with inclusion:

T3: There's probably slight differences [between CCB and community development] ... but I think maybe they're broadly similar. Community development for me, is that involving people in the decisions that effect them.

T4's account also showed a similar pattern by initially suggesting that CCB and community development were essentially equivalent. Like T3, she was then able to identify and articulate differences between CCB and community development:

T4: Maybe that's the difference that I'm getting at here...community development is a way of working, of involving people and listening to them and people managing the things that affect them. The capacity building bit is ensuring they've got the skills to do that. 
In comparison to stakeholders and some tutors, a number of other tutors considered $\mathrm{CCB}$ as being synonymous with community development:

RP: So you see community development and capacity building as the same thing?

T6: I would yes, from my perspective. I'm sure not everybody would agree with that.

T7: It's the current jargon phrase for community development and it doesn't really mean much more than that.

The similarity between community development and CCB has been noted elsewhere. For example, Smith, Baugh-Littlejohns and Thompson (2001: 31) state that '[i]n many ways capacity building is the essence of community development'. In addition, according to Gibbon et al. (2002: 485) CCB is not a 'new' concept, rather 'practitioners' should view the idea of capacity building as a 'refinement of ideas found within the literature and practice of both community development and community empowerment'.

In the discussion with $\mathrm{T} 4$ about $\mathrm{CCB}$, she suggested that it was being superseded by social capital. Describing the use of different concepts by health professionals (practitioners, policy makers and researchers) in the past ten years, Labonte (2004: 116) argued that in the 1990s a new 'social lexicon' was introduced as, '[c]ommunity competence and capacity gave way to social capital. Community participation and development yielded to social inclusion'. According to Wallerstein (2002: 73), the idea of social capital has 'displaced many other community-level protective concepts' such as CCB. However, Wallerstein argues that it is more reasonable to incorporate social capital as a dimension of $\mathrm{CCB}$, for example, in relation to support networks (see for example Goodman et al. 1998), and considers social capital a lesser 'feature within the whole'. 


\subsection{Community capacity building interview exercise}

As noted for the purposes of this thesis CCB was conceptualised using four dimensions: participation, links with others, resource mobilisation and role of outside agents. For the tutor interviews, I devised an exercise that was used as a discussion tool and as way to illustrate CCB. The four dimensions were written on a piece of paper and I asked the tutors if the dimensions were relevant to their experiences of HIIC and if so, to record examples. Each completed exercise can be found in appendix xiii. In the following sections, I present each dimension from the exercise, discuss the idea of a missing dimension and finally, consider why two tutors found completing the exercise problematic.

\subsubsection{Participation}

After reflecting on the responses about this dimension, I would argue that different levels of participation can be identified. The first level could be classified as 'internal' and refers to discussions about participation being confined to the experience of the HIIC course. For example, T10 noted that there were students who seemed more willing to take part than others who were reluctant and, according to $\mathrm{T} 2$, her group discussed how they might achieve participation:

T10: You have some people who obviously participate more easily than others, but we made sure that everybody did participate...well facilitated participation, which meant, I mean we literally would tell some people to shut up for a while (laughs)...let others have a go.

T2: In relation to the course, we didn't go out and do any participation, we talked about it, we talked about how to participate.

The second level, 'developmental', refers to a process of personal growth. For example, according to T5:

T5: The course gives individuals confidence to participate, encourages them to take part. 
T4 spoke about the course raising the students' awareness that they had a right to participate. According to Sidell (2002b: 62) facilitating individuals to participate in their community through raising their consciousness and confidence has been 'characterised as psychological empowerment' (Rissel 1994).

The third level, 'agency', characterises participation as an active process and includes involvement in decision-making processes. As Sidell (2002b: 61) argued, '[i]n order to participate, communities need access to the political structures, organisations and institutions which affect their lives.' T1 and T4 spoke about various interpretations of participation, and T1 suggested that true participation occurs when people are involved at the 'ideas' stage of a process:

T1: Participation...to me it only occurs, when we are talking about HIIC or community development... when people are involved at the ideas stage, everything before that is consultation.

Otherwise, participation is really a consultation exercise. I would argue that T6's comments below demonstrate that for some students the course had an accumulative effect on deepening their involvement within their community, which began with an increase in self-worth:

T6: Participation, is a huge part of the course, I would say, huge importance...that's about in the course, but also in the wider community...I saw that happen...that evolved during the course as well, and that is in direct relation to confidence as well.

T13 did not make any comment while writing about participation, but wrote about the number of students attending the course and noted how:

T13: All participants influenced something they felt was wrong in their community.

T11 identified how participating in a HIIC course had a positive effect on levels of participation:

T11: I think from that group I worked with...their participation in the community, it definitely increased. 
To illustrate this T11 described a student who felt very passionate about being a parent and who subsequently found employment with Sure Start, a government programme designed to provide support for children in disadvantaged areas (Hodgson 2004).

T7 discussed participation in the context of a greater appreciation and awareness of 'systems', and raised the issue of voting in elections:

T7: I can't say that there's been like [an] increase in voting, but they've [the students] certainly, it's like some of the conversations we had and then you see a light going on in people's head and...

RP: It's like engaging?

T7: That's a good word, engagement.

RP: In community structures?

T7: Yeah, government, systems...systems of control...more understanding of it... and willingness to engage, i.e. voting.

T12 argued that participation required resources and responsive agencies to deliver those resources:

T12: Good quality participation, I would define that as the resource getting to the people who would benefit most from it, and you could argue that they would be people who are in communities who don't participate...but there's a need for managers and strategists and planners and all the people that have got the resources...to know more about it [HIIC].

\subsubsection{Role of outside agents}

Discussions about the 'role of outside agents' can be organised into two broad themes: how outside agents were represented and service provision. Outside agents were portrayed in a number of different ways. First, with a negative emphasis; for example, it was implied that certain agencies, whilst initially appearing supportive of the HIIC course, exploited the forum of the course as a way of engaging with community groups. In addition, another agency was perceived as being characterised by anonymous and dispassionate bureaucrats: 
T11: They [outside agencies] just thought the Health Issues in the Community [course] was brilliant, because they could then consult with these groups of people that had gone through the course, but [they] would never provide them with transport... or any of the needs or means for them to participate, like what we did for the course.

T6 described her experience of going through a lengthy process of a funding application, which resulted in the funding body declining any resources:

T6: Local people had to come up with a health agenda and you would then apply to them [funding body] for potential[ly] five year funding....and then [funding body] said, 'no, you're not good enough'. We got through the first stage, did everything, this was three years down the line after doing all the work, and then they said, 'no',

RP: and it's a lot of hard work,

T6: Huge amount of work...the workers time, the amount of resources the community put in, the amount of consultation exercises we did.

T2, who wrote a few words on her sheet, spoke more about this dimension and referred to the 'wee grey men', which portrayed a sense of anonymous officials who made pronouncements and then withdrew. T2 also spoke about 'wee grey men' in the context of what type of person would benefit from completing HIIC:

T2: The role of outside agents, now in the HIIC course we did look at that a lot...because that was dead relevant to the stuff they were doing in the community...that takes it back to who should be on the course, you know the wee grey men in their wee grey suits that had the power...they just turn up and pontificate on how life should be, rather than maybe get the handle on it for themselves.

An interpretation of T4's comments below about this dimension was that she viewed outside agents as a negative influence and somewhat obstructive. She spoke about people needing specific attributes to engage with organisations:

T4: People having the skills...to become involved with outside agents. 
Comments were also made regarding how outside agents needed to adapt a more reflective approach:

T4: Organisational capacity building is about the ability of the organisation to have the skills to engage with communities as well.

T1: I also think that there's a bit of capacity building needs to go on within the services by the way, like health services and local authority... [so that they] understand how not to exclude people.

The role of organisations in the context of capacity building has been noted by other writers (Chaskin 2001; Crisp, Swerissen, \& Duckett 2000). Chaskin developed a multi-dimensional model of CCB, and in the second dimension, locates organisational activity as a level of social agency and argues that community-based organisations, service providers or development agencies might reflect community capacity through their ability to deliver their 'functions responsively, effectively and efficiently' (2001: 298) as part of a wider context beyond the community. How an organisation adapts their service provision was considered by Yeatman and Nove (2002) who explored measures designed to assist community health staff undertake a health promoting role. Yeatman and Nove argued that the organisational environment, ability to work in partnership with other stakeholders, leadership and commitment were important aspects in achieving change at an organisational level.

The second theme identified in relation to discussions about CCB was service provision and can be characterised in a number of ways. First, provision to facilitate or fund HIIC courses; for example T5, who had a health promotion and health psychology background, considered herself to be part of an outside agency in her role as a HIIC tutor:

T5: [reading from completed exercise] Role of outside agents, I put, well obviously we ran Health Issues course, I think of us as an outside agent, we provided support and resources. 
T9: Like the role of outside agents, that might be the health board in a supporting role.

T8: [in response to T9] Right, so I think the role of outside agencies would be, well obviously funding.

Baker and Teaser-Polk (1998) argued that there are productive roles that outsiders can fulfil in encouraging $\mathrm{CCB}$, for example as neutral facilitators or by providing research skills. T12's written response reflected this viewpoint:

T12: [A] coordinated approach need[ed] to be creative in how we use resources. Research role...Strategic role. Money \& people to develop in a strategic way.

Second, scrutiny of service provision by HIIC students. During some of the courses tutors critically discussed the function of outside agencies. T1 spoke about students identifying concerns they had and then discussing which outside agent could address this concern. T1 suggested that this exercise helped students to recognise 'the limitations of some helping agencies and people'. T6 and T13 noted how:

T6: Role of outside agents...aye, folk were able to challenge them.

T13: Participants made contact with MP, local councillors, recycling agencies and school authorities. None would have done this before the course.

T7 spoke about a raised awareness concerning the function of outside agencies:

T7: I think the [course] participants did gain a much better understanding of just what outside agents did and what they should do... and what responsibilities they had.

Experiences of service provision were also described; for example, T6 talked about the inconsistent nature of service provision:

T6: Agencies, people were saying, were really good...you know, it comes down to the individual workers, like their level of support say from social work, would depend on who you get...it wasn't across the board...sometimes 
that came down to, if you were in this area you were lucky, 'cause you got it, but if you were in that one, then forget it...people became aware of that.

Third, service provision was described. For example, T10 who facilitated a course in a rural highland area, noted agencies such as housing associations and the NHS that were connected to the issues raised by her students. However, T10 also expressed a view, which was seemed based on her experience of working in the NHS, that it was difficult to establish what impact certain outside agencies had despite receiving considerable funding.

\subsubsection{Resource mobilisation}

Understandings of resource mobilisation can be categorised by tutors locating the 'resource' either internally or externally to the course. Internal resources were generated within the confines of the course's influence; for example by the students:

T1: Resource mobilisation...that makes me think of mobilising people's own interest in something...I have to think of the people as the most important resource...mobilising somebody's ability.

T5 suggested that resource mobilisation could be applied to the course students as:

T5: Being the resource and they gain skills from the Health Issues course and these skills can then be mobile and transfer the skills to different things...in their social lives or looking for a job.

However, T5 suggested that she could not be definite about whether this had occurred because she no longer had any contact with the students.

T6 described how participating in the course was an emotional experience for a number of her students and identified how this emotion was constructively channelled:

T6: Our course was very emotional at times... and there was a lot of anger, but it was how we used that... [it was] used positively to kinda turn that round, which was linked to a lot of the resources. 
In addition, T6 went on to illustrate her above comment in the CCB exercise by writing the following:

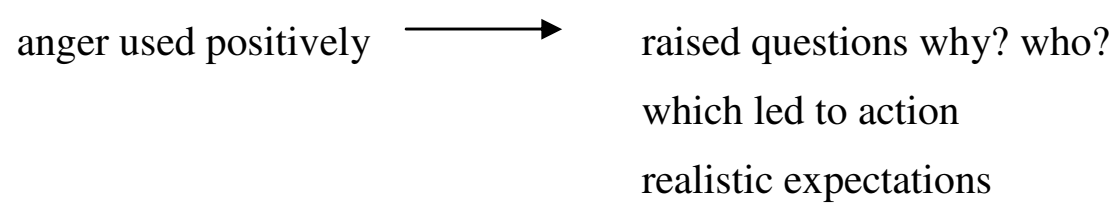

T6 then went onto to state:

T6: They [students] weren't being dolly [unrealistically extravagant] about it and sayin', 'we deserve Disney Land in our back garden, you know it was quite realistic.

Similarly, T7 talked about students from her course who after exploring the units on power, participation and social justice became more assertive in securing overdue repairs to their properties.

External resources could also refer to assets procured from outside the course. For example, T10 discussed the financing of a course in a rural area and the short-term nature of most funding:

T10: The problem I think with that [resource mobilisation] though is the rural versus urban costs...you would have transport... So to actually put a course on...in this area would cost you a lot more money that it would do in the town. So it's whether or not the resources would be allocated...usually they are not given for long enough to allow anything to take place... you'll get annual funding, [but it] need really to be about five years.

T4 felt that resource mobilisation meant 'attracting more resources'. Initially she suggested that:

T4: I don't think there's been [resource mobilisation] as a result of people going on Health Issues courses, I don't think there's been a huge increase in that. 
However, as the discussion progressed T4 applied resource mobilisation in a wider sense and spoke about how her line manager was supportive of the Health Issues course because of its perceived impact on communities. T4 argued that HIIC was part of a wider context in which her colleagues were developing a broader understanding of health, which had in turn led to the creation of specialised teams and projects to tackle inequalities. Seeing the course as a resource in a wider context was a theme echoed by T12, who worked for a Health Council. She identified that the Health Council had resources such as money, experience and time, but that it needed to be linked to strategic planning in terms of targeting the HIIC course towards people who would benefit most, including managers, planners and people in statutory agencies who were unaware of the course:

T12: About things like capacity building, and they [are] just completely missing it. They need to be smarter and think about how are we going to use the resources we've got already? That's people and you know resource[s] such as the course.

Other tutors were unclear about what resource mobilisation meant and asked for clarification:

T11: What's resource mobilisation? Is that where like resources are used to get courses off the ground?

T8: Is that resources in terms of communities?

RP: Yeah, I guess it's what it would mean to you through your experiences of the course...I thought that maybe, for example, a community group doing the course and then getting funding...to do one of their projects...but there's only been one person who had that take on it...But then other people have said, 'well the people themselves who did the course were a resource', so there has been different takes on it.

T8 then went onto to say:

T8: I'm not sure about resource mobilisation...I was thinking of Sally [course student] being in the health issues and then going into social companies. 
T11 considered resource mobilisation in relation to the means required to support volunteers and to address the barriers to participation. T11 also argued that more should be done to help HIIC students after they complete a course, for example notifying organisations about the availability of students who could be employed or work as volunteers. In this sense, the students are seen as a resource:

T11: I think that health issues in the community isn't too different from my degree course, which...enabled me to get this job. There should be...positions, paid positions for people...We've got the NHS desperate for staff...they should be offering opportunities, there's lots of organisations that could offer real paid opportunities for people that do a course like this. They should spend more time looking at that as a vocational course in my opinion.

\subsubsection{Links with others}

According to T1, links with others was an important aspect of CCB. Viewing this dimension in the context of collective action, T1, perhaps reflecting her community development background, talked about people uniting if they wanted to improve local provision, such as establishing a play scheme or if there was a concern that needed to be addressed:

T1: [If] you've got an issue you want to agitate about, you...link with others... [it's the] essence of getting together for resources, help ideas, strategies and that came out in HIIC.

T1 also referred to the role of outside agents and more specifically the limitations of agencies, and stated that health was such a crucial issue that it should not be the sole preserve of a single organisation. In addition, T1 discussed the idea of making links not just at a local level but globally and referred to a student who had gone to Canada to speak about a community project she was involved with.

T11 spoke about HIIC students who had widened their social networks:

T11: I think that's probably one of the best benefits of the course, that there is a lot of people that go onto to do a course like that who have been isolated 
and all of a sudden...they become part of a group and then linking in with other organisations.

During the written exercise, T5 wrote that through participating in HIIC the students had developed:

T5: Better social contacts.

The idea that participating in a HIIC course helped students to overcome isolation was a theme that was also noted by $\mathrm{T} 5$ in her interview:

T5: The person that was very socially isolated, [HIIC] made a huge difference to them, they were mixing with people. They were very quiet to begin with and they came into their own and that was fantastic to see.

Both T12 and T10 discussed the format of their respective courses and gave examples of different people who had been involved with the HIIC course, for example a GP who was also from the Council, and representatives from a community development organisation and a Health Board. T7 spoke about how as a group they had developed levels of empathy and applied links with others to a situation that had arisen during the course, which was challenging and thought provoking:

T7: There was a lot done on being in someone else's shoes and seeing the situation from someone else's point of view, and to me that kind of put that with links with others...I think particularly because we had this personality clash too, it meant...there was a lot of tolerance where people felt that...they could appreciate other people's points of view, but also...people were...faced with their own intolerances and prejudice, me included.

In addition, both $\mathrm{T} 6$ and $\mathrm{T} 5$ highlighted the fact that students had made links with others through their HIIC course project work:

T6: Links with others happened in the course. Obviously there was the kinda inter-course links with others, between participants and the different areas, 'cause we had the two kinda communities...but I think with the rise in confidence, people....were able to make the links... with health, but also within groups and individuals. 
T5: It could mean that HIIC gives people confidence to approach outside organisations like councils... That was one of the things that happened during the course.

T11 discussed the idea of local voluntary groups, charities, or public sector employees creating opportunities for HIIC students who had finished the course and who were in a position to take their learning further. In this sense, T11 saw links with others as a means to manage the students after completing their course.

T2 tried to apply the dimension of link with others to the course content. She considered this dimension to be related to the dimension of participation and suggested that the issue of 'how to work collectively' was not given adequate attention in the course materials:

T2: Links with others, did we look at that? I suppose that goes with participation. What I would say is, I always think this is missing from community development, because they have all the knowledge... and nobody links [it's] difficult isn't it?...I don't know if there was enough in the course about how to work collectively.

Links with others was also viewed as a dynamic and empowering process:

T4: [Students] became aware of the power of this linking with other people.

T13 did not make any verbal comment, but wrote about some of the outcomes of making links with other people based on her observations of what happened during the course:

T13: By linking with others they [students] - a) increased awareness of recycling issues b) altered the food presented to their own children in their local school.

T8, during the written exercise, was thinking aloud and queried:

T8: Links with others, that would be, that could be people who you get funding from. It's not statutory organisation funding. Isn't it? Or is that links with others? 
Finally, T8 and T9 wrote a list of partnership agencies. When I asked for clarification about the relationship between these bodies and the course, T8 spoke about them being a target for 'our funding'.

\subsubsection{Missing dimension and issues about completing the exercise}

During the CCB paper exercise T12 suggested that there was a dimension missing. In her view 'vision' was absent from the model of CCB:

T12: I think that's a dimension that's missing, well it's missing from here [the exercise]...we need to have vision, to have the strategy, that will then come together to provide a coordinated approach...I think that's one of the things that's been missing; that we've had some vision, obviously to create the course, but in order for it to be implemented and to be a really useful tool in relation to capacity building...the big vision isn't there. I think that's what we need.

Two tutors expressed a difficulty in completing the exercise. T2 said that she found it hard to relate each dimension to the course. On reflection, I felt that she was trying to think of examples from the course materials, rather than the students' experiences. Another influencing factor was that $\mathrm{T} 2$ was only the second tutor interviewed and my instructions about how to complete the exercise were perhaps unclear. T2 did, however complete the exercise writing a few words for each dimension, although she did express a degree of dissatisfaction with the activity. T3 did not write down anything on her sheet, although she stated that the course had covered the four dimensions, for example through the exercises in the course pack. The reason T3 gave for being unable to complete the exercise was that she was not aware what had happened to the students after finishing the course:

T3: I think students became more aware through the exercises within the course, but afterwards, there is a difficulty in keeping track of participants. 


\subsection{Conclusion}

There was disagreement whether the concept of CCB refers to processes that develop the abilities of an individual or of a community. One way to clarify this was to draw from empowerment theory, which makes a distinction between individual and community empowerment and suggests that three elements constitute empowerment at a community level: an increased psychological empowerment among members, participants engaged in a form of political action, and a redistribution of resources to the benefit of the group or community. A number of tutors when describing their understandings of CCB suggested that building skills was a major objective or component of CCB. I argued that a skill dimension needed careful consideration to avoid focussing on a community's deficits rather than its assets. In addition, skill training should perhaps be viewed as a contribution towards reducing inequalities rather than as an isolated solution.

Stakeholders discussed certain indicators that would demonstrate CCB, for example students' actions or levels of community involvement. However, other research suggested that involvement may not be confined to community-based groups and could occur informally. In a number of interviews, tutors described CCB as a jargon phrase and were more sceptical about using the concept. However, others implied that as a community development worker they needed to be aware of contemporary phraseology related to their work. The use of terminology is especially relevant in the context of funding community development / health promotion work and one tutor suggested that CCB was an externally imposed concept (by funding bodies).

Community development and CCB were considered to be essentially the same. However, some participants initially held this view, then expressed that there were slight differences between the two concepts, in that CCB meant ensuring people were equipped with certain skills, whereas community development was viewed a way of working with or involving people. In addition, stakeholders questioned whether 
$\mathrm{CCB}$ and community development shared similar values or if $\mathrm{CCB}$ was just a process to achieve a variety of objectives.

Generally, the responses to CCB could be characterised as being negative or sceptical. However, when presented with the CCB dimensions paper exercise tutors were (with one exception) able to make comments and draw from their own experiences of the course. Although caution should be exercised regarding how much meaning should be drawn from the interview exercise, it demonstrated that it might be beneficial to discuss the concept of CCB with community workers and health promoters.

The next chapter reports the data concerning participants' understanding of health, the social determinants and introduces the concept of medicalization. 


\section{Findings - health}

Health, as established in Chapter 2, is one of the fundamental concepts in this study and the following three points can sum up its relevance. First, health is central to the HIIC course, which is the contextual focus of this thesis. It has been suggested that participating in HIIC may enable individuals to develop their awareness not only of health, but also how to take an active role in improving their own and their community's health (Allan 2004b). Second, HIIC emphasises a particular interpretation of health and according to the tutor guidelines is informed by a social model of health, which accepts that health and illness is influenced by economic and social factors as well as individual behaviour (Health Education Board for Scotland 2002b). Third, it has been argued that cultural ideas of well-being and observations made about the quality of 'physical, emotional and social existence' are reflected in how people speak about health (Crawford 1984: 62). Thus, exploring participants' understanding of health and discussing if HIIC had influenced their health, might contribute towards conceptualising the relationship between $\mathrm{CCB}$, community development, and health.

This chapter is divided into three main sections. Data relating to how participants constructed their understanding of health is presented and I argue that these were influenced by various themes which inform how health is perceived. Then three examples of resisting attempts to medicalize aspects of health are discussed. Finally, the factors participants reported as affecting health are considered. The data from this study showed that participants drew from different experiences when they presented their constructions of health and identified multiple and often interconnected factors that influenced health.

\subsection{Understandings of health}

In this section, participants' reported understandings of the concept of health are explored. A way to view these responses is to consider them as informed by certain 
themes which influence their construction. In this study, five such themes could be identified. The first reported understanding of health was orientated around functionality or being able to fulfil an everyday role:

S7: Health was just can you put one foot in front of the other? Do you feel alright getting out of bed in the morning to go and do a days work?

The above quote was similar to results found in other research which reported that health was related to being able to fulfil daily expectations such as domestic work or paid employment (Calnan 1987; McKague \& Verhoef 2003).

S7 also felt that her health status was preordained:

S7: Prior to that [HIIC \& other courses], I was of the mind, if you're goin' die, you're goin' die.

I would suggest that this signified a deterministic discourse about health and illness. Cornwell in her study of health and illness accounts in East London reported that certain accounts of health stated that inequalities were a natural product and that health was 'a matter of luck, fate or destiny'(1984: 127). According to one participant, '[t]he things you have wrong with you, you're normally born with' (Cornwell 1984: 128). However, S7 indicated elsewhere during her interview that her understanding of health was changing and was more informed about why certain behaviours, such as smoking, might be detrimental (see pages 220).

Second, health was understood by emphasising physical conditions and behaviours that affect the body:

S5: I mean if somebody said to me, 'health', I thought well, 'they're talking about my blood pressure, they' re talking about my weight, talking about if you smoke'.

S6: You talk about health...the first thing that pops into your head is somebody's ill. 
RP: What does health mean to you?

S7: That is quite an individualistic question, to me health was always physical health, you know, could you get up in the morning, still breathe right?

S7: Did you feel sick through the day?

S7 constructed a meaning of health around the absence of feeling physically unwell. However, in the following quotes, the meaning of health was positively constructed by including references to both physical and psychological health:

RP: So what does the word health mean to you?

S11: Health, erm, happy, healthy, physically fit and the whole lot, the whole thing.

S17: My philosophy, a feeling, a mental and physical well-being.

These responses indicated an understanding of health that incorporates not just physical health but emotional well-being. Health viewed in this way reflects the WHO definition of health as a 'state of complete physical, mental, and social wellbeing and not merely the absence of disease or infirmity'(WHO 1946).

Third, in the following statements by female participants, the meaning of health was located in gender roles:

RP: Do you think you learnt anything new about health. For example, if you could say what the world health means to you now?

S13: Ok. Well beforehand health was typically from a mums' point of view, mumps, measles, chicken-pox, cuts. You didn't really think anything beyond that.

S5: I had two kids...I mean that was my main focus, I wanted to bring these kids up healthily, I wanted to feed them healthily.

S20: I encourage my children...to be fit and do exercise and eat healthily. 
That women have responsibility for health and health promotion within families has been well documented (Graham 1984; Graham 1988). S5 and S20 articulate this responsibility with reference to physical actions (eating and exercise) and do not include emotional aspects of health. It is also noteworthy that S20 while articulating the role of health promoter for her children suggested that on a personal level one could be too concerned with health:

S20: What does health mean to me? What good health? I'm quite...I'm not obsessed with health, but yeah I'm quite into being healthy and being fit and the importance of looking after yourself. I mean, I'm not a complete fanatic or anything.

S20 appears to construct a limit to her health behaviour by distancing herself from the perception of being too interested in health, which was labelled as fanaticism.

In the fourth theme, health was perceived as being concerned with aspects of selffulfilment and achievement, notably without any reference to medical related physical symptoms:

S4: I mean the actual definition of [health] is, it's about enjoyment, it's about actually living, it's about family and work.

After reflecting on S4's definition of health, I would argue that it can be understood as combining the ideas of 'release' with physical 'capacity'. The notion that health is 'about enjoyment' was found in a study exploring health concepts among middleclass Americans, where Crawford (1984) argued that health could be understood as either control or release. Health as control related to practices of self-control, selfdiscipline, or self-denial in the pursuit of healthy behaviour. However, health as release refers to states of emotional happiness and enjoying oneself. S4's understanding of health incorporated the release element of Crawford's theory.

Hughner and Kleine (2004: 408) in their recent review exploring 'lay' health research suggested that the category of 'health is freedom, the capacity to do' could 
be applied to studies which reported a perception of health that was not confined to everyday tasks. Health in this context is viewed as an 'unfolding fulfilment' when:

[t]here is a feeling of purpose and satisfaction... what one does matters, and what matters, one does! Life is worthy of participation. Life is seen as a challenge, not a tribulation. One is involved in investing energy in meaningful activities. There is a will to live, a trust and confidence in being.

(Jensen \& Allen 1994: 356)

The sentiments in the above reference reflect my general impression of S4 and are also demonstrated by his voluntary involvement with a number of health-related organisations and stated intellectual and practical engagement with the organisation of local health services.

The final theme concerned professional and educational experience. A number of participants stated that they worked in a health-related capacity, for example health promoters /community workers or social service manager. Definitions of health contained references to professional roles, for example when asked about their understandings of health both S14 and S16 expressed a particular ethos underlying their approach to health promotion:

[S14: Health Promotion worker]

S14: It's not just about sending a message of healthy eating or other health promotion, it's about empowering people to do that as well, when we're not there to carry that on. It's also about understanding where they're coming from and why if you set up a seminar and only two people turn up, it's not because they don't want to come to the seminar...they have so many other issues that are far more important in their lives.

As illustrated, S14 suggests that health is not just about giving people information; it involves enabling people to choose a healthy lifestyle without the long-term support of a health promoter. S14 also recognised that her project's target population may not give health, or at least S14's conceptualisation of health, the same priority as S14. 
S16 was concerned with how information about health was communicated and implied that the concept of risk can be related to health. In this account S16 introduces the notion that people can harm their own health as well as the health of others. She suggests that a person's behaviour may pose a risk and threaten individual and collective health and that in response health information should be presented in an accessible and entertaining way:

[S16: Community / health worker]

RP: What would you say health means to you as an idea?

S16: Well without it you're in trouble. Obviously it's about being aware of what is out there, the damages that you can do to yourself...to other people's health and what's out there to help you to live a more healthy lifestyle and imparting that information as widely as you can, without making it too clinical, you know, make it a fun thing.

S8 articulates an ethos that supports a particular way of working with people in a health-related context. S8 suggests that health has both physical and emotional elements and that people need encouragement to express themselves:

[S8: Community / health worker]

S8: It's all very well talking about, you know, we all eat the wrong things or...you're probably overweight or whatever, but to me I think until you get people to talk about health in the round, i.e. health is about your head as well as your heart.

The above quotes demonstrated that a number of participants constructed their understanding of health as an extension of their professional role. That practitioners refer to their occupation when discussing the concept of health has been noted by other research, which demonstrated that health care providers made references to their professional roles when talking about the definitions of health and health determinants (see for example McKague \& Verhoef 2003).

The following participant distinguishes between a professional and a personal account of health. S12 referred to a tension between allocating resources to health and social need in his role as a social services manager: 
S12: Because [it's] always debated between health and social services about what's a health need, what's a social need...the big argument is 'well if you don't address the social need it becomes a health need'...if housing stock is poor, damp [then] people's health deteriorates and if people have social problems, then they need a social worker, if they don't get [one] they get depressed, if they get depressed, it becomes a health issue...from my own point of view health is a big issue, not just about hospitals and doctors and nurses.

When S12 states 'from my own point of view...' he draws attention to two distinct perspectives of health- the professional and the personal.

Other participants drew from their previous educational experiences when they constructed their definitions of health:

[Graduate]

S18: Health is a psycho-social construct [laughs].

[S19: Graduate]

S19: [laughs] I can reel off the definition if you want, erm health, physical and mental well-being, isn't it?

However, S18 presents both a formal (see above) and a personal understanding of health (see following quote):

S18: Health just basically means having the ability to do what you want to do, physically, mentally, being able to enjoy life...having the capabilities to do it. I've always held the view of health...it's classed as old fashioned now, but I have always classified health as something very physiological, good diet, exercise...I can't help thinking though, health to me it's more like....an absence of disease.

S18: I just believe in healthy bodies, minds that kind of thing, rather than just a kind of enabling thing.

S18's statements begin with a generalised holistic model of health, which is an acknowledgment of a formal definition of health. She then refers to health as capability- the means to live an 'enjoyable' life- before locating health within an 
individualistic medical model by referring to 'absence of disease' and 'healthy bodies' and in the end favours this over the previously stated 'health is the capability to...' definition.

In summary, participants' understanding of the idea of health was viewed as being influenced by five themes. First, functionality, where health was related to the ability to fulfil certain functions and gender roles. Second, absence or presence of corporeal symptoms. Third, parental responsibilities, which were concerned with aspects of physical health, such as exercise, diet, and diseases. Fourth, fulfilment and achievement when health was considered as 'release' to enjoyment and 'capacity' to achieve, without reference to physical symptoms. The final theme was professional and educational experience; participants' understanding of health was expressed in terms of the ethos underpinning the delivery of health promotion programmes, for example empowering people to adopt healthy behaviours without reliance on professionals. It was also shown that these orientations were expressed in addition to personalised understandings of health.

\subsubsection{Resistance to medical opinion}

In the previous section participants understandings of health were articulated with a degree of objectivity, for example health as a social construct, rather than subjective accounts of their own health. However, a few participants did discuss aspects of their personal health by describing consultations with a general practitioner (GP). These accounts were characterised by participants resisting or challenging medical opinion and advice. The other participant included in this section questioned the efficacy of certain types of geriatric care and mental health treatments.

While recounting specific episodes of ill-health S5 and S8 demonstrated their disagreement with health professionals. In this account, S5 challenges attempts by her GP to dismiss the claim that poverty influences health choices: 
S5: I've had a [foot related complaint] and when I got treatment for it, the doctor told me, I was overweight and that's why I had it and it was my fault...I said to him 'well it's not, because I'm overweight because of everything that I have to go through and because I lived in poverty... we didn't have the money to eat healthily...then the doctor argued with me, 'of course you do, everybody does'... then he said, 'oh that's nothing to do with this', and I'm thinking, 'but it is'....So I was starting to look at the connections between health and well-being and lifestyle, but I hadn't actually made it, I mean I wouldn't have been able to say to you, 'it's my lifestyle, that cause my ill-health', I just thought it's because I'm skint...I'm constantly on about stress, because I didn't have enough money to pay bills, so I worried all the time...So, once I started doing the course it really started to fall into place for me.

By resisting medical opinion, S5 attempted to demonstrate that the cause of her condition was related to material conditions and the effects of living on a low income. Barry (2005) cites other research in which it is argued that consuming comfort foods, which often contain high levels of sugar and fat, is one response people have to stress, sadness and unfulfilled emotional needs (Wilkinson 1996). I would argue that this understanding might be applied to S5's account above.

In the following account, S8 suggested that pursuing medical treatment recommended by his GP would have been detrimental to his health:

S8: When I was ill, when I first came to [place], I had a major operation and I was seriously ill, alright initially things were a bit rocky, but anyway I got there. I actually had to plead with my doctor to take me off the sick, which is quite scary actually, and he says, 'you're not ready', I said, 'for fuck's sake, I'm ready, I'm getting cabin fever in the flat, come on, I want to be doing something, even as a volunteer...'. I said, 'you're going to make me even more depressed and wacko by just feeding me full of sweeties and saying, 'go and watch Richard and Judy all day'.

The critique of medical care that argues it can be detrimental to health has been widely expressed. Illich one of the key figures extolling this perspective argued that the medical establishment represented a significant threat to health through turning pain, illness and death from a personal challenge into a technical problem, medical practice expropriates the potential of people to deal with the human 
condition in an autonomous way and becomes the source of a new kind of unhealth.

(Illich 1975: 918)

Other iatrogenic effects of medical practices that have been recently reported include a million NHS hospital patients suffering various forms of harm, such as falls, serious injuries or even death (Boseley 2002) and hospital-acquired infections, for example MRSA- a bacteria methicillin-resistant Staphylococcus aureus (Hardie 2005). However, others have argued that modern medicine has also made an important contribution to improving the quality of life of many in the West (Williams $2003 \mathrm{~b}$ ) and to dismiss this is to "deny the validity of the everyday experiences of the lay public in modern Britain. In stressing the limitations and costs of medical interventions, the physical and social contributions of modern medicine are all too frequently ignored' (Kelly \& Field 1994: 36).

Another participant also challenged the perceived medical convention for treating certain conditions. S4 questioned whether aspects of geriatric care and treatment of mental illness might be more effective using alternative methods:

S4: I'm certainly encouraging the befriending, I'm involved with [voluntary organisation concerned with well-being of the elderly] and we've got befriending services and telephone befriending services as ways of keeping people out of hospital.

S4: It may be better to spend money, rather than on a new primary care service, to have it for children, training at schools, so they can play football after hours...or a befriending service or a childminding service...you can actually argue that these can contribute to people's health, rather than handing out Valium tablets.

Considering the idea of medicalization in relation to participants' experiences may be more appropriate than an iatrogenic critique. The concept of medicalization defines 'a problem in medical terms, [uses] medical language to describe a problem, [adopts] a medical framework to understand a problem, or [uses] a medical intervention to "treat" it' (Conrad 1992: 211). S5 and S8 constructed accounts that reported how 
they resisted and rejected attempts to medicalize their circumstances, the explanation for those circumstances and the proposed solution. However, as these accounts also demonstrate, 'medicalization' is a dual process between health professionals and individuals (Conrad 1992). S4, while not referring to a personal health episode, also questioned the medicalization of aspects of health care.

\subsection{Determinants of health}

Health is sensitive to the social environment (Wilkinson \& Marmot 2003) and as Barr, Fenton and Edwards (2004) noted there is variation in health status in the UK among different geographical or social groups occurring from determinants such as poverty, income, education, housing, environment, pollution, transport and nutrition (Acheson 1998). In this section, I discuss participants' understandings of factors affecting health. Analysis of the data indicated that participants referred to health determinants in a broad sense and with references to their own experiences. I draw from the work of McKague and Verhoef (2003) concerning perceptions of health and its determinants and their overarching typology classifying determinants into three main themes; social, physical and psychological.

Participants discussed the determinants of health in two main ways. First, in a generalised sense: a number of participants indicated that the idea of health incorporated factors other than those relating solely to medical or physical symptoms:

S8: What people forget is that health covers all aspects of our lives... and the reason why I liked health issues course was that health cuts across every topic area or every boundary in my life and yours, whether it's poverty, poor housing, no job, a job, relationships, divorce...It's not about just going to my doctor and getting a quick fix.

S17: No one has the same meaning of health, it's individual because of their socio-economic circumstances, it's different. 
S9: It's not just the medical side of things, you have to look at the whole big picture...You take some things like good housing and stuff like that for granted, but now when you do that you realise that, that's not always the case.

Participants articulated the idea that health involves a wide range of often interlinking factors. The view that health is a pervasive issue, rather than confined to the medical sphere, has been noted elsewhere. O'Brien (1995) suggests that healthrelated workers, such as policy makers, analysts, service users, have been encouraged to broaden their understanding of health. In this context, health is no longer understood just as an absence of disease or in terms of functionality, and encompasses social concerns, for example transport, employment and housing.

However, S1 demonstrated that viewing health as described by O'Brien can be a personal opinion, based on experience:

S1: It was always obvious to me that health was more than just about having something physically wrong with you, to me that was just a small part of your health and issues like where you lived, your relationships, what you did [in] everyday life, to me always had a bigger impact on me than anything I could develop physically.

O'Brien viewed broadening the definition of health as presenting questions about the political system in which 'lifestyle and wellness interventions are constructed' (1995: 194). O'Brien also argued that conceptualisations of health that encompassed factors concerning well-being can be understood as a process of dedifferentiation ('openingup') of health in the circumstances of daily life. O'Brien critically suggests that this has transformed health from an achievable condition into an ordered and regular observation process. As Cribb (2002: 275) notes, it is problematic to combine the effects of and riposte to specific conditions of health and illness, and socially organised relations of power and authority. Cribb suggests that these relations rather than 'disease states' inform how 'individual and / or collective health is administered and experienced.' 
However, although the so-called 'surveillance' critiques highlight power relations, I would argue that they may also obscure the role of human and collective agency in resisting and challenging institutional power. For example, forms of health promotion, such as HIIC, influenced by Freireian principles (Freire 1972), seek to empower individuals / communities through awareness raising, and teaching new skills, so that power relations can be challenged. A number of health promoters have also emphasised that prevention programmes should include both cooperation and empowerment (Israel et al. 1994; Labonte 1997; Wallerstein 1992).

Participants also discussed health determinants with specific references to their local area, community and personal experiences. I organised this data by applying an analytical framework from McKague and Verhoef's (2003) qualitative study concerning health care providers perception of health and health determinants. From their analysis, McKague and Verhoef categorised the determinants of health using the following overarching framework: social: immediate and broader environment; psychological: emotional and personal; and physical: intrinsic and extrinsic.

McKague and Verhoef also identified additional factors which they applied to each broader category. For example, in the social: immediate environment category the additional factors of social support, family relationships, housing and employment were identified. As these factors were developed from McKague and Verhoef's data, it would be unsuitable to apply them to the data from this research project. However, the generalised categories of social, physical and psychological determinants of health were used to analyse the following data.

\section{$\underline{\text { Social }}$}

Participants identified features of their local vicinity which they identified as influencing health, such as aspects of communal relations. For example, S6 spoke about the behaviour of young people:

RP: Perhaps thinking about the community here, what sort of things affect the community's health living here? 
S6: To me, I would say that the way people act towards each other...how they do things...how people act in a community as in youths, older generation... especially the youths, I mean they effect people's health and state of mind and well-being, because they're may be not causing trouble directly to them, but they're causing trouble within the community, which causes tension in the community.

S13 discussed a lack of community spirit and low levels of reciprocity:

S13: It's a black bag syndrome as I call it, you know, someone has a black bag in their garden, so next door neighbour will phone the council rather than going [to] say, 'Do you know about all the different collection days.... and are you ok?'... and there's no family support unit as there used to be and everyone very much keeps themselves to themselves.

RP: So would you say in your 20 years of being here, have you noticed changes...so there was more [community spirit]?

S13: Oh far more...yeah...I think there's far more community spirit before.

\section{Physical}

A number of participants highlighted certain factors which they perceived as compromising the health status of the body:

S12: Poor diet is the other thing [that affects health].

RP: What sort of things do you think affects a community's health?

S10: Obviously industry.

S10 went on to speculate that incidents of a particular disease were related to a local company.

The data from this study could be used to broaden the physical determinant category from McKague and Verhoef's framework, which encompassed factors such as exposure to environmental toxins, but omitted the influence of the physical environment on health, such as adverse climatic conditions or difficulties of access to health services due to physical geography: 
RP: What do you think affects the health of the community?

S11: Well the weather, I think, the weather a lot of time.

$\mathrm{S} 17$, who lived in a remote, rural highland area raised the issue of the proposed closure of the nearest hospital:

S17: I always believed if Ben Nevis was there, the [name of hospital] was safe, but tell me if I took a heart attack, had to go to Inverness, I'll be dead...and be rattled around in an ambulance, no thank you.

The impact of distances and emergency care has been examined by Roderick (1999) who argued that ambulance minimum response times were five minutes longer in rural areas compared to urban areas. Roderick goes on to state that

there is evidence that supports the contention that the inadequate provision and inaccessibility of health service provision in rural areas may have a detrimental effect on health (1999: 46).

In contrast, the physical attributes of an area were also described as health enhancing. S20 talked about how she utilised the natural environment with her children:

S20: I mean we live somewhere that's, it's safe...I mean I'm here 'cause it's safe for the children and I've got family, you know my parents live here...my kids, I take them horse riding and stuff, it's great you know, it's good for children up here, it's brilliant. I think I would just feel like I was dying if I lived somewhere like that [referring to an urban deprived housing scheme]... Summer time is not so bad, if you get nice weather...you can go to the beach [in] two minutes...I can pick the kids up from school, go straight to the beach and that's brilliant.

However, as S17 stated, the 'natural' facilities can be health enhancing, but may also represent a health risk:

S17: [The] closest swimming pool is [town] and that is a major health issue. There is a lot of water around here... and I know people from my generation that cannot swim.

\section{Psychological}


The psychological category of health determinants includes emotional-related factors such as mental health, self-confidence and sense of meaning. S5 constructs an account that contextualised her current position as a health promotions specialist and reported how she recognised the negative impact on health of being employed in a position with low job satisfaction:

S5: I thought, 'I'd rather not have any money coming in and struggle than go to a dead-end [job]', 'cause I knew if I went into a dead-end job, I would not [only] be fed up with my home life, but I'd also be fed up at work and that would just make me feel worse.

S5 highlighted the emotional effect and consequences of being unemployed.

Another participant also reported how a negative working environment influenced her health. S2 described how she had been poorly treated by another colleague and went on and stated how this had been detrimental to her emotional health:

S2: I was becoming a nutter, a total nutter over just this one issue, that this man had done to me, like chip-chip-chip chipped away until you think, 'I shouldn't be here'.

Reflecting on her experiences S2 stated:

S2: I kinda credit myself with having some intelligence; I do know that stress is a psychological thing that can make you physically ill.

Whilst it was possible in the examples above to place participants' responses in one of three discrete categories, other factors identified by respondents were more complex and referred to a combination of categories. For example, S13 talks about health being linked to multiple factors such as employment, personal relationships, social provision and communal relations:

RP: What affects the health in this community?

S13: Poor wages, and [the] single mother issue, not enough housing, severe lack of community spirit, which in turn causes, you know, quite a lot of problems, mental health problems. 
S13's understandings of what affects health could be classified under both the social and psychological categories. This example raises the importance of using categories without obscuring how the determinants of health can often be interrelated. Thus, viewing these categories in isolation, without critical reflection, may result in a failure to appreciate the wider political, social and economic factors which can influence health status in an area or community. To illustrate this point further, consider the example of unemployment, which has been shown to increase the risk of premature death. In addition, people whose jobs are insecure, i.e. threatened with unemployment, are also more likely to suffer from psychological problems such as anxiety and depression (Wilkinson \& Marmot 2003). The complex way in which an issue such as unemployment affects health was highlighted by S19. In the following quote, she refers to a piece of research that she had conducted for a degree course, which examined the factors that influence men's health in the local area:

RP: What were some of the things you found out?

S19: Basically, I think, it was, unemployment was the main one. Unemployment had a knock-on effect, like drugs, alcohol, depression, mental health issues.

The issue of unemployment might be assigned to the social: immediate environment category if an individual lives in an area where employment is scarce. However, job losses may result from wider forces such as higher overheads from gas and oil price increases or currency fluctuations affecting the costs of exporting and importing. Thus, in this context unemployment could be placed in the social: broader environment. However, an alternative analysis could focus on the impact of unemployment on mental health, which would place it in the psychological: emotional category.

Following consideration of the above criticisms regarding the use of categories, the health determinants in the next section were deemed too inter-related with wider social, political, and economic contexts and were explored without McKague and Verhoef's framework. 
In summary, this section reported the participants' understanding of the factors which influenced health. Some participants spoke about health and its determinants in an abstract and impersonal manner, whereas others drew from their personal experiences and related aspects of their local area or community. Categories from a related qualitative study were applied to data from this study and it was argued that the physical determinant category should be broadened to accommodate the influence of the physical environment on health, for example, geographical features such as lochs may promote health through physical activity, but also represent a health risk. Some responses supported a combination of categories and this pointed to the complex inter-relationship of health determinants, making the use of categories to classify them problematic.

\subsubsection{Area reputation}

It has been argued that an area's reputation may be viewed as influencing well-being, for example by affecting self-esteem and morale (Macintyre, MacIver, \& Sooman 1993). However, data from this study indicated that participants were able to employ ways to resist preconceived ideas about their local area. This process could represent attempts to construct health-protecting strategies:

RP: What would you say affects the community's health in this area?

S15: Where I live? Being up the new end it's not so bad. But [place], it's had a lot of unemployment...it's always been quite a bad area...I think the shopping mall got changed as well, so I think that's affected people quite a bit...there's not half of what there used to be...But I think just the general aura of the place is just, it's just [place] and that's it...you can never pin it down.

It was interesting to note that although S15 was asked to discuss the community's health, she made a distinction between the 'new end' of the local area and the area with high levels of unemployment. By doing so, I would argue that S15 figuratively distances herself from the 'unhealthy' area. 
S8 indicated concern about how images of his local area were used in the media and gave an example of how he challenged a reporter's perception of young people:

S8: Every time there's any hassle in Glasgow, they show you, always come to [place].... and I just bounced down this reporters throat, and I said, 'see all these wee guys, they're all nice as pie actually, they're just bored out of their tits, because they've got nowhere to go... all they want is a safe place to play.

In a recent study concerning the perceptions of an inner city area in London, Whitley and Prince (2005) argued that a negative reputation may be an external construction and can be utilised benevolently, for example to secure regeneration funding, but is a construct that may not correspond to residents' views and perceptions.

It was interesting to note that later in his interview S8 appeared to reinforce a negative perception of his local area by referring to the high consumption levels of prescription drugs for certain conditions supporting absenteeism:

S8: That's what it's like in [place]. It's a running joke that if you're unwell, you go to your doctor, you get a bag of sweeties and a sick note for a month.

Positive and negative perceptions of an area coexisted in participants' accounts: both within a single participant's narrative as shown above or, as below, between two participants' interpretation of the same area.

S12 and S13 attended the same HIIC course and they expressed different opinions regarding their local town. S12, who lived outside of the town, suggested that there was a problem with drug misuse:

S12: There's a lot of alcoholism...there's drugs...There's a lot of drugs in [name of town].

However, S13, who lived on an estate within the town, suggested that

S13: People think the [estate name] is terrible...it's not, you know. The same problems are in [place name], which is just a wee village across the 
road...it's basically, there's a lot of young people with a lot of time on their hands.

I would suggest that S13 minimised the negative reputation of the area and offered a benign explanation for the 'problems'.

Other participants reported how they contrasted their current circumstances and living space with the information they received from the HIIC course:

S3: I know that this is classed as a deprived area and sometimes I think, 'aye'. But when you listen to other people's point of view, I thought, 'doin' right, och we've got, you know, we're quite lucky... [the tutor told us about] some of the places in Glasgow...they haven't got such nice houses, nice heating, nice bathrooms...we' re kinda isolated from all that and you think everybody's like yourself.

Some participants' tendency to portray their area positively can be explained by research which has suggested that individuals living in deprived areas may attempt to create a 'spatial hierarchy of health risk', whereby their own area is not considered the most risky (Airey 2003: 134). Such distancing strategies enable these individuals to keep their sense of well-being secure from the potentially harmful effects of contextual psycho-social stressors (Airey 2003).

Negative human interactions and conditions of the built environment can also influence health and undermine the quality of life. For example, Herbert (1993: 46) applied the concept of 'incivilities' to describe 'visible neighbourhood conditions such as dilapidated buildings, litter and vandalism, and such things as noisy neighbours, unruly youths hanging about, and drunks on the street'. Some participants described examples of such incivilities:

S8: I know one close not far from me, every flat on the close is using drugs...the amount of alcohol use I see when I walk to work at half-eight. 
S2: Just before I came in here, I had to go down the road to the volunteers and walking up through [place name], I'm thinking 'this is a really, really nice place to live', you know the sun's out, the houses are getting all done, very nice, tons of places for children to play and there's not a soul and you think 'why'?, but then you know why, because you go back to night time and the gangs and the poverty and the nothing to do and the inequality...it makes it an unhealthy place to live.

The influence of public policy as a determinant of health has been acknowledged (Bambra, Fox, \& Scott-Samuel 2005) and access to health and or social services was identified as a determinant by some participants:

RP: What [does] the word health means to you?

S10: Well, I think part of it is that people, all people should have access to medical help, I've always believed that. I mean that wasn't just the course that did that.

S12: Two things actually, the major issue for health services is getting health services to people or access to services because they are rural...I think there's also inadequate social services, if social needs aren't addressed they become health needs and housing issues.

Pierret (1993) used in-depth interviews and a closed questionnaire to understand the lay meaning of health in a research study in Paris and rural areas in France. Pierret organised her data using four registers (health-illness, health-tool, health-product and health-institution), which characterised participants' interest in and broad views about health. According to Pierret, health-institution categorised participants who viewed health as a concern of public policy and organisations. Participants from the current study also perceived health as contingent on access to services. For example, S12 spoke about the possible closure of the local hospital and highlighted one of the reasons why it might be shut and how this might impact on health:

S12: Any specialists you do have here; you do have some general consultants, they don't get the volume through to keep up their skills... and I think that also effects people's health if you like, because [if] you know the consultants aren't on the ball, then they're not really be giving the best treatment. 
The remoteness of certain areas in conjunction with the availability of services was also a factor:

RP: What do you think affects the health of the community in this area?

S17: Right, positively a first class GP, wonderful surgery, marvellous dental surgery in the village.... and then adversely, [the] distance of the hospital...you're talking forty-three miles.

\subsubsection{Food}

It is suggested that 'a good diet and adequate food supply are central to promoting health and well-being' and that social and economic circumstances 'result in a social gradient in diet quality that contributes to health inequalities' (Wilkinson \& Marmot 2003: 26). Access to quality and affordable food was a concern raised by the following participants:

S12: I mean like if you'd come here ten years ago, even in the supermarket, you'd only be getting turnips and carrots...but it's all pie and chips... whiskey, pie, chips. Those are big factors here.... and choice of course, people don't have a choice, I mean there's only one supermarket basically.

RP: What do you think affects the health of the community in this area?

S20: Erm, drink's a big problem, 'cause it's a rural area...but a lot of people don't see it as being so serious... also I'd say, lack of education. I mean there's still people who don't eat [healthily]...There's a lot of people that surprisingly don't and also... Safeway [is] like an hours drive away...if you run out of fruit and that, you're stuck...I find then my kids diet isn't as good as I would like it...the shop down there's so expensive.

S8: You can't buy decent fruit and veg in [place], it's expensive and it's shite and unless you've got a motor or can afford a taxi, you can't get to Asda.

Belief in the benefits of a healthy diet has been demonstrated by other research. For example, in a study comparing health beliefs among middle-class and working-class women, Calnan (1987) noted that having a good diet was considered one of the components of being healthy and that the importance of fresh fruit and vegetables 
was shared by both classes. Other research has shown that the higher costs of fruit and vegetables deter people on low incomes from eating more healthily (Marshall et al. 1995; Reicks, Randall, \& Haynes 1994). A recent study explored participants' experience of a healthy eating intervention and found that cost and access to fruit and vegetables were significant barriers to healthy eating (John \& Ziebland 2004). Therefore, findings on diet and health from the current study are supported by other research.

\subsubsection{Poverty}

Some participants spoke about the effects of having a low income on health. For example, by describing their experience of a benefit system which did not reflect the economic implications of living in a remote rural area:

S20: We get the same benefits as someone living in Edinburgh...but they don't need to run a car... [which] is a necessity living here, it's not a luxury.

This viewpoint has been presented in a report about poverty in rural Scotland, where transport and the accessibility of welfare benefits were identified as contributing to social exclusion. It was found that benefit take-up in rural areas was lower compared to urban areas. It was suggested that this could be due to the complexity of completing claim forms, a lack of awareness about entitlement and cultural factors. For example, in some rural areas there was a strong work ethic, which contributed to the stigma associated with receiving benefits. The recommendations called for agencies to work closely with local groups through the community planning process to ensure that service delivery was sensitive to the needs of people in rural areas (Rural Poverty and Inclusion Working Group 2001).

Other participants also described the effects of deprivation on health and well-being:

RP: What sort of things do you think [affect your health]?

S7: If you're talking about lack of money...I can actually feel this might sound crazy, I feel a wee bit healthier in the fact that coming on this course [not HIIC], it's the basic minimum wage right, but it's more than benefit 
money... and sometimes I think that gives me a feel[ing] of well-being, knowing that I can walk into a shop now and say, 'I like that and I can buy it'. Whereas when I was on benefits, I didnae look at something I couldnae buy and that does effect you mentally...Aye, so, definitely finances, if you're poor through no choice and I don't mean just poor as in a low wage, I mean not having an extra penny, that has definitely goin' to effect your health, your physical health as well as your mental health.

S7's statements support the argument suggesting that exclusion from 'social, economic, political and cultural systems...determine the social integration of a person in society' (Walker \& Walker 1997: 8). S7 expressed the importance of the ability to consume in order to participate in society:

S7: As I say, if I look back at that scheme, born and brought up in it and we had nothing, and that was a good scheme and yet 40 years down the line, it's the deterioration... if you've not got a job, that's what it's all down to, it's all down to money. It doesn't matter how much self-esteem and self-worth that all these wee courses bring you, at the end of the day, we cannot sustain that unless you've got a lifestyle that can maintain it, because you don't see many poor happy people within themselves, you know.

S20 indicated the way in which material circumstances can act as a barrier to adopting a healthier lifestyle when talking about supermarkets, food availability and cost of food:

S20: Especially in this country, we are so...

RP: Expensive?

S20: Yeah, organic food and stuff...I can't buy it...prices are normally so extortionate and even free range you know?

That issues of poverty and social factors can be a barrier to adopting healthier choices has been demonstrated by others, for example, Hilary Graham's work $(1984 ; 1988)$ on smoking showed how the interplay between social and economic circumstances and gender impacted on attitudes towards smoking tobacco. 
One participant, S4, reflected in more depth on the relationship between health and poverty and admitted that he struggled to understand the nature of the link between them:

S4: We discussed that [relationship between poverty and health] in great depth and I wasn't really convinced we actually know what the link is... I've worked in poor areas...I come from a working-class background myself and I'm not $100 \%$ sure that there is a direct link between poverty and health...it's there if you look at it statistically...I couldn't get my head round what the actual factor on the two was. That if you give people money, that you improve their health... because sometimes people with money have got an unhealthy lifestyle, you might spend it on more drink (laughs) or eating too much.

While S4 recognised the influence of poverty on health, he also was unconvinced that there was a causal link and acknowledged that individuals may choose to adopt 'unhealthy' practices regardless of their wealth. However, as Barry states,

wherever adverse conditions exacerbate the bad effects of 'unhealthy' choices, a class gradient in such behaviour will turn into a bigger class gradient in health outcomes. Even if we hold people fully responsible for their choices, therefore, we still have to say that members of different classes are only partly responsible for differential outcomes.

In addition, in the Health in Scotland 2004 report (Armstrong 2005) it was recognised that the relationship between wealth and health was complex. Armstrong noted that after comparing English and Scots from similar socio-economic backgrounds, it was found that the latter experienced poorer health across a variety of indicators, for example mortality and particular disease outcomes (2005: 2). This has been termed the 'Scottish Effect'.

\subsubsection{Healthy and unhealthy groups}

Participants suggested that certain people displayed unhealthy behaviour, such as drinking alcohol and driving, smoking, and poor diet. The 'older generation' and crofters were identified as unhealthy groups: 
S18: I think a lot of the effects on the community depend on what kind of community...[and]...their social circumstances. We've got [an] older community in particular, what you'll find is, I think, isolation comes into effect a lot of the time... We've got older generations, they're not so conscious about generalised health advice...like you shouldn't be drinking and then going off in your tractor... you shouldn't be smoking big bags of tobacco.

In addition, S8 included himself in an age group that was resistant to health-related behavioural change:

S8: It takes a while for health to filter through...' cause like people of my generation and my parent's generation, we're just too long in the our tooth now and they know best.

S20: You get a lot of [the] older generation, you know with, they must have really bad problems, health problems due to it [alcohol misuse]...you know, like the crofters that are left. Also I'd say lack of education, I mean there's still people who don't eat [healthily].

S20 suggested reasons why certain people have health problems, for example, lack of education. However, later in her interview she described how living on a low income and in a rural area without convenient access to affordable, good quality food made it difficult for her to adopt a more healthy lifestyle. This raises the question why S20 did not think these reasons might also explain the actions of the 'unhealthy' older generation she identified earlier.

It is, however, perhaps too simplistic to suggest that specific groups are unhealthy. For example, Blaxter (1990) demonstrated that the majority of her research participants did not have either a totally healthy or unhealthy lifestyle. Other research has demonstrated that elderly people self-defined successful ageing as maintaining health, mobility and independence (Wenger 1997; Wenger 1998). Thus, to imply, as the above participants did, that older people are unconcerned with health is questionable. Rather it may be that older people have a different conception of what constitutes healthy behaviour. 
S20 identified the family as the place where healthy behaviours are learnt:

S20: Well because I suppose I was brought up quite well... sort of middle class and you get fed properly...you're encouraged from a young age...I haven't been brought up in poverty, so I've got the education and maybe the knowledge that I know about healthy eating and I know what you should eat...if you don't learn from your parents or people around you...how are you goin' learn? And it's, how are people going to be educated...properly, so they understand?

She also constructs an account in which she illustrates a distinction between middle and working class based on the types of food consumed:

S20: When I had my daughter and I lived in [place] and it was round [father's] family and they're quite different, they're working class, very. You know, like when the baby's in her pram, give the baby some chocolate, and I was like, 'no'... you would get this view that they think you were being cruel almost... and I wouldn't eat... a lot of the stuff they ate and I just couldn't bring myself to eat some of it.

As Crawford (1994) argued, health has become symbolic of contemporary Western identity as a result of traditional forms of identity diminishing under the influence of significant social, cultural and economic changes. For the burgeoning middle classes in Europe and America the aim of health became 'an essential component of what it meant to be modern, progressive, rational and distinctive'(Crawford 1994: 1349). In addition, Calnan (2004) argued that social and economic circumstances provide the context in which health-related behaviours and practices are restricted, constrained or enabled. These perspectives are included in the following participant's account of healthy groups:

S12: But I think people are more conscious about health and the need for exercise and so on...but it tends to be Caucasian, white middle-class...that sort of group tend to be down the gym, you know get down the gym, couple of glasses of wine...nice meal, keep trim, you know? But if you work in the shipyards it's different isn't it? The government would like to make us all nice, white middle-class.

Arguing that groups value health differently has been questioned by Barry who states ' $[\mathrm{t}]$ here is no reason for thinking that the poor value health less than the rich'(2005: 75). 
In conclusion, participants discussed and identified a number of different health determinants, which were partly based on personal experiences or observations about their immediate locality. The data from this study suggests that categorising health determinants can be problematic and indicated the complex and inter-related nature of social determinants of health. The implications of participant's understanding of health and conceptualisation of the determinants of health will be discussed in Chapter 11. The next chapter examines the impact of students' learning from the HIIC course in their lives. 


\section{Findings - impact of learning}

The aim of this chapter is to explore how participating in a HIIC course may have influenced people's lives. The structure and content of this chapter was informed by Tom Schuller's et al. (2004) recent research on adult education, which I reviewed after completion of data collection and prior to data analysis. Schuller's work is helpful to consider because it recognised the complex way in which learning impacts both at a personal and community level. According to Schuller learning is a 'process whereby people build up- consciously or not- their assets in the shape of human, social or identity capital' and 'then benefit from the returns on the investment'; such benefits could be improved health or broader social networks (2004: 12).

Schuller developed a matrix as an exploratory tool based on narrative accounts of adult learners (see Figure 10.1). The matrix consists of two intersecting axis that form four quadrants. The vertical axis portrays how the effects of learning can occur at an individual through to a community or collective level and the horizontal axis indicates learning can be transforming- a life changing event- as well as sustaining- a less visible effect which may contribute to a person's daily functionality. A brief description of each quadrant is outlined below.

Quadrant A- personal change: learning has been instrumental in personal or professional change. Quadrant B- self-maintenance: the effects of learning have provided stability and maintained both emotional and physical well-being.

Schuller's analysis reported examples of poor health being averted and the sustaining of positive health states. Quadrant C- social fabric: Schuller suggests that one of the consequences of sustaining individuals is that they can contribute to the "collective environment that is conducive to sustaining health' (2004: 27). Maintaining the social fabric also includes the socialising impact of learning when, for example, community members appreciate other people's values and opinions. Quadrant Dcommunity activism: learning leads to social change, through individuals or groups. 
The important way of confirming community activism, according to Schuller, is that the collective milieu is changed.

As stated above, the 'impact of learning' matrix was conceived as an exploratory tool rather than as a device to record an individual's experiences and Schuller goes onto to observe that,

The overall point is that the individual/collective dimension, like the sustaining/transforming dimension, cannot be treated definitively as a linear axis along which individual cases can be plotted. This means that both dimensions of the matrix are to be understood as heuristic rather than definitively reporting devices. It prompts us to think about the dynamic interaction between on the one hand continuity and changes, and on the other hand individual and collective effects.

Following Schuller et al., I do not attempt to 'plot' individual cases on the matrix. The rich data generated from this study involved analysing complex personal accounts that do not fit easily into analytical categories. However, in this chapter, for the sake of clarity some of the data has been collated under the above four 'sites' of impact. It should also be noted that this analysis was informed by an appreciation of participants' entire accounts, rather than a process of merely splicing pieces of data to correspond to four classifications. First, themes emerging from data relating to personal change are presented: participants' understanding of health; participants' personal health; and respondents' skills, knowledge and understanding. Second, selfmaintenance: I illustrate how competing HIIC provided a focus or opportunity for achievement for participants experiencing personal difficulties. Third, social fabric: I describe participants' accounts illustrating how their awareness of wider social issues and tolerance of others had developed as a consequence of completing HIIC. Fourth, community activism: manifestations of community involvement are presented including further analysis concerning CCB. In the final section some of the analytical limitations of applying Schuller's matrix are discussed. 


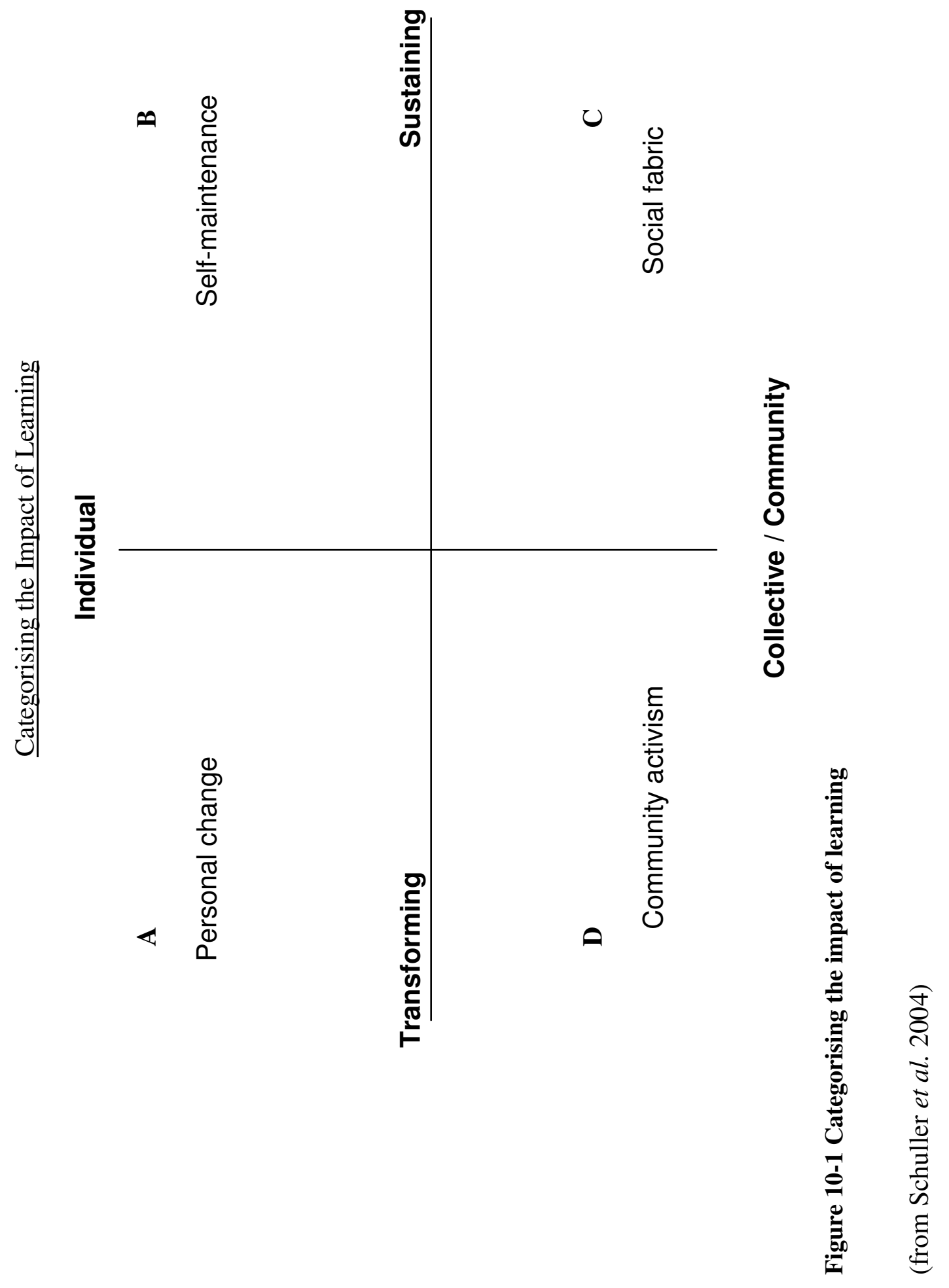




\subsection{Personal change}

The data presented in this section are divided into three main parts. First, I discuss the influence of HIIC on students' understandings of health. Whilst some respondents reported no change, others felt that their understandings had been reaffirmed, broadened or made qualitatively different after completing HIIC. Second, I consider participants' health experience, which was influenced by the process of completing HIIC in the following ways: a) by an increase in selfconfidence, which had various health-related benefits, for example career development and ameliorating negative personal circumstances b) by influencing health beliefs, which in turn informed health behaviour in relation to diet and smoking, and c) by changing participants' emotional well-being, although this had both positive and negative effects. Third, I present data relating to personal change in skills, knowledge and understanding, which related to career development and interpersonal skills.

\subsubsection{HIIC's influence on understandings of health}

The topic of health is an important component of the HIIC course. A social model of health is used, which simply stated assumes that economic and social factors impact on health. During their interviews, participants were asked to reflect on their definition of health and to identify some of the factors that affected health (as presented in Chapter 9). It is therefore perhaps unsurprising that course materials and the experience of participating in HIIC influenced some respondents' accounts.

The influences of HIIC on students' understanding of health are categorised in the following way: reaffirmed, broadened, and changed. Reaffirmed- their HIIC experience and the course materials confirmed students' existing ideas about health. For example, S1, who had worked in a health / community context both as a full-time employee and as a volunteer, described how the course materials mirrored her own understandings: 
S1: It was always obvious to me that health was more than just about having something physically wrong with you, to me that was just a small part of your health and issues like where you lived, your relationships, what you did [in] everyday life, to me always had a bigger impact... and to have a course that recognised that, I thought, 'oh this is the way forward'.

Two participants reported that the themes raised in the HIIC course were broadly comparable to other courses they had completed:

RP: Was your degree quite similar to some of the issues that came up [in HIIC]?

S18: It's like I say, it [HIIC] was very, very, very similar to what I'd done, so it was more kind of reinforcing than changing.

RP: Thinking about after you finished HIIC, did you feel that your knowledge about health or your community had changed?

S19: I don't think so, but I think I was kind of different, because I'd done the rural health studies course, a lot of it kind of overlapped. It...refreshed my mind.

Therefore, some participants' knowledge relating to health had been reconfirmed, rather than extended.

Broadened-some students indicated that their understanding about health had already reflected a holistic or social model of health prior to HIIC. However, after completing the course they suggested that they had developed an awareness regarding some of the other factors that might influence health:

S12: I know this anyway, but I suppose I just got a bit more insight into...the range of things that affect health.

RP: Did you understand what health means in a different way?

S4: It was a roundness about health.

S1: [The course] made me think about [the] obstacles and barriers to health.

RP: Could you think of an example? 
S1: Power barriers, race barriers, excluded groups, homeless and things like that.

In addition, one participant identified that a particular aspect of her health-related knowledge was increased:

RP: Do you think you learnt anything new about health by going on the course?

S9: Yeah, I learnt that cough medicines are absolutely no bleedin' good [laughs], they're a waste of money.

S10's understandings of health was broadened in the context of other people's behaviour:

S10: Although on the course...it did open my eyes a lot to my classmates and their attitudes to health. If you were worried about your health, would you go out on the piddle every night? And drink yourself stupid? No, I don't think so...And yet they're happy enough to do it and go on a health course... Now I'm not condemning them, don't get that in your head.

In the above quote, a number of assumptions are made. First, that the other students' behaviours correlated with their views about health. Second, that the other students were concerned about their health. Third, that drinking alcohol was incompatible with being 'worried about health'. Raising health awareness in this way was an unintended consequence of HIIC. It is possible that this quote reflected a problematic relationship between S10 and some of the other students.

Changed-students' understandings of health had altered after participating in HIIC. Some respondents initially held the view that health was related to physical symptoms or to being able to function and fulfil daily tasks. However, after attending HIIC these students considered health to incorporate other aspects and not just physical factors:

S7: Aye, health, I can see a bigger picture now, before to me health was just can you put one foot in front of the other? Do you feel alright getting out of 
bed in the morning to go and do a days work? You know, but I now realise that there's more to health than physical health.

S6: Before hand it meant, like you talk about health, I used to just, you know the first thing that pops into your head is 'oh somebody's ill...', but after the [HIIC] course, it made me see that health isn't just about illness and having to go to the doctors or hospitals. It taught you about health, about general wellbeing...it's the way you live...there's a lot wider variety of issues covering health that what I thought...Y You don't realise that health covers so many things...it's about living, how you live really.

S3: Where that [HIIC] made you see that you know other things effect your health, rather than just your actual illnesses.

Health was also linked to concepts such as power and deprivation, for example, S2 identified how her experience of HIIC had prompted her to reflect about wider social issues, which she related to a personal experience when she had felt manipulated by an ex-colleague:

S2: Yeah, I suppose, because I think you learn that health is not just physical...it made me look at things in a different way, definitely, just about again the poverty and inequality, power. I mean the power made me physically ill, mentally ill...So I would never, three years ago, never have thought that in my life that something like that could have made me physically ill and it did through somebody else's power...yeah, it made me understand a lot of things more, you know, to do with my health.

In addition, $\mathrm{S} 15$ identified that her attitude to health had changed by becoming aware that poverty was still a contemporary issue through reading some of the course materials:

S15: I think when you cover the poverty and inequality [in the course] and things like that...you know, nowadays, I didn't think poverty that was something that, you know, I just associate that with like 1900 and whatever, so to still find out that, nowadays, like the reports, some of them were like into the [19]90s and it was still...kids living in some kind of poverty and deprivation. 
Remained unchanged - Some students reported that participating in HIIC had a negligible influence on their understanding of health:

RP: Do you think any of your attitudes have changed say to your own health or what you think about the community, where you live?

S11: Nah, don't think so.

S17, a retired physical education teacher, taught physical exercise for older people in her local community centre:

RP: Did you think you learnt anything new about health by going on the course?

S17: No.

I would argue that S17's existing understanding of health meant that the opportunities for health-related learning from participating in HIIC were reduced compared to others with a different background.

In summary, the first aspect of personal change related to participants' understandings of health and it was shown that these were reaffirmed, broadened, changed, or had remained the same after HIIC.

\subsubsection{Health-related change}

A number of participants discussed how their own health may have been influenced by participating in a HIIC course. These experiences are categorised below according to the health-related context in which they occurred. First, at an emotional level, students spoke about HIIC having a positive impact on their confidence or selfesteem. For example, S15, who had begun a career in licensee management, identified that she felt more confident and was reconsidering her career:

RP: I was wondering if you feel if you've changed in anyway after going on the course? 
S15: As I say, it's encouraged me to, it gave me a boost, to go on to learn again... and I would like to do something... maybe health based or I quite fancy community education work.

S3 also found HIIC had increased her confidence and helped her to engage with another training course:

RP: Did you feel that you changed in any way?

S3: Well, I'd say I was a wee bit more confident... shortly after that [HIIC] I had to go on courses with my work, because they were opening a new care home and we were getting training... and a lot of us had to go to college for so many days, and a lot of them were saying, 'oh, I'm not', people a lot younger than me, 'oh, I'm not, how am I going to manage, I'm no good at writing'. That didn't worry me, 'cause I'd done that.

Similarly, S1 felt that attending HIIC had positively influenced her sense of selfconfidence, which had contributed towards her involvement in a residents' group (see page 232). In addition, she stated that:

S1: I value more what I've got to say myself now and I'll speak out more. I wouldn't put up with things that I might of, put up with before.

S6 articulated in depth how her increased self-efficacy had changed her personal and physical circumstances. Firstly, in the context of a previous relationship:

S6: I actually met somebody that I was with for seven months before I met my current partner...I was kinda lonely in my own house and it was a friend that I'd knew... we kinda got together and he moved in with me and then he started treating me badly and it was through doing the course that I realised how to deal with him, so it helped. I think if I'd never done that course and I didn't have the confidence in knowing what I knew, I'd probably stayed with him and continued letting him hit me and treat me bad. Whereas the course gave me the strength...I knew [what] I could do to stop it, I knew I wasn't alone.

Secondly, in adapting to and accepting her role as a mother:

S6: Then when I had my daughter I kinda let myself go and didn't care what I looked like...I mean, I was prescribed anti-depressants and I wasn't coping with having a daughter so young and the course gave me the 
confidence to realise that it doesn't have to be like that...you can make things different in your life.

Thirdly, by securing financial resources:

S6: During this course...I found out that I was entitled to a lot more help in raising my daughter... When I got my house, I took out a top floor [flat] and the best way to describe it was a dump and I took it thinking, 'I' $m$ a single mother, they're not going to give a single lassey a good house', and then it wasn't until after the course that I started fighting and I thought, 'I'm entitled to something better...' The course basically gave me confidence to fight... what I'd a right to, I never thought I had the rights before.

However, one participant's narrative suggested that an increase in self-confidence from completing HIIC, while beneficial to emotional and mental well-being, could also be problematic and lead to confrontation with other people. S5 spoke about conflicts she had experienced with a health professional and with other members of a local community organisation (a group that S5 had been involved with before starting HIIC):

S5: And she [health visitor] seemed to think that because I did the health issues in the community training, that I had become quite bolshie...I was just asking for what we were entitled to and she didn't like that, because before I had been an insecure mother, who had a two-year old who was a nightmare...because she was my health visitor and the roles really turned.

S5: Often what happened was they [community group] would do stuff, you know make decisions and I didn't agree with the decisions, but I thought, 'well, if it's got that the community agree with it and that's the consensus, then I'll go with that...but then they would say, 'well, what do you think?', I said, 'I can't say what I think because I get shot down, because I think differently from anybody else'....they used to find it really difficult, 'we don't understand why you don't feel the same as us'...I said, 'I'm an individual, I'm entitled to my own opinion and until you respect other people's opinions, you're not going to get anywhere'....there's a lot more folk involved, which is good and I'm still taking a back seat, but I would like to see that addressed, what happened to me.

Whilst reluctant to continue her active involvement in the group, S5 referred elsewhere to how developing a belief in her own abilities had contributed towards securing employment (see page 224). 
The second health-related change concerned health behaviour and beliefs. For example, S6 referred to adopting a different diet after HIIC:

S6: I was a terrible eater until I started that course... and because it was to do with health issues in the community... at lunch times you were only given a healthy choice meals and since I've had a lot better diet, because it encouraged me to try things.

S11 reported how completing one of the course assignments had increased her knowledge about nutrition:

RP: Do you think you learnt anything new?

S11: Yeah, yes.

RP: What type of thing?

S11: Well the way I looked, you know, into the healthy eating...I found out quite a bit, different things...like diets and what-not.

In another example, a student expressed how the course experience had begun to influence her beliefs about smoking and diet:

RP: Do you think it changed your attitude about health?

S7: Now, everything's bad for you, everything you like to do is bad for you...But when you start to actually get an education on it and see that folk arenae just saying it for the sake of saying it, there are reasons and you start to make the links, I'm now actually consciously trying to make changes to what I eat, to the smokin'. I'm still smokin', [but] my mind-set [is] changing, I'm believin' that's the difference, I'm believin' that things are bad for you.

The final context of change related to participants' mental well-being:

S8: I think that when I first started the course...I was quite depressed and felt like shit, don't want to be here and all that crap and I think what I found interesting was that as the course developed...rather than being told 'this is shite', it's like 'well, I know it is and I can do something about it'.

Similarly, S5 also referred to a positive outcome after completing a HIIC course: 
S5: I think up and till I had been on the health issues course, I kinda lived in a bit of a fog. I was fed up and I wasn't depressed as such, but I lived at home with two kids, I['d] nae money, I struggled all the time and although when I started the HIIC course, I still never had any money, I was actually starting to feel alive again...I was starting to feel that there is something out there...I thought, 'yeah, I can see a way forward'.

In contrast, S7 described the negative impact on her mental health of reflecting on her circumstances coupled with the overall management of the course:

RP: Did you find any of the course challenging or difficult?

S7: It was very challenging...You wanted to see changes, you knew that changes should come about, but you then started to realise that, 'how can you change that?'...I didnae have enough understanding...I didnae have a view of the bigger picture, it gave me a bigger picture on my situation, but it wasnae big enough for me...I felt in a kinda time-warp...[I] thought it [HIIC] gives you a lot of answers, but you're left just, but where do you go from here?, and actually for me personally, I kinda slid back into depression...for all that I found it good...I found it stressful, I found it quite traumatic, because of the group dynamics.

In summary, the data in this section highlighted how participants' health experience had been influenced. Completing HIIC increased some participants' self-confidence, which had health-related benefits. Participants were also exposed to health promoting messages, notably regarding nutrition and smoking. It was also reported that HIIC had a positive and negative impact on participants' mental health.

\subsubsection{Skills, knowledge and understanding}

In this section, I highlight examples of how participants' experiences of HIIC contributed towards increasing their general skills, knowledge and understanding:

T6: It's given me additional resources that I can use and contacts too.

The above quote suggests that participating on HIIC could widen social networks. This was also demonstrated by data relating to course I, co-tutored by T8 and T9, which was delivered in a highland, island location. It is possible to consider some of 
the benefits and unintended consequences of networks by referring to the concept of social capital.

T8 reported that an awareness about potential HIIC students, prior to the course, had helped to present the course materials at an appropriate level:

T8: I think you know the last course, even though we knew the abilities of the people that came on the course... we didn't know them that well, but we kind of had an idea and we could pitch the course.

In addition, T8 identified how prior knowledge about the students had informed the recruitment strategy:

T8: That was almost like me looking at people who you'd think, 'well, she'll be good for the next health group...'cause we got involved in a lot of that so we knew everybody, so you've got an idea about who would be appropriate to be involved in [HIIC].

A student, S19, from course I, described how she was approached to participate on the course:

RP: Could you tell me how you decided to go on the health issues course?

S19: When I was doing my degree, I had done my research project on male health in the [place] and as part of that I'd interviewed T9, who worked in the [name] community project...T9 knew that I was interested in health and was looking to do anything... She [T9] phoned up and asked if I' $\mathrm{d}$ be interested in [HIIC].

S19 also stated that completing the course had helped secure employment as her current employers had valued her participation in HIIC:

S19: They [employers] were quite pleased that I'd done [HIIC], when I came for my interview. It was quite handy to say I'd done it, it did help in the interview.

The above accounts from T8 and S19 can be related to the concept of social capital, which according to Coleman (1988b), a key figure exploring social capital, flows 
through networks and information channels (Gamarnikow \& Green 1999). T8 and T9 accessed their social networks to identify potential HIIC students who (in their judgement) would benefit from the experience and who had existing knowledge about the themes and issues raised in the course.

Social capital is the basis of social mobility (Bourdieu 1985). Despite scarce employment opportunities in the local area, S19 influenced her economic circumstances by finding employment after completing HIIC. In addition, T8's and S19's accounts demonstrate how aspects of social capital can 'limit participation, as well as to promote it' (Field, Schuller, \& Baron 2000: 261). S19 accepted an opportunity to participate in a HIIC course via an invitation by a tutor. However, T8's description of recruiting potential students (selected by degree of appropriateness) by implication would restrict opportunity for those considered 'unsuitable'.

Another example of how networks were utilised was found in S16's account. S16, a community development worker asked other students (S18 and S19) to complete a piece of work, which she subsequently used in a funding application:

S16: Two of the students that were there...they asked to come here [S16's project] and do work placements after [HIIC] for work experience and they both came along and they actually carried out a, [it] wasn't an appraisal as such, it was more just a community profile... which was very good...very instrumental in our funding package that we got.

There were additional examples of students who stated they were motivated to complete HIIC because they recognised that it might improve their employment prospects, for example, by acquiring relevant information and experience:

S13: I wasn't working at that point and I thought, 'yeah, this will be a good idea'. [I] wanted all the training and information that I could get, 'cause I was wanting to do youth work, well work in the community. 
Similarly, an increased sense of confidence in one's capabilities could influence jobseeking behaviour:

S5: I think it does, whether they're the main aims of it [HIIC] or not, but it actually raises the self-esteem of the folk who are on the course, "cause I certainly felt able to go and be interviewed for a job, and I would have never gone for that job if I hadn't done the health issues.

S8 saw the course as an opportunity to 'test' his capabilities after being unwell and suggested that completing HIIC was an indication of whether he would be able to return to work again:

S8: Because I'd been long term ill, I was not sure whether I could hold down a job to be honest, but I felt I had to challenge myself somehow.

Other participants described applying their learning from HIIC to their current professional roles. For example, S13, a community school / youth worker had developed a more assertive approach:

S13: That's one of the other things I learnt as well...is that it's ok to say 'no'. Which I never have said before, so that's one thing that was really, I found very, very useful...Yeah, it's taken me forty-eight years to learn that...I'm passing that onto the young people as well.

S14, a manager of a health promotion project, had assumed that the HIIC course involved examining clinical health, rather than exploring the social determinants of health and the community development processes used to address health inequalities. However, she reported that after completing HIIC, she had a better understanding about some of the community development issues that related to her role:

S14: Because of the sort of project that I manage, it [HIIC] would help in my work. So going along thinking it would be talking about specific health issues and of course totally like [expression of surprise], I don't know what this is all about, but it was fantastic, I'm so glad I went...it's helped me more actually, even more than I thought it would, because the issues I learned around the community issues are far more valuable and important to the work I do. 
In addition, S2, a community worker, explained how she thought one of the units in the course had helped:

S2: I probably use it quite a lot in my job, that I would never before...I know I keep harping on about that, but probably the dimensions of power is probably the one, because I work with volunteers quite a lot...because of the [fruit project] and there is quite a lot of power struggles going on there and as a worker there's a lot that I can't do... because these are volunteers and there's ways to deal with that...I can recognise [the power struggles] as coming up now.

S7, who had suffered from depression, described how she felt that participating in HIIC, (as part of a pre-employment training scheme) had been a motivating influence in her life:

S7: Basically, to get me out of the house... as much as anything...so it wasnae [was not] the job that enticed me, it was, I think it was more the kinda [kind of] knowledge, the information and just to see what I could get out of it.

S4, an active health council volunteer, had applied aspects of the HIIC course to a public consultation involving local health care providers:

S4: With the out-of-hours [service], the [Primary Care] Trust came and held a public meeting in the town centre, there was seventy people there, [who] all came with a political agenda. There was a top-table... with an audience more or less throwing stones at each other. Whereas, I'd been through this course [HIIC] and I knew that the room was laid out wrongly to start with.

The participants were asked to reflect on whether they had acquired any new skills by completing a HIIC course and there were four main responses. Firstly, participants gained abilities relating to negotiating the course successfully:

RP: Was there any new skills that you learned?

S5: My academic skills, I mean, I had never written an assignment since high school...probably about twenty years, since I had last written anything on paper.

S13: Getting back into the discipline of learning. 
Secondly, participants referred to developing skills that enabled them to work with other HIIC students during the course:

S4: I enjoyed team-working skills.

S15: I've never been bad at participating in a group, but I think...its been improved and speaking up as well...I find it easier now to participate.

S13: The only drawback...was one disruptive influence, which caused quite a lot of problems, but we dealt with it and in dealing with it, that was also a learning process as well.

RP: Do you think you learnt any new skills after going on the course?

S20: See, I don't think I learnt anything really new because I'd just did that other course, but I think it helped just with group skills... and speaking in front of people.

Thirdly, the HIIC experience appeared to encourage the development of interpersonal skills:

S9: Listening a wee bit more probably.

S14: Yeah, probably to listen a bit more.

Finally, a few participants could not identify any new skills they had developed through HIIC:

S7: Skills? [laughs], aye how to body-swerve, how to run from people who were going to give you grief. No, I think any skills I came out with, I went in with, no.

S12: Erh, no, no I'd have to say no.

S11: [shakes head, indicating no]

In summary, data from this thesis indicated how participating in HIIC influenced employment opportunities, although selective recruitment methods may restrict opportunity. Some participants' accounts suggested that they had developed their 
interpersonal skills through the group work aspect of the course, while others could not identify any change in overall skills, knowledge or understanding.

\subsection{Self-maintenance}

In this section, data concerning the self-maintaining effect of learning is presented. Schuller et al. (2004) makes particular reference to the sustaining impact of learning, finding that regular attendance at educational classes prevented depression, or those already suffering from depression reported that their condition stabilised or improved. Data from the current study indicated that the experience of participating in a HIIC course had a sustaining effect by firstly, providing a structure or routine for participants during challenging personal circumstances and secondly, by presenting opportunities to form personal relationships.

Initially, S10 expressed a negative opinion about HIIC. For example, she was sceptical about the claims on a leaflet advertising the course, which implied that it might improve employment prospects by increasing skill levels. S10 also reported episodes of conflict with another course participant and cited examples of how her religious beliefs had been ridiculed on occasion during these exchanges. Despite S10's negative experiences of the course, she stated that her reasons for participating were:

S10: To occupy my time, I take up courses to occupy my time. I think it's quite a good idea 'cause it keeps the old grey cells ticking over.

However, she later stated that there were other reasons for attending HIIC aside from mental stimulation:

S10: I think that's why I do courses and things like that, not just sort of to occupy the brain, but I think it's meeting the folk and doing the thing, it's quite good. 
S10 described a number of life events and challenging personal circumstances, for example nursing a dying parent, and coping with the associated loss of a significant relationship. Based on S10's account, HIIC could be seen to have a sustaining effect, illustrated by the course occupying her time and by the positive effects of meeting new people. I would suggest that S10's motivation to participate on a HIIC programme was partly to alleviate a sense of isolation or loneliness.

Perhaps a more explicit example of how participating in a course can lessen the affects of isolation can be found in the following quote by S5, who highlighted how she appreciated the contact she had with the other students, especially when her children were younger:

S5: [I] got to know these three other girls who were in my group....and we started going for lunch together and things like that. So we felt kinda happier in knowing these people and we all often continued the discussion...At that point I lived with two, [five and seven years old]... kids who can't really hold much conversation. It was absolutely great...to have those four days when you were actually going out and having intelligent conversation [laughs].

Another student identified how participating in the course had provided a different environment and a purposeful routine at a time when she was managing difficult personal circumstances:

S15: I went through quite a rough time when the course started...I ended up being on my own with [daughter's name], so I had quite a lot on board at [the] time...it was good for me that way, 'cause I knew I had something to go to, I had something to focus on, but it certainly kept me going.

The process of completing a HIIC course provided a structure for S15 while a personal relationship ended as well as representing an opportunity for achievement, all of which contributed to a sustaining effect.

In summary, accounts of the self-maintenance effect of HIIC were particularly evident in relation to personal difficulties. 


\subsection{Social fabric}

According to Schuller et al. (2004) the social fabric or collective environment concerns aspects of communal living and working, which can influence health states. In addition, maintaining the social fabric also encompasses certain 'socialisation effects' as community members gain a deeper understanding about one another. Data from this study suggest that participants' experience of HIIC can be related to the social fabric, such as developing a broader awareness about social issues such as drug misuse:

RP: Have any of your attitudes changed? For example, about health or about where you live?

S6: mmm [recognition], before I would judge people...I wouldn't trust people so easy...I was like, if somebody took drugs or if somebody drank...I would be very judgemental and think they're bad people, whereas the course made you see that it's because of the things people went through in their life, that's why they become like that and therefore...they only need one person to trust them and to help them along.

Similarly, the course enabled participants to reflect on their interpersonal skills:

RP: After you finished the course do you think you changed in anyway?

S13: Yeah, I think... although I'm quite an open person and I've always believed in the ethos of listening to both sides of a story before you judge...I think that was more intensified and [made] me more aware that observation in the first instance is more useful than just going on firing all guns.

S13: I think it's probably given me a little bit more patience in dealing with [laughs] some of the older generation up here.

The experience of HIIC also challenged how some participants related not only to other course students, but also to other community members:

RP: After you finished the course, do you think you changed in any way?

S12: What it did do, it gave me an insight into the amount of people that are wandering round who have a lot of skills... So I suppose it changed my attitude to that point of view, I began to look at other people a bit differently. 
S17: Maybe more tolerant to other people's viewpoint and this being such a small community, there's very little chance to sit down and speak and debate like that, you become very insular...round here... [in addition] I never realised how the mothers around here felt about the school meals...they felt that the elderly around here are better fed.

Therefore, some participants identified how their HIIC experiences had influenced how they understood and related to other people or groups, and this appeared to be a broadly positive experience.

Compared to the above examples of HIIC influencing participants in relation to others, some respondents reflected on the wider social fabric in the process of trying to understand or explain their personal circumstances. S20, S5 and S7's accounts made references to how their HIIC experiences had enabled them to understand and contextualise aspects of their own lives:

S20: I enjoyed... [aspects of the course units] a lot about poverty and you know equality and equity... when I was on benefits...somehow you realise 'hey, I'm on the poverty line', 'cause you are really, I mean you're like on benefits and I found it really hard... and I suppose I quite enjoyed it 'cause I'd been [in poverty].

S5: I suppose it started to make sense to me, because before then, although I knew what I knew, I couldn't make the connection and yeah it just started to kinda make things clearer to me and certainly I was able to understand. I felt as though I'd achieved something.

After reflecting on S5 and S20's interview transcripts, I would suggest that they found the process of understanding their circumstances helpful. However, for S7 this process was a challenging experience. The HIIC course S7 attended was part of a pre-employment training package, which included other courses such as first aid and food hygiene. S7 described a number of negative aspects of her experience, for example a lack of appropriate support after discussing difficult issues. Although she was able to demonstrate a broader comprehension of her circumstances, there were detrimental consequences: 
S7: I think the poverty [unit in the course], I found that quite mind blowing, because I thought, 'Jeso, I could slot right in there', and I never thought that I grew up in poverty (laughs), I never thought I was deprived... and yet when I was reading that I thought, 'that's me, I'm part of that process'. I found that quite, quite interesting, mind blowing as well. I found that's where it brought feelings out of me, anger...it left me kinda finger pointing... at my parents...It's not her [mother] fault, I can see that now.

RP: Did you begin to feel different?

S7: Oh aye, definitely... Oh God, I had that many different feelings about it. I started to go through a process of 'how can people not see what's happening?, how are people not doing something?', and then I thought to myself, 'they're not doing it because they don't know, right?' and do you bring it to their attention?. It was terrible, I mean the conflict that goes on inside you're head, it's murder.

In summary, data suggest that participating in a HIIC course had a socialising effect, notably in relation to appreciating social issues, such as drug misuse, and to interpersonal skills. In addition, some participants were able to understand and explain their personal circumstances through applying aspects of the course, although this was both a negative and positive experience.

\subsection{Community activism}

As noted at the beginning of this chapter, community activism, according to Schuller et al., is characterised by a 'transformation of the collective environment, or features of it' (2004: 27). In this section, I discuss whether participation in HIIC influenced respondents' community activism. However, in the context of the study design and methodology this is a problematic question because this study did not set out to evaluate or measure the impact of HIIC. One way to address this question is to consider how community activism is manifested. In this section, data relating to five different perspectives on community activism are presented.

The first variant of community activism might be considered as an 'ideal type' and is found in the following account. S1 described her role in a local residents' group that 
had campaigned and obtained funds to secure gates to an area of land to the rear of their properties, which had been subjected to illegal refuse disposal, and had been used for selling illicit substances and other low-level incivilities:

S1: We've a back-lane that runs up our house, up everyone's house....and the lane at the back of the houses caused problems for years because...if there's a shop been robbed or if there's drugs being sold or people coming out of the pubs at night, that would all happen in our lane...there would be fly tipping, it was just an absolute dump. So after the being on that [HIIC], I knew that if we got people together, then this street, we could collectively do something about it. [So we] set up a group, got in contact with our local councillors, local MSP and got ourselves organised, got funding... and now we've got gates on our lane after two years. Even filling in a funding application is something I wouldn't of thought of doing for myself before, but definitely being on that course and working in this environment that's effected my life and life of people living around us, sort of vulnerable groups, elderly, children.

Attendance on the HIIC course encouraged S1 to form the residents' group to address an issue they identified as having a negative impact in their residential locality. The group lobbied politicians and secured funding and was able to make the improvements. In addition, at the time of S1's interview the group was still meeting and had identified further concerns. Prior to undertaking this study, I had expected to encounter more examples of this type of community activism. However, after S1's account remained unique in this regard.

The second variation of community activism involved participating as a volunteer in a community-based group or organisation; on this basis a number of students could be considered active in their community:

S6: With the [place name] Housing [membership committee] and that's about it really. I mean I help out with the nursery, like parents and things like that to go on trips...I'll help out wherever I can if somebody needs me to help out...It's all experience for me, I mean I like to do it because I like to help, but also because it benefits me in the long run as well.

RP: Have you been involved with any community projects? 
S15: I'm trying to volunteer with a [project] in [place], it's like a drop-in centre, so I was waiting on my disclosure for that...I still try and help out with the toddlers, I know it's not the age group that I want to be at, but it's still something to put down [laughs].

RP: Have you been involved with any community projects?

S11: Aye, play groups and mothers and toddlers and erm out of school care, done that a couple of times.

The three participants above indicated that they had been involved, or were in the process of becoming involved, in community activities. It was notable that some participants had an active role in local childcare provision, which their children were attending.

Notably, other participants initially denied any involvement with local groups or projects:

S3: Not really, I've been too busy with the grandchildren [laughs].

However, S3 also referred to her role as a church elder and as a committee member for a local community centre. Similarly:

RP: And have you been involved with any community projects since going on the course?

S20: No, not really. I've just done the face painting and...mural paintings [as part of summer activity club at a local school].

It is unclear why the above participants responded in this way. One explanation might be that these participants did not classify their actions as community involvement.

The third type of community activism related to a community-based professional role. The data from this study suggest that some participants appeared to construct their understandings of community involvement in terms of their paid employment: 
S14 [Health promotion project manager]

RP: I was going to ask, are you involved with any community projects? But you do that for a living.

S14: That's my work here.

S19 [literacy project worker]

RP: Have you got involved with any community projects outside of your work?

S19: I do voluntary work, but that's through work as well, so probably not. I don't really have time working three jobs [laughs].

However, I am unsure whether a definition of community activism which encompasses professional / paid activities, is valid or whether community activism is restricted to voluntary activities only.

One participant (S5) reported (see page 224) how attending HIIC had resulted in her self-confidence increasing which had a positive effect on her job-seeking behaviour. In addition, she had developed a more assertive approach when dealing with other members of a community group, of which she was a part. However, this participant found that she experienced conflict with others, which resulted in reducing her community activity with the voluntary group. This participant's subsequent experiences illustrated how completing HIIC can displace community activism from one context to another. Thus, a simplified version of this account would state that S5's immediate community lost an active member and that she was 're-deployed' in a different type of community through her professional role.

Fourth, it has been argued that community activism entails social and political change (Schuller et al. 2004; Wallerstein 1992) and in the following quote S5 relates her experience of HIIC to political institutions:

S5: The other thing [that] surprised me was that how we can influence local policies, because you often think we can't do anything about this, because it's just happened...these things happen, it's written by the [Scottish ] Executive, local government takes it on and it's fed through to the people and it's done to us, not for us. But actually when I was on the health course [I] could see, 
[and]...that was the biggest thing for me, was I could see how I as an individual had an opportunity to influence it... unfortunately when I did try to influence what was happening, I kind of got met with a lot of resistance and I think the important thing to learn from that is that you actually need more people on your side.

There are a number of points that can be raised from the above quote. S5 acknowledges the difficulty in achieving change at this level, especially as an individual. In addition, S5's initial sentences appear to be a statement regarding the condition of national democratic procedures and her other comments relate to the local community group and the disagreements she had with a health professional.

Participants did not report similar examples of community activism at this level (change in the collective environment) other than by completing course assignments, whereby they identify a local health issue and the processes involved that would begin to address it. Thus, data generated within the time-scale of this project did not support the assumption that participating in a HIIC course encourages community activism that affects political and social structures.

Fifth, community activism can be considered in terms of potential or latent activism:

S20: [HIIC] did teach us...how you can work as a community to sometimes gain, you know, things that will benefit...like if you all work together as a team...That would be interesting... if we wanted to do anything in this community, I would probably pull in that stuff what we learnt... say if we wanted to campaign for something...I would go back to the notes about how to work together and what you do and the steps you take.

In addition, HIIC could also be seen as part of a process that may facilitate opportunities for participants to obtain community/health related roles (for example S13 on page 223). The experience of completing a HIIC course had been a significant experience for S6 and she reported a number of ways in which HIIC had influenced her circumstances. It is in this context that $\mathrm{S} 6$ referred to her career aspiration: 
S6: I've not been on any courses or training, but now...I've only been doing it for three months, I'm doing voluntary work, you see I want to be a social worker.

In comparison to the above examples of different types of community activism, one participant reported that she was not involved in any community activity:

RP: And have you been able to get involved with any community projects since?

S9: No, unfortunately not.

RP: That's alright, is that just a question of time?

S9: Really, yep, it is yeah.

According to other research everyday demands of family responsibilities and work commitments- especially when jobs are poorly paid or scarce- means that some people have little spare time, motivation or capacity to be involved with local groups (Campbell, Wood, \& Kelly 1999).

In summary, I would suggest that completing a HIIC course increases the potential for individuals to be active in their community in two main ways. First, participants retain and then apply their learning of community development processes to address a health-related concern. Second, completing HIIC can enable individuals to gain work in a community / health related context.

\subsubsection{Community capacity building}

The model of CCB used in this thesis was based on four dimensions: participation, resource mobilisation, links with others and role of outside agents (Labonte \& Laverack 2001b). Only one participant's account (see page 232) corresponded to this model, by forming a group with other residents (participation and links with others), contacting the local council and MSP (role of outside agents), and obtaining funding (resource mobilisation) to secure an area of land near their properties. In other words, this participant's completion of HIIC influenced her to take collective 
action in her residential locality on a voluntary basis. This was the only example of this type found in the data. However, three dimensions of CCB were exemplified in the following accounts; it was not possible to locate explicit examples of the role of outside agents in CCB.

\subsubsection{Participation}

It could be suggested that attending a HIIC course in itself represented this dimension of CCB. However, one student questioned the meaning of participation and who might be involved in that process:

RP: Was there anything else about the course that you found challenging or difficult perhaps?

S4: Involving people, you know, how do you actually involve the public? How do you involve the community? I mean, I'm involved in groups that cause problems...they fall out among themselves, it is very difficult to take decisions and satisfy people. How do you take decisions?...if we set up a community forum in [place name], is that giving more power to the community or is it just giving power to one or two people in the group, who are motivated to do it?

Therefore, it is debatable whether participation in HIIC was a meaningful component of $\mathrm{CCB}$.

\subsubsection{Links with others}

The rationale behind discussing with the participants if they had formed relationships with any of the other course participants beyond the duration of HIIC was to ascertain to what extent the process of completing the course had affected participants' networks. A number of respondents had expanded their social networks:

RP: Do you still see any of the other students?

S6: Really just Sally, she's just turned thirty, she's quite a wee bit older than me, but we've become really good friends. She's actually my bridesmaid for my wedding next year, aye, so we've become that close... She's helped me through when I was in the violent relationship, she was there helping me 
through it and I've been there for her kid, she's been there for mine...we've been there for each other, we've got a really strong friendship from it [the course].

S14: Well the two community reps, yes they are both friends and I made friends with another girl there, who I still see...So I've now got a new friend, so that's good.

However, the frequency and quality of the contact was varied:

RP: I assume you still see some of the people around [due to rural location], do you feel that you are a bit more closer to them from going on the course?

S20: Yeah, you do in a way, 'cause you've, even if you don't really kind of speak to them all the time...' cause you've been on a course together, you've worked together, you've talked together, you've chatted about you own lives a bit even, you learn, you get a wee glimpse into their lives, so yeah it gives you more knowledge doesn't it, whereas you wouldn't have that before.

RP: So do you see quite a few of the people from the group?

S13: Yes, I work with two of them and I see a couple of them, well I see two others fairly regularly when they're in town.

S15 reported she had infrequent contact with former students:

RP: Did you know them before the course?

S15: I had seen a couple of them the two that were from [place], I had seen them because I used to go in and out of the [name of shopping centre], but I didn't know them to talk to.

RP: Have you seen them since the course?

S15: We had like a wee graduation ceremony for getting my certificates, January would have been the last time [participant interviewed in May].

However, one participant, S7, reported how she avoided one of the other course students:

RP: Do you still see any of the other people from the groups?

S7: I saw a couple in the passin', but one of them I won't even look at the road she's on. That's what that course done. 
In summary, data from this study suggest that involvement with the HIIC course had a variable influence on social networks. Some participants reported that they had formed new friendships with other course students, others stated that they had little further contact, and there were examples of active hostility towards fellow HIIC students.

In the context of this analysis, it is worth considering a critique of social capital, which questions the assumption that minor instances of cooperation that can nurture reciprocity and trust can evolve into inter-group cooperation (Levi 1996). Thus, examples of interpersonal sociability (forming new relationships with other HIIC students) and specific collective activity (working together on a HIIC group project) do not necessarily correspond to the formation of groups that then address social or health issues. However, participation in a HIIC course does present students and tutors with the opportunity to expand their social networks, which is considered potentially beneficial in the context of community development (Gilchrist 2003b).

\subsubsection{Resource mobilisation}

Labonte and Laverack (2001b) referred to financial resources and personal resources, such as self-confidence when describing the health-related benefits of resource mobilisation. This thesis also suggests that individuals can be viewed as a 'resource'. For example, at the time of their interview eight student participants were employed in a health promotion / community capacity. Although knowledge of participants' professional roles does not illuminate the nature of this 'resource', such as the quality or effectiveness of the worker and their practice, two broad points can be made. First, a number of these participants reported that completing HIIC had broadened their understanding of their professional role. Others highlighted how their experience of the course had enhanced their interpersonal skills, which were then applied in their professional role. Second, a few participants stated that their motivation to participate in a HIIC course, in part, was to secure employment in a social and health context. Thus, in this sense, it could be argued that participation in 
HIIC can contribute towards realising potential resources. However, this is based on the debatable assumption that paid employment in a community context can be included into a model of CCB.

\subsection{Analytical limitation}

Schuller recognised that learning can also have a negative effect in an individual's life and argued that this effect could be applied to his exploratory framework. However, I would suggest that Schuller's matrix implicitly reflects broadly positive outcomes. When attempting to engage with data from this thesis using Schuller's analytical tool, negative or negligible effects of learning were difficult to accommodate. For example, S3 said that she enjoyed the course and stressed that she had learned about the structure of the local health board. However, in terms of her experience of the course having a wider impact, S3 stated that:

S3: It was good in that I felt if you could've got younger ones onto it, it would have been really good for them...I'm not saying I was too old, but I did admit I'm quite happy with the way my life is going, if you know what I mean, whereas if you could have got some of these young ones on and get them out of the house and maybe get them motivated to get a job or something, it would have been ideal.

Another student (S7) described how there was a lack of support in dealing with the negative emotions that she experienced during the course and that she felt vulnerable and exposed. I would argue that Schuller's matrix appears unable to reflect the nature or degree of negative effects of learning.

\subsection{Conclusion}

The data presented in this chapter were analysed with reference to an exploratory framework, which categorised the effects of learning (Schuller et al. 2004). It was recognised that the ways in which learning can influence people's lives are complex. The findings from this study suggested that participating in a HIIC course was 
influential at a personal level, notably in relation to understanding the idea of health, actual experience of health and well-being, and interpersonal skills. It was also suggested that learning can have a sustaining effect, as a number of participants recounted periods of experiencing challenging personal circumstances, such as illness or the breakdown of a relationship, which coincided with HIIC. The action of completing HIIC provided a sense of structure or an opportunity to achieve.

Participants also discussed the socialisation effect of learning in the context of wider social issues, for example, drug misuse, and in some cases this was manifested in a reflection on personal circumstances and history. This process was viewed as being a positive influence, for example by developing tolerance and empathy towards other people's perspectives or by being able to make sense of previous experiences.

However, this process was also problematic as one participant in particular struggled to deal with her emotional response to her circumstances. It was also argued that the exploratory tool used in the analysis reflected positive learning outcomes and that experiences that were negative or minor seemed difficult to apply to this framework.

The accounts from this study supported different interpretations of community activism, although only one was interpreted as being concerned with changing the collective milieu or at least aspects of it. It was also suggested that participating in a HIIC course may promote latent or potential activism through the provision of information about community development processes and by experiential learning in completing the assignments.

The concept of CCB was revisited by examining the data for accounts which could be interpreted as representing the four dimensions of CCB. It was argued that examples showing three dimensions could be found, although the extent to which this could be translated beyond an individual to a collective level, to confidently conclude that CCB was occurring was highly questionable. 


\section{Discussion and conclusion}

This study explored community capacity building (CCB) within the context of the Health Issues in the Community course (HIIC). CCB broadly refers to the development of attributes within a community which enable it to engage with particular concerns or issues identified by its members. HIIC is a learning resource used to help programme students understand some of the social, political, educational and community development processes involved in tackling health-related issues in a community. The aim of this thesis was to further understanding regarding the relationship between $\mathrm{CCB}$, community development and health. In addition, this study attempted to address the following research questions: 'How did HIIC tutors and students understand the concept of community and was this understanding influenced by completing HIIC?', 'How did stakeholders and tutors understand the notion of community capacity building?', 'Was community capacity building evident in the experiences of the students after their involvement with the course?', 'Did participating in the HIIC course contribute towards furthering students' understanding about health?', and 'Did participating in the HIIC course have any other impact on participants?'

This chapter is arranged into three main parts. First, the contribution this study has made is considered, followed by a brief overview of the research process. Second, each research question and the aim of this project are discussed. The research questions are addressed by referring to data from different findings chapters. The final section describes some of the limitations of this study, identifies a number of implications for CHEX and NHS Health Scotland and finally presents some suggestions for further research. 


\subsection{Contribution}

After reflecting on key features of this $\mathrm{PhD}$ a number of points can be made concerning its potential contribution. There has been a paucity of research on CCB, and at the time of writing none had been conducted in a Scottish context, although one study was located in the North of England (Banks \& Shenton 2001). By using HIIC, a Scottish-wide programme, this study was able to explore concepts at a national level, for example by examining policy documents, and at a local level by recruiting participants from HIIC courses. The HIIC programme also offered a distinctive research context in that the course focuses on community development and health together with other related concepts, such as power and poverty. In recognition that HIIC could be placed in a political and social context, I decided to draw from different academic literatures rather than situating this study within one particular disciplinary approach. This was a challenging undertaking, yet gave a broader appreciation of the main issues and concepts. Whilst not a major contribution to methodological development, the study also developed and used a novel method to explore CCB with tutors. This interview tool was used successfully and may inform further research in this area.

During the analysis phase, I was able to consider participants' accounts from three different levels of involvement with HIIC: stakeholders, tutors and students. For example, I was able to draw attention to similarities and differences between stakeholders' and tutors' understandings of CCB. The sampling technique and successful recruitment strategy also meant that participants came from a range of 'local settings', such as urban and rural areas, and an island community. Some participants made a number of references to their locality notably when discussing the concept of community and when identifying factors that influenced health. This contributed towards the construction of rich and often detailed accounts including experiences beyond the confines of the course, such as personal health problems and descriptions of relationship breakdowns. 
This project was not designed as an ethnographic study and so I did not collect detailed or systematic observations during visits to data collection sites. However, I did consider the impressions from my brief visits or travels when I was interviewing participants. I would argue that such observations helped develop a sense of empathy. For example, conducting interviews with S17, S20, T13 and T10 involved visiting the same remote location twice. During this time, I was able to appreciate the level of local amenities. Consequently, when S20 spoke about the difficulties of purchasing fresh fruit and vegetables (see page 203), I could partly relate to that experience. However, in order to make robust claims, for example, about the relevance of local amenities or public transport provision to participants' circumstances rigorous observational and interview data would be required to further explore these factors.

This case study also made some contributions to theoretical and conceptual understandings of CCB and related concepts such as community development and social capital. At the time of writing this thesis, other studies exploring the construct of CCB with UK health promotion practitioners could not be found. Therefore, I would argue that this case study made an initial attempt to understand practitioners' interpretations of $\mathrm{CCB}$ and so formed a useful basis from which to conduct further research in this area. In addition, one of the features of this case study was that it involved interviewing participants from a range of HIIC courses as well as from different geographical locations. This was important because it meant that CCB could be potentially explored within various types of communities, whereas other studies had conceptualised CCB by focussing on one area or on a particular project (see for example, Chaskin 2001; Goodman et al. 1998).

Findings from this case study also provided support for existing conceptualisations of CCB. For example, a number of participants stated that CCB involved equipping people with skills so that they could play an active role in the community (see pages 154-6). This finding corresponds to other studies that conceptualised CCB as having a 'skills' component (Chaskin 2001; Goodman et al. 1998; Scottish Community 
Development Centre 2003). However, I would argue that further research into the skills aspect of CCB is needed to clarify what type of skills are necessary to facilitate community participation.

The contribution this study made to community development theory concerns the importance of the wider political context in which community development programmes are situated. Shaw (2006: 3) argued that the origins of community development contain conflicting perspectives, those of welfare paternalism and those of self-determining working-class endeavour, which consequently resulted in the evolution of a 'curiously hybrid practice'. Shaw suggested that community development activity should reflect a concern with power and its facilitating and constraining effects. However,

[d]ominant community development paradigms have inevitably been framed within existing relations of power, aimed at adaptive approaches to 'social inclusion', whereas radical versions have been more concerned with exposing and transforming those structures and relations of power which systematically marginalize and exclude. (Shaw 2006: 4)

I would argue that considering the wider political context was a feature of this case study. For example, in Chapter 2 I highlighted some of the key developments in health policy that may have influenced HIIC's development. Indeed, it is possible to perceive the early development of HIIC as a particular response to a political ideology that did not officially accept the concept of health inequalities, favouring instead health 'variations'. At that time the health improvement agenda was focussed on individual lifestyle choices rather than structural factors that can influence health (see page 34 ).

However, as Chapter 4 indicated, political and policy discourse changed and communities are now encouraged to address health concerns and are expected to participate in local institutions with the aim of ensuring that public services are responsive to local need. This was demonstrated by Improving Health in ScotlandThe Challenge (Scottish Executive 2003), the Scottish Executive's policy framework 
to support health improvement, which cited programmes like HIIC as having a key role in 'empowering the public and enabling people to become more involved in community issues' (2003: 25). However, one of the unforeseen consequences arising from the acceptance of community development programmes into mainstream political discourse is that programmes like HIIC might be seen as supporting a particular agenda rather than serving as a forum to challenge prevailing ideology. By critically engaging with policy context and political discourse this case study was able to indicate how a broader appreciation of community development theory was possible by considering other structural influences.

This thesis also furthered understanding about the relationship between community development and CCB. In Chapter 4, I showed that theoretical definitions of community development and CCB were similar and that academics had begun to question whether CCB was a distinctive process or if it was just community development by a different name. However, little work could be found on the relationship between community development and CCB. An explanation for this might be that theorists view the two concepts as essentially the same and so there is no perceived need to consider this issue. However, data from this case study suggested that participants perceived CCB to be distinct from community development. For example, some stakeholders understood CCB as an outcome of community development or as a generic 'tool' to achieve a range of goals, but argued that community development was distinctive because it was underpinned by a certain ethos. I would argue that further research exploring the relationship between CCB and community development should consider the role of values in framing conceptual understandings.

The concept of social capital was reviewed in Chapter 3 and was again referred to in Chapter 10 when I described how participants used their social networks to influence their circumstances. Whilst social capital was not a major consideration in this thesis, I would argue that the research indicated that exploring networks, a feature of social capital, might further theoretical understanding about how people access 
resources that can have a health-related impact. The importance of considering networks has been confirmed by other academics who argued that the literature concerning social capital and public health has been dominated by two particular interpretations of social capital. Consequently, the marginalisation of a network approach has led to an incomplete conceptual appreciation of social capital (Moore et al. 2006). This research project indicated the importance of considering the impact that programmes like HIIC can have on expanding people's social networks. In addition, I would suggest that further social capital and health research could examine the nature and quality of social networks in order to understand the type of networks that may influence community health.

\subsection{Synthesis of research process}

The first phase of the research process was to describe HIIC and to contextualise the main theoretical concepts used: CCB, community development and health. Community development and health have been widely debated and consequently extensive bodies of work on these topics exist. In addition, this work often incorporates other concepts and themes, such as community or social capital. HIIC, funded through NHS Health Scotland by public money, can be located in political and social contexts, which are also susceptible to wider influences and can be understood from a variety of theoretical perspectives. Thus, placing the related concepts and terms in an appropriate and meaningful context was a complex task. This process was approached by exploring these concepts within three bodies of knowledge, which were classified as health promotion, community development, and social policy and political science.

The second phase of this thesis involved establishing the methodological and analytical approach. The research strategy adopted for this study was a subtle constructionist approach, which assumes that the world is both objectively real and socially constructed. For example, diseases can be said to exist and epidemiological methods can be employed in a meaningful way to trace their distribution within a 
population. However, health, disease and illness are also socially constructed categories (Blaxter 2004). In addition, an abductive methodology was deemed the most appropriate for this study. This perspective assumes that concepts and meanings used by individuals can be used as a basis to construct social scientific accounts of social life (Blaikie 1993). A researcher can take the accounts people present of their own actions and the actions of others and attempt to understand them in relation to existing social theories and perspectives.

Methods are techniques used to construct data and it is important to use the most appropriate ones for any given study. In Chapter 5, I argued that qualitative, semistructured face-to-face interviews were the most appropriate method for this project. In addition, a paper exercise was designed for the CCB component of the tutors' interviews, primarily in order to introduce a potentially unfamiliar idea in a meaningful way and to aid discussion. Interviews were conducted in disparate areas of Scotland, such as rural and remote regions, island communities and urban areas. From a sample of three participant groups- stakeholders, tutors, and students- thirtyfive interviews were completed in total. Data were explored using thematic analysis. Through a process of iterative reflection on interview transcripts, literature cited in the reviews (Chapters 2, 3, and 4), and in conjunction with additional literature read during the analysis phase, four main themes were identified: community, $\mathrm{CCB}$, health, and impact of learning.

In the following sections, I address each research question and then consider the aim of this study.

RQ1) How did HIIC tutors and students understand the concept of community and was this understanding influenced by completing HIIC?

Data in Chapter 7 suggested that tutors' conceptualisations of community contained different features, such as geographical location or common interests. Other aspects of community were a sense of belonging and that it was also perceived as a network 
of communication. A number of tutors with a community development / health promotion background gave similar definitions of community in their interviews. In addition, community was expressed as a site of professional practice; for example, tutors referring to their full-time roles described how they organised certain community-based service provision by geographical area. Finally, a tutor from a rural area expressed an expectation that members of a community should help each other.

Findings in Chapter 7 suggested that tutors' conceptualisations of community were not influenced by HIIC and I would argue that their professional practice and training appeared to be a greater influence. For example, Chapter 7 and Table 6.4 (see page 122) showed that a number of HIIC tutors were employed in a community-related role. I would argue that the existence of such roles reflects, in part, the interest in community and subsequent support for community-based initiatives found within political discourse and policies (Amin 2005; Fremeaux 2005; Levitas 2000; Muir 2004), as community can be conceptualised as being an intermediary site between everyday life and political, social and economic contexts (Casswell 2001). However, data indicated that such a perspective may be problematic as the concept of community can be 'chosen, bestowed, ephemeral and static' (Calder 2003). For example, a number of tutors referred to geographical communities in relation to their professional work. In this context, a community is identified by its location and services and provision are organised on this basis. However, some students spoke about a sense of belonging, which was not synonymous with locality and it was also suggested that place of residence can be different to one's community.

Students' accounts of community also mentioned geographical location and contained relational references as well, such as interacting with other people. Students, similarly to the tutors, also suggested that community could be based on a common interest and that community was about a sense of belonging. In a related observation, one student identified her community as where she grew up, rather than where she currently lived, because the former was where she felt safe and secure. 
One student also perceived specific relationships, such as with family and neighbours, as community.

Some students articulated positive characteristics of community, for example an inclusive social environment or a sense of equality. Conversely, others identified negative aspects of community, such as conflicts of interests or feeling isolated within a community. Students also expressed an expectation of reciprocity among community members, which appeared to be a lived reality for those from a rural area. However, according to their accounts students from urban locations did not appear to share this experience. In Chapters 7 and 10, students indicated that completing HIIC had widened their conceptual appreciation of community. Generally, students expressed this by having a more tolerant attitude towards other people and their circumstances. In addition, students gained an awareness of how a community might work collectively. However, the majority of students did not refer to their experiences of HIIC when constructing their conceptualisations of community.

As noted, many participants referred to a sense of belonging when describing the concept of community. This is echoed by Delanty (2005: 187) who argued that one of the reasons why community is still debated and sought after is that it is able to 'communicate ways of belonging', which according to Delanty have become increasingly important in a world that is perceived as being characterised by change and fragmentation. Delanty goes on to suggest that "community as belonging is constructed in communicative processes rather than in...spaces'(2005: 187).

However, findings from this study indicate that place and locality were important features of participants' understandings of community.

In summary, tutors and students conceptualised community in similar ways. Professional practice and training seemed to inform tutors' definitions of community. Students' personal definitions of community did not appear to be influenced by 
HIIC. However, their awareness of the structure and processes involved in community were increased by their involvement in HIIC.

\section{RQ2) How did stakeholders and tutors understand the concept of community} capacity building?

Chapter 8 illustrated how stakeholders gave differing views as to whether CCB was a collective level construct or was initiated at an individual level. Two stakeholders referred to collective action as a way of recognising CCB. However, the other stakeholder described an example of CCB involving an individual who having completed a HIIC course, then became active in their local community and started a higher education course. I would argue that while it is possible to identify how this would be beneficial to the individual concerned, it is perhaps problematic to assume that such activity will result in a community-wide effect.

Participants' accounts suggest that opinion is divided as to whether the locus of CCB should be located on an individual or on a collective level. The policy discourse relating to community is also characterised by ambiguity. For example, Taylor (2003) argued that policy makers often confuse descriptive and normative meanings of community. Descriptive meanings refer to characteristics such as age, gender or ethnic origin that are shared among members of a community. A normative interpretation of community relates to assumptions about how people should conduct themselves or the way they should live. According to Taylor, politicians and policy makers confound descriptive and normative meanings of community by assuming that 'common location or interests bring with them social and moral cohesion, a sense of security, and mutual trust' (Taylor 2003: 38). In addition, there is a tendency to assume that norms of community can be translated into altruistic activity where community members care for one another and act collectively to alter their circumstances. This expectation of collective activity was often referred to by participants in their interviews about CCB (see page 154) or in descriptions about what community means (see 7.5, page 143-4). The ambivalence within policy discourse around community and associated concepts may provide an explanation for 
the differing perspectives of participants on whether CCB operates on an individual or collective level.

As indicated in Chapter 8, two stakeholders discussed CCB and community development by referring to 'a value base'. There appeared to be a slight difference between these accounts in that one stakeholder perceived CCB to be a 'tool' or process, which they contrasted to HIIC and which they viewed as being informed by a set of values. However, another stakeholder stated that CCB and community development shared a similar value base. This perspective of CCB follows Gilchrist's (2003b) observation that CCB's appearance in policy documents acted as a conduit for community development values and practice.

A number of tutors perceived CCB as being concerned with equipping people with skills to be involved in their local community. This perspective, represents a strategy which seeks to address 'inequalities of abilities' and is a less radical interpretation of CCB than a strategy seeking to address 'inequalities of resources and opportunities' (Warburton 1998: 27). Tutors had mixed responses regarding whether or not CCB was relevant to them. Some dismissed the phrase as being rather meaningless, or at least it was perceived as offering little vis-à-vis the concept of community development. Such accounts were characterised by scepticism and cynicism, perhaps in response to a perception that CCB was just the latest 'fashionable' phrase.

A number of tutors suggested that CCB was a jargon term. Raymond Williams (1988) suggested that jargon has a dual meaning; first, as a signifier of professional or specialised language and second, an altogether less complementary connotation as being a common 'way to describe, unfavourably or contemptuously, the vocabulary of certain unfamiliar branches of knowledge or intellectual positions' (Williams 1988: 174). Williams goes on to argue that professional or specialised language does not usually attract the term jargon if it remains 'sufficiently specialized'; rather, a problem arises when the term in question enters into 'more general talk and writing'. 
However, Williams also suggests that new terms can be seen as challenging existing conventions or signifying new and different understandings. The data from this study suggest that CCB was not wholly accepted and in some cases was dismissed as a meaningless concept. Thus, some tutors did not appear ready to accept CCB into their canon of specialised language. Instead, CCB was perceived in their accounts as an externally prescribed construct. However, other tutors accepted the concept and appeared willing to engage with the idea during their interview. One tutor suggested the term CCB might be helpful and that it may describe something about the nature of community work not covered by other terms, although this participant did not specify in what way this might occur.

I argued above that tutors had both positive and negative responses to CCB when they were asked to define the concept. However, it is interesting to compare their responses to my initial query with their willingness to engage with the $\mathrm{CCB}$ interview exercise based on four dimensions. Appendix xiii shows copies of the completed exercise and indicates that the majority of tutors (only one did not complete the exercise) were able to think about the concept of $\mathrm{CCB}$ in relation to their experiences of HIIC.

RQ3) Was community capacity building evident in the experiences of the students after their involvement with the course?

The influence of participating in a HIIC course was reported through participants' narrative accounts. As noted in Chapter10, one student described how she had formed a residents' group which had been successful in making improvements in her local area. I argued that this reflected the model of CCB adopted in this study. In addition, I would suggest that HIIC participants may have experienced a form of CCB at a micro-level or group level with other HIIC students when they worked to complete course assignments. For example, one participant described how HIIC students from her course researched meal provision in a local school with the aim to improve the service. 
The above example can be applied to the model of CCB adopted in this thesis. Students are participating by working collectively and so linking with others. They engage with the role of outside agents, for example by researching the procurement process for school meals, and finally resource mobilisation might occur through attracting further support to highlight the campaign, which may result in funds being made available or redirected to raise the quality of the meals.

However, whether group level CCB can be still be perceived as CCB is perhaps debatable. Other data indicated that participating in a HIIC course had not influenced the other students in relation to the model of CCB used in this thesis. However, CCB-type activities may not conform to a predefined model and can be difficult to identify (Diamond 2004); for example, low-level activity (neighbourliness) contributes to a collective effect and has been shown to be found in less affluent areas (Williams \& Windebank 2003). Further analysis indicated that in terms of involvement with community groups / projects, a shift in participation patterns had not occurred. In other words, participants who stated that they had not been involved with community groups or projects before completing HIIC also indicated that they remained uninvolved after completing HIIC. Conversely, participants who reported involvement with groups before HIIC continued an involvement (perhaps in a different way) afterwards. In addition, while some students expressed a sense that their awareness about social issues, such as poverty, had been raised, they did not demonstrate whether this has led to any specific action occurring.

Although it is debatable whether evidence of CCB was viewed in the accounts of participants in this study, other data supported the view that completing HIIC impacted at an individual level. Chapter 10 described how some participants experienced an increase in self-confidence after completing HIIC, which contributed towards them seeking employment or further training in a community / health setting. It could be argued that this may contribute towards CCB indirectly. However, it is unclear the degree to which understanding of the processes involved 
in transforming individual empowerment to community level CCB has been furthered by this project. The interviews demonstrated that people's lived experiences are multi-faceted. CCB is also a complex process that may occur under certain conditions. These perhaps need to coincide before collective action takes place. Schuller et al. ‘s (2004: 183) 'critical mass' effect (when enough people are motivated then action occurs) is an idea which may help to reduce the conceptual gap between individual and community level empowerment and which might be worth exploring in more detail by further research.

In Chapter 10, I presented findings that suggested that CCB had not generally occurred within the timescale of this study, apart from one account. However, one participant speculated whether participating in HIIC would influence any future community-related action, which I termed 'latent CCB'. I would argue that this can be related to the broader social context. Other academics have suggested that one way to recognise if community development or forms of empowerment have taken place is to look for changes in the social environment (Schuller et al. 2004;

Wallerstein 1992). Thus, developing latent CCB could be perceived as contributing to a social or collective environment whereby people are receptive to participating in forms of community action at a future date. In addition, facilitating and promoting HIIC courses and attempts to facilitate CCB are also part of a wider political context that can influence the social environment in which individuals and communities attempt to address health issues. However, as Wright noted, the wider context is also subjected to other influences that may constrain such initiatives:

[i]t is questionable whether those in power, such as governments, truly want to transfer power to local communities or indeed whether communities should take on the responsibility for decisions in healthcare provision.

(Wright 2003: 74)

The role of institutions was also highlighted in an article which argues that previous social capital analysis failed to consider the part public authorities have in the creation of social capital (Maloney, Smith, \& Stoker 2000); similarly, I would argue 
that it is important for CCB researchers to be mindful of the role of institutions in creating an environment conducive to $\mathrm{CCB}$.

The debates raised so far concerning this research question can be linked to discussions about individual / community empowerment and health. Bridgen (2004) argued that evidence in the psychological literature suggests that powerlessness or a perceived lack of control over life circumstances can lead to a vulnerability to poor health; notably for those groups who are marginalised (Wallerstein 1992). In reflecting on the attempts to address this issue, Bridgen noted that there has been an emphasis on developing an individual's capabilities and self-esteem in order to address their sense of powerlessness. However, powerlessness can also occur from social or economic circumstances and not because someone lacks certain competencies. In this sense people are 'politically and socially disadvantaged' (Bridgen 2004: 294) and empowerment is realised, according to Zimmerman and Rappaport (1988), when people obtain mastery over their own lives through participating with others to alter their social and political contexts. Consequently, community empowerment has been conceptualised as a three-stage model involving personal development, collective participation and social and political change (Rissel 1994: 41-3).

In the context of the findings from this project, completing HIIC for some participants appeared to positively influence their sense of powerlessness or lack of control at an individual level. In their accounts, participants described how they felt a sense of achievement, and that they had become more confident in their own abilities. Others also developed more awareness about their own circumstances and the wider community. However, it was more difficult to find data suggesting that participants had worked collectively to change their social / political circumstances after finishing the course. 
In summary, involvement in HIIC appeared to be influential in terms of personal development and in a more limited way promoted collective participation through group work. However, data illustrating social and political change was less forthcoming.

RQ4) Did participating in the HIIC course contribute towards furthering students' understandings about health?

Data presented in Chapter 10 indicated that for some participants, their understanding of health had been affirmed, broadened or had changed through their involvement in a HIIC course. Accounts described in Chapter 9 showed how before their involvement in HIIC, students had conceptualised health in terms of illness, being able to function, or gender roles. These views can be contrasted with data presented in Chapter 10 concerning the impact of learning. Participants were able to reflect on the influence of HIIC on their understanding of health. For some this included developing a deeper appreciation of the range of factors that can influence health. Other participants understood health was not just related to physical illness, but involved the concept of well-being and mental health. One participant expressed a view that health permeated the way an individual lived and presented a holistic perspective on health.

Participants also expressed awareness of a social model of health as featured in the HIIC programme. This model assumes that factors such as unemployment, poverty, and housing can influence health. In reviewing the theoretical developments in health inequalities research, Popay et al. (1998) questioned the extent to which a social model represented a significant philosophical shift from other models and cited Kelly and Charlton (1995: 82), who argued that:

[i]n the medical model the pathogens are microbes, viruses or malfunctioning cellular reproduction. In the social model they are poor housing, poverty, unemployment and powerlessness. The discourse may be different but the epistemology is the same. 
Kelly and Charlton go on to suggest that one of the main sociological implications of this is that individuals become demoted to a 'system outcome'(1995: 83), rather than perceived as functioning and reflexive beings. Essentially, Popay et al. argued that the large corpus of quantitative health inequalities research does not adequately reflect the idea that individuals do or at least can potentially exercise a degree of agency over their circumstances. As noted in Chapter 9, some participants gave accounts of how they resisted or challenged medical opinion. I would argue that such examples illustrated how individuals can influence their own circumstances in the context of wider structural forces.

As suggested in Chapter 9, for some participants the concept of health incorporated a range of aspects and they identified a number of factors that can influence health. However, if health is conceptualised in this way, i.e. encompassing all of life, can this be perceived as still referring to the concept of health? Another way to think about these findings is to consider an aspect of Bok's (2004) critique of the WHO definition of health. Bok cites Callahan (1973: 87) who questioned the validity of coupling health to a state of complete physical, mental and social well-being and argued that health should be defined as a state of physical well-being. In view of Callahan's argument, Bok suggested that a distinction can be made between contributing and defining factors of health. In other words, while acknowledging that social, environmental and genetic factors influence health, it should not be assumed that they define health. In a personal communication on 5 May 2006, Bok suggested that identifying these factors is problematic, but argued that a defining factor is one which if missing would mean an absence of health. However, a contributing factor could be absent without a person's health collapsing.

However, I would argue that a broad conceptualisation of health may encourage resources to be directed towards alternative methods to tackle health inequalities, rather than solutions dominated by hospitals and pharmaceutical products. In addition, accepting that health can be influenced by a range of factors might 
encourage reflection on the condition of social, political and physical environments as well as issues of equality and equity.

In short, data from this research study suggested that participants were influenced by the HIIC course in terms of widening their understanding of the contributing factors to health. However, accounts regarding participants' definitions of health did not include references to participating in HIIC.

$\underline{\text { RQ5) Did participating in the HIIC course have any other impact? }}$

Findings in Chapter 10 indicated that involvement with a HIIC course influenced participants in the following ways:

a) Providing health-related knowledge / experience e.g. about healthy diets and nutrition.

b) Increasing self-confidence, knock on effects e.g. employment.

c) Promoting emotional well-being, through achievement, meeting others, provided a structure when facing challenging life events.

Similar findings were noted by Schuller et al. (2004) who explored the effects of attending adult education classes. This may signify that the type of course is less influential when exploring this type of impact. Schuller's work and framework categorising the impact of learning emphasised the interrelated nature of the effects of learning and the complex consequences this can have. For example, learning at a personal change level may have a wider impact if that person becomes active in their community or learning relating to the social fabric may stimulate action at a community level. However, I would argue that in exploring the themes in the HIIC course, tutors and students can develop a broader understanding about health within social, economic and political contexts. Data in Chapters 7 and 10 also illustrated how some participants used what they learnt from completing HIIC to inform their 
understanding about aspects of their lives. As previously noted, this was both a positive and negative experience.

Another impact of involvement in HIIC, as described in Chapter 10, related to employment. For example, students who were seeking work prior to course participation suggested that HIIC was an opportunity to learn new skills that could enhance their chances to obtain employment. Another participant who had been unemployed through ill health stated that he viewed completing HIIC as a guide to see if he could cope with full-time employment again. Others stated that they had been able to apply aspects of HIIC in their professional role. In addition, another notable impact was the development of students' interpersonal attributes, such as listening skills or a more tolerant attitude.

Aim: to further understanding regarding the relationship between $\mathrm{CCB}$, community development and health.

Findings from this study suggested that links were made between $\mathrm{CCB}$, community development and health. As already shown, participants' accounts in Chapter 8 illustrated how they perceived a connection between CCB and community development. A relationship between $\mathrm{CCB}$, community development and health could be identified in a range of ways. Understandings about health appeared to be influenced through community development methods used in HIIC. Examples of how involvement with HIIC had positive effects on participants' health were also found and described in Chapter 10. However, some participants recounted negative and stressful experiences relating to working in a group context, as indicated in Chapter10. I would argue that the process of completing HIIC course assignments represents a connection between health and community development. To complete the assignments students are asked to write about a health issue relevant to their community and to describe the ways in which it could be addressed using community development principles. In addition, one student's account described her experiences of participating in a residents' group after completing a HIIC course. 
This narrative fitted the model of CCB adopted for this study and the student identified this experience as having a positive influence on well-being.

However, addressing health issues through $\mathrm{CCB}$ or community development can be challenging and problematic. The input required, such as time and emotional and the physical and financial resources should not be underestimated. It is clear that this approach is not an easy option and as Gilchrist states:

[C]ommunity development can only ameliorate the circumstances of our most deprived communities. It cannot change the world, but it surely can make a difference in many people's everyday lives, raising collective and individual aspirations and challenging the existing system of power relations.

(2003b: 23)

\subsection{Limitations of this study}

After reflecting on the research process, a number of limitations were identified. It might be argued that participants who agreed to be interviewed are those with favourable opinions. However, both negative and positive experiences of the course were recorded, indicating that the recruitment strategy did access a range of viewpoints. Any research sample influences data and it is important to consider why people agreed to be interviewed and to reflect on the scope and limits of their narrative accounts. The interview for some participants appeared to represent an opportunity to speak about their professional practice, although that was a minor feature of the topic guide. For example, there are a number of instances where participants (S8, S16 and S14) described how they might organise or deliver a health promotion programme. In addition, these accounts also included statements relating to the values and the ethos underpinning health promotion. T8 and T9 also related how they would strategically promote HIIC to local institutions and decision makers.

Other participants spoke about their negative experiences of HIIC. For example, S7 stated that she had yet to receive notification about her final assignments after completing the course. S10 described how she felt her religious beliefs were criticised by another participant and that the promise of HIIC helping people to gain 
employment (as stated in promotional literature) was unfounded in her experience. S9 suggested that she had felt marginalised in the process of deciding the topic of the group assignment. She also disclosed that she wanted to complete HIIC in order to do the HIIC tutor training course, because her employing organisation was being reorganised and she had doubts about her future employment prospects. However, S9 stated that she had been discouraged from applying for tutor training by her linemanager (who also facilitated S9's HIIC course), and so S9 had become resentful and found it difficult to remain motivated to complete her final HIIC assignment. The examples cited above suggest that participants took part for a range of reasons that may have influenced the information they disclosed in their interview.

Participants' interpretations of the research process may have also influenced data construction. However, it is recognised that these are speculative reflections based on my interpretation of how participants presented their accounts. As shown in Table 6.4 (see page 122) tutors mostly had a background in health promotion / community work. During their interviews, these tutors talked about their professional roles in addition to their experiences of HIIC. This may have been because they facilitated courses as part of this role rather than on a voluntary basis. Tutors may have perceived the interview process as an examination of their professional knowledge and practice, which might account for the standardised responses to some of the questions, for example, about the meaning of community.

Some students interviewed also presented accounts of their professional roles, which included details of how health promotion programmes should be conducted. In these cases, students may have been responding to a research context that was perceived as an opportunity to demonstrate competence and knowledge. This study was funded partly by NHS Health Scotland and involved close links with CHEX, who have responsibility for managing HIIC. For example, the initial recruitment letter was sent by CHEX (see Appendix v) in order to comply with ethical procedures concerning access to participants. It is possible, therefore, that tutors and students perceived that I was representing NHS Health Scotland or that I had a more formal 
role with CHEX / HIIC. For example, participants may have thought they were taking part in a HIIC evaluation exercise. This perception may have meant that participants were reluctant to express negative opinions or experiences. In addition, this could have been a reason for why people did not wish to take part in the research project.

My role as researcher is implicit in the data construction, as above participants' perceptions of my role may have influenced their accounts. This study was funded through an ESRC / NHS Health Scotland CASE studentship, which aims to encourage collaborative research between academia and public sector bodies. Two of my $\mathrm{PhD}$ supervisors had close links with HIIC, namely involvement with strategic policy and with the accreditation of tutor training and students' coursework.

However, when presenting the project to potential participants, I only stated that the research project was funded by ESRC and NHS Health Scotland (see Appendix vi), rather than the collaborative emphasis of that arrangement. Also, my supervisory arrangements were not spoken about with participants (with one exception), so participants were not aware of the close links between those involved with the study in a supervisory capacity and HIIC administration. However, one participant shared her concern regarding an essay submitted for HIIC accreditation some months previously that she had not received feedback on. I informed her that I did have contact with those responsible for accreditation and offered to pass on her concerns to them on her behalf, to which she agreed. This exchange occurred towards the beginning of the interview and may have influenced the way in which the participant perceived me and her subsequent interview. For example, she could have been reluctant to be critical of the course if she perceived me to represent it in some way or because I had agreed to assist her. However, in reality this participant was one of most vocally critical of how the course had been managed, as part of a preemployment training package. Thus, the interview could have been perceived as a means to express criticism to the course organisers. 
In addition, the way in which I posed questions may have affected responses. For example, a commonly used phrase in response to the term CCB was that it is was jargon. However, some tutors seemed to accept the introduction of new terms in relation to their work as something that they needed to engage with and one recognised that the term might be helpful in describing the community / healthrelated work they did. Other tutors were more sceptical about the term CCB and related it to bureaucratic procedures. I played a role in co-constructing data; for example, in some interviews I asked 'Do you feel CCB is meaningful or a jargon word?' This was partly because the term 'jargon' was linked to CCB in some of the early tutor interviews. However, I may have influenced other participants in later interviews by presenting this question. The findings from the CCB interview exercise, as shown in Chapter 8 and appendix xiii, indicated that participants were able to impose a sense of meaning on the concept of CCB.

I also discussed with participants if they had been involved in any community projects since they had completed HIIC. The rationale behind this was to explore the extent to which participants may have been motivated by their experiences of HIIC to take an active part in their community. The phrase 'involvement with community projects' used in framing this question may have constructed data that did not represent the lived experiences of participants who, for example, were active in their community in an informal or ad hoc basis. This point was illustrated in a recent report that discussed ways to improve data collection about volunteering in Scotland. Stevenson (2005: 8) noted that a more positive result was achieved when participants were asked if they had done any of the activities on a list (shown to each participant), compared to being asked 'Have you taken part in your community in an unpaid, voluntary capacity in the last twelve months?'

On pages 236-7, I suggested that only one participant's experiences could be applied to the model of CCB used in this thesis. However, it may be that a pre-conceived model of CCB may be inadequate to account for other forms of community activity (see also page 254). Indeed, others have warned against transplanting 
conceptualisations of CCB from one study into another without prior testing for validity and appropriateness (Eng \& Parker 1994).

The presence of CCB and related terms in policy discourse raises questions of why and how they are used. There is a body of literature that critically questions the use of concepts such as community, social capital and CCB (see for example, Amin 2005; Fremeaux 2005; Hall 2003; Levitas 2000; Rose 1996; Rose 2001; Taylor 2003; Walters 2002). For example, Talyor (2003) argues that policy makers before advocating ideas of community to those living in deprived areas, need to accept that social responsibility is not just confined to individuals, families and communities but should also be applied to those public institutions whose activities directly impact on the daily lives of ordinary people. In addition, careful consideration should be given to the form of community that policy discourse is espousing. Taylor goes on to suggest that closely-knit communities, as imagined to exist the past, are not appropriate as '[s]uccessful communities are characterised as much by weak as strong ties and people relate to many overlapping communities, each of which may take precedence at different times' (Taylor 2003: 84). In short, Taylor calls for a better understanding of how community works in a range of contexts and for different people.

As already noted (see pages 65-6) others have drawn attention to the assumption that it is groups of people who often lack basic resources who are expected to organise themselves to address particular social problems (Levitas 2000). Levitas also questions the reliance on voluntary work in providing certain services and argues that this lessens public accountability and transfers the cost of service provision onto volunteers. Finally, Levitas suggests that fundamental and unanswered questions remain, for example, 'What is the political reaction to groups who challenge existing institutions through collective action?'; 'Who defines community?' and 'Who represents the community?' Therefore, there are convincing arguments that highlight how community and its related concepts can be problematic within both a policy context and discourse. These criticisms of community can also be applied to my 
research role. For example, it is possible that that participants viewed my association with HIIC and or NHS Health Scotland and my research interests as supporting current policy discourse concerning community and related ideas.

Another limitation related to the extent to which individual face-to-face interviews can reproduce accounts that reflect activity at a community level. For example, USA social capital research attempted to examine community level indicators, such as clearing snow from residential pavements, by using observational methods (Lochner, Kawachi, \& Kennedy 1999). Thus, exploring whether CCB occurred could be achieved using different methods. For example, a longer study recording the experiences of course participants before, during and after completing HIIC, in conjunction with qualitative interviews. Another possibility might be asking participants to keep a diary record of their actions, opinions and reflections during a course and afterwards.

The data from this study also questioned the extent to which participating in HIIC can instigate political and social change. However,

it is widely recognized that any changes to the external environment as a result of community-based schemes are only likely to occur in the longer term. Given this, and the complexity and openness of such schemes, it is almost impossible to determine the extent to which the scheme itself is responsible for any change.

(Bridgen 2004: 292)

The above quote by Bridgen highlights a key issue in this study. As noted, one of the criteria for selecting participants was that they had at least six months post-HIIC experience. It was assumed that this would allow enough time for reflection and for participants to take action that was informed by their learning from the course. The above quote by Bridgen implied that change to the 'external environment' could take a considerable length of time compared to the six months allowed in this project. However, my experience of conducting interviews in this study indicated that allowing for a longer time-period might also be problematic. In a number of 
interviews, participants found it difficult to recall their experiences about the course and one student could not remember when she had completed HIIC. Clearly, there is a balance to be found between when to engage with participants and how much time they are allowed to reflect on their own experiences.

It was questioned above whether the findings from the case study indicated that HIIC instigated change at a political or social level. However, I argued (see page 235) that completing HIIC may develop latent CCB. Whilst caution should be exercised regarding the importance placed on this idea, as it was based on just one interview, it does highlight the possible longer-term effects of interventions. For example, Head Start and Early Head Start are US public programmes designed for prospective parents and their families and children from birth to five years to help prepare children for school. Since 1965 over thirteen million Head Start graduates 'have entered school healthier and better prepared to learn; their parents have acquired better child-rearing skills, [and] become involved in their children's education' (Zigler 1991: 37). Zigler concludes that children who have healthy lives and who develop the abilities and desire to learn have a 'good chance of learning' and that 'the small investment made in their early years will have compounded to reap a handsome dividend' (1991: 46 -7). An example of one of the longer-term effects are that African-Americans who took part in Head Start are less likely to have been booked or charged with a crime (Garces, Thomas, \& Currie 2002).

Towards the end of this study I reflected further on the work of Goffman (1959), who explored the concept of role creation. Some participants in this research project drew upon their professional identity to frame and inform certain responses. It is possible that these participants' accounts were influenced by the location of their interviews, in that participants interviewed in their work place adopted their 'professional role' more readily, which in turn informed their interview account. 
Other factors may have also informed participants' accounts, such as their motivations for completing HIIC. For example, a number of students stated that their reasons for being involved with HIIC related to their wish for a career change; indeed, some reported that their HIIC qualification had subsequently helped them secure employment. Thus, participants saw HIIC as a resource that could potentially alter their personal circumstances. In addition, other participants described how their pre-existing understandings of concepts such as health or community had been confirmed by HIIC's content. As some participants perceived HIIC as being instrumental in some significant life change or in affirming their understanding of society, they gave positive accounts about the course. In other words, some participants' positions were supportive of the values and ethos expressed in the HIIC programme. Participants' alignment with the conceptual framework of the course was demonstrated by the views that were not presented, such as those that challenged HIIC's aims or content. For example, no participants questioned the efficacy of community development to address health issues or expressed doubts that community is a viable construct.

Another salient factor shaping participants' views could be social class. It is possible that there is a relationship between an individual's socio-economic status and their experiences and conceptualisations of community, health and their attitude to participating in courses such as HIIC. Some participants specifically located their own social position; for example, S20 (see page 208) referred to being middle class and demonstrated that this had influenced her attitude towards health and nutrition, speaking of the difficulty of obtaining affordable fresh fruit and vegetables locally on her low income. However, information on participants' social class was not collected systematically throughout this study. It is acknowledged that participants' class, defined in terms of ones relationship to the labour market, would inform the content of participants' interviews, for example, single mothers had different experiences compared to those in full-time employment. However, it is difficult to confirm whether social class consistently affected participants' understandings of the concepts discussed. For example, a range of participants referred to having an 
expectation of community members helping one another. Rather the affects of social class are evident in health indicators and not in the expression of conceptual understandings.

Having identified a number of limitations to this study, in the following section I describe some reflections on the research process.

\subsection{Some reflections on the research process}

It is recognised that the accounts constructed in a face-to-face interview are a joint endeavour between the researcher and the interviewee. This complex process is also informed by many different factors, such as participants' understanding of their experiences, their values, beliefs, world view and life experiences. These factors also apply to the researcher who is also engaged with interpreting what is said as the interview proceeds in order to clarify or to probe further. During the initial stages of the fieldwork phase, I became aware of the likelihood that the majority of participants in this study might be female. (This assumption was confirmed at the end of the study and is illustrated in Tables 6.2, 6.3 and 6.4, which showed thirty-two female participants and four male participants). I was concerned whether my gender would have a negative effect on negotiating access to female participants, an issue raised by other academics. For example, McKeganey and Bloor (1991) observed that as male researchers, access to certain research settings was constrained; for example, interviewing and observing female residents in a psychiatric community was confined to common areas, such as the kitchen, lounge and television room.

However, the extent to which my gender restricted access to female participants was unclear. For example, that I was able to interview thirty-two female participants may suggest that my gender did not influence levels of access. In addition, when arranging interviews with participants I stressed that they chose where they wanted to be interviewed. Thus, this condition may have helped to alleviate participants' concerns, because they had control over the interview venue. As noted in Chapter 6, 
interviews were conducted in a variety of places, including participants' homes and places of work. On some occasions participants were alone and other times there were other people present or in the vicinity. Only one participant made an explicit reference about not allowing strangers into her home, but that was not restricted to males. Consequently, this participant was interviewed in a public library.

Other academics have argued that a researcher's gender can influence the type of accounts generated. For example, Krueger (1994) suggested that individuals are more likely to share information with others like themselves. Similarly, Deatrick and Faux (1991) stated that the gender of the researcher becomes important when exploring sensitive issues. In my experience, both female and male participants were willing to discuss sensitive information. For example, participants described their experiences of domestic violence, relationship breakdowns and personal health problems. Therefore, in this instance I would question Krueger's and Deatrick's and Faux's assertions and argue that being a male researcher did not appear to greatly influence the quality of the accounts given.

As noted above, gender did not appear to be an important factor in terms of constraining access to participants or influencing the types of accounts generated. However, other factors such as class and age might be key influences in the research process (Brown 2001). After reviewing the literature on gender and sociological research McKeganey and Bloor (1991) argued that there was a tendency to use gender as an explanatory concept when other factors were more salient. For example, Easterday et al. (1977: 344) asserted that female researchers were seen as 'powerless and non-threatening' and so find fewer difficulties in negotiating access to participants. However, McKeganey and Bloor suggested that the perception of women researchers as non-threatening was more about the low social status of sociological research rather than whether it was conducted by men or women. 
In addition, according to Brown (2001: 189), a feminist approach to research has often emphasised the 'commonality between women'. She goes on to cite Finch (1984: 86) who stated that 'a feminist sociologist doing research on women actually shares the powerless position of those she researches'. This dynamic, Finch argued, often produces extensive and revealing narratives. However, Chandler (1990) observed in her research with Navy wives that simply being the same gender does not automatically ensure that research encounters are characterised by empathy or greater understanding and that culture and conceptualisations of power can also impact on the interview process. Therefore, while gender can influence the research process it should not be conflated with other factors such as power and class.

In my experience, it was difficult to identify explicitly whether issues of power or class influenced the research process. However, in the face-to-face encounters with participants, unless asked directly, I consciously avoided mentioning that I was hoping to gain a $\mathrm{PhD}$ as I felt the intellectual connotations of doing so may alienate certain interviewees. Overall, the influence of my perceived status as a researcher from the University of Edinburgh did not appear to be a major influence during the interviews. However, I felt that in some interviews participants informed me about how they would organise and manage a health promotion project, made references to being a graduate and implied they were different from other HIIC students, or talked about how the HIIC programme should be developed at a national level. I was unsure whether these observations implied that some participants perceived me as having a different role other than that of a student researcher.

In the following section, I outline some implications this study has raised for CHEX and NHS Health Scotland.

\subsection{Implications for CHEX and NHS Health Scotland}

This section deals with some implications for two of the organisations involved with HIIC. CHEX has responsibility for managing HIIC, including arranging tutor 
training, providing support and networking opportunities for tutors, and keeping statistics concerning the number of students completing HIIC. NHS Health Scotland provides funding for HIIC and has a strategic role in promoting the course. As already noted, this study was funded by an ESRC / NHS Health Scotland CASE studentship. This arrangement was informed by an assumption and expectation that any subsequent research might be used to inform policy and practice. In writing about implications for key organisations, I am beginning to use the findings from this thesis as a form of evaluation and so moving beyond the scope of the research questions. The following implications are informed by statements made by HIIC students and tutors during their interviews.

1. Overall, HIIC was highly regarded by many participants, both students and tutors. It was reported that involvement in the course was a rewarding experience and examples of positive outcomes were recorded in the accounts given.

2. Tutors and students raised concerns regarding what happened after a HIIC course had finished. Tutors noted how they were not often able to provide appropriate support for students after completing HIIC. Reasons for this included inadequate time and financial resources allocated for projects. Some students expressed dissatisfaction at how they had been treated at the end of their course and it was unclear if they had been able to utilise their HIIC experiences in a meaningful way. Course funders and organisers should be aware of the possible need for both follow-up and short / mid-term support for students and consider ways that this could be built into the programme timescale.

3. As noted, HIIC tutors used both community development processes and group work to deliver course materials. Some interview accounts suggested that this was an intensive experience for both students and tutors. Managing this process successfully has implications for tutor training, for example ensuring tutors can deal with group conflicts. In addition, it is important that 
tutors are offered support during and after their course. CHEX could consider organising a form of mentoring involving more experienced tutors supporting those with less experience.

4. Consideration should be given to how tutors promote HIIC when trying to recruit students. Some courses were advertised as a way to develop skills in order to help secure employment. This may be an outcome, but the extent to which it is compatible with the stated aims of HIIC, which are to explore processes involved in addressing health issues, is perhaps questionable. Thus, CHEX and NHS Health Scotland could review this practice or issue guidelines for tutors advising them how to promote HIIC in their area.

5. As noted in this study, one course was facilitated in conjunction with a preemployment training programme. According to participants' interviews an additional complex dynamic influencing the group was the incentive of a guaranteed interview upon programme completion. It is debatable whether this was an appropriate forum for a HIIC course. As some students found aspects of HIIC challenging and emotive, I would question whether it is desirable or reasonable to expect students to engage with other materials in addition to HIIC. CHEX and NHS Health Scotland could advise tutors / course organisers about the potential difficulties arising from facilitating HIIC alongside other courses.

In summary, CHEX and NHS Health Scotland should encourage further awareness among tutors and stakeholders that HIIC course may be completed by students who have complex needs and difficult issues to deal with. Reasonable steps should be taken so that both tutors and students can reflect on their HIIC experience as being positive and rewarding. 
In the following section, I draw on work in this $\mathrm{PhD}$ and outline suggestions for further research.

\subsection{Suggestions for further research}

After reviewing the literature, the concept of $\mathrm{CCB}$ was constructed in this study as containing a number of dimensions. However, during this process I noted that there was a dearth of critical consideration about the nature of the relationships between the different dimensions of CCB. Therefore, I would suggest that it would be worthwhile to evaluate the existing dimension models of CCB and to explore the interplay between the dimensions. This could be addressed by conducting focus groups with HIIC tutors and students. Tutors could critically discuss and consider the concept of CCB based on their real-life experiences in community / health work and reach a consensus about which were the most important dimensions to include in a model of CCB. Data generated from this focus group could be presented in focus groups with HIIC students, where they could discuss whether the identified dimensions related to their experiences after completing HIIC.

In addition, after reviewing the CCB-related literature, I noted that there appeared to be little critical engagement with the concept of CCB; for example, the tendency for policy makers at the time of writing to use the term CCB over community development was not challenged in the literature. Documentary analysis could examine relevant policy papers recording when the terms CCB and community development occurred. Further analysis could trace how and when these terms were used and explore if CCB had superseded community development in policy documents.

Following this research study, I was interested in exploring in more detail the influence of HIIC on CCB. An appropriate method to do this would be participant observation, which has been described as a process where 'data [are] gathered by the researcher being present, and participating in the activities of the subjects under 
investigation; directly observing them and the other social phenomena relevant to the research question' (Sánchez-Jankowski 2002: 145). This research could provide an in-depth exploration of the processes involved in completing a HIIC programme and indicate how a group applies aspects of the course to tackle health issues in their community. This exploration may provide an insight into the social conditions that are conducive to promoting community level action or CCB.

The final suggestion for further research builds on the previous idea and involves exploring whether completing HIIC displaces CCB from one area to another. A way to address this question would be to compile a community profile including types of existing health-related service provision, levels of voluntary activity in related projects and explore if local people are involved on a voluntary basis or as a full-time paid professional. In-depth interviews would then be conducted with people completing HIIC to ascertain if the course had influenced them to remain in their community or if they had pursued opportunities in a different community.

\subsection{Conclusion}

In conclusion, this study indicated that by exploring the concepts of $\mathrm{CCB}$, community and health, a contribution was made towards understanding the processes by which participating in a HIIC course influenced students to address health-related concerns.

In addition, it is possible to view the development of $\mathrm{HIIC}$ as a response to a particular political ideology and as a forum to promote community development as a way of addressing health-related issues. As HIIC became more established, a change occurred in the political and social agendas. The emphasis on community in Third Way political discourse may present both positive and unforeseen consequences for those responsible for managing and promoting HIIC. On the one hand the current policy environment may present practice opportunities for community / healthrelated workers (Ingamells 2006) and enable workers to engage in CCB activities. 
However, the assumptions underpinning this perspective raises into relief a concern that courses such as HIIC could be placed in a potentially unwelcome position in relation to New Labour's neo-liberal reformist agenda (Hall 2003) or at the very least lose their critical voice as:

those responsible for community action will become agents for the 'domestication' of local politics, charged to deliver a consensual and responsible citizenry that performs the regeneration expectations of ruling elites. No longer will they be the collective voice of the disadvantaged, the marginal, and the excluded, pressing for alternatives that may well be at radical odds with the policy solutions on offer.

(Ilcan \& Basok 2004 as cited by Amin 2005: 620)

How HIIC is managed in relation to the political context is a concern for key stakeholders and represents a possible tension; for example, adhering to HIIC's community development ethos, while deciding if HIIC should be used as part of a staff development programme. In addition, HIIC was developed at a time when the term 'health inequalities' was generally resisted by the then government. The change in government resulted in an acknowledgement of health inequalities, which was a welcome development. However, it is clear that HIIC's content was designed to encourage people to challenge existing power and political structures as they tackled health-related concerns. This process also enables individuals and groups to develop a critical awareness about those in power and the policies they formulate and implement. In view of the persistence of health inequalities, the need for such a contribution remains undiminished. 


\section{Appendices}

\subsection{Appendix i Topic guide for stakeholder interviews}

Theme 1: HIIC

Could you tell me about your involvement/role with HIIC?

How and why did you become involved?

What are the main aims of the HIIC program?

Have these aims changed or developed?

Could you talk more about these changes?

What role does HIIC have in addressing or influencing issues around health?

Could you tell me more about the 'HIIC processes?

- How are tutors recruited / trained?

- How are courses organised and facilitated?

- Who makes the decision to run a HIIC program?

- How do you know if HIIC is effective?

- What type of people participate on a HIIC program?

- Issue of those who don't participate...

Theme 2: CCB

In the context of HIIC how is CCB defined/understood?

- organisation view point / personal understanding

Do you think that CCB and the HIIC program are linked?

- Could you talk more about the relationship between CCB \& HIIC.

How important is the idea of CCB to a program like HIIC?

- Why?

If HIIC is linked to the process of $\mathrm{CCB}$, how would this recognised in communities?

How could CCB be demonstrated to be taking place? 
Appendix i (continued)

Theme 3: Links to other ideas

HIIC uses a community development approach. Could you explain what this means?

What do you think is the relationship between community development and CCB?

Do you think they refer to the same things? Or do they mean different things?

$\mathrm{CCB}$ is referred to in a number of publications from the Scottish Parliament. How would you account for this interest in CCB? 


\subsection{Appendix ii Topic guide for tutor interviews}

1. Story of involvement in HIIC

What has been / is your current involvement with HIIC?

How long have you been interested in HIIC?

How did you become interested in being involved with HIIC?

Could you tell me about the groups/types of people you have worked with when delivering HIIC?

What have you enjoyed about your involvement with HIIC?

What have you found disappointing or negative?

2. Aims of HIIC

What do you think is the main aim(s) of the HIIC program?

3. HIIC and health

Do you think the HIIC program impacts on health?

Could you tell me how you think HIIC does that?

4. HIIC and their work

Has HIIC influenced you in anyway? (your work, outlook)

What have you learnt since being a HIIC tutor?

Could you tell me more about your learning? - What influence has it had on you? For example, your own understanding about health, your community involvement, or professional practice.

\section{Community development, $\mathrm{CCB}$ and HIIC}

The HIIC program uses a community development approach. Could you tell me what a community development approach means to you?

Could you think of examples from your own 'HIIC experiences' showing community development occurring? 
Appendix ii (continued)

How do you interpret your community? What does community mean to you?

Thinking about when you tutored HIIC, which community did you work with?

Is the phrase community capacity building meaningful to you? In what way (in relation to HIIC)? 

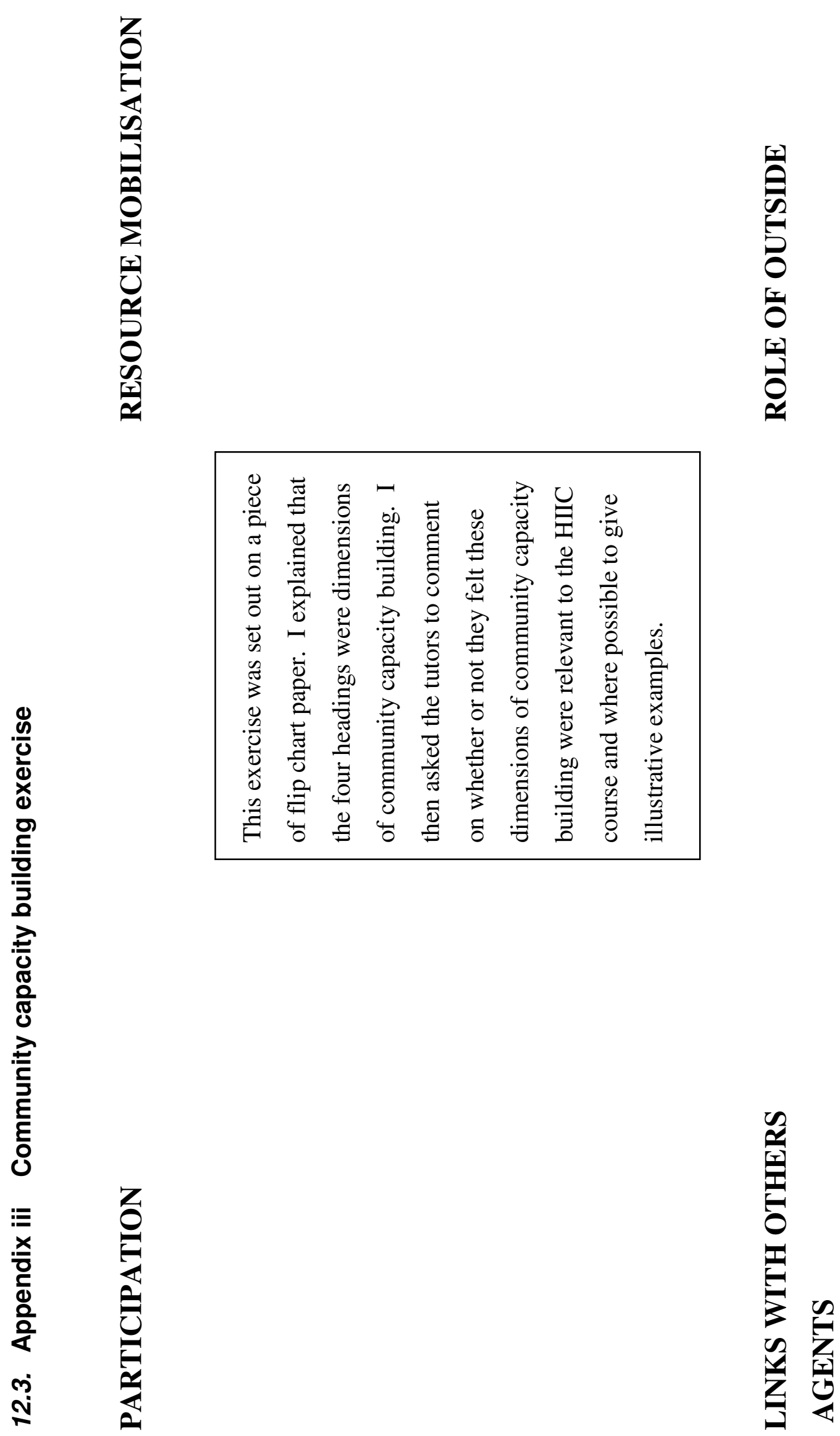


\subsection{Appendix iv Topic guide for student interviews}

\section{Background}

a) Could you tell me a bit about yourself?

- How long have you lived here?

- Work?

- Age?

- Family?

\section{Story of your involvement with HIIC}

a) Could you tell me about how you decided to go on a 'Health Issues In the Community' course?

b) Had been involved with anything like HIIC before?

c) Before you started the HIIC course, did you have any thoughts about what it was going to be like? Did you have any expectations about the course?

\section{Your HIIC experience}

a) How much of the course did you do?

b) Some courses are run once a week, others over weekends. Could you describe how your course was organised?

c) Did you enjoy doing the course?

- What parts did you enjoy the most?

- Could you tell me why you enjoyed them?

d) Was there anything you didn't enjoy about the HIIC course?

- Would you like to change anything about the course?

e) Did you find any parts of the course challenging or difficult?

- Could you tell me why you found them challenging/difficult? 
Appendix iv (continued)

f) We talked about what you expected the course to be like a moment ago. Did your tutors talk about what they expected you to learn from HIIC?

- Was that different to your own expectations?

- What do you think was the main aim of the Health Issues course?

g) Was there anything which surprised you about the course?

- Or did not expect?

\section{Your learning and HIIC}

a) Thinking about after you finished the 'Health Issues' course, do you feel you have changed in anyway?

- What about your knowledge?

- What about your attitudes? - to health, your community or where you live?

- career?

- How you feel about yourself? (confidence, self-esteem)

- Could you tell me how you think HIIC changed you?

b) Do you feel that you have learnt anything new after going on the HIIC course?

- Could you tell me more about that?

- Could you tell me about an example of being able to use your new knowledge?

If 'No', Could you tell why you think that? 
Appendix iv (continued)

c) The course talks about health. Did you feel that you learnt anything new about health by going on the course?

- What does the word 'health' mean for you?

- What do you think effects your health/communities health?

Do you feel your learning about health has influenced you in anyway?

- within your family?

- wider community?

d) During the course you may have had discussions about what community means to you. Do you feel that you learnt anything new about what community means?

- Could you tell me more about that?

- Did your ideas change after going on the course?

\section{Your HIIC group}

This section of the interview is about the other people you did the course with.

a) Did you know any of the other students before going on the course?

- What was your group like?

- Could you tell me more about the other students?

- Where the other people older or younger than you?

- Did they come from the same area/community as you?

b) How did you find working with the other students?

- Did you find it a good/not so good experience?

- Did you get on ok with each other?

c) Do you still see any of the other people in your group?

- Are you still in contact with them? Is that just socially/community/ or work?

- (If another context) Could you tell me more about that?

- Any advice about contacting them to take part in this study? 
Appendix iv (continued)

\section{Your experiences after finishing the HIIC course}

As I mentioned before the aim of this project is to see how HIIC helps individuals and communities.

a) Thinking again about your experiences after completing HIIC. Have you gone on anymore courses or training since?

- If 'Yes', Could you tell me more about that?

- If 'No', would you like to? May be it isn't a suitable time at the moment?

- Barriers to access?

\section{$\underline{\text { 7. Accreditation }}$}

a) As you know the Health Issues course is accredited. Some people go for accreditation and some do not. Did you want to go for accreditation?

- If 'yes', how did you find that? Did you find it difficult?

- If 'no', can you think of anything that stopped you going for the accreditation?

- not enough free time

- family commitments

- decided that you didn't want the accreditation 


\title{
12.5. Appendix v Initial participant recruitment letter
}

\author{
(Address) \\ (date) \\ Dear (name)
}

\section{Re: Research project on the 'Health Issues in the Community' course}

Hello. My name is Dave Allan and I co-ordinate the 'Health Issues in the Community' course across Scotland. The University of Edinburgh is currently involved in a research project, which is looking at this course. The main aim of this project is to look at how this course can help individuals and communities. As part of this project the researcher, Richard Phillips, would like to speak to former 'Health Issues in the Community' students about their experiences during and after the course. I have included a letter from Richard giving you more details about the study to help you decide if you would like to take part in this project.

Whatever you decide, your involvement with 'Health Issues in the Community' course will not be affected. I stress that your contact details and any information you give will be treated as strictly confidential.

If you are interested in being part of this research project you don't need to do anything just now as Richard will contact you in two weeks. However, if you do not want to take any further part, please fill in the slip and return using the enclosed envelope.

Your help in this study would be very much appreciated.

Thank you.

David Allan

(title) 
Appendix v (continued)

'Opt Out' form

I do not wish to receive any further information about the 'Health Issues in the Community' research project.

Signed $\ldots \ldots \ldots \ldots \ldots \ldots \ldots \ldots \ldots \ldots \ldots \ldots \ldots \ldots \ldots \ldots$ Print name

Date 


\subsection{Appendix vi Participant information sheet}

\section{$\underline{\text { Information sheet }}$}

Hello,

\section{Re: Taking part in the 'Health Issues in the Community' research project.}

My name is Richard Phillips and I am a student researcher from the University of Edinburgh. I am currently involved in a study which is looking at the 'Health Issues in the Community' (HIIC) course. This letter gives you some more information about the project and looks at some of the questions you may have about taking part in this research project.

\section{What is the aim of this research?}

The aim of this research is to understand how the 'Health Issues in the Community' course can help individuals and communities.

\section{Why was I asked to take part?}

You were asked to take part because you have been on a 'Health Issues in the Community' course. I also hope to speak to former students from other HIIC courses.

\section{If I decide to take part in the research project, what will happen next?}

You will be contacted either by phone or letter and asked if you are still interested in taking part in the project. If you would like to take part, we would then arrange a convenient time and place to meet to talk about your experiences of the 'Health Issues in the Community' course.

\section{What will happen in the interview?}

Before I ask you any questions, I will go through the details of the project. With your consent the interview will start. You do not have to answer any question you do not want to. You are free to stop the interview at any time. The interview will last between 1 and $1 \frac{1}{2}$ hours. With your permission, I would like to record the conversation we have so that I have an accurate account of what has been said. 
Appendix vi (continued)

\section{Information sheet continued}

\section{What will happen to anything I say during my interview?}

Anything that you say during your interview will be strictly confidential between me and my supervisors. You will not be identified by name either on the recording or in any notes. Any identifying details you give will be kept in a locked filing cabinet and destroyed at the end of the study, September 2005. What you say in the interview may be used as part of my $\mathrm{PhD}$, articles or reports. You will not be personally identified in any of these.

\section{Who is organising and funding the research?}

The research is being done by Richard Phillips from Edinburgh University. Dr Amanda Amos, Professor Lyn Tett from Edinburgh University and Emma Witney from NHS Health Scotland are supervising this project. This research is funded by the Economic and Social Research Council and NHS Health Scotland.

\section{Who do I contact if I have any questions or would like any further information about this research project?}

You are welcome to contact me, Richard Phillips at:

Public Health Sciences

University of Edinburgh

Medical School

Teviot Place

Edinburgh

EH8 9AG

Telephone: (0131) 6503210

E-mail: Richard.Phillips@ed.ac.uk 


\subsection{Appendix vii Student letter $2^{\text {nd }}$ stage}

Date

Address

Dear (student)

\section{Re: Research project on the 'Health Issues in the Community' course}

Hello. My name is Richard Phillips and I am a student researcher from the University of Edinburgh. I am carrying out a study which is looking at how the 'Health Issues in the Community' (HIIC) course may help individuals and communities.

You have recently been sent some information about the study. The next stage of the project involves speaking to HIIC students from different courses, and I would like to interview you about your experiences of the course. This interview would last between 1 and $1 \frac{1}{2}$ hours and would take place at a time and location convenient to you.

If you would like to take part in this project, please fill out the attached sheet with your contact details and return using the enclosed envelope. Alternatively, please feel free to phone me on 01316503210 with your details or leave them on my answer machine. After receiving your details, I will be in touch to arrange a suitable time and place to meet. I stress that your contact details and any information you give will be treated as strictly confidential.

If you would like any further information about the project or have a chat about your involvement, please ring me on the number above.

Thank you.

Richard Phillips

Student Researcher 
Appendix vii (continued)

\section{'Health Issues in the Community' research project}

\section{Research Participant contact details}

Name:

Postal Address:

(Please change if incorrect)

Phone number:

Mobile:

E-mail:

Please underline preferred means of contact.

Many thanks for your involvement

Richard Phillips

Student Researcher 


\subsection{Appendix viii Student reminder letter}

Address

Date

Dear

\section{Re: Health Issues in the Community (HIIC) research project}

Hello. My name is Richard Phillips and I recently sent you some information about taking part in a study, which is looking at how the HIIC course may help individuals and communities.

I am writing to let you know that I would still like to ask you about your experiences of the course. I have enclosed some information to help you decide if you would like to take part in this study.

If you would like to be interviewed, please fill out the contact details sheet and return to me using the stamped addressed envelop provided. After I receive your details I will be touch to arrange a time / place to meet that is convenient to you.

Regards

Richard Phillips

Student Researcher 


\subsection{Appendix ix Participant consent form}

\section{$\underline{\text { Interview Consent Form }}$}

My name is Richard Phillips and I am a PhD researcher from the University of Edinburgh. The interview in which you are about to take part forms part of my research. The title of the study is 'Health Issues in the Community and Community Capacity Building- A Case Study'. The aim of this project is to understand how the 'Health Issues in the Community' course may help individuals and communities. The purpose of this interview is to hear your views regarding this. This research is funded by the Economic and Social Research Council (ESRC) and NHS Health Scotland. However, I would like to reassure you that this study is an independent piece of research conducted by the University of Edinburgh.

Please read the following information before signing below.

I agree to participate in this interview and understand that:

- My interview will last approximately $1 \frac{1}{12} 2$ hours.

- Participation is on a voluntary basis and I am free to end the interview at any time. I can refuse to answer any question I am uncomfortable with.

- The interview will be tape-recorded with my permission. The recording will be transcribed and analysed by Richard Phillips. The recording and the transcript will remain confidential. The only people who will have access to the transcript will be Richard Phillips, Dr Amanda Amos (principal supervisor), Professor Lyn Tett and Emma Witney (NHS Health Scotland) within the University of Edinburgh. All recordings will be destroyed upon completion of the research.

- The data from this interview may form the basis of a PhD. Any quotations will be used anonymously; my name and the name of my organisation will not be linked with the quotations used in any of the PhD outputs (eg thesis, journals).

If I have any queries about this interview or research at any stage, then I can contact Richard Phillips: telephone 01316503210 or e-mail richard.phillips@ed.ac.uk 
12.10. Appendix x Coding: $2^{\text {nd }}$ and $4^{\text {th }}$ draft

$\underline{\text { Based on a stakeholder (SH2) interview }}$

Story of involvement with HIIC

HIIC's development

HIIC's development

Change/ political agenda

Role/ aspects of role

Role/ values

Aims of HIIC

Role/ professionalisation

HIIC \& health/ influence

HIIC \& health/ location

Assessing HIIC's effectiveness

Tutors/ types

Tutors/ evaluating tutors

Reflection
Tutors/ types/ view of health

Reflection

Influence

Support 
Appendix x (continued)

Understanding of Community

$\mathrm{CCB} /$ action

$\mathrm{CCB} /$ locality/level

$\mathrm{CCB} /$ process

$\mathrm{CCB} /$ links with others/challenge

$\mathrm{CCB} /$ indicators

Community development/ awareness/ action/ change 
Appendix x (continued)

\section{Coding $4^{\text {th }}$ draft}

1) Context

- community

- self

- political

- motivation

2) Role

- values

- identity

- professional

- personal

- other

3) Models of working

4) Perceived aims of HIIC

- expectations

5) How HIIC is delivered

- experience

- format

- ethos

- impact

- health

- community

- self

- others

- other

6) Understanding

- community / self

- community development

- community capacity building / HIIC

- power

- participation 


\title{
12.11. Appendix xi Ethical guidelines- stakeholders
}

\author{
University of Edinburgh
}

Public Health Sciences

\section{POSTGRADUATE RESEARCH ETHICS REVIEW FORM}

This form should be completed for every postgraduate student research project involving human participants. Its use is intended to foster good ethical standards of research practice in postgraduate students within this Public Health Sciences. Before completing this form, please refer to PHS's Code of Practice on Ethical Standards for Social Research Involving Human Participants. If the student's project involves only secondary data analysis, the supervisor will nevertheless be required to sign off the form.

The student's supervisor is responsible for exercising appropriate professional judgement on the information given and should complete Section III of this form.

Students should retain a copy of the form and submit it with their dissertation (bound in as an appendix). Please note that it is your responsibility to follow PHS's Code of Practice on Ethical Standards and any other relevant academic or professional guidelines in the conduct of your study. This includes providing appropriate information sheets and consent forms, copies of which should be submitted with your dissertation, and ensuring confidentiality in the storage and use of data.

This checklist must be completed before potential participants are approached to take part in any research.

Section 1: Postgraduate Student Details

\begin{tabular}{|c|c|}
\hline 1. Student's name & Richard Phillips \\
\hline 2. Email address & richard.phillips@ed.ac.uk \\
\hline 3. Course name & $\mathrm{PhD}$ \\
\hline 4. Supervisor's name & Dr Amanda Amos \\
\hline 5. Email address & amanda.amos@ed.ac.uk \\
\hline
\end{tabular}

Section II: Research Project Details

\begin{tabular}{l|l} 
6. Project Title & Health Issues In the Community and Community Capacity Building - a case
\end{tabular} study 


\section{Appendix xi (continued)}

Section III: For Supervisor completion (please tick boxes)

\begin{tabular}{|l|l|}
\hline The student has read the Division's Code of Practice & \\
\hline The topic merits further research & \\
\hline The student has the skills to carry out the research & \\
\hline $\begin{array}{l}\text { The participant information sheet or leaflet is appropriate or not required (please } \\
\text { specify) }\end{array}$ & \\
\hline $\begin{array}{l}\text { The procedures for recruitment and obtaining informed consent are appropriate or } \\
\text { net required (please-specify) }\end{array}$ & \\
\hline
\end{tabular}

Section IV: $\quad$ Preliminary Checklist (please tick boxes)

\begin{tabular}{|c|c|c|}
\hline & YES & NO \\
\hline $\begin{array}{l}\text { 1. Does the study involve participants who are particularly vulnerable or } \\
\text { unable to give informed consent? (e.g. young children, people with } \\
\text { severe learning disabilities, your own patients or employees) }\end{array}$ & & No \\
\hline $\begin{array}{l}\text { 2. Will the study require the co-operation of a gatekeeper for initial access } \\
\text { to the groups or individuals to be recruited? (e.g. students at school, } \\
\text { members of self-help group, residents of nursing homes) }\end{array}$ & & No \\
\hline $\begin{array}{l}\text { 3. Will it be necessary for participants to take part in the study without } \\
\text { their knowledge/consent at the time? (e.g. covert observation of people } \\
\text { in non-public places) }\end{array}$ & & No \\
\hline $\begin{array}{l}\text { 4. Will the study involve discussion of topics which the participants may } \\
\text { find sensitive? (e.g. sexual activity, personal drug use) }\end{array}$ & & No \\
\hline $\begin{array}{l}\text { 5. Are drugs, placebos or other substances (e.g. food substances, } \\
\text { vitamins) to be administered to the study participants? }\end{array}$ & & No \\
\hline $\begin{array}{l}\text { 6. Will the study involve invasive, intrusive or potentially harmful } \\
\text { procedures of any kind? }\end{array}$ & & No \\
\hline 7. Will blood or tissue samples be obtained from participants? & & No \\
\hline 8. Is pain or more than mild discomfort likely to result from the study? & & No \\
\hline $\begin{array}{l}\text { 9. Could the study induce psychological distress or anxiety or cause harm } \\
\text { or negative consequences beyond the risks encountered in normal life? }\end{array}$ & & No \\
\hline
\end{tabular}




\section{Appendix xi (continued)}

\begin{tabular}{|l|l|l|}
\hline 10. Will the study involve prolonged or repetitive testing? & No \\
\hline $\begin{array}{l}\text { 11. Will financial inducements (other than reasonable expenses and } \\
\text { compensation for time) be offered to participants? }\end{array}$ & No \\
\hline $\begin{array}{l}\text { 12. Will the study involve recruitment of patients or staff through the } \\
\text { NHS? }\end{array}$ & No \\
\hline
\end{tabular}

If you answered 'yes' to any of the questions in Section IV, you will need to describe how you plan to deal with the ethical issues raised by your research in Question 18 below. If you answered 'yes' to Question 12, you must also submit an application to the appropriate external health board ethics committee.

\section{Section V: Summary of Proposed Research}

\section{Background and rationale for study}

Community capacity building is an under-researched, but widely used, concept, which may contribute to understanding the relationship between social factors and health at community level. For example, the role of community capacity building in establishing community networks, reciprocal arrangements between community members and active citizenship. The study is based on a health education program - Health Issues In the Community, developed by NHS Health Scotland. This program uses a community development approach based on a social model of health. Program participants are encouraged to explore and understand the educational, social, political and community development processes that are involved in addressing health issues in their communities. The study will examine with previous course participants how far a community development approach to health has enabled them to explore health issues, engage in action and build their capacity to change their communities' approaches to health.

14. Aims and objectives of the research or the research question(s)

To explore, clarify and critically examine community capacity building in relation to community development and health referring to the Health Issues In the Community initiative. 


\title{
Appendix xi (continued)
}

\author{
15. Methods of data collection \\ (Briefly outline how data will be collected and attach a copy of any questionnaires, \\ interview schedules or observation guidelines to be used.)
}

Individual interviews, focus groups and documentary analysis.

16. Recruitment of participants

(Outline the number of participants involved; how potential participants will be identified and invited to take part in the study; how informed consent will be obtained.)

Number of participants $30-40$

Participants identified by data collected by HIIC tutors about HIIC students.

Participants will be contacted by telephone, e-mail or letter to be invited to take part in the study.

If participants express a willingness to take part in the study an information sheet and consent form will be posted to them. In addition, consent forms and information sheets will be made available prior to interview for relevant participants.

17. Please attach a copy of your information sheet and, if appropriate, your consent form.

$\rightarrow$ Information sheet attached $>$ Consent form attached

18. Potential adverse effects and steps to be taken to deal with them

(Outline any invasive procedures, potential psychological distress, anxiety or upset,

or any harm or negative consequences which may be induced by the study, and the steps to be taken to address them. These should relate to the questions you have answered 'yes' to in Section IV)

Not applicable 


\section{Appendix xi (continued)}

\section{Potential benefits of proposed research}

(Outline the benefits of the research for participants involved and more generally) The qualitative nature of the research methods should present an opportunity for key stakeholders, HIIC tutors and HIIC students to tell their story of their involvement with HIIC. Through conducting focus groups, participants will be able to learn from each other, hear about different experiences and renew or develop new networks. This process could have a positive effect in the context of how participants subsequently work in the community.

This study will contribute to further understanding about the processes of community capacity building, which may have wider implications for policy development, practice and evaluation of community health initiatives.

20. Steps to be taken to ensure confidentiality of data

(Outline steps to ensure confidentiality, privacy and anonymity of data during collection, storage and publication)

Data such as interview transcriptions will be stored on researcher's computer, which is password protected.

The interview transcripts will be erased after the research is completed. Any quotations used from the interviews will have any identifying features removed. Participants are guaranteed their anonymity; their names and names of any organisations they work for will not be quoted.

\section{Section VI: Funding}

21. Please indicate source of research funding: Internal Department/University funds (please indicate source)

Yes External funds (please indicate source) ESRC case studentship and NHS Health Scotland 
Appendix xi (continued)

As part of degree/training or 'own account' research

Signed: $8 \mathrm{Ph}$. P ............................ Postgraduate Student

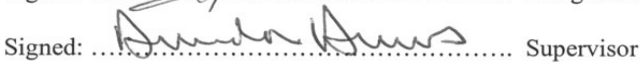

Date: $11 / .9 / 2003$ 


\title{
12.12. Appendix xii Ethical guidelines- students and tutors
}

\author{
University of Edinburgh
}

\author{
Public Health Sciences
}

\section{POSTGRADUATE RESEARCH ETHICS REVIEW FORM}

This form should be completed for every postgraduate student research project involving human participants. Its use is intended to foster good ethical standards of research practice in postgraduate students within this Public Health Sciences. Before completing this form, please refer to PHS's Code of Practice on Ethical Standards for Social Research Involving Human Participants. If the student's project involves only secondary data analysis, the supervisor will nevertheless be required to sign off the form.

The student's supervisor is responsible for exercising appropriate professional judgement on the information given and should complete Section III of this form.

Students should retain a copy of the form and submit it with their dissertation (bound in as an appendix). Please note that it is your responsibility to follow PHS's Code of Practice on Ethical Standards and any other relevant academic or professional guidelines in the conduct of your study. This includes providing appropriate information sheets and consent forms, copies of which should be submitted with your dissertation, and ensuring confidentiality in the storage and use of data.

This checklist must be completed before potential participants are approached to take part in any research.

Section 1: Postgraduate Student Details

\begin{tabular}{|l|l|}
\hline 1. Student's name & Richard Phillips \\
\hline 2. Email address & Richard.phillips@ed.ac.uk \\
\hline 3. Course name & $\mathrm{PhD}$ \\
\hline 4. Supervisor's name & Dr Amanda Amos \\
\hline 5. Email address & amanda.amos@ed.ac.uk \\
\hline
\end{tabular}

Section II: Research Project Details

6. Project Title $\quad$ Health Issues In the Community and Community Capacity Building - a case study 


\section{Appenix xii (continued)}

Section III: For Supervisor completion (please tick boxes)

\begin{tabular}{|l|l|}
\hline The student has read the Division's Code of Practice & \\
\hline The topic merits further research & \\
\hline The student has the skills to carry out the research & \\
\hline $\begin{array}{l}\text { The participant information sheet or leaflet is appropriate or not required (please } \\
\text { specify) }\end{array}$ & \\
\hline $\begin{array}{l}\text { The procedures for recruitment and obtaining informed consent are appropriate or } \\
\text { not required (please specify) }\end{array}$ & \\
\hline
\end{tabular}

\section{Section IV: Preliminary Checklist (please tick boxes)}

\begin{tabular}{|c|c|c|}
\hline & YES & NO \\
\hline $\begin{array}{l}\text { 1. Does the study involve participants who are particularly vulnerable or } \\
\text { unable to give informed consent? (e.g. young children, people with } \\
\text { severe learning disabilities, your own patients or employees) }\end{array}$ & & No \\
\hline $\begin{array}{l}\text { 2. Will the study require the co-operation of a gatekeeper for initial access } \\
\text { to the groups or individuals to be recruited? (e.g. students at school, } \\
\text { members of self-help group, residents of nursing homes) }\end{array}$ & & No \\
\hline $\begin{array}{l}\text { 3. Will it be necessary for participants to take part in the study without } \\
\text { their knowledge/consent at the time? (e.g. covert observation of people } \\
\text { in non-public places) }\end{array}$ & & No \\
\hline $\begin{array}{l}\text { 4. Will the study involve discussion of topics which the participants may } \\
\text { find sensitive? (e.g. sexual activity, personal drug use) }\end{array}$ & & No \\
\hline $\begin{array}{l}\text { 5. Are drugs, placebos or other substances (e.g. food substances, } \\
\text { vitamins) to be administered to the study participants? }\end{array}$ & & No \\
\hline $\begin{array}{l}\text { 6. Will the study involve invasive, intrusive or potentially harmful } \\
\text { procedures of any kind? }\end{array}$ & & No \\
\hline 7. Will blood or tissue samples be obtained from participants? & & No \\
\hline 8. Is pain or more than mild discomfort likely to result from the study? & & No \\
\hline $\begin{array}{l}\text { 9. Could the study induce psychological distress or anxiety or cause harm } \\
\text { or negative consequences beyond the risks encountered in normal life? }\end{array}$ & & No \\
\hline
\end{tabular}




\section{Appendix xii (continued)}

\begin{tabular}{|l|l|l|}
\hline 10. Will the study involve prolonged or repetitive testing? & No \\
\hline $\begin{array}{l}\text { 11. Will financial inducements (other than reasonable expenses and } \\
\text { compensation for time) be offered to participants? }\end{array}$ & No \\
\hline $\begin{array}{l}\text { 12. Will the study involve recruitment of patients or staff through the } \\
\text { NHS? }\end{array}$ & No \\
\hline
\end{tabular}

If you answered 'yes' to any of the questions in Section IV, you will need to describe how you plan to deal with the ethical issues raised by your research in Question 18 below. If you answered 'yes' to Question 12, you must also submit an application to the appropriate external health board ethics committee.

\section{Section V: Summary of Proposed Research}

\section{Background and rationale for study}

Community capacity building is an under-researched, but widely used, concept which may contribute to understanding the relationship between social factors and health at community level. For example, the role of community capacity building in establishing community networks, reciprocal arrangements between community members and active citizenship. This research project is based on a health education program Health Issues In the Community (HIIC) developed by NHS Health Scotland. This program uses a community development approach based on a social model of health. Program participants are encouraged community development approach based on a social model of health. Program participants are encouraged
to explore and understand the educational, social, political and community development processes that are involved in addressing issues around health in their communities. The study will examine with previous course participants how far a community development approach to health has enabled them to explore health issues, engage in action and build their capacity to change their communities' approaches to health.

14. Aims and objectives of the research or the research question(s)

To explore, clarify and critically examine community capacity building in relation to community development and health within the context of the Health Issues In the Community initiative. 


\section{Appendix xii (continued)}

15. Methods of data collection

(Briefly outline how data will be collected and attach a copy of any questionnaires, interview schedules or observation guidelines to be used.)

Individual in-depth interviews, focus groups and documentary analysis.

16. Recruitment of participants

(Outline the number of participants involved; how potential participants will be identified and invited to take part in the study; how informed consent will be obtained.)

Number of participants $30-40$.

Participants (HIIC Tutors) identified by data collected by Community Health Exchange (CHEX).

HIIC students will be contacted via HIIC tutors.

All participants will be initially contacted by telephone, e-mail or letter to be invited to take part in the study.

If participants express a willingness to take part in the study an information sheet and consent form will be sent to them. In addition, consent forms and information sheets will be made available prior to interview for relevant participants.

17. Please attach a copy of your information sheet and, if appropriate, your consent form.
Information sheet attached
Consent form attached

18. Potential adverse effects and steps to be taken to deal with them (Outline any invasive procedures, potential psychological distress, anxiety or upset, or any harm or negative consequences which may be induced by the study, and the steps to be taken to address them. These should relate to the questions you have answered 'yes' to in Section IV)

Not applicable 


\section{Appendix xii (continued)}

19. Potential benefits of proposed research

(Outline the benefits of the research for participants involved and more generally)

The qualitative nature of the research methods used in this research project present an opportunity for key stakeholders, HIIC tutors and HIIC students to tell their story of their involvement with HIIC. Through conducting focus groups participants will be able to learn from each other, hear about different experiences and renew or develop networks. This process could have a positive effect in the context of how participants subsequently work in the community.

20. Steps to be taken to ensure confidentiality of data

(Outline steps to ensure confidentiality, privacy and anonymity of data during collection, storage and publication)

Data such as interview transcriptions will be stored on the researcher's computer, which is password protected. The transcripts will be erased after the research is completed. Any quotations used from the interviews will have any identifying features removed. Participants are guaranteed their anonymity; their names and names of any organization they work for will not be quoted and where necessary pseudonyms will be used.

Section VI: Funding

\begin{tabular}{|l|l|}
\hline \multicolumn{2}{|l|}{ 21. Please indicate source of research funding: } \\
\hline & Internal Department/University funds (please indicate source) \\
\hline Yes & $\begin{array}{l}\text { External funds (please indicate source) } \\
\text { ESRC case studentship and NHS Health Scotland }\end{array}$ \\
\hline & As part of degree/training or 'own account' research \\
\hline
\end{tabular}


Appendix xii (continued)

Signed:


12.13. Appendix xiii Community capacity building exercise findings

PARTICIPATION- ITIS IS a

RESOURCE MOBSLISATION

cracker, so many inter pretations. abiflublising someone's

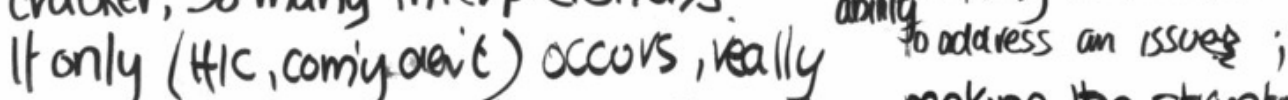
when peopleave involved at 'ideas. making ithe structore of anavea more covious to those living

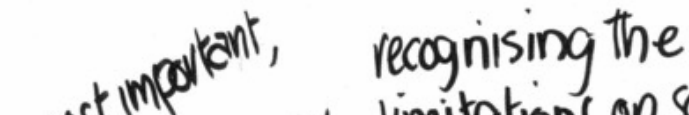 mos of tor limitations on some describing our forms of lessene efurev, inelping', agencies/people gov't so people can express

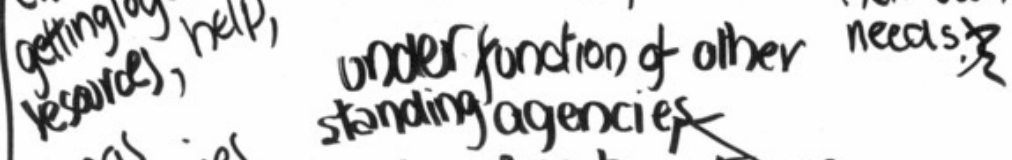 a valueges. knowing how to ose srallocal global. othet people, whether its rol orgor not. there -showmg gaps; 
Appendix xiii (continued)

$\mathrm{T} 2$

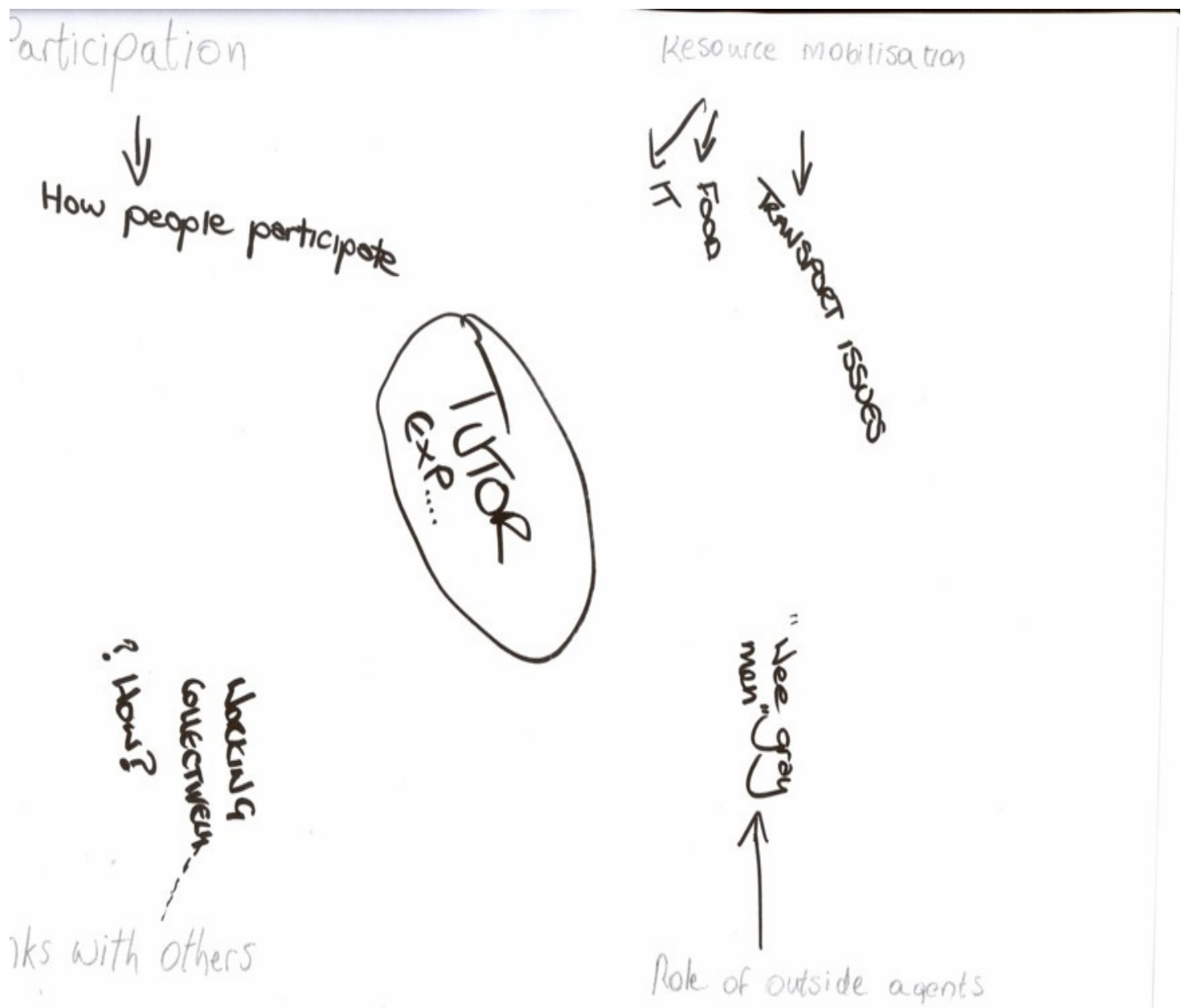


Appendix xiii (continued)

$\mathrm{T} 4$

\section{PARTICIPATION}

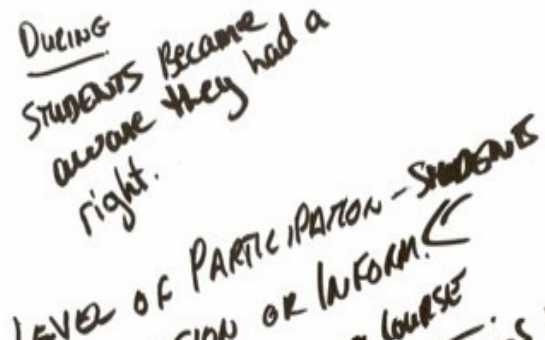

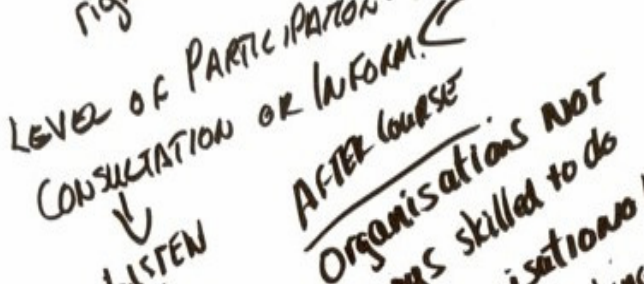
wank oris ow ong building

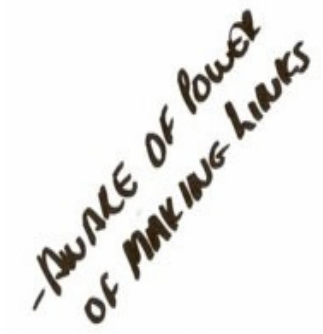

IINKS WITH OTHERS

\section{KroOUKCE MIOISILISATION}

- Not Huse IUXRense

- Hi.i. - Development of Unogrestand ina or MANAGETSS

H. I. F. Projects

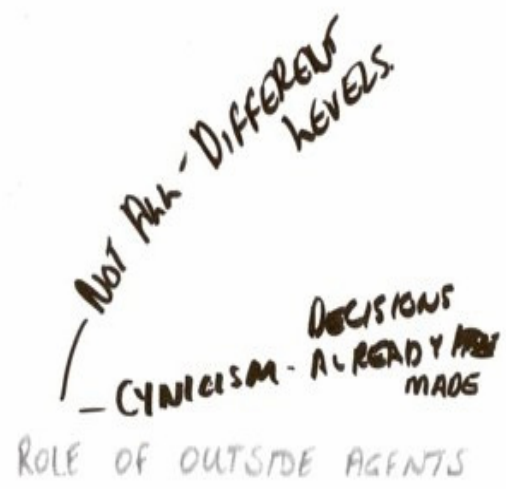


Appendix xiii (continued)

PARTICIPATION

x Cives individuals confidence to parhieate Encavays them to take part Gives them a serse of community Makes them foel they can change things for the better in their community

\section{(1) RESOURCE MOBILISATION}

Jaccion.

you think about it it cold apply to participants as a' resource', then gain skulb foum HIC, hence car be

modale a transfer these stuils
* Depends who'others ' are. Could mean HIC qives people confiderce to appoach outiside orgs i.e Councis.

- Butter social coutacts $x$ Ron UIC course

$x$ Provide support + resarces

INKS WITH OTHERS 
Appendix xiii (continued)

T6

PARTICIPATION

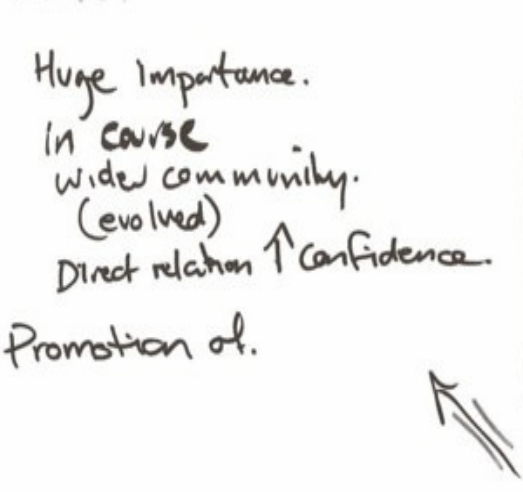

Emotive $\rightarrow$ Raised ? Why Who.

positively. whichled to action

Practical-reatistic expectations.

HAN AMES. //

Ralses issues Galvausing experience

$$
\text { HPowerful I. communitien to diff. }
$$

Inter - coure

Able to make rinks

i health/groups/ind.

Impadr

challenge

Ask / Make Desmands

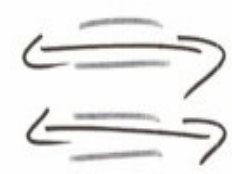

$\uparrow$ knowledge of.

Level of invdvement of comunty. who set the agenda. Support - "objective"

\section{LINKS WITH OTHERS}


Appendix xiii (continued)

$$
\begin{aligned}
& \text { Encouraps Participaion in } \\
& \text { sociery/ } \\
& \text { conmunity }
\end{aligned}
$$

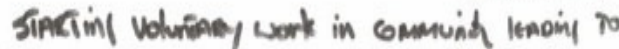
Ajos. Petuloust Hno no centact will oimats. isolains.

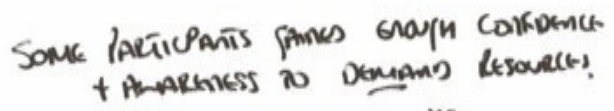
- Harse Roparies

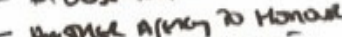

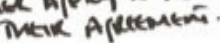

\section{Moe undersinnowy of t willingers to upale \\ u. cotrif}

Heepo undecsianding of mod teoples Sinvions

$$
\begin{aligned}
& \text { L sharing of line siocles } \\
& \text { Experiencts } \\
& \text { - Fimpiri common prouns } \\
& \text { - Priminim-ase Nitil yourself } \\
& \text { in Someone elses shos } \\
& \text { - Tocenancer - connectións }
\end{aligned}
$$

Maknil links wilk Gomenumita - STACinis Vol, work IEnoini wo a jos

LINKS WITH OTHERS
Also incecases undersianon of HIlk foc Hefercles - Haps fol Resourcind RolE Of OUTSIDE AGENTS 
Appendix xiii (continued)

T8 and T9

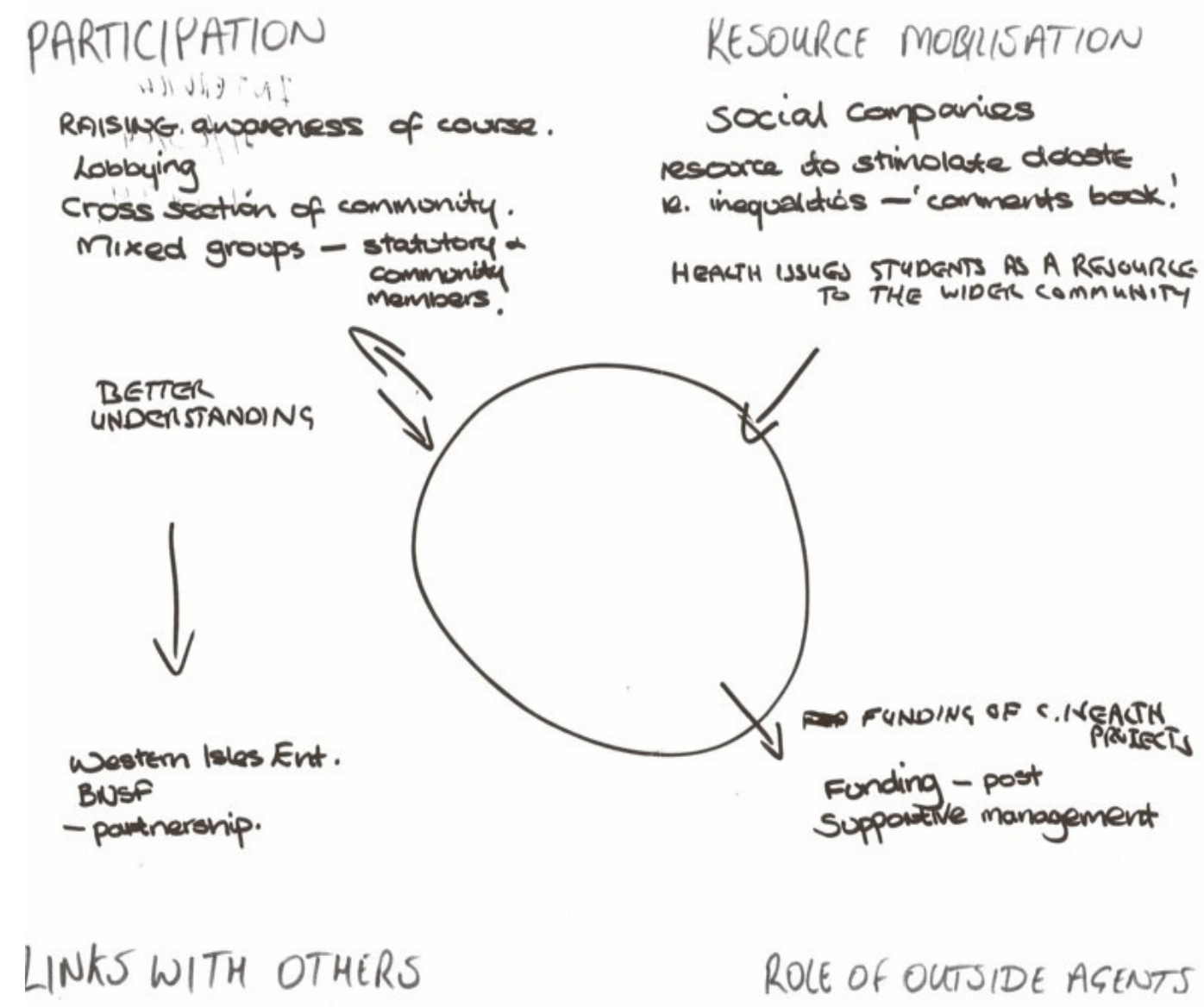


Appendix xiii (continued)

$\mathrm{T} 10$

PARTICIPATION

FACILITATED

INVOLVED OTHERS THeOVGH INTEXVIEWS/MEETINA
RESOURCE MOBILISATION

RURAL V URBAN costs. transport LENGTH UF FUND'NG TOO SHORT Evaluatiun + AccountaBility OF E SRENT.

-NKKS WITH OTHERS
1.A.T.E. $\rightarrow$ COMmunity S.I.P.S SOCiAL SERVICES NHS

Housing ASSOCIATION

L.C.N.L. - Website

SKILLS IN THE COMM UNITY

HIGHLAND CONNCLL

I. H.T. E

HOUSING ASSOCIATION

ROLE OF OUTSIDE AGENTS 
Appendix xiii (continued)

T11

PARTICIPATION

IN DIFFERENT WAYS THE GURSE INCREASED

people's participation

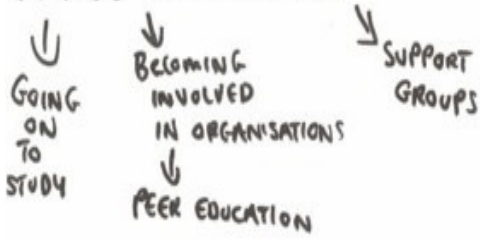

7 like to guote givdents in their development

plans.

$\rightarrow($ Could be toknisitic? $)$

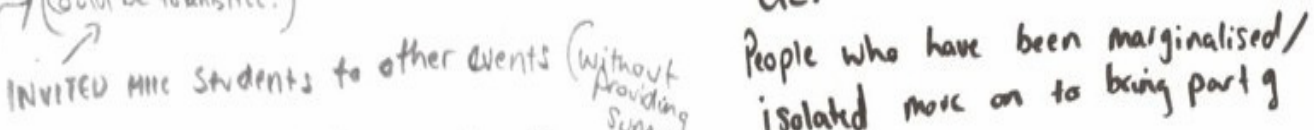

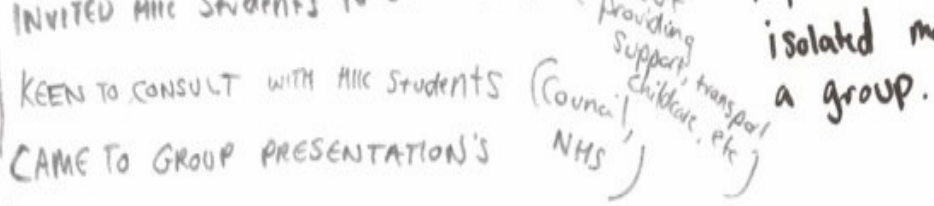

LOLE OF OUTSIDE AGENTS
KESOUKCE MOBB/LISATION

Courses short term funded -

need to fond support for porticipants

following the course - place to meet, trand costs, childcare, ete

TACKLE THE Bapriers to Parilcita:

Not evergone in a position to volunteer.

may want to but need support.

Orgonisations/could be mare prepared to utilise

P.

Course hugely increases

participants social networks -

linking with community groups, services,

I community councils, organisation

etc.

LINKS WITH OTHERS
HIIC strients - Peer ed, group werk, etc.. 
Appendix xiii (continued)

\section{PARTICIPATION}

$\checkmark$ ie staned witha

"captive audience" ie volunteer members/staff who had needs in relat ion to Undestarding heacth issues $\alpha$ developing the invoWement in health agends.
RESOURCE MOSILISHIION

We rad nesources (Headthcouncil) time skills

\&E⿰

willingness/goodwill experierce

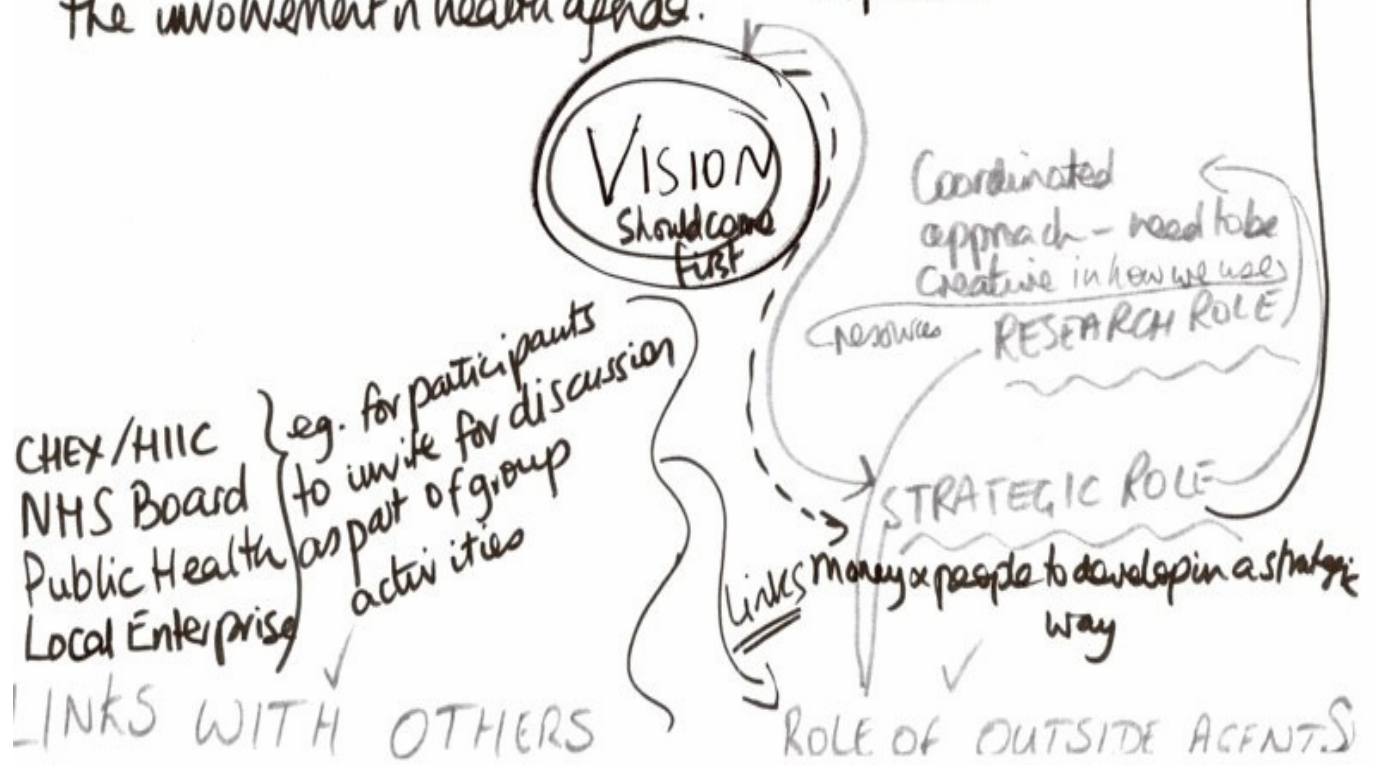


Appendix xiii (continued)

T13

PARTICIPATION

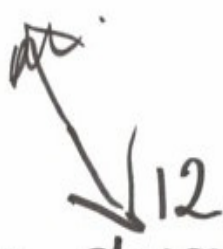

One stopped Caming

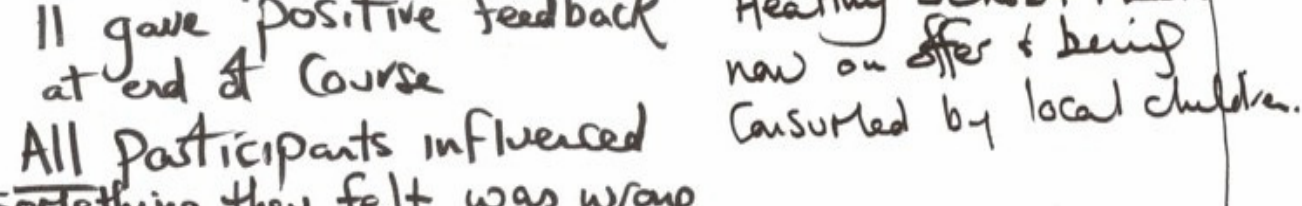

sorething they felt was wrong

in their courrunty.

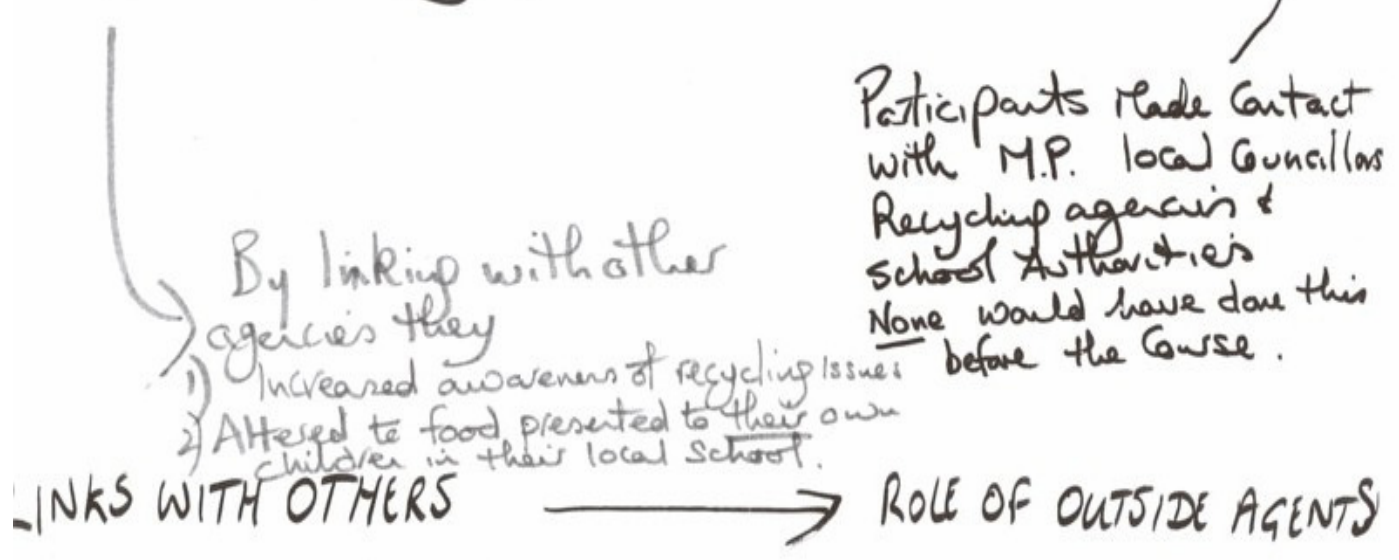




\section{References}

Abercrombie, N., Hill, S., \& Turner, B. S. (1988) Dictionary of sociology. Penguin Books, London.

Acheson, E. D. (1998) Independent inquiry into inequalities in health: report. Stationery Office, London.

Airey, L. (2003) ""Nae as nice a scheme as it used to be": lay accounts of neighbourhood incivilities and well-being". Health and Place, vol. 9, pp. 129-37.

Alcock, C., Payne, S., \& Sullivan, M. (2004) Introducing social policy. Revised edn, Pearson Education Limited, Harlow.

Alinsky, S. D. (1972) Rules for radicals. Random House, New York.

Allan, D. Health Issues in the Community course statistics. (3/25/2004a).

Allan, D. HIIC promotional flyer. (2004b). Glasgow, CHEX. (26-9-2005b.)

Allan, G. (1983) "Informal networks of care: issues raised by Barclay". British Journal of Social Work, vol. 13, pp. 417-34.

Amin, A. (2005) "Local community on trial". Economy and Society, vol. 34, no. 4, pp. 612-33.

Antonovsky, A. (1996) "The salutogenic model as a theory to guide health promotion". Health Promotion International, vol. 11, no. 1, pp. 11-8.

Argyle, M. (1987) The psychology of happiness. Methuen, London.

Arksey, H. (1996) "Collecting data through joint interviews". Social Research Update no. 15, pp. 1-6.

Armstrong, E. M. (2005) Health in Scotland 2004. Scottish Executive, Edinburgh, 5th.

Atkinson, P., Coffey, A., \& Delamont, S. (2003) Key themes in qualitative research: continuities and change. AltaMira Press, California. 
Avis, M. (2003) "Do we need methodological theory to do qualitative research?". Qualitative Health Research, vol. 13, no. 7, pp. 995-1004.

Bain, K. \& Hicks, N. Building social capital and reaching out to excluded groups: the challenge of partnerships. (1998). Washington DC, CELAM.

Bainson, K. A. (1994) "Integrating leprosy control into primary health care: the experience in Ghana". Leprosy Review, vol. 65, pp. 376-84.

Baker, E. A. \& Teaser-Polk, C. (1998) "Measuring Community Capacity: Where do we go from here?". Health Education and Behavior, vol. 25, no. 3, pp. 279-283.

Baker, J. (1987) Arguing for equality. Verso, London.

Bambra, C., Fox, D., \& Scott-Samuel, A. (2005) "Towards a politics of health". Health Promotion International, vol. 20, no. 2, pp. 187-93.

Banks, S. \& Shenton, F. (2001) "Regenerating Neighbourhoods: A Critical Look at the Role of Community Capacity Building". Local Economy, vol. 16, no. 4, pp. 286298.

Barnes, J. (1979) Who should know what? Penguin, Harmondsworth.

Barr, D., Fenton, L., \& Edwards, D. (2004) "Editorial: politics and health". QJM Monthly Journal of the Association of Physicians, vol. 97, no. 2, pp. 61-2.

Barry, B. M. (2005) Why social justice matters. Polity, Oxford.

Basit, T. N. (2003) "Manual or electronic? The role of coding in qualitative data analysis". Educational Research, vol. 45, no. 2, pp. 143-54.

Baum, F. (1999) "Social capital: is it good for your health? Issues for a public health agenda". Journal of Epidemiology and Community Health, vol. 53, pp. 195-96.

Bauman, Z. (2001) Community: seeking safety in an insecure world. Polity Press, Cambridge.

BBC Blair seeks to tackle extremism.

http://news.bbc.co.uk/2/hi/uk_news/politics/4678821.stm . (2006). (24-2-2006.)

Blaikie, N. (1993) Approaches to social enquiry. Polity Press, Cambridge.

Blaikie, N. (2000) Designing social research. Polity Press, Cambridge. 
Blamey, A., Hanlon, P., Judge, K., \& Muirie, J. H. (2002) Health inequalities in the new Scotland. Public Health Institute of Scotland, Glasgow.

Blaxter, M. (1983) "The causes of disease: women talking". Social Science and Medicine, vol. 17, pp. 59-69.

Blaxter, M. (1990) Health and lifestyles. Tavistock-Routledge, London.

Blaxter, M. (2004) Health. Polity Press, Cambridge.

Bloor, M., Frankland, J., Thomas, M., \& Robson, K. (2001) Focus groups in social research. Sage, London.

Bok, S. Rethinking the WHO definition of health. 14 (7). (2004). Cambridge MA, Harvard Centre for Population and Development Studies. Working Paper Series.

Bopp, M., Germann, K., Bopp, J., Littlejohns, L. B., \& Smith, N. (1999) Assessing community capacity for change. Four Worlds Development, Calgary.

Borrell-Carrió, F., Suchman, A. L., \& Epstein, R. M. (2004) "The biopsychosocial model 25 years later: principles, practice, and scientific inquiry". Annals of Family Medicine, vol. 2, no. 6, pp. 576-82.

Boseley, S. 1m patients "suffer harm in hospitals". Guardian , 4. (6/19/2002). (19-62002.)

Bourdieu, P. (1985) "The forms of capital," in Handbook of Theory and Research for the Sociology of Education. J. G. Richardson, ed., Greenwood, New York, pp. 24158 .

Bourdieu, P. \& Passeron, J. C. (1977) Reproduction in education, society and culture. Sage, Beverley Hills.

Boutilier, M., Cleverly, S., \& Labonte, R. (2000) "Community as a setting for health promotion," in Settings for Health Promotion. B. D. Poland, L. W. Green, \& I. Rootman, eds., Sage, London, pp. 250-79.

Brent, J. (1997) "Community without unity," in Contested Communities. Experiences, struggles, policies. P. Hoggett, ed., The Policy Press, Bristol.

Brent, J. (2004) "The desire for community: illusion, confusion and paradox". Community Development Journal, vol. 39, no. 3, pp. 213-23. 
Bridgen, P. (2004) "Evaluating the empowering potential of community-based health schemes: the case of community health policies in the UK since 1997". Community Development Journal, vol. 39, no. 3, pp. 289-302.

Brint, S. (2001) "Gemeinschaft revisited: a critique and reconstruction of the community concept". Sociological Theory, vol. 19, no. 1, pp. 1-23.

Brown, S. (2001) "What makes men talk about health?". Journal of Gender Studies, vol. 10, no. 2, pp. 187-95.

Bruhn, J. G. \& Wolf, S. (1979) The Roseto story. Oklahoma Press, Oklahoma.

Bryman, A. (2001) Social research methods. Oxford University Press, Oxford.

Bulmer, M. (1988) Neighbours: the work of Philip Abrams. Cambridge University Press, Cambridge.

Bunton, R. \& MacDonald, G. (1992) "Introduction," in Health Promotion:

Disciplines and Diversity. R. Bunton \& G. MacDonald, eds., Routledge, London, pp. 1-19.

Burgess, R. G. (1984) In the field: an introduction to field research. Unwin Hyman, London.

Burns, D., Forrest, R., Flint, J., \& Kearns, A. (2001) Empowering communities: the impact of Registered Social Landlords on social capital. Scottish Homes, Edinburgh, 94.

Calder, G. Communitarianism and New Labour.

http://www.whb.co.uk/socialissues/vol2gc.htm 2[1], 1-8. (2003). (14-3-2006.)

Callahan, D. The WHO definition of 'health'. Hasting Center Studies 1[3], 77-87. (1973).

Calnan, M. (1987) Health and illness: the lay perspective. Tavistock, London.

Calnan, M. (2004) "'Lifestyle" and its social meaning," in The Sociology of Health and Illness: a reader. M. Bury \& J. Gabe, eds., Routledge, London, pp. 59-68.

Campbell, C. \& McLean, C. (2002) "Ethnic identities, social capital and health inequalities: factors shaping African-Caribbean participation in local community networks in the UK". Social Science and Medicine, vol. 55, pp. 643-57. 
Campbell, C. (2000) "Social capital and health: contextualizing health promotion within local community networks," in Social Capital: critical perspectives. S. Baron, J. Field, \& T. Schuller, eds., Oxford University Press, Oxford.

Campbell, C., Wood, R., \& Kelly, M. (1999) Social capital and health. Health Education Authority, London.

Casswell, S. (2001) "Community Capacity Building and Social Policy: What can be achieved?". Social Policy Journal of New Zealand no. 17, pp. 22-35.

Cattell, V. (2001) "Poor people, poor places, and poor health: the mediating role of social networks and social capital". Social Science and Medicine, vol. 52, pp. 150116.

Chadwick, E. (1842) Report on the sanitary condition of the labouring population of Great Britain. HMSO, London.

Chandler, J. (1990) "Researching the relevance of gender," in Studies in Qualitative Methodology. vol. 2 R. G. Burgess, ed., JAI Press, Connecticut.

Chapman, M. \& Kirk, K. (2001) Lessons for Community Capacity Building: a summary of research evidence. Scottish Homes, Edinburgh.

Charity Commission RR5 - The Promotion of Community Capacity Building. (2000).

Chaskin, R. J. (2001) "Building community capacity: a definitional framework and case studies from a comprehensive community initiative". Urban Affairs Review, vol. 36, no. 3, pp. 291-323.

CHEX Health issues in the community- introduction.

http://www.chex.org.uk/hiic/hiicintroduction.htm . (2005). Glasgow, Community Health Exchange. (23-2-2005.)

Cloke, P., Cooke, P., Cursons, J., Milbourne, P., \& Widdowfield, R. (2000) "Ethics, reflexivity and research: encounters with homeless people". Ethics, Place and Environment, vol. 3, no. 2, pp. 133-54.

Cohen, A. P. (1992) The symbolic construction of community. Routledge, London.

Coleman, J. (1988b) "Social capital in the creation of human capital". American Journal of Sociology, vol. 94, pp. 13-39. 
Coleman, J. (1988a) "Social capital in the creation of human capital". American Journal of Sociology, vol. 94, p. S95-S120.

Conrad, P. (1992) "Medicalization and social control". Annual Review of Sociology, vol. 18, no. 1, pp. 209-32.

Cornwell, J. (1984) Hard-earned lives. Tavistock Publications, London.

Cottrell, L. (1976) "The competent community," in Further Explorations in Social Psychiatry. B. Kaplan, B. Wilson, \& A. Leighton, eds., Basic Books, New York.

Cox, R. \& Findlay, G. (1990) Community development health project: a review of achievements so far. Health Promotion Service, Cambridge.

Craig, G. \& Taylor, M. (2002) "Dangerous liaisons," in Partnerships, New Labour and the Local Governance of Welfare. C. Glendinning, M. Powell, \& K. Rummery, eds., Policy Press, Bristol.

Crawford, M. \& Acorn, S. (1997) "Focus groups: their use in administrative research". Journal of Nursing Administration, vol. 27, pp. 15-8.

Crawford, R. (1984) "A cultural account of "health": control, release, and the social body," in Issues in the Political Economy of Health Care. J. B. McKinay, ed., Tavistock Publications, New York, pp. 60-103.

Crawford, R. (1994) "The boundaries of the self and the unhealthy other: reflections on health, culture and AIDS". Social Science and Medicine, vol. 38, no. 10, pp. 1347-65.

Cribb, A. (2002) "Health promotion and society: critical perspectives," in The Challenge of Promoting Health: exploration and action. 2nd edn, L. Jones, M. Sidell, \& J. Douglas, eds., MacMillan Press Ltd, Basingstoke, pp. 274-84.

Crinson, I. (2005) "The direction of health policy in New Labour's third term". Critical Social Policy, vol. 25, no. 4, pp. 507-16.

Crisp, B. R., Swerissen, H., \& Duckett, S. J. (2000) "Four approaches to capacity building in health: consequences for measurement and accountability". Health Promotion International, vol. 15, no. 2, pp. 99-107.

Croft, S. \& Beresford, P. (1992) "The politics of participation". Critical Social Policy, vol. 12, no. 2, pp. 20-44.

Crotty, M. (1998) The foundations of social research. Sage, London. 
Curtis, S., Gesler, W., Smith, G., \& Washburn, S. (2000) "Approaches to sampling and case selection in qualitative research: examples in the geography of health". Social Science and Medicine, vol. 50, no. 7-8, pp. 1001-14.

CWHPIN (1998) Community capacity in the context of health: a review of the literature. ON, Hamilton.

Dahlin Ivanoff, S. (2002) "Focus group discussions as a tool for developing a health education programme for elderly persons with visual impairment". Scandinavian Journal of Occupational Therapy, vol. 9, pp. 3-9.

Davey-Smith, G. \& Lynch, J. (2004) "Commentary: social capital, social epidemiology and disease aetiology". International Journal of Epidemiology, vol. 33, no. 4, pp. 691-700.

Davey-Smith, G., Dorling, D., \& Shaw, M. (2001) Poverty, inequality and health in Britain: 1800-2000- a reader. Policy Press, Bristol.

Davidson, D. (2001) Subjective, intersubjective, objective. Oxford University Press, Oxford.

Deatrick, J. \& Faux, S. (1991) "Conducting qualitative studies with children and adolescents," in Qualitative nursing research: a contemporary dialogue. J. Mosrse, ed., Sage, California, pp. 203-223.

DeFilippis, J. (2001) "The myth of social capital in community development". Housing Policy Debate, vol. 12, no. 4, pp. 781-806.

Delanty, G. (2005) Community. Routledge, London.

Demos (2003) Inside out: rethinking inclusive communities. Demos, London.

Denzin, N. (1983) "Interpretive interactionism," in Beyond Method: strategies for social research. G. Morgan, ed., Sage, Beverly Hills.

Department of Health (1992) The health of the nation: a strategy for health in England. HMSO, London.

Department of Health and Social Security (1980) Inequalities in health: report of a working group chaired by Sir Douglas Black. DHSS, London.

Diamond, J. (2004) "Local regeneration initiatives and capacity building: whose 'capacity' and 'building' for what?". Community Development Journal, vol. 39, no. 2, pp. 177-89. 
Drevdahl, D. (1999) "Meanings of community in a community health center". Public Health Nursing, vol. 16, no. 6, pp. 417-25.

Driver, S. \& Martell, L. (1997) "New Labour's communitarianisms'". Critical Social Policy, vol. 17, no. 3, pp. 27-46.

Driver, S. \& Martell, L. (2000) "Left, Right and the Third Way". Policy and Politics, vol. 28, no. 2, pp. 147-61.

Dubos, R. (2001) "Mirage of health," in Health and Disease: A Reader. 3rd edn, B. Davey, A. Gray, \& C. Seale, eds., Open University Press, Buckingham, pp. 4-9.

Durkheim, E. (1897) Suicide: a study in sociology. Free Press, Glencoe.

Eade, D. (1997) Capacity building - an approach to people-centred development. Oxfam, Oxford.

Easterday, L., Papademas, D., Schorr, L., \& Valentine, C. (1977) "The making of a female researcher: role problems in field work". Urban Life, vol. 6, no. 3, pp. 33341.

Edwards, B. \& Foley, M. (1997) "Social capital and the political economy of our discontent". American Behavioral Scientist, vol. 40, no. 5, pp. 669-78.

Edwards, B. \& Foley, M. (1998) "Civil society and social capital beyond Putnam". American Behavioral Scientist, vol. 42, no. 1, pp. 124-39.

Edwards, J. (1997) "Urban policy: the victory of form over substance". Urban Studies, vol. 34, no. 5/6, pp. 825-43.

Eng, E. \& Parker, E. (1994) "Measuring community competence in the Mississippi Delta: The interface between program evaluation and empowerment". Health Education Quarterly, vol. 21, no. 2, pp. 199-220.

Engel, G. (1977) "The need for a new medical model: a challenge for biomedicine". Science, vol. 196, pp. 129-36.

Engels, F. (1888) Condition of the working class in England in 1844. With appendix written 1886 and preface 1887. Translated by Florence Kelly Wischnewetzky. William Reeves, London.

Etzioni, A. (1995) The spirit of community. Fontana, London. 
Ezzy, D. (2002) Qualitative analysis: practice and innovation. Routledge, London.

Fallon, G. \& Brown, R. B. (2002) "Focusing on focus groups: lessons from a research project involving a Bangladeshi community". Qualitative Research, vol. 2, no. 2, pp. 195-208.

Feijoo, M. Condicionantes de genero y capital social. cited by Molyneux, M (2002) Gender and the Silences of Social Capital: lessons from Latin America . (2000).

Field, J., Schuller, T., \& Baron, S. (2000) "Social capital and human capital revisited," in Social Capital: critical perspectives. S. Baron, J. Field, \& T. Schuller, eds., Oxford University Press, Oxford, pp. 243-63.

Fielding, J. \& Gilbert, N. (2000) Understanding social statistics. Sage, London.

Fielding, N. G. (2002) "Automating the ineffable: qualitative software and the meaning of qualitative research," in Qualitative Research in Action. T. May, ed., Sage, London, pp. 161-78.

Finch, J. (1984) "It's great to have someone to talk to: ethics and the politics of interviewing women," in Social Researching: Politics, Problems and Practice. C. Bell \& H. Roberts, eds., Routledge and Kegan Paul, London, pp. 70-87.

Fine, B. (1998) "From Bourdieu to Becker: economics confronts the social sciences". International Papers in Political Economy, vol. 5, no. 3, pp. 1-43.

Fine, B. (2001) Social capital versus social theory: political economy and social science at the turn of the millennium. Routledge, London.

Finlay, L. (2002) ""Outing" the researcher: the provenance, process and practice of reflexivity". Qualitative Health Research, vol. 12, no. 4, pp. 531-45.

Finn, J. L. \& Checkoway, B. (1998) "Young people as competent community builders: a challenge to social work". Social Work, vol. 43, pp. 335-45.

Fish, S. (1990) "How to recognize a poem when you see one," in Ways of Reading: An Anthology for Writers. Second edn, D. Bartholomae \& A. Petrosky, eds., Bedford Books of St Martin's Press, Boston, pp. 178-91.

Fleitas, J. (1998) "Spinning tales from the World Wide Web: qualitative research in an electronic environment". Qualitative Health Research, vol. 8, no. 2, pp. 283-92.

Foster, G. (1994) "Fishing the Net for research data". British Journal of Educational Technology, vol. 25, no. 2, pp. 91-7. 
Foucault, M. (1980) Power / knowledge: selected interviews and other writings. Vintage Books, New York.

Foucault, M. (1997) "The birth of biopolitics," in Michel Foucault. Ethics: subjectivity and truth. P. Rabinow, ed., New Press, New York.

Fraser, H. (2005) "Four different approaches to community participation". Community Development Journal, vol. 40, no. 3, pp. 286-300.

Frazer, E. \& Lacey, N. (1993) The politics of community: a feminist critique of the liberal-communitarian debate. Harvester Wheatsheaf, London.

Freire, P. (1972) Pedagogy of the oppressed. Penguin, Harmondsworth.

Fremeaux, I. (2005) "New Labour's appropriation of the concept of community: a critique". Community Development Journal, vol. DOI: 10.1093/cdj/bsi017.

Gamarnikow, E. \& Green, A. G. (1999) "The Third Way and social capital:

Education Action Zones and a new agenda for education, parents and community?". International Studies in Sociology of Education, vol. 9, no. 1, pp. 3-22.

Garces, E., Thomas, D., \& Currie, J. (2002) "Longer-term effects of Head Start". The American Economic Review, vol. 92, no. 4, pp. 999-1012.

Geddes, M. (1998) Local partnership: a successful strategy for social cohesion. European Foundation for the Improvement of Living and Working Conditions, Dublin.

Gerhardt, U. (1991) "The roles of the wife and marital reality construction in the narrative interview: conceptual models in qualitative data interpretation". Sociology of Health and Illness, vol. 13, no. 3, pp. 411-28.

Gibbon, M., Labonte, R., \& Laverack, G. (2002) "Evaluating community capacity". Health and Social Care in the Community, vol. 10, no. 6, pp. 485-91.

Gibbs, A. Focus groups. Social Research Update [19]. (1997). (5-8-2003.)

Giddens, A. (1998) The Third Way: the renewal of social democracy. Policy Press, Cambridge.

Giddens, A. (2000) The Third Way and its critics. Polity Press, Cambridge. 
Gilchrist, A. (2003a) "Community development and networking for health," in Public Health for the 21st Century: new perspectives on policy, participation and practice. J. Orme et al., eds., Open University Press, Buckingham, pp. 146-59.

Gilchrist, A. (2003b) "Community development in the UK - possibilities and paradoxes". Community Development Journal, vol. 38, no. 1, pp. 16-25.

Gillies, P. (1998) "Effectiveness of alliances and partnerships for health promotion". Health Promotion International, vol. 13, no. 2, pp. 99-120.

Glen, A. (1993) "Methods and themes in community practice," in Community and Public Policy. H. Butcher et al., eds., Pluto Press, London.

Goffman, E. (1959) The presentation of self in everyday life. Anchor, Garden City.

Goffman, E. (1961) Asylums. Anchor, New York.

Goffman, E. (1968) Stigma: notes of the management of spoiled identity. Penguin, London.

Goodman, R., Speers, M., McLeroy, K., Fawcett, S., Kegler, M., Parker, E., Rathgeb-Smith, S., Sterling, T. D., \& Wallerstein, N. (1998) "Identifying and defining the dimensions of community capacity to provide a base for measurement". Health Education and Behaviour, vol. 25, no. 3, pp. 258-78.

Goodman, R., Steckler, A., Hoover, S., \& Schwartz, R. (1993) "A critique of contemporary community health promotion approaches based on a qualitative review of six programs in Maine". American Journal of Health Promotion, vol. 7, pp. 20821.

Grace, V. M. (1991) "The marketing of empowerment and the construction of the health consumer: a critique of health promotion". International Journal of Health Services, vol. 21, no. 2, pp. 329-43.

Graham, H. (1984) Women, health and the family. Harvester Wheatsheaf, Brighton.

Graham, H. (1988) "Women and smoking in the UK: the implications for health promotion". Health Promotion, vol. 4, pp. 371-82.

Granovetter, M. (1973) "The strength of weak ties". American Journal of Sociology, vol. 78 , pp. $1360-80$. 
Green, L. W. \& Raeburn, J. (1990) "Community wide change: theory and practice," in Health Promotion at the Community Level. 1st edn, N. Bracht, ed., Sage, California.

Gregg, S. (2002), Examining the Impact of Long-term Iatrogenic HIV/HCV upon Haemophiliacs in the UK, MA, University of Birmingham.

Grix, J. (2001a) Demystifying postgraduate research: from MA to PhD. University of Birmingham Press, Birmingham.

Grix, J. (2001b) "Social capital as a concept in the social sciences: the current state of the debate". Democratization, vol. 8, no. 3, pp. 189-210.

Guba, E. \& Lincoln, Y. (1983) "Epistemological and methodological bases of naturalistic enquiry". Education Communication and Technology Journal, vol. 30, pp. 233-52.

Hall, N. \& Best, J. (1997) "Health promotion practice and public health: challenge for the 1990s". Canadian Journal of Public Health, vol. 88, pp. 409-15.

Hall, P. A. (1999) "Social capital in Britain". British Journal of Political Science, vol. 29, pp. 417-61.

Hall, S. (2003) "New Labour's double-shuffle". Soundings, vol. 24, pp. 10-24.

Halpern, D. \& Mikosz, D. The Third Way: summary of the NEXUS Online Debate. (1998). London, NEXUS.

Hammersley, M. \& Atkinson, P. (1995) Ethnography: principles in practice. 2nd edn, Routledge, London.

Hardie, A. MRSA infection rates still high despite major NHS hygiene drive. The Scotsman . (12/2/2005).

Harpham, T., Grant, E., \& Thomas, E. (2002) "Measuring social capital within health surveys: key issues". Health Policy and Planning, vol. 17, no. 1, pp. 106-11.

Hawe, P. (1994) "Capturing the meaning of 'community' in community intervention evaluation: some contributions from community psychology". Health Promotion International, vol. 9, no. 3, pp. 199-210.

Hawe, P., King, L., Noort, M., Gifford, S. M., \& Lloyd, B. (1998) "Working invisibly: health workers talk about capacity-building in health promotion". Health Promotion International, vol. 13, no. 4, pp. 285-95. 
Hawe, P., King, L., Noort, M., Jordens, C., \& Lloyd, B. (1999) Indicators to help with capacity building in health promotion. NSW Health Department, North Sydney.

Hawe, P. \& Shiell, A. (2000) "Social capital and health promotion: a review". Social Science and Medicine, vol. 51, pp. 871-85.

Hay, C. (2002) Political analysis: a critical introduction. Palgrave, Hampshire.

Health Education Board for Scotland (2002a) Health Issues in the Community. 2nd edn, Health Education Board for Scotland, Edinburgh.

Health Education Board for Scotland (2002b) Health Issues in the Community: a community development approach; Tutor Guidelines. 2nd edn, Health Education Board for Scotland, Edinburgh.

Herbert, D. (1993) "Neighbourhood incivilities and the study of crime in place". Area, vol. 25, no. 1, pp. 45-54.

Heritage, J. (1984) Garfinkel and Ethnomethodology. Polity Press, Cambridge.

Herzlich, C. (1973) Health and illness: a social and psychological approach. Academic Press, London.

Hillery, G. (1955) "Definitions of community: areas of agreement". Rural Sociology, vol. 20, pp. 111-23.

HMI How good is our community learning and development? 1-63. (2002). HM Inspectors of Education.

HMSO (1942) Social insurance and allied services (Beveridge Report). HMSO, London, Cmnd 6404.

Hodgson, L. (2004) "Manufactured civil society: counting the cost". Critical Social Policy, vol. 24, no. 2, pp. 139-64.

Hoggett, P. (1997) "Contested communities," in Contested Communities. Experiences, struggles, policies. P. Hoggett, ed., Polity Press, Bristol.

Hopf, C. (2004) "Qualitative interviews: an overview," in A Companion to Qualitative Research. U. Flick, E. von Karorff, \& I. Steinke, eds., Sage, London, pp. 203-08. 
Huby, M. \& Dix, G. (1992) Evaluating the Social Fund. HMSO, London, Department of Social Security Research Report 9.

Hughner, R. S. \& Kleine, S. S. (2004) "Views of health in the lay sector: a compilation and review of how individuals think about health". Health, vol. 8, no. 4, pp. 395-422.

Hyyppä, M. T. \& Mäki, J. (2003) "Social participation and health in a community rich in stock of social capital". Health Education Research, vol. 18, no. 6, pp. 77079.

Ilcan, S. \& Basok, T. (2004) "Community government: voluntary agencies, social justice, and the responsibilities of citizens". Citizenship Studies, vol. 8, no. 2, pp. 129-44.

Illich, I. (1975) Medical nemesis. Calder and Boyars, London.

Illich, I. (1976) Limits to medicine: medical nemesis: the expropriation of health. Marion Boyers, London.

Ingamells, A. (2006) "Community development and community renewal: tracing the workings of power". Community Development Journal, vol. doi:10.1093/cdj/bsi111, pp. 1-14.

Iscoe, I. (1974) "Community psychology and the competent community". American Psychologist, vol. 29, pp. 607-13.

Israel, B., Chekoway, B., Schulz, A., \& Zimmerman, M. (1994) "Health education and community empowerment: conceptualising and measuring perceptions of individual, organisational, and community control". Health Education Quarterly, vol. 21 , no. 2 , pp. 149-70.

Jackson, S., Cleverly, S., Burman, D., Edwards, R., Poland, B., \& Robertson, A. (1999a) Towards indicators of community capacity. Centre for Health Promotion, Toronto.

Jackson, S., Cleverly, S., Burman, D., Edwards, R., Poland, B., \& Robertson, A. (1999b) Towards indicators of community capacity: a study in four Toronto communities. Centre for Health Promotion, Toronto.

Jensen, L. A. \& Allen, M. N. (1994) "A synthesis of qualitative research on wellnessillness". Qualitative Health Research, vol. 4, pp. 349-69. 
Jewkes, R. \& Murcott, A. (1996) "Meanings of community". Social Science and Medicine, vol. 43, no. 4, pp. 555-63.

John, J. H. \& Ziebland, S. (2004) "Reported barriers to eating more fruit and vegetables before and after participation in a randomized controlled trial: a qualitative study". Health Education Research, vol. 19, no. 2, pp. 165-74.

Johnson, J. M. (2002) "In-depth interviewing," in Handbook of Interview Research: context and method. J. F. Gubrium \& J. A. Holstein, eds., Sage, Thousand Oaks, pp. 103-19.

Jordan, B., James, S., Kay, H., \& Redley, M. (1992) Trapped in poverty? Labourmarket decisions in low-income households. Routledge, London.

Jupp, B. (2000) Working together: creating a better environment for cross-sector partnerships. Demos, London.

Kamara, A. (1997) "Lessons learnt from the PMM network experience". International Journal of Gynecology and Obstetrics, vol. 59, pp. S253-8.

Kawachi, I. (2001) "Social capital for health and human development". Development, vol. 44, no. 1, pp. 31-5.

Kawachi, I., Kennedy, B. P., Lochner, K., \& Prothrow-Stith, D. (1997) "Social capital, income inequality and mortality". American Journal of Public Health, vol. 87, no. 9, pp. 1491-98.

Kelly, M. \& Charlton, B. (1995) "The modern and the postmodern in health promotion," in The Sociology of Health Promotion: critical analyses of consumption, lifestyle and risk. R. Bunton, R. Burrows, \& S. Nettleton, eds., Routledge, London.

Kelly, M. \& Field, D. (1994) "Comments on the rejection of the biomedical model in sociological discourse". Medical Sociology News, vol. 19, pp. 34-7.

Kenny, S. (2002) "Tensions and dilemmas in community development: new discourses, new Trojans?". Community Development Journal, vol. 37, no. 4, pp. 284-99.

Kidd, P. S. \& Parshall, M. B. (2000) "Getting the focus and the group: enhancing analytical rigor in focus group research". Qualitative Health Research, vol. 10, no. 3, pp. 293-308. 
King, N. (1994) "The qualitative research interview," in Qualitative Methods in Organizational Research: a practical guide. C. Cassell \& G. Symon, eds., Sage, London.

Kitzinger, J. (1995) "Introducing focus groups". British Medical Journal, vol. 311, no. 7000 , pp. 299-302.

Konig, R. (1968) The community. Routledge \& Kegan Paul, London.

Kretzman, J. P. \& McKnight, J. (1993) Building community from the inside out: a path toward finding and mobilizing community assets. Center for Urban Affairs and Policy Research, Northwestern University, Evanston.

Krueger, R. A. (1994) Focus groups: a practical guide for applied research. 2 edn, Sage, London.

Kwan, B., Frankish, J., Quantz, D., \& Flores, J. (2003) A synthesis paper on the conceptualization and measurement of community capacity. Institute of Health Promotion Research, University of British Columbia.

Labonte, R. (1997) "Community, community development and the forming of authentic partnerships," in Community Organising and Community Building for Health. M. Minkler, ed., Rutgers University Press, New Jersey.

Labonte, R. (1998) A community development approach to health promotion: a background paper on practice tensions, strategic models and accountability requirements for health authority work on the broad determinants of health. Health Education Board for Scotland, Edinburgh.

Labonte, R. (2004) "Social inclusion / exclusion: dancing the dialectic". Health Promotion International, vol. 19, no. 1, pp. 115-21.

Labonte, R. \& Laverack, G. (2001a) "Capacity building in health promotion, part 2: whose use? And with what measurement?". Critical Public Health, vol. 11, no. 2 , pp. 129-38.

Labonte, R. \& Laverack, G. (2001b) "Capacity building in health promotion: part 1: for whom? And for what purpose?". Critical Public Health, vol. 11, no. 2, pp. 11127.

Lakeman, R. (1997) "Using the Internet for data collection in nursing research". Computers in Nursing no. 15, pp. 269-75. 
Lalonde, M. (1974) A new perspective on the health of Canadians. Information Canada, Ottawa.

Larson, J. S. (1999) "The conceptualization of health". Medical Care Research and Review, vol. 56, no. 2, pp. 123-36.

Last, J. (2004) "Landmarks in the history of public health," in Public Health: Past, Present and Future. R. Bhopal \& J. Last, eds., The Nuffield Trust, London, pp. 111.

Laverack, G. (1999), Addressing the contradiction between discourse and practicing health promotion, Deakin University, Melbourne.

Laverack, G. (2005) "Evaluating community capacity: visual representation and interpretation". Community Development Journal, vol. doi:10.1093/cdj/bsi047, pp. $1-11$.

Laverack, G. \& Wallerstein, N. (2001) "Measuring community empowerment: a fresh look at organizational domains". Health Promotion International, vol. 16, no. 2, pp. 179-85.

Lawton, J. (2003) "Lay experiences of health and illness: past research and future agendas". Sociology of Health and Illness, vol. 25, no. Silver Anniversary Issue, pp. 23-40.

Levi, M. (1996) "Social and unsocial capital". Politics and Society, vol. 24, no. 1, pp. 45-55.

Levitas, R. (2000) "Community, utopia and New Labour". Local Economy, vol. 15, no. 3, pp. 188-97.

Lochner, K., Kawachi, I., \& Kennedy, B. P. (1999) "Social capital: a guide to its measurement". Health and Place, vol. 5, pp. 259-70.

Lomas, J. (1998) "Social capital and health: implications for public health and epidemiology". Social Science and Medicine, vol. 47, pp. 1181-88.

Lupton, D. (1995) The imperative of health: public health and the regulated body. Sage Publications, London.

Lynch, J., Davey-Smith, G., Hillemeier, M., Shaw, M., Raghunathan, T., \& Kaplan, G. (2001) "Income inequality, the psychosocial environment and health: comparisons of wealthy nations". British Medical Journal, vol. 358, pp. 194-200. 
Lynch, J. W. \& Kaplan, G. A. (1997) "Wither studies on the socioeconomic foundations of population health". American Journal of Health Promotion, vol. 87, pp. 1409-11.

Lyon, L. (1989) The community in urban society. Lexington, Toronto.

MacInnes, A. \& Milburn, K. (1994) "Belief systems and social circumstances influencing the health choices of people in Lochaber". Health Education Journal, vol. 53, no. 1, pp. 58-72.

MacIntyre, S. (1997) "The Black Report and beyond: what are the issues?". Social Science and Medicine, vol. 44, pp. 723-45.

Macintyre, S., MacIver, S., \& Sooman, A. (1993) "Area, class and health: should we be focussing on places or people?". Journal of Social Policy, vol. 22, no. 2, pp. 213 34.

Mackey, E. (1997) "The cultural politics of populism: celebrating Canadian national identity," in Anthropology of Policy: Critical Perspectives on Governance and Power. C. Shore \& S. Wright, eds., Routledge, London.

Mackian, S. (2002) "Complex cultures: rereading the story about health and social capital". Critical Social Policy, vol. 22, no. 2, pp. 203-25.

MacMillan, K. \& McLachlan, S. (1999) "Theory-building with NUD*IST: using computer assisted qualitative analysis in a media case study". Sociological Research Online, vol. 4, no. 2, pp. 1-17.

Maloney, W., Smith, G., \& Stoker, G. (2000) "Social capital and urban governance: adding a more contextualised 'top-down' perspective". Political Studies, vol. 48, pp. 802-20.

Marinetto, M. (2003) "Who wants to be an active citizen? The politics and practice of community involvement". Sociology, vol. 37, no. 1, pp. 103-20.

Marmot, M. (2001) "From Black to Acheson: two decades of concern with inequalities in health. A celebration of the 90th birthday of Professor Jerry Morris". International Epidemiological Association, vol. 30, no. 5, pp. 1165-71.

Marsh, D. \& Furlong, P. (2000) "A skin, not a sweater: ontology and epistemology in political science," in Theory and Methods in Political Science. 2nd edn, D. Marsh \& G. Stoker, eds., Palgrave MacMillan, Basingstoke, pp. 17-41. 
Marshall, D., Anderson, A., Lean, M., \& Foster, A. (1995) "Eat your greens: the Scottish consumer's perspective on fruit and vegetables". Health Education Journal, vol. 54, pp. 186-97.

Mason, A. (2000) Community, solidarity and belonging: levels of community and their normative significance. Cambridge University Press, Cambridge.

Mason, J. (1989) "Reconstructing the public and the private: the home and marriage in later life," in Home and Family: creating the domestic sphere. G. Allan \& G. Crow, eds., Macmillan, Basingstoke.

Mason, J. (1996) Qualitative researching. Sage, London.

Mason, J. (2002) Qualitative researching. 2nd edn, Sage, London.

Mayo, M. (1994) Communities and caring. Macmillan, Basingstoke.

McKague, M. \& Verhoef, M. (2003) "Understandings of health and its determinants among clients and providers at an urban community health center". Qualitative Health Research, vol. 13, no. 5, pp. 703-17.

McKee, L. \& O'Brien, M. (1983) "Interviewing men: 'taking gender seriously'," in The Public and the Private. E. Gamarnikow et al., eds., Heinemann, London.

McKeganey, N. \& Bloor, M. (1991) "Spotting the invisible man: the influence of male gender on fieldwork relations". The British Journal of Sociolgy, vol. 42, no. 2, pp. 195-210.

McKenzie, K., Whitley, R., \& Weich, S. (2002) "Social capital and mental health". British Journal of Psychiatry, vol. 181, pp. 280-83.

McKeown, T. (1976) The role of medicine: dream, mirage or nemesis? Nuffield Provincial Hospitals Trust, London.

McMillan, D. \& Chavis, D. (1986) "Sense of community: a definition and theory". Journal of Community Psychology, vol. 14, no. 1, pp. 6-23.

Miles, M. \& Huberman, A. (1994) Qualitative data analysis. Sage, London.

Minkler, M. (1989) "Health education, health promotion and the open society: an historical perspective.". Health Education Quarterly, vol. 16, no. 1, pp. 17-30. 
Mishler, E. G. (1981) "Critical perspectives on the biomedical model, and the social construction of illness," in Social contexts of health, illness, and patient care. E. G. Mishler et al., eds., Cambridge University Press, Cambridge.

Mittelmark, M. B. (1999) "Health promotion at the communitywide level: lessons from diverse perspectives," in Health Promotion at the Community Level: New Advances. 2nd edn, N. Bracht, ed., Sage Publications, California, pp. 3-27.

Molyneux, M. (2002) "Gender and the silences of social capital: lessons from Latin America". Development and Change, vol. 33, no. 2, pp. 167-88.

Moore, R. (1982) The social impact of oil: the case of Peterhead. Routledge and Kegan Paul, London.

Moore, S., Haines, V., Hawe, P., \& Shiell, A. (2006) "Lost in translation: a genealoy of the "social capital" concept in public health". Journal of Epidemiology and Community Health, vol. 60, no. 8, pp. 729-34.

Morgan, J. (1988) "Living with renal failure on home haemodialysis," in Living with Chronic Illness: the experience of patients and their families. M. Bury, ed., Unwin Hyman, London.

Morrow, V. (1999) "Conceptualising social capital in relation to the well-being of children and young people: a critical review". The Sociological Review, vol. 47, no. 4, pp. 744-65.

Morrow, V. (2001) Networks and Neighbourhoods: children's and young people's perspectives. Health Development Agency, London.

Muir, J. (2004) "Community development in health- a Scottish perspective". Journal of Community Work and Development no. 5, pp. 9-29.

Muntaner, C. \& Lynch, J. (1999) "Income inequality and social cohesion versus class relations: a critique of Wilkinson's neo-Durkheimian research program". International Journal of Health Services, vol. 29, no. 1, pp. 59-82.

Muntaner, C., Lynch, J., \& Davey-Smith, G. (2000) "Social capital and the Third Way in public health". Critical Public Health, vol. 10, no. 2, pp. 107-24.

Muntaner, C., Lynch, J., \& Davey-Smith, G. (2001) "Social capital, disorganized communities, and the third way: understanding the retreat from structural inequalities in epidemiology and public health". International Journal of Health Services, vol. 31, no. 2, pp. 213-37. 
Murray, C. (1994) Underclass: the crisis deepens. Institute of Economic Affairs, London.

Murray, M. (2000) "Social capital formation and healthy communities: insights from the Colorado Healthy Communities Initiative". Community Development Journal, vol. 35, no. 2, pp. 99-108.

Naidoo, J. \& Wills, J. (2000) Health promotion: foundations for practice. 2nd edn, Bailliére Tindall, London.

Narayan, D. (1999) Bonds and bridges: social capital and poverty. World Bank, Washington DC.

Navarro, V. (2002) "A critique of social capital". International Journal of Health Services, vol. 32, no. 3, pp. 423-32.

Neighbourhood Renewal Unit The national strategy for neighbourhood renewal: factsheet 2. (2002). Wetherby, Neighbourhood Renewal Unit. (17-6-2003.)

NHS Health Scotland (2005) NHS Health Scotland corporate plan 2005-08. NHS Health Scotland, Edinburgh.

Nisbet, R. (1960) "Moral values and community". International Review of Community Development, vol. 5, pp. 77-85.

O'Brien, M. (1995) "Health and lifestyle: a critical mess? Notes on the dedifferentiation of health," in The Sociology of Health Promotion: critical analyses of consumption, lifestyle and risk. R. Bunton, S. Nettleton, \& R. Burrows, eds., pp. 191-205.

Oakley, A. (2000) Experiments in knowing. The New Press, New York.

Ortiz, S. (2001) "How interviewing became therapy for wives of professional atheletes". Qualitative Inquiry, vol. 7, no. 2, pp. 192-220.

Paley, J. (2000) "Paradigms and presuppositions: the difference between qualitative and quantitative research". Scholarly Inquiry for Nursing Practice, vol. 14, no. 2, pp. 143-55.

Paley, J. (2001) "Positivism and qualitative nursing research". Scholarly Inquiry for Nursing Practice, vol. 15, no. 4, pp. 371-87.

Parker, G. (1993) With this body: caring and disability in marriage. Open University Press, Buckingham. 
Parsons, T. (1951) The social system. Free Press, New York.

Paton, C. (1999) "New Labour's health policy: the new healthcare state," in New Labour, New Welfare State? M. Powell, ed., The Policy Press, Bristol, pp. 51-75.

Patton, M. Q. (1990) Qualitative evaluation and research methods. 2nd edn, Sage, Newbury Park.

Pawson, R. \& Tilley, N. (1998) "Caring communities, paradigm polemics, design debates". Evaluation, vol. 4, no. 1, pp. 73-90.

Pearlin, L. I. (1985) "Social structure and processes of social support," in Social Support and Health. S. Cohen \& S. L. Syme, eds., Academic Press, New York, pp. 43-60.

Pflanz, M. \& Rhode, J. J. (1970) "Illness: deviant behaviour or conformity?". Social Science and Medicine, vol. 4, pp. 645-53.

Phillips, R. (2002), Prostate cancer and masculinities, MA in Social Research, University of Birmingham.

Pierret, J. (1993) "Constructing discourses about health and their social determinants," in Worlds of Illness: biographical and cultural perspectives. A. Radley, ed., Routledge, London, pp. 9-26.

Pilisuk, M. \& Parks, S. H. (1986) The healing web: social networks and human survival. University Press of New England, Hanover.

Pilkington, P. (2002) "Social capital and health: measuring and understanding social capital at a local level could help to tackle health inequalities more effectively". Journal of Public Health Medicine, vol. 24, no. 3, pp. 156-59.

Player, D. \& Murray, P. (2003) "The growing social significance of health promotion in twentieth-century Scotland," in The Social Significance of Health Promotion. T. H. MacDonald, ed., Routledge, London, pp. 183-203.

Popay, J., Williams, G., Thomas, C., \& Gatrell, A. (1998) "Theorising inequalities in health: the place of lay knowledge". Sociology of Health and Illness, vol. 20, no. 5, pp. 619-44.

Pope, J. (2003) Social capital and social capital indicators: a reading list. Public Health Information Development Unit, University of Adelaide, Working paper series no. 1 . 
Popple, K. \& Redmond, M. (2000) "Community development and the voluntary sector in the new millennium: the implications of the Third Way in the UK". Community Development Journal, vol. 35, no. 4, pp. 391-400.

Portes, A. (1998) "Social capital: its origins and applications in modern sociology". Annual Review of Sociology, vol. 24, pp. 1-24.

Powell, M. (1996) "Granny's footsteps, fractures and the principles of the NHS". Critical Social Policy, vol. 47, no. 16, pp. 27-44.

Powell, R. A. \& Single, H. M. (1996) "Methodology matters - V: focus groups". International Journal for Quality in Health Care, vol. 8, pp. 499-504.

Preston, P. There is no such thing as community. Guardian . (7/18/2005).

Proudfoot, J. \& Guest, D. (1997) "Effect of cognitive-behavioural training on job finding among long-term unemployed people". Lancet, vol. 350, no. 9071, pp. 96100.

Punch, K. (2000) Developing effective research proposals. Sage, London.

Punch, K. F. (1998) Introduction to social research: quantitative and qualitative approaches. Sage, London.

Purdue, D., Razzaque, K., Hambleton, R., Stewart, M., Huxham, C., \& Vangen, S. (2000) Community leadership in area regeneration. The Policy Press, Bristol.

Putnam, R. D. (1993) Making democracy work. Princeton University Press, Princeton.

Putnam, R. D. (2000) Bowling alone: the collapse and revival of American community. Simon and Schuster, New York.

Pyett, P. M. (2003) "Validation of qualitative research in the "real world"". Qualitative Health Research, vol. 13, no. 8, pp. 1170-79.

Radley, A. \& Billig, M. (1996) "Accounts of health and illness: dilemmas and representations". Sociology of Health and Illness, vol. 18, no. 2, pp. 220-40.

Ramphele, M. \& Thornton, J. (1988) "The quest for community," in The South African Keywords: The uses and abuses of political concepts. E. Bouzaier \& J. Sharp, eds., David Philip, Cape Town. 
Rapley, T. J. (2001) "The art(fulness) of open-ended interviewing: some considerations on analysing interviews". Qualitative Research, vol. 1, no. 3, pp. 303-23.

Reicks, M., Randall, J. L., \& Haynes, B. J. (1994) "Factors affecting consumption of fruit and vegetables by low-income families". Journal of the American Dietetic Association, vol. 94, pp. 1309-11.

Richards, L. (1999) "Data alive! The thinking behind NVivo". Qualitative Health Research, vol. 9, no. 3, pp. 412-28.

Riessman, C. (1994) Qualitative studies in social work. Sage, California.

Rissel, C. (1994) "Empowerment: the holy grail of health promotion?". Health Promotion International, vol. 9, no. 1, pp. 39-47.

Ritchie, D., Parry, O., Gnich, W., \& Platt, S. (2004) "Issues of participation, ownership and empowerment in a community development programme: tackling smoking in a low-income area in Scotland". Health Promotion International, vol. 19, no. 1, pp. 51-9.

Roberts, L. D., Smith, L. M., \& Pollock, C. 'u r a lot bolder on the net': The social use of text-based virtual environments by shy individuals. (1997). Cardiff University, First International Conference on Shyness and Self-Consciousness.

Robinson, K. L. \& Elliott, S. J. (2000) "The practice of community development approaches in heart health promotion". Health Education Research, vol. 15, no. 2, pp. 219-31.

Robinson, N. (1999) "The use of focus group methodology- with selected examples from sexual health research". Journal of Advanced Nursing, vol. 29, no. 4, pp. 90513.

Robinson, R. (1994) "Private pain and public behaviours: sexual abuse and delinquent girls," in Qualitative Studies in Social Work Research. C. Riessman, ed., Sage, California.

Robson, C. (2002) Real world research. 2nd edn, Blackwell, Oxford.

Roderick, P. (1999) Health and health services. Arkleton Centre for Rural Development Research, Aberdeen.

Roger, J. (2000) From a welfare state to a welfare society: the changing context of social policy in a postmodern era. Macmillan, Basingstoke. 
Rose, N. (1996) "The death of the social? Re-figuring the territory of government". Economy and Society, vol. 25, no. 3, pp. 327-56.

Rose, N. (1999) "Inventiveness in politics". Economy and Society, vol. 28, pp. 46793.

Rose, N. (2001) "The politics of life itself". Theory, Culture and Society, vol. 18, no. 6, pp. 1-30.

Rowntree, S. (1902) Poverty: a study of town life. 3rd edn, Longmans, Green and Co., London.

Rural Poverty and Inclusion Working Group (2001) Poverty and social exclusion in rural Scotland. Scottish Executive, Edinburgh.

Ryan, G. W. \& Bernard, H. R. (2000) "Data management and analysis methods," in Handbook of Qualitative Research. 2nd edn, N. K. Denzin \& Y. S. Lincoln, eds., Sage, California, pp. 769-802.

Saeed, O. Back to you Mr Blair. Guardian . (7/23/2005).

Sampson, R. J., Raundenbush, S. W., \& Earls, F. (1997) "Neighborhoods and violent crime: a multilevel study of collective efficacy". Science, vol. 277, pp. 918-24.

Sánchez-Jankowski, M. (2002) "Representation, responsibility and reliability in participant-observation," in Qualitative research in action. T. May, ed., Sage, London, pp. 144-60.

SAT (1999) Inclusive communities: report of the Strategy Action Team. Scottish Executive, Edinburgh.

Schuftan, C. (1996) "The community development dilemma: what is really empowering?". Community Development Journal, vol. 31, pp. 261-63.

Schuller, T., Preston, J., Hammond, C., Brassett-Grundy, A., \& Bynner, J. (2004) The benefits of learning: the impact of education on health, family life and social capital. RoutledgeFalmer, London.

Scottish Community Development Centre L.E.A.P . http://www.scdc.org.uk/leap_index.htm . (2003). The Scottish Community Development Centre. (21-5-2003.)

Scottish Executive (1999a) Social justice - a Scotland where everyone matters (milestones, sources and definitions). Scottish Executive, Edinburgh. 
Scottish Executive Towards a Healthier Scotland - A White Paper on Health. (1999b).

Scottish Executive (2000) Empowering communities: social justice action note: June 2000. Scottish Executive, Edinburgh.

Scottish Executive (2003) Improving health in Scotland: the challenge. Scottish Executive, Edinburgh.

Seedhouse, D. (1986) Health: the foundations for achievement. John Wiley \& Sons Ltd, Chichester.

Seedhouse, D. (1994) Fortress NHS. John Wiley and Sons, Chichester.

Seidel, J. \& Kelle, U. (1995) "Different functions of coding in the analysis of textual data," in Computer-aided Qualitative Data Analysis: Theory, methods and practice. U. Kelle, ed., Sage, London.

Seligman, M. (1975) Helplessness: on depression, development and death. W. H. Freeman, San Francisco.

Seligman, M. (1990) Learned optimism. Pocket Books, Toronto.

Selwyn, N. \& Robson, K. Using e-mail as a research tool. Social Research Update [21]. (1998). (5-6-2004.)

Seymour, J., Dix, G., \& Eardley, T. (1995) Joint accounts: methodology and practice in research interviews with couples. Social Policy Research Unit, University of York.

Shaw, M. (2006) "Community development and the politics of community". Community Development Journal, vol. 10.1093/cdj/bsl1035.

Shiell, A. \& Hawe, P. (1996) "Health promotion, community development and the tyranny of individualism". Health Economics, vol. 5, pp. 241-47.

Shirlow, P. \& Murtagh, B. (2004) "Capacity-building, representation and intracommunity conflict". Urban Studies, vol. 41, no. 1, pp. 57-70.

Sidell, M. (2002) "Partnerships and collaborations: the promise of participation," in The Challenge of Promoting Health. 2nd edn, J. Jones, M. Sidell, \& J. Douglas, eds., MacMillan Press Ltd, Basingstoke, pp. 45-65. 
Sihlongonyane, M. F. (2001) "The rhetoric of the community in project management: the case of Mohlakeng township". Development in Practice, vol. 11, no. 1, pp. 3444.

Silverman, D. (2000) Doing qualitative Research. Sage, London.

Simpson, L., Wood, L., \& Daws, L. (2003) "Community capacity building: starting with people not projects". Community Development Journal, vol. 38, no. 4, pp. 27786.

Smith, G. (1996) "Elastic band: community in the postmodern city". Community Development Journal, vol. 31, no. 3, pp. 250-59.

Smith, M. K. Introducing informal education. http://www.infed.org/i-into.htm, 1-9. (1997). (10-3-2006.)

Smith, M. K. 'Community' . http://www.infed.org/community/community.htm . (2001). (26-3-2006.)

Smith, N., Baugh-Littlejohns, L., \& Thompson, D. (2001) "Shaking out the cobwebs: insights into community capacity and its relation to health outcomes". Community Development Journal, vol. 36, no. 1, pp. 30-40.

Smith, S. S. \& Kulynych, J. (2002) "It may be social, but why is it capital? The social construction of social capital and the politics of language". Politics and Society, vol. 30, no. 1, pp. 149-86.

Social Economy Scotland Registered Social Landlords (RSLs).

http://www.socialeconomyscotland.info/ses.php? $p p=1 \&$ fileid=registered_social_lan dlords.html . (7/15/2005).

Sooman, A. \& MacIntyre, S. (1995) "Health and perceptions of the local environment in socially contrasting neighbourhoods in Glasgow". Health and Place, vol. 1, pp. 15-26.

Spring-Rice, M. (1939) Working class wives: their health and condition. Penguin, Harmondsworth.

St John, W. (1998) "Just what do we mean by community? Conceptualizations from the field". Health and Social Care in the Community, vol. 6, no. 2, pp. 63-70.

Standing Conference for Community Development Strategic framework for community development. (2001). Sheffield, Standing Conference for Community Development. (17-6-2003.) 
Statham, D. Differences will make the difference. Guardian . (1/3/2001).

Steckler, A., Dawson, L., Israel, B., \& Eng, E. (1993) "Community health development: an overview of the works of Guy W. Steuart". Health Education Quarterly, vol. Supplement 1, pp. S3-20.

Stevenson, R. (2005) Improving the collection of volunteering data in Scotland. Scottish Executive, Edinburgh.

Stewart, D. W. \& Shamdasani, P. N. (1990) Focus groups: theory and practice. Sage, California.

Stoker, G. \& Bottom, K. A. "Community capacity building: notes for a talk given to MAV conference, Lorne, 25-27 July 2003".

Tam, H. (1998) Communitarianism: a new agenda for politics and citizenship. Macmillan, Basingstoke.

Tatano Beck, C. (2005) "Benefits of participating in Internet interviews: women helping women". Qualitative Health Research, vol. 15, no. 3, pp. 411-22.

Taylor, M. (2003) Public policy in the community. Palgrave MacMillan, Basingstoke.

Taylor, M., Barr, A., \& West, A. (2000) Signposts to community development. Community Development Foundation, London.

Taylor, P. (2002) Understanding the policy maze. 2nd edn, Health Education Board for Scotland, Edinburgh.

Thomas, B., Stamler, L. L., LaFreniere, K., \& Dumala, R. (2000) "The Internet: an effective tool for nursing research with women". Computers in Nursing no. 18, pp. $13-8$.

Thomas, R. \& Purdon, S. Telephone methods for social surveys. Social Research Update [8]. (1994). (24-3-2004.)

Thompson, B. \& Kinne, S. (1999) "Social change theory: applications to community health," in Health Promotion at the Community Level: New Advances. 2 edn, N. Bracht, ed., Sage Publications, California, pp. 29-46.

Timmins, N. (1996) The five giants: a biography of the welfare state. Fontana Press, London. 
Tones, K. (1990) "Why theorise: ideology in health education". Health Education Journal, vol. 49, no. 1, pp. 2-6.

Tones, K. \& Green, J. (2004) Health promotion: planning and strategies. Sage, London.

Tudor Hart, J. (1971) "The inverse care law". The Lancet, vol. 297, no. 7696, pp. 405-12.

Turner, B. (2003) "Social capital, inequality and health: the Durkheimian revival". Social Theory and Health, vol. 1, no. 1, pp. 4-20.

Vicary, J. R., Doebler, M. K., Bridger, J. C., Gurgevich, E. A., \& Deike, R. C. (1996) "A community systems approach to substance abuse prevention in a rural setting". Journal of Primary Prevention, vol. 16, pp. 303-18.

Voysey, M. (1975) A constant burden: the reconstitution of family life. Routledge \& Kegan Paul, London.

VSTU "Capacity building. The holistic approach to organisational and individual growth through accreditation and training", VSTU, Middlesborough.

Wade, D. T. \& Halligan, P. W. (2004) "Do biomedical models of illness make for good healthcare systems?". British Medical Journal, vol. 329, pp. 1398-1401.

Walker, A. \& Walker, C. (1997) Britain divided: the growth of social exclusion in the 1980s and 1990s. CPAG, London.

Wallerstein, N. (1992) "Powerlessness, empowerment and health: implications for health promotion programs". American Journal of Health Promotion, vol. 6, no. 3, pp. 197-205.

Wallerstein, N. (2002) "Empowerment to reduce health disparities". Scandinavian Journal of Public Health, vol. 30, no. (suppl 59), pp. 72-7.

Walters, W. (2002) "Social capital and political sociology: re-imagining politics?". Sociology, vol. 36, no. 2, pp. 377-97.

Warburton, D. (1998) "A passionate dialogue: community and sustainable development," in Community and Sustainable Development: participation in the future. D. Warburton, ed., Earthscan, London, pp. 1-39.

Warren, C. A. B. (2002) "Qualitative interviewing," in Handbook of Interview Research. J. F. Gubrium \& J. A. Holstein, eds., Sage, Thousand Oaks, pp. 83-101. 
Webb, B. (2002) "Using focus groups as a research method: a personal experience". Journal of Nursing Management, vol. 10, pp. 27-35.

Weber, R. (2004) "The rhetoric of positivism versus interpretivism: a personal view". MIS Quarterly, vol. 28, no. 1, pp. 3-12.

Weiss, P. \& Friedman, M. (1995) Feminism and community. Temple University Press, Philadelphia.

Weitzman, E. R. \& Kawachi, I. (2000) "Giving means receiving: the effects of social capitalon binge drinking across college campuses". American Journal of Public Health, vol. 90, no. 12, pp. 1936-39.

Wenger, G. C. (1997) "Successful ageing from the point of view of old people: findings from the Bangor longitudinal study of ageing". Baseline: Journal of the British Association for Service to the Elderly, vol. 64, pp. 16-20.

Wenger, G. C. (1998) "Reflections: success and disappointment- octogenarians current and retrospective perspectives". Health Care in Later Life, vol. 2, no. 4, pp. 213-26.

Wengraf, T. (2004) Qualitative research interviewing. Sage, London.

White, K. (2002) An introduction to the sociology of health and illness. Sage, London.

Whitehead, D. (2003) "Incorporating socio-political health promotion activities in clinical practice". Journal of Clinical Nursing, vol. 12, no. 5, pp. 668-77.

Whitehead, D. (2004) "Health promotion and health education: advancing the concepts". Journal of Advanced Nursing, vol. 47, no. 3, pp. 311-20.

Whitehead, M. (1987) The health divide. Health Education Authority, London.

Whiteley, P. F. (1999) "The origins of social capital," in Social Capital and European Democracy. J. W. van Deth et al., eds., Routledge, London.

Whitley, R. \& Prince, M. (2005) "Are inner-cities bad for your health? Comparisons of residents' and third parties' perceptions of the urban neighbourhood of Gospel Oak, London". Sociology of Health and Illness, vol. 27, no. 1, pp. 44-67.

WHO "Preamble to the constitution of the World Health Organization as adopted by the International Health Conference, New York 19-22 June, 1946", WHO, New York. 
WHO (1978) Alma Ata declaration. World Health Organisation, Geneva.

WHO 1986, "Ottawa charter for health promotion", WHO, Ontario.

WHO (1998) Health 21 - world health declaration. World Health Organisation, Geneva.

Wilkinson, R. (1996) Unhealthy societies: the afflictions of inequality. Routledge, London.

Wilkinson, R. \& Marmot, M. (2003) Social determinants of health: the Solid Facts second edition. WHO, Copenhagen.

Wilkinson, S. (1998) "Focus groups in feminist research: power, interaction and the co-production of meaning". Woman's Studies International Forum, vol. 21, pp. 11125 .

Williams, C. \& Windebank, J. (2003) "Alternative employment spaces," in Alternative Economic Spaces. A. Leyshon, R. Lee, \& C. Williams, eds., Sage, London, pp. 128-50.

Williams, C. C. (2005) "A critical evaluation of hierarchical representations of community involvement: some lessons from the UK". Community Development Journal, vol. 40, no. 1, pp. 30-8.

Williams, M. (2000) "Interpretivism and generalisation". Sociology, vol. 34, no. 2, pp. 209-34.

Williams, M. (2002) "Generalization in interpretive research," in Qualitative Research in Action. T. May, ed., Sage, London, pp. 125-43.

Williams, R. (1988) Keywords: a vocabulary of culture and society. Fontana Press, London.

Williams, S. J. (2003a) "Beyond meaning, discourse and the empirical world: critical realist reflections on health". Social Theory and Health, vol. 1, no. 1, pp. 42-71.

Williams, S. J. (2003b) Medicine and the body. Sage Publications Ltd, London.

Willmott, P. (1987) Friendship networks and social support. Policy Studies Institute, London. 
Woods, K. J. (2004) "Political devolution and the health services in Great Britain". International Journal of Health Services, vol. 34, no. 2, pp. 323-39.

Woolcock, M. (1998) "Social capital and economic development: toward a theoretical synthesis and policy framework". Theory and Society, vol. 27, pp. 151208.

Worley, C. (2005) "'It's not about race. It's about the community': New Labour and 'community cohesion'". Critical Social Policy, vol. 25, no. 4, pp. 483-496.

Wright, G. D. (2003) "Social inclusion and inequalities in health," in The Social Significance of Health Promotion. T. H. MacDonald, ed., Routledge, London, pp. 66-87.

Yeatman, H. R. \& Nove, T. (2002) "Reorientating health services with capacity building: a case study of the Core Skills in Health Promotion Project". Health Promotion International, vol. 17, no. 4, pp. 341-50.

Yen, I. \& Syme, S. (1999) "The social environment and health: a discussion of the epidemiological literature". Annual Review of Public Health, vol. 20, pp. 287-308.

Zealley, H. (2004) "Some historical notes on health and public health in Edinburgh," in Public Health: past, present and future. R. Bhopal \& J. Last, eds., The Nuffield Trust, London, pp. 12-24.

Zigler, E. (1991) "Reshaping early childhood intervention to be a more effective weapon against poverty". American Journal of Community Psychology, vol. 22, no. 1, pp. 37-47.

Zimmerman, M. \& Rappaport, J. (1988) "Citizen participation, perceived control and psychological empowerment". American Journal of Community Psychology, vol. 16, no. 5 , pp. $725-50$.

Zola, I. K. (1972) "Medicine as an instrument of social control". Sociological Review, vol. 20, no. 4, pp. 487-504. 